\title{
Experimental and Modeling Studies of the \\ Characteristics of Liquid Biofuels for Enhanced Combustion
}

\section{Final Report}

Award Number: DOE DE-FC26-07NT43065

Recipient: Reaction Design

PI: Ellen Meeks

Reporting Period: July 1, 2007 - September 30, 2009

Report Number: DOE/NT/43065-3
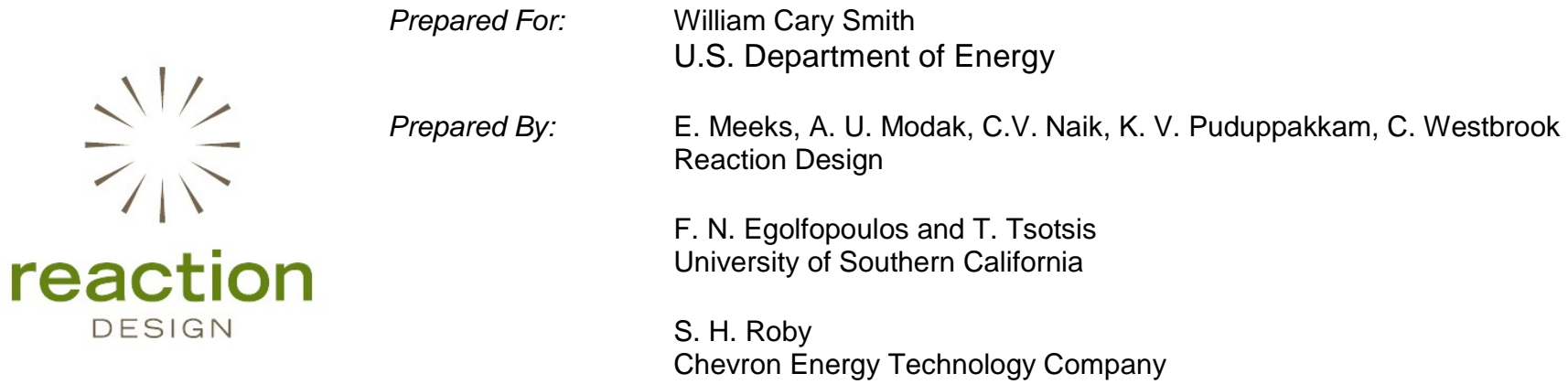


\section{DISCLAIMER}

This report was prepared as an account of work sponsored by an agency of the United States Government. Neither the United States Government nor any agency thereof, nor any of their employees, makes any warranty, express or implied, or assumes any legal liability or responsibility for the accuracy, completeness, or usefulness of any information, apparatus, product, or process disclosed, or represents that its use would not infringe privately owned rights. Reference herein to any specific commercial product, process, or service by trade name, trademark, manufacturer, or otherwise does not necessarily constitute or imply its endorsement, recommendation, or favoring by the United States Government or any agency thereof. The views and opinions of authors expressed herein do not necessarily state or reflect those of the United States Government or any agency thereof. 


\section{Table of Contents}

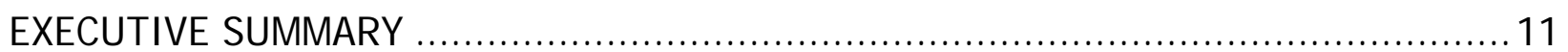

1. BIODIESEL PROPERTIES AND PROCESSES SURVEY ........................................ 13

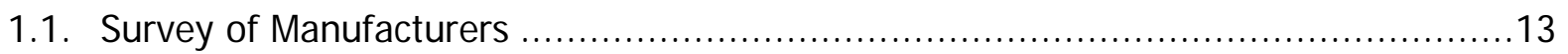

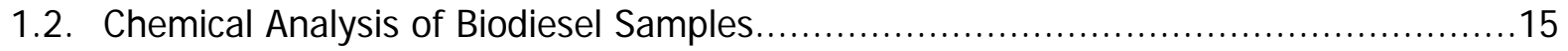

1.3. IQT Testing of Biodiesel Samples and Blends ..............................................16

2. FUNDAMENTAL EXPERI MENTS OF BI ODIESELS AND SURROGATES ..................... 18

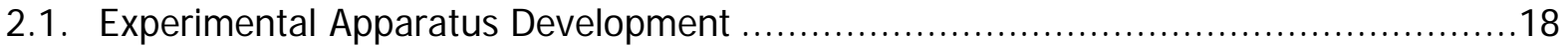

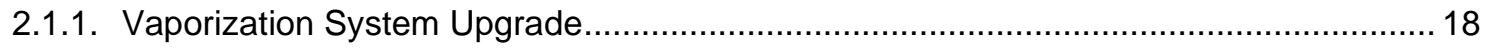

2.1.2. Effect of Thermal Boundary Layer on Radial Temperature Profile ............................... 20

2.1.3. Effect of Flow Rate on Burner Exit Temperature ....................................................... 21

2.1.4. Effect of Probe Location on Flame Speeds in Counterflow Flames................................ 24

2.1.5. Development of a Laser Extinction System For Measuring Soot.................................. 28

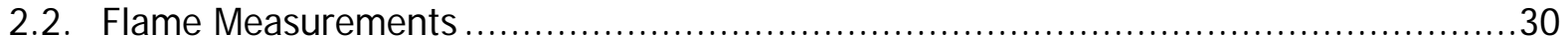

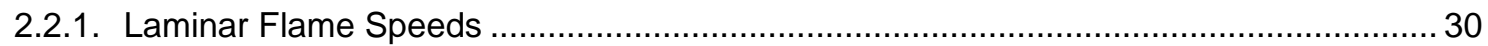

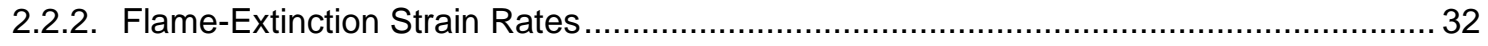

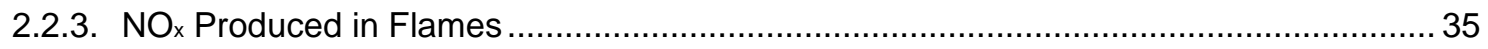

3. KINETIC MODEL DEVELOPMENT FOR BIODIESEL MODELS.............................. 40

3.1. Assembly of Mechanisms and a Surrogate-Component Palette...........................40

3.1.1. Development of a Mechanism for Methyl Decanoate ............................................... 41

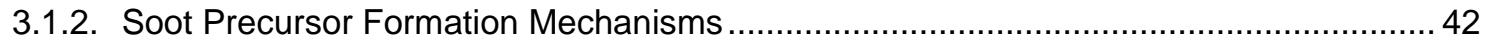

3.1.3. Low-Temperature Mechanism Development for Engine Simulations ........................... 42

3.2. Identification of Appropriate Surrogate-Fuel Blends .........................................43

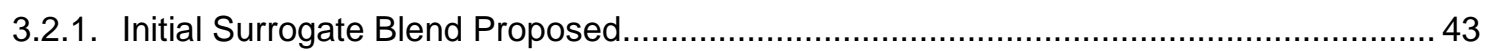

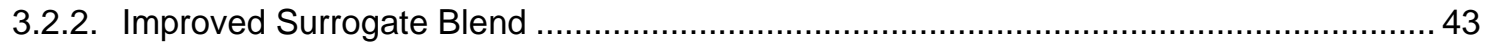

4. VALIDATION OF SURROGATE COMPONENT MECHANISMS ............................. 45

4.1. Details about the Computational Method for Simulating Flames .............................45

4.2. Validation of Surrogate Components: Methyl Butanoate and Methyl Crotonate.........46

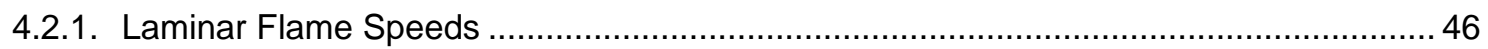

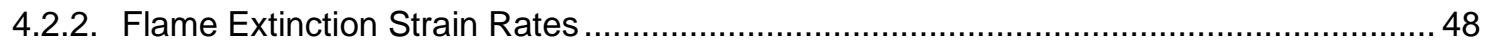

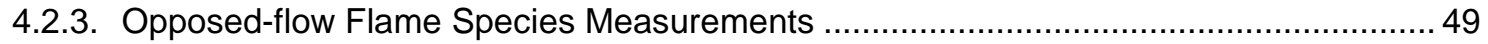

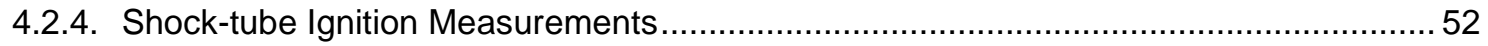

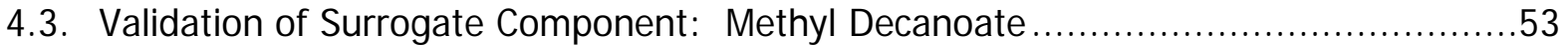

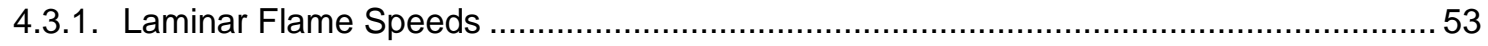

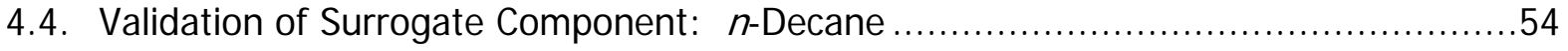




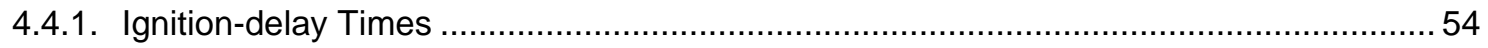

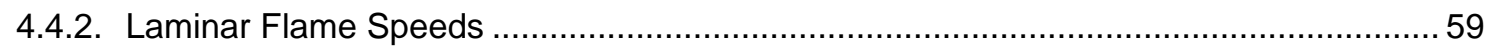

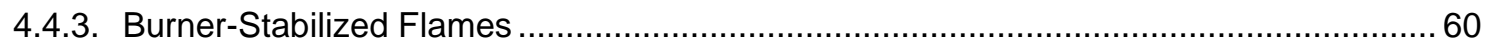

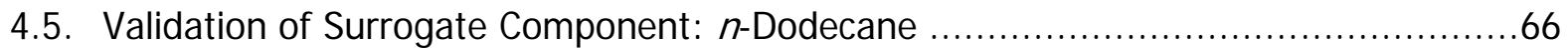

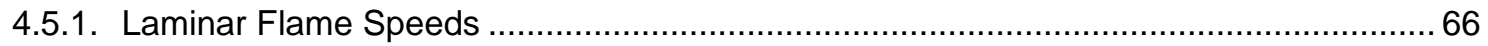

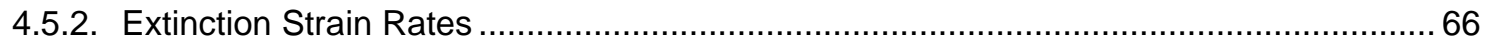

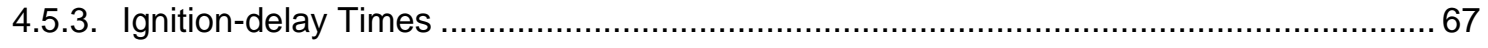

4.6. Conclusions of the Component Mechanism Validation Studies..........................69

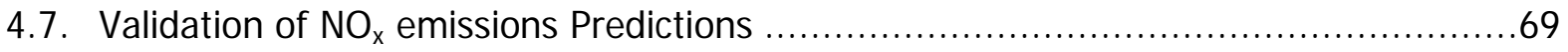

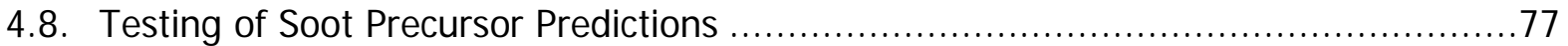

4.8.1. Effects of Molecular Structure on PAH and NOx Emissions......................................... 79

5. COMPARI SONS OF B100 DATA AND BI ODI ESEL SURROGATE.......................... 85

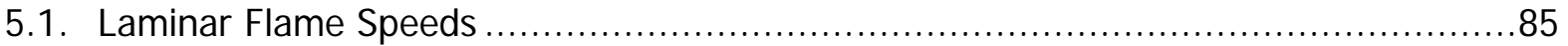

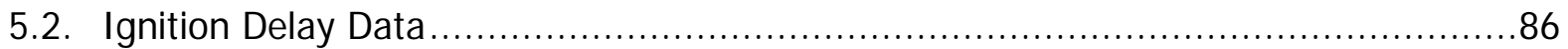

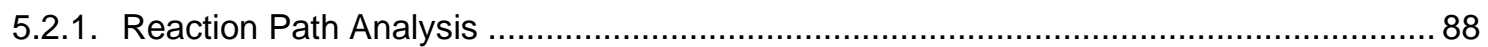

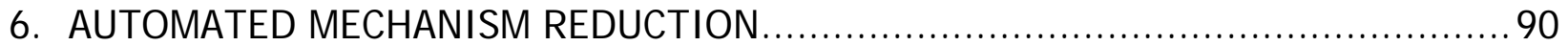

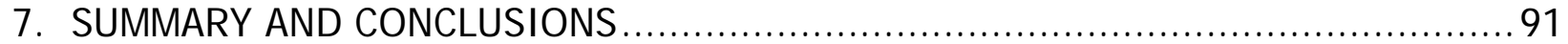

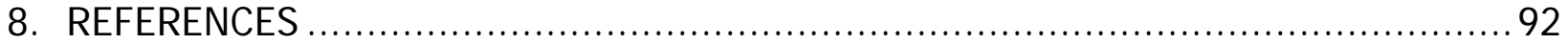




\section{List of Figures}

Figure 1. Schematic of the upgraded vaporization system.......................................................................19

Figure 2. Photographs of the upgraded vaporization system..............................................................19

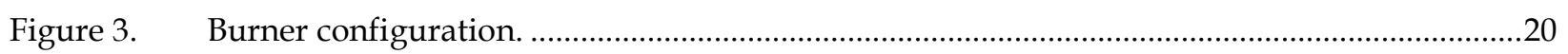

Figure 4. Radial temperature distribution at the nozzle exit................................................................21

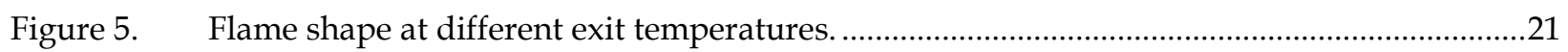

Figure 6. Laminar flame speed determination. ................................................................................22

Figure 7. Variation of exit temperature versus strain rate......................................................................22

Figure 8. Variation of laminar flame speed with unburned gas temperature. ........................................23

Figure 9. Variation of the reference flame speed with strain rate with no temperature correction.......23

Figure 10. Variation of the reference flame speed versus strain rate with temperature correction, showing the expected independence of slope vs. strain rate with initial temperature...........24

Figure 11. Radial variation of the radial and axial exit velocity components of a counterflow jet at room temperature.

Figure 12. Radial variation of the minimum axial velocity and maximum absolute axial strain rate for flames at room temperature.

Figure 13. Radial variation of the radial and axial exit velocity components of a counterflow jet at elevated temperature.

Figure 14. Radial variation of the reference flame speed and stretch rate for a flame at elevated temperature.

Figure 15. Radial variation of the $u_{\min }$ location relative to the nozzle exit..............................................26

Figure 16. Radial variation of the slope of the flame surface. .....................................................................27

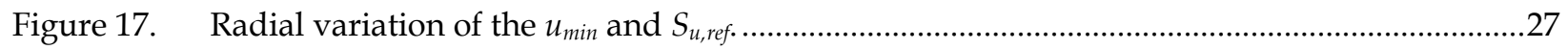

Figure 18. Schematic of a non-premixed sooting flame with laser light extinction set-up. ......................28

Figure 19. Picture of current set-up of a non-premixed sooting flame with a laser light extinction setup.

Figure 20. Line of transmittance fraction $\left(I / I_{0}\right)$ vs. distance from bottom burner. .....................................30

Figure 21. Experimentally determined laminar flame speeds of methyl-butanoate/air, methylcrotonate/air and n-petane/air mixtures at an unburned mixture temperature of $60^{\circ} \mathrm{C}$ as functions of equivalence ratio, $\phi$.

Figure 22. Experimentally determined laminar flame speeds of methyl-butanoate/air, methylcrotonate/air and methyl-decanoate/air mixtures at an unburned mixture temperature of $130^{\circ} \mathrm{C}$ as functions of equivalence ratio, $\phi$.

Figure 23. Experimentally determined laminar flame speeds of methyl-decanoate/air, $n$-decane/air and a biodiesel surrogate/air mixtures at an unburned mixture temperature of $130^{\circ} \mathrm{C}$ as functions of equivalence ratio, $\phi$. 
Figure 24. Measured flame-extinction strain rates for methyl butanoate, methyl crotonate, and npentane, for an unburned temperature of $333 \mathrm{~K}$, as a function of equivalence ratio. Symbols include bars to indicate uncertainties in the measurements.

Figure 25. Measured flame-extinction strain rates for methyl decanoate, $n$-decane, and $n$-dodecane, for an unburned temperature of $403 \mathrm{~K}$, as a function of equivalence ratio. Symbols include bars to indicate uncertainties in the measurements.

Figure 26. Measured flame-extinction strain rates for a Surrogate mixture, comprised of $15 \%$ methyl butanoate, $35 \%$ methyl crotonate and 50\% $n$-decane, compared with data for neat $n$ dodecane and methyl decanoate, for an unburned temperature of $403 \mathrm{~K}$, as a function of equivalence ratio. Symbols include bars to indicate uncertainties in the measurements.......35

Figure 27. Experimentally determined NOx concentration profiles as a function of distance from the bottom burner for $n$-pentane/air, methyl-butanoate/air and methyl-crotonate/air flames (equivalence ratio $=0.8, \mathrm{~K}=168 \mathrm{~s}^{-1} ; \mathrm{T}_{\mathrm{u}}=60^{\circ} \mathrm{C}$ ).

Figure 28. Experimentally determined $\mathrm{NO}_{x}$ concentration profiles as a function of distance from the bottom burner for $n$-pentane/air, methyl-butanoate/air and methyl-crotonate/air flames (equivalence ratio=1.0, $K=168 \mathrm{~s}^{-1} ; T_{\mathrm{u}}=60^{\circ} \mathrm{C}$ ).

Figure 29. Experimentally determined $\mathrm{NO}_{x}$ concentration profiles as a function of distance from the bottom burner for $n$-pentane/air, methyl-butanoate/air and methyl-crotonate/air flames (equivalence ratio $=1.2, K=168 \mathrm{~s}^{-1} ; T_{\mathrm{u}}=60^{\circ} \mathrm{C}$ ).

Figure 30. Experimentally determined $\mathrm{NO}_{\mathrm{x}}$ concentration profiles as a function of distance from the bottom burner for $n$-decane/air, $n$-dodecane/air, and methyl-decanoate/air flames (equivalence ratio $=0.8, K=168 \mathrm{~s}^{-1} ; T_{\mathrm{u}}=130^{\circ} \mathrm{C}$ ).

Figure 31. Experimentally determined $\mathrm{NO}_{x}$ concentration profiles as a function of distance from the bottom burner for $n$-decane/air, $n$-dodecane/air and methyl-decanoate/air flames (equivalence ratio=1.0, $K=168 \mathrm{~s}^{-1} ; T_{\mathrm{u}}=130^{\circ} \mathrm{C}$ ).

Figure 32. Experimentally determined $\mathrm{NO}_{x}$ concentration profiles as a function of distance from the bottom burner for $n$-decane/air, $n$-dodecane/air and methyl-decanoate/air flames (equivalence ratio $=1.2, \mathrm{~K}=168 \mathrm{~s}^{-1} ; T_{\mathrm{u}}=130^{\circ} \mathrm{C}$ )

Figure 33. Experimentally determined laminar flame speeds of $\mathrm{C}_{3} \mathrm{H}_{8}$ / air mixtures at atmospheric pressure and $300 \mathrm{~K}$ along with simulation results using a detailed propane chemistry mechanism.

Figure 34. Effect of transport model on calculated extinction strain rates for methyl butanoate/air flames.

Figure 35. Comparison of predicted flame speeds of methyl butanoate (MB) and methyl crotonate (MC) to those measured at USC at unburned mixture temperature of $333 \mathrm{~K}$ at $1 \mathrm{~atm}$. Lines represent predictions and symbols represent the experimental values. The dashed/dotted lines indicates the original models for these components reported by Fisher [5]

Figure 36. Comparison of predicted flame speeds of MB to those measured at USC at two different unburned mixture temperature of $333 \mathrm{~K}$ and $403 \mathrm{~K}$, at $1 \mathrm{~atm}$. Lines represent predictions and symbols represent the experimental values.

Figure 37. Comparison of predicted flame speeds of MC to those measured at USC at two different unburned mixture temperature of $333 \mathrm{~K}$ and $403 \mathrm{~K}$, at $1 \mathrm{~atm}$. Lines represent predictions and symbols represent the experimental values. 
Figure 38. Comparison of predicted and measured extinction strain rate of methyl butanoate/air mixture at $333 \mathrm{~K}, 1 \mathrm{~atm}$ using opposed flow flame configuration.

Figure 39. Comparison of predicted and measured concentration of methyl butanoate in opposedflow flame configuration. Also shown is the measured temperature profile which is used as input to the simulation.

Figure 40. Predicted and measured $\mathrm{CO}$ and $\mathrm{CO}_{2}$ in oxidation of $4.7 \%$ methyl butanoate in opposed-

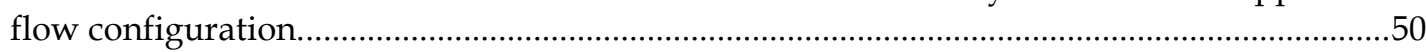

Figure 41. Predicted and measured $\mathrm{CH}_{4}$ and $\mathrm{C}_{2} \mathrm{H}_{4}$ in oxidation of $4.7 \%$ methyl butanoate in the opposed-flow configuration.

Figure 42. Predicted and measured $\mathrm{C}_{2} \mathrm{H}_{2}, \mathrm{C}_{2} \mathrm{H}_{6}$, and $\mathrm{C}_{3} \mathrm{H}_{6}$ in oxidation of $4.7 \%$ methyl butanoate in the opposed-flow configuration.

Figure 43. Comparison of predicted and measured ignition delay for methyl butanoate [19]. Three different equivalence ratios are used. The pressure is set to $1 \mathrm{~atm}$.

Figure 44. Comparison of predicted and measured ignition delay for methyl butanoate. Equivalence ratio is set to unity.

Figure 45. Comparison of the predicted and measured laminar flame speeds for methyl decanoate....54

Figure 46. Calculated $n$-decane/air ignition delay times compared with the data of Zhukov et al. [21]. Conditions include pressure of $13 \mathrm{~atm}$ and a stoichiometric mixture.

Figure 47. Calculated n-decane/air ignition-delay times compared with the data of Pfahl et al. [20]. Conditions include pressure of $13 \mathrm{~atm}$ and a stoichiometric mixture.

Figure 48. Calculated ignition times for $n$-decane/air mixtures at $8.9 \mathrm{~atm}$, in comparison with the experimental data of Dean et al. [22].

Figure 49. Calculated ignition times for $n$-decane/air mixtures at 2 and $10 \mathrm{~atm}$, in comparison with the experimental data correlation of Olchanski et al. [24].

Figure 50. Calculated ignition times for $n$-decane/air mixtures at $6 \mathrm{~atm}$, in comparison with the experimental data correlation of Horning et al. [23] for an equivalence ratio of $2\left(\mathrm{O}_{2}\right.$ mole fraction $=0.1$.

Figure 51. Ignition delay times for an n-decane/air mixture at $13 \mathrm{~atm}$ and an equivalence ratio of 0.5 .

Figure 51. Impact of linear and non-linear extrapolation of flame velocity to zero stretch to obtain laminar flame speed of $n$-dodecane using opposed flow burner configuration at USC Flame Facility. Data from Kumar and Sung [25] are based on linear extrapolation method.

Figure 52. Plot from paper of Kumar et al. [25] showing extrapolation to zero stretch rate.

Figure 53. Comparison of predicted laminar flame speed of $n$-decane to the experimental data from USC and Kumar and Sung [25]...

Figure 54. Calculated $n$-decane and $\mathrm{O}_{2}$ concentration profiles for the $n$-decane $/ \mathrm{O}_{2} / \mathrm{N}_{2}$ premixed burner-stabilized flame with an equivalence ratio of 1.7, compared with the data of Doute et al. [27]. Inlet velocity $=11.7 \mathrm{~cm} / \mathrm{sec}$, pressure $=1 \mathrm{~atm}$, reactant mole fractions: $\mathrm{n}$ decane $=0.032, \mathrm{O}_{2}=0.286, \mathrm{~N}_{2}=0.682$.

Figure 55. Calculated $\mathrm{CO}$ and $\mathrm{CO}_{2}$ concentration profiles for the $\mathrm{n}$ decane $/ \mathrm{O}_{2} / \mathrm{N}_{2}$ premixed burnerstabilized flame with an equivalence ratio of 1.7, compared with the data of Doute et al. 
[27]. Inlet velocity $=11.7 \mathrm{~cm} / \mathrm{sec}$, pressure $=1 \mathrm{~atm}$, reactant mole fractions: $n$-decane $=0.032$, $\mathrm{O}_{2}=0.286, \mathrm{~N}_{2}=0.682$.

Figure 56. Calculated $\mathrm{H}_{2}$ concentration profile for the $n$-decane $/ \mathrm{O}_{2} / \mathrm{N}_{2}$ premixed burner-stabilized flame with an equivalence ratio of 1.7, compared with the data of Doute et al. [27]. Inlet velocity $=11.7 \mathrm{~cm} / \mathrm{sec}$, pressure $=1 \mathrm{~atm}$, reactant mole fractions: $n$-decane $=0.032, \mathrm{O}_{2}=0.286$, $\mathrm{N}_{2}=0.682$.

Figure 57. Calculated $\mathrm{C}_{2} \mathrm{H}_{4}$ and $\mathrm{C}_{2} \mathrm{H}_{2}$ concentration profiles for the $n$-decane/ $\mathrm{O}_{2} / \mathrm{N}_{2}$ premixed burner-stabilized flame with an equivalence ratio of 1.7, compared with the data of Doute et al. [27]. Inlet velocity $=11.7 \mathrm{~cm} / \mathrm{sec}$, pressure $=1 \mathrm{~atm}$, reactant mole fractions: $n$ decane $=0.032, \mathrm{O}_{2}=0.286, \mathrm{~N}_{2}=0.682$

Figure 58. Calculated $\mathrm{CH}_{4}$ and $\mathrm{C}_{2} \mathrm{H}_{6}$ concentration profiles for the $n$-decane $/ \mathrm{O}_{2} / \mathrm{N}_{2}$ premixed burner-stabilized flame with an equivalence ratio of 1.7, compared with the data of Doute et al. [27]. Inlet velocity $=11.7 \mathrm{~cm} / \mathrm{sec}$, pressure $=1 \mathrm{~atm}$, reactant mole fractions: $\mathrm{n}$ decane $=0.032, \mathrm{O}_{2}=0.286, \mathrm{~N}_{2}=0.682$

Figure 59. Calculated $\mathrm{CO}_{2}$ and $\mathrm{CO}$ concentration profiles for $\mathrm{n}$ decane/ $\mathrm{O}_{2} /$ Ar premixed burnerstabilized flame with an equivalence ratio of 1.9, compared with the data of Delfau et al. [26]. Inlet velocity $=18.6 \mathrm{~cm} / \mathrm{sec}$, pressure $=1 \mathrm{~atm}$, reactant mole fractions: $\mathrm{n}$ decane $=0.051$, $\mathrm{O}_{2}=0.412, \mathrm{Ar}=0.537$.

Figure 60: Calculated $\mathrm{C}_{2} \mathrm{H}_{4}$ concentration profiles for $\mathrm{n}$ decane $/ \mathrm{O}_{2} /$ Ar premixed burner-stabilized flame with an equivalence ratio of 1.9, compared with the data of Delfau et al. [26]. Inlet velocity $=18.6 \mathrm{~cm} / \mathrm{sec}$, pressure $=1 \mathrm{~atm}$, reactant mole fractions: $\mathrm{n}$ decane $=0.051, \mathrm{O}_{2}=0.412$, $\mathrm{Ar}=0.537$.

Figure 61. Comparison of predicted and measured laminar flame speeds for n-dodecane/ air flames. Pressure is $1 \mathrm{~atm}$ while unburned gas temperatures of $400 \mathrm{~K}$ and $470 \mathrm{~K}$ are used...66

Figure 62. Comparison of predicted and measured extinction strain rate of $n$-dodecane/air mixture at $403 \mathrm{~K}, 1 \mathrm{~atm}$ using opposed flow flame configuration.

Figure 63. Calculated $n$-dodecane/air ignition-delay times compared with the data of Hanson et al. Conditions include pressure of $20 \mathrm{~atm}$ and a stoichiometric mixture.

Figure 65 Ignition delay times for an n-dodecane/air mixture at $20 \mathrm{~atm}$ and an equivalence ratio of 0.5 .

Figure 64. Comparison of predicted and measured $\mathrm{NO}_{x}$ from $n$-pentane, methyl butanoate, and methyl crotonate. Premixed fuel/air is injected at $323 \mathrm{~K}$ from the bottom burner and nitrogen at room temperature from the top burner.

Figure 65. Comparison of predicted $\mathrm{NO}_{x}$ from $n$-decane and methyl decanoate with initial measurements obtained from USC. Premixed fuel/air is injected at $403 \mathrm{~K}$ from the bottom burner and nitrogen at room temperature from the top burner.

Figure 66. Rate of production and sensitivity analysis for NO near the peak for the $n$-pentane flame shown in Figure 64

Figure 67 Comparison of predicted and the latest measured $\mathrm{NO}_{\mathrm{x}}$ values for methyl decanoate/air flames. Symbols represent experimental data and lines represent model predictions. ...........73

Figure 68. Effect of strain rate on $\mathrm{NO}_{x}$. Comparison of predicted and measured $\mathrm{NO}_{\mathrm{x}}$ values for $n$-dodecane/air flames at strain rates of 120 and $166 \mathrm{sec}^{-1}$, with an equivalence ratio of 0.8 .74 
Figure 69. Effect of equivalence ratio on $\mathrm{NO}_{x}$. Comparison of predicted and measured $\mathrm{NO}_{x}$ values for $n$-dodecane/ air flames at equivalence ratios of 0.8-1.2. Symbols represent experimental data and lines represent model predictions.

Figure 70. Comparison of predicted and measured $\mathrm{NO}_{\mathrm{x}}$ levels for $n$-decane/air and $n$-dodecane/air flames with an equivalence ratio of 0.8. Symbols represent experimental data and lines represent model predictions.

Figure 71. Impact of uncertainty in nozzle velocities and nitrogen burner (top burner) temperature on $\mathrm{NO}_{x}$ predictions for $n$-dodecane/air flames. Gray symbols represent predictions from Uncertainty Analyses in CHEMKIN-PRO. Filled circles are the experimental data.

Figure 72. Comparison of predicted and measured acetylene profile by Senkan and Castaldi [30] for a burner stabilized propane flame.

Figure 73. Comparison of predicted and measured propyne-propadiene $(\mathrm{C} 3 \mathrm{H} 4)$ and butadiene $(\mathrm{C} 4 \mathrm{H} 2)$ profile by Senkan and Castaldi [30] for a burner stabilized propane flame.

Figure 74. Comparison of predicted and measured benzene profile by Senkan and Castaldi [30] for a burner stabilized propane flame.

Figure 75. Comparison of predicted and measured PAH species profiles by Senkan and Castaldi [30] for a burner stabilized propane flame.

Figure 76. Predicted adiabatic temperature profiles for burner stabilized premixed fuel/air flames at $1 \mathrm{~atm}$ with equivalence ratio of 2 and inlet temperature of $550 \mathrm{~K}$.

Figure 77. Predicted profiles of acetylene concentrations in burner stabilized premixed fuel/air adiabatic flames at $1 \mathrm{~atm}$ with equivalence ratio of 2 and inlet temperature of $550 \mathrm{~K}$. Dashed lines represent predictions using the fixed-temperature profile.

Figure 78. Predicted profiles of propyne+propadiene concentrations in burner stabilized premixed fuel/air adiabatic flames at $1 \mathrm{~atm}$ with equivalence ratio of 2 and inlet temperature of 550 $\mathrm{K}$. Dashed lines represent predictions using the fixed-temperature profile.

Figure 79. Predicted profiles of 1,3-butadiyne concentrations in burner stabilized premixed fuel/air adiabatic flames at $1 \mathrm{~atm}$ with equivalence ratio of 2 and inlet temperature of $550 \mathrm{~K}$. Dashed lines represent predictions using the fixed-temperature profile.

Figure 80. Predicted profiles of benzene concentrations in burner stabilized premixed fuel/air adiabatic flames at $1 \mathrm{~atm}$ with equivalence ratio of 2 and inlet temperature of $550 \mathrm{~K}$. Dashed lines represent predictions using the fixed-temperature profile.

Figure 81. Predicted profiles of total $\mathrm{NO}_{\mathrm{x}}$ concentrations in burner stabilized premixed fuel/air adiabatic flames at $1 \mathrm{~atm}$ with equivalence ratio of 2 and inlet temperature of $550 \mathrm{~K}$. Dashed lines represent predictions using the fixed-temperature profile.

Figure 82. Comparison of the measured laminar flame speeds for Nexol biodiesel (USC-02) at unburned mixture temperature of $493 \mathrm{~K}$ at $1 \mathrm{~atm}$, and those predicted using the 3component surrogate containing $n$-dodecane/methyl butanoate/methyl crotonate. The dashed line shows model predictions shifted to the left by $0.005 \mathrm{fuel} /$ air mass ratio.

Figure 83. Comparison of the measured laminar flame speeds for the surrogate blend, $15 \% \mathrm{MB}$, $35 \% \mathrm{MC}, 50 \% \mathrm{n}$-decane, at unburned mixture temperature of $403 \mathrm{~K}$ at $1 \mathrm{~atm}$, and those predicted using the same 3-component blend.

Figure 84. Comparison of calculated ignition delay for biodiesel surrogate with experimental data for diesel [28]. 
Figure 85. Reaction path diagrams for methyl crotonate (mb2d) (top left), methyl butanoate (mb), and $n$-dodecane (nc12h26) (bottom) at 10\% conversion of model biodiesel under conditions of freely propagating flame at $1 \mathrm{~atm}$ and unburned mixture temperature of $470 \mathrm{~K}$.

Figure 86. Comparison of the predicted flame speeds using the full master vs. skeletal mechanism for a 3-component biodiesel surrogate. 


\section{List of Tables}

Table 1. List of BQ-9000 certified biodiesel manufacturers....................................................................14

Table 2. Gas Chromatography Fraction Datasheet. .......................................................................15

Table 3. Gas Chromatography Fraction Datasheet - Normalized to 100\% Recovery...........................15

Table 4. Mass Spectrometry Analysis Datasheet for Biofuels Samples..................................................16

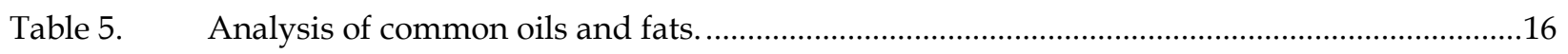

Table 6. Results of IQT testing of biodiesel samples and biodiesel/ULSD blends...............................17

Table 7. Initial 3-component model biodiesel studied..........................................................................43

Table 8. Various possible surrogates for a typical biodiesel. Composition is in mol \%.........................44

Table 9. $\quad n$-Decane shock-tube experiments in the literature...............................................................55

Table 10. $\quad n$-Decane burner-stabilized flame experiments in the literature.............................................61 


\section{Executive Summary}

The objectives of this project have been to develop a comprehensive set of fundamental data regarding the combustion behavior of biodiesel fuels and appropriately associated model fuels that may represent biodiesels in automotive engineering simulation. Based on the fundamental study results, an auxiliary objective was to identify differentiating characteristics of molecular fuel components that can be used to explain different fuel behavior and that may ultimately be used in the planning and design of optimal fuel-production processes.

The fuels studied in this project were BQ-9000 certified biodiesel fuels that are certified for use in automotive engine applications. Prior to this project, there were no systematic experimental flame data available for such fuels. One of the key goals has been to generate such data, and to use this data in developing and verifying effective kinetic models. The models have then been reduced through automated means to enable multi-dimensional simulation of the combustion characteristics of such fuels in reciprocating engines. Such reliable kinetics models, validated against fundamental data derived from laminar flames using idealized flow models, are key to the development and design of optimal engines, engine operation and fuels. The models provide direct information about the relative contribution of different molecular constituents to the fuel performance and can be used to assess both combustion and emissions characteristics.

At the beginning of this project, we conducted a survey of and collected samples from certified biodiesel suppliers in the U.S. With cooperation from our partners at Chevron, we were able to obtain detailed fuel analyses, as well as IQ test results, for the fuel samples obtained. This analysis provided important insight into the fuel composition and physical properties of the fuel, which allowed us to identify appropriate surrogate-fuel compounds for further study. We next demonstrated the methodology for measuring key combustion characteristics in a controlled laboratory environment for these heavy liquid fuels. Idealized flow models that represent the laboratory experiments were compared with the experimental data as a means of verifying the fundamental kinetics of the fuel combustion for both model-fuel components and surrogate-fuel blends. Analysis of initial comparisons between model and experiment yielded improvements to both the chemistry model and to the experimental procedures. We have made improvements to the flame experiments to allow more reproducible measurements for heavy liquid fuels and produced unique sets of data as a result.

Throughout this project, Reaction Design has collaborated closely with researchers at the University of Southern California (USC) and Dr. Charles Westbrook, a consultant to Reaction Design, in the analysis and testing of the biodiesels and the fuel surrogates. Led by Professors Egolfopoulos and Tsotsis, USC performed fundamental combustion studies that directly compared the combustion behavior of different fuels and fuel components in terms of flame-propagation and flame-extinction characteristics. These experiments provided insight into the differences and similarities between the different fuels. The data were used in verification and improvement of detailed kinetics mechanisms for surrogate fuel components, through comparison of 1-D flame simulations with data from the USC experiments. The flame experiments were designed to facilitate accurate simulation of the flow-field using one-dimensional models, allowing focus on kinetics and species-transport effects. The collaboration between Reaction Design and USC involved iterative comparisons between data and model that led to the discovery of issues with the experimental procedures as well as with the chemistry models; improvements to both were important outcomes of the project.

Reaction Design's efforts were centered on assembling and improving the kinetics mechanism for biodiesel components and surrogate-biodiesel components, using both the fundamental data provided by USC and supplementary data available from the literature for non-flame conditions. As part of this activity, simulations were performed for a wide variety of experimental conditions, as well as a wide range of temperatures and equivalence ratios for fuel/air mixtures. A new flame-extinction model was developed and tested during the project, supplementing the flame-speed simulation capabilities already 
available in CHEMKIN-PRO [1]. These two models provided complementary tests of the hightemperature kinetics representation in the mechanisms. Another result of the project was the demonstration of flame simulations using a comprehensive soot-formation model, including prediction of particle-size distribution function information. From the literature, shock-tube measurements of ignition and stirred-reactor measurements of species profiles were obtained and modeled to provide a more comprehensive test of the models' predictive capabilities. The results of these activities include well validated models of key fuel components that are important to modeling combustion of biodiesels and biodiesel blends in automotive engines.

In addition to fundamental experiments and detailed-kinetics mechanism validation, we applied systematic mechanism-reduction strategies to reduce the size of the final "master" mechanism for our surrogate fuel blends. The goal of this activity was to maintain reasonable accuracy over a range of conditions that would be appropriate for engine simulations. A skeletal mechanism was produced using software based on the Directed Relation Graph Method [2,3]. The results of these activities are a recommended surrogate blend for typical FAME-based biodiesels and a validated and reduced mechanism for that surrogate, ready for use in B100 combustion simulations. Such mechanisms may also be merged with surrogates for conventional diesel fuels to simulate biodiesel/diesel blends.

The remainder of this report provides technical details on the methods employed in each of the tasks performed under the project, as well as the data and results that support the conclusions from this study. 


\section{Biodiesel Properties and Processes Survey}

This systematic study of biodiesel fuels began by collecting detailed information about certified biodiesel fuels readily available in the U.S. This study provided chemical analysis of the fuels, which allowed determination of appropriate surrogate-fuel components for the fundamental combustion studies.

\subsection{Survey of Manufacturers}

A survey of available biodiesel fuels and manufacturers yielded information about the processes in use, as well as a collection of samples obtained from the certified biodiesel suppliers. Samples for several types of fuels allowed testing and analysis at the USC Combustion and Fuels Laboratory and at Chevron. The National Biodiesel Accreditation Program (NBAP) offers a list of certified manufacturers, called BQ9000 members, that pass a rigorous set of standards in storage, sampling, testing, blending, shipping, distribution, and fuel management practices. Manufacturers that were not BQ-9000-certified were omitted from the survey because the quality standards of their fuel could not be guaranteed. Every manufacturer on the NBAP list was contacted and asked to both participate in this survey and also to provide small samples of their product to be used in this study. Table 1 provides a list of the fourteen companies that were able to answer questions regarding feedstock, processing methods, products, size of operation, and the regional/national impact they have on both growers and consumers. In the table, missing entries are either due to proprietary information that the company would not divulge or due to the fact that the representative of the company simply did not know the answer.

In the survey, the companies were asked about the type of feedstock that was used in their facility, since the amount of energy required to extract the oils will depend on the type of feedstock used. One feedstock may yield a higher quantity of oil but at a much higher energy cost than another feedstock. The survey showed that in the USA, soybean oil is the feedstock of choice in the biodiesel manufacturing field. Some of the companies also use animal fats, likely due to contracts with other companies or to regional availability.

We inquired about the type of processing method used in order to determine if a batch process, continuous process, or another innovative process was used. The processing method directly relates to the quantity of biodiesel that the company is able to output each year. Of the companies that were able/willing to respond, the majority used either a purely continuous processing method, which allows for higher yields to be generated, or a batch processing method that simply produces one batch at a time. The small operation facilities were strictly capable of using only batch process methods. The key byproduct in biodiesel manufacturing is glycerol. This by-product can either be wasted or refined to a pharmacological grade of glycerol. The survey found that approximately a third of the companies chose to expend the extra energy to generate this other salable item. 
Table 1. List of BQ-9000 certified biodiesel manufacturers.

\begin{tabular}{|c|c|c|c|c|c|}
\hline Company & Feedstock & $\begin{array}{l}\text { Processing } \\
\text { Methods }\end{array}$ & Products & $\begin{array}{l}\text { Size of } \\
\text { Operation } \\
(\mathrm{mgy})\end{array}$ & $\begin{array}{c}\text { Regional or } \\
\text { National Impact } \\
(\mathrm{g}=\text { Growers } \\
\mathrm{c}=\text { Consumers })\end{array}$ \\
\hline AG Processing & soy & & SoyGold Biodiesel & 30 & $\begin{array}{l}\text { g - national / } \\
\text { c - }\end{array}$ \\
\hline Cargill Inc. & soy & continuous & $\begin{array}{l}\text { biodiesel and } \\
\text { glycerin }\end{array}$ & 38 & $\begin{array}{l}\mathrm{g} \text { - regional / } \\
\mathrm{c} \text { - national }\end{array}$ \\
\hline $\begin{array}{l}\text { Northland } \\
\text { Choice }\end{array}$ & $\begin{array}{l}\text { soy and animal } \\
\text { fats }\end{array}$ & & biodiesel & 3 & \\
\hline $\begin{array}{l}\text { FutureFuel } \\
\text { Chemicals }\end{array}$ & soy & $\begin{array}{l}\text { batch and } \\
\text { continuous }\end{array}$ & biodiesel & 24 & \\
\hline $\begin{array}{l}\text { Griffin } \\
\text { Industries }\end{array}$ & pork fats & batch & $\begin{array}{l}\text { Bio G-3000 } \\
\text { Biodiesel }\end{array}$ & 2 & $\begin{array}{l}\mathrm{g} \text { - national / } \\
\mathrm{c} \text { - national }\end{array}$ \\
\hline $\begin{array}{l}\text { Imperial } \\
\text { Western Prod. }\end{array}$ & $\begin{array}{l}\text { recycled } \\
\text { cooking oil and } \\
\text { virgin oils } \\
\end{array}$ & batch & $\begin{array}{l}\text { Biotane Biodiesel } \\
\text { (Imperial \& } \\
\text { Supreme) }\end{array}$ & 8 & $\begin{array}{l}\mathrm{g} \text { - regional / } \\
\mathrm{c} \text { - regional }\end{array}$ \\
\hline $\begin{array}{l}\text { Dow } \\
\text { Haltermann } \\
\text { Ltd. }\end{array}$ & soy & $\begin{array}{l}\text { batch and } \\
\text { continuous }\end{array}$ & biodiesel & 20 & \\
\hline $\begin{array}{l}\text { Minn. Soybean } \\
\text { Proc. }\end{array}$ & soy & continuous & $\begin{array}{l}\text { SoySupreme } \\
\text { Biodiesel and } \\
\text { glycerin }\end{array}$ & 30 & $\begin{array}{l}\mathrm{g} \text { - regional / } \\
\mathrm{c} \text { - national }\end{array}$ \\
\hline $\begin{array}{l}\text { Organic Fuels } \\
\text { Ltd. }\end{array}$ & $\begin{array}{l}\text { soy, fats, and } \\
\text { tallow }\end{array}$ & continuous & $\begin{array}{l}\text { biodiesel and } \\
\text { glycerin }\end{array}$ & 30 & $\begin{array}{l}\mathrm{g} \text { - national / } \\
\mathrm{c} \text { - national }\end{array}$ \\
\hline $\begin{array}{l}\text { Peter Cremer } \\
\text { N.A. }\end{array}$ & soy & continuous & $\begin{array}{l}\text { Nexsol Biodiesel } \\
\text { and glycerin }\end{array}$ & 40 & $\begin{array}{l}\mathrm{g} \text { - regional / } \\
\mathrm{c} \text { - national }\end{array}$ \\
\hline $\begin{array}{l}\text { Renewable } \\
\text { Energy }\end{array}$ & soy & continuous & $\begin{array}{l}\text { SoyPower } \\
\text { Biodiesel }\end{array}$ & 12 & \\
\hline $\begin{array}{l}\text { Western Iowa } \\
\text { Energy }\end{array}$ & $\begin{array}{l}\text { soy and animal } \\
\text { fats }\end{array}$ & & biodiesel & 30 & \\
\hline $\begin{array}{l}\text { SoyMor } \\
\text { Biodiesel }\end{array}$ & soy & & biodiesel & 30 & $\begin{array}{l}\mathrm{g} \text { - regional / } \\
\mathrm{c} \text { - }\end{array}$ \\
\hline $\begin{array}{l}\text { Seattle } \\
\text { Biodiesel }\end{array}$ & canola & $\begin{array}{l}\text { batch and } \\
\text { continuous }\end{array}$ & $\begin{array}{l}\text { biodiesel and } \\
\text { glycerin }\end{array}$ & 100 & $\begin{array}{l}\text { g - regional / } \\
\text { c - national }\end{array}$ \\
\hline
\end{tabular}

The companies were asked about the size of their operation in terms of millions of gallons of biodiesel per year (mgy). Ten out of the fourteen in the survey were producing at least 20 mgy and most indicated that within twelve months they intended to double or even triple their production capabilities. The other four companies operated in relatively small capacities. They are small companies with a small workforce that typically serve a small region of the country.

The impact that the manufacturers have on both the growers that they receive the feedstock from, and on the consumers they sell the fuel to was evaluated. Most of the companies in this survey did not own, grow, or harvest the feedstock. They simply bought the feedstock from the growers and processed it at the facility. Since the feedstock has a "shelf-life" before it begins decaying, it must be transported quickly. As a result, a majority of the suppliers originate very close to the production facility. Therefore, the biofuel companies typically have a regional impact on the growers. The geographic location of the production facility can allow the company to have an impact that is further reaching. Facilities that can utilize water transport, such as those along the Gulf of Mexico or the Mississippi River, can ship the 
feedstock in on a national level. Virtually all the companies responded that their products were sold to fuel distributors and delivered to locations across the country. The consumer impact was then shown to be generally at a national level.

\subsection{Chemical Analysis of Biodiesel Samples}

Small quantities of these materials were procured (6 different samples, about 1 gal each) from the manufacturers surveyed. These samples were then analyzed for their composition with the goal to identify all the key fatty acid ester components and other impurities (unreacted alcohols and fatty acids, glycerol, etc.) that may be present in each fuel. Based on the data collected, a number of pure fatty acid esters were also procured, as model compounds for the fundamental investigations.

Later in the project, we also procured biodiesels that derived from rapeseed and palm oil, which appear to be the primary feedstocks outside the USA for commercial biodiesel production. We identified Imperium Renewables as the only BQ-9000-certified biodiesel manufacturer that strictly uses rapeseed as a feedstock. Samples of rapeseed-derived biodiesel, also known as canola oil, were procured from Imperium Renewables and were analyzed by solvent elution and GC-MS techniques. Our industrial partner, Chevron, has also procured two additional canola samples from Europe.

Results from the analysis of all the samples are shown in Table 2 through Table 4 (the blue highlighted rows show the Canola-sample results, while the others are the soy-based results). As shown in Table 4, there are significant differences in the molecular composition for the canola-based samples, compared to the soy-based samples. This information helped us to identify appropriate surrogate-molecule blends to represent biodiesels from different regions.

Based on these results, we selected samples USC-01 and USC-03 (soy-based FAMEs) and sample USC-07 (canola based FAME) for fundamental experimental testing, as they contain the lowest fraction of impurities (free fatty acid, etc).

Table 2. Gas Chromatography Fraction Datasheet.

\begin{tabular}{|c|c|c|c|c|c|c|c|}
\hline \multirow{3}{*}{ Sample ID } & \multirow{3}{*}{$\begin{array}{l}\text { Initial } \\
\text { Weight }\end{array}$} & \multicolumn{4}{|c|}{ Weight of Eluted Fraction (Percentage) } & \multirow{2}{*}{$\begin{array}{l}\text { Total } \\
\text { Fraction }\end{array}$} & \multirow{2}{*}{$\begin{array}{l}\text { Percentage } \\
\text { Recovery }\end{array}$} \\
\hline & & A & B & $\mathrm{C}$ & D & & \\
\hline & & Hexane & Toluene & $\mathrm{CH} 2 \mathrm{Cl} 2$ & $\mathrm{CH} 2 \mathrm{Cl} 2-\mathrm{MeOH}$ & Weight, g & $\% \mathrm{R}$ \\
\hline USC-01 & 0.1218 & 0.0004 & $0.1184 \quad(97.4)$ & 0.0006 & 0.0022 & 0.1216 & 99.8 \\
\hline USC-02 & 0.1103 & 0.0000 & $0.1072(93.9)$ & 0.0003 & 0.0067 & 0.1142 & 103.5 \\
\hline USC-03 & 0.1103 & 0.0002 & $0.1075 \quad(97.2)$ & 0.0009 & 0.0023 & 0.1106 & 100.3 \\
\hline USC-04 & 0.1188 & 0.0004 & $0.111 \quad(93.6)$ & 0.0013 & 0.0059 & 0.1186 & 99.8 \\
\hline USC-05 & 0.1065 & 0.0003 & $0.0988 \quad(93.7)$ & 0.0014 & 0.0049 & 0.1054 & 99.0 \\
\hline USC-06 & 0.1333 & 0.0002 & $0.1302 \quad(94.7)$ & 0.0005 & 0.0033 & 0.1342 & 100.7 \\
\hline USC-07 & 0.1027 & 0.0017 & 0.1002 (97.6) & 0.0016 & 0.0016 & 0.1035 & 102.3 \\
\hline
\end{tabular}

Table 3. Gas Chromatography Fraction Datasheet - Normalized to 100\% Recovery.

\begin{tabular}{|c|c|c|c|c|c|}
\cline { 3 - 6 } \multicolumn{2}{c|}{} & \multicolumn{3}{l|}{$\begin{array}{l}\text { Weight Percentage of Eluted Fraction Normalized to 100\% } \\
\text { Total }\end{array}$} \\
\hline Sample ID & Source & A & B & C & D \\
\hline USC-01 & Soy FAME & $0.3 \%$ & $97.4 \%$ & $0.5 \%$ & $1.8 \%$ \\
\hline USC-02 & Soy FAME & $0.0 \%$ & $93.9 \%$ & $0.3 \%$ & $5.9 \%$ \\
\hline USC-03 & Soy FAME & $0.2 \%$ & $96.9 \%$ & $0.8 \%$ & $2.1 \%$ \\
\hline USC-04 & Vegetable Oil & $0.3 \%$ & $93.6 \%$ & $1.1 \%$ & $5.0 \%$ \\
\hline USC-05 & Restaurant & $0.3 \%$ & $93.7 \%$ & $1.3 \%$ & $4.6 \%$ \\
\hline USC-06 & Soy FAME & $0.1 \%$ & $97.0 \%$ & $0.4 \%$ & $2.5 \%$ \\
\hline USC-07 & Canola FAME & $1.6 \%$ & $95.4 \%$ & $1.5 \%$ & $1.5 \%$ \\
\hline
\end{tabular}


Table 4. Mass Spectrometry Analysis Datasheet for Biofuels Samples.

\begin{tabular}{|c|l|l|l|l|l|l|l|}
\cline { 2 - 8 } \multicolumn{1}{l|}{} & \multicolumn{9}{l}{ Carboxylic Acid Content (weight \%) } \\
\hline Compound & Source & Palmitic & Stearic & Oleic & Linoleic & Lenoleic & Erucic \\
\hline & & C16:0 & C18:0 & C18:1 & C18:2 & C18:3 & C22:1 \\
\hline USC-01 & Soy & 13 & 6 & 29 & 56 & & \\
\hline USC-02 & Soy? & 14 & 5 & 23 & 58 & & \\
\hline USC-03 & Soy? & 14 & 7 & 20 & 59 & & \\
\hline USC-04 & vegetable/fat & 12 & 5 & 36 & 49 & & \\
\hline USC-05 & waste oil & 9 & 10 & 40 & 34 & & \\
\hline USC-06 & Soy & 15 & 8 & 21 & 56 & & \\
\hline USC-07 & Canola & 3 & 2 & 66 & 29 & & \\
\hline European-1 & Canola & 4 & 2 & 64 & 30 & & \\
\hline European-2 & Canola & 5 & 2 & 66 & 28 & & \\
\hline
\end{tabular}

Table 5 contains a similar composition analysis of a number of oils and fats commonly utilized in the production of biodiesels. Table 4 shows that all of the samples, except USC-05, have as their primary component $\mathrm{C}_{18}$ molecules with two double bonds. The next most significant fraction are $\mathrm{C}_{18}$ molecules with only one double bond. Other, less significant, lower energy molecules are also present; these include saturated $\mathrm{C}_{18}(\mathrm{C} 18: 0)$ and $\mathrm{C}_{16}(\mathrm{C} 16: 0)$ molecules. Comparing the mass weight percentages of the samples shown in Table 4 to the composition of sources of various oils and fats in Table 5 indicates that samples USC-01, USC-02, USC-03 and USC-06 all have mass compositions close to that of soybean oil, as expected, since these samples were prepared by the transesterification of this oil. Sample USC-04, according to the manufacturer, was prepared using a mixture of both virgin vegetable oil and animal fats. As the results in Table 4 indicate, the composition of this sample is not similar to any of the oils and fats provided in Table 5. Sample USC- 05 was the only sample in the batch that was derived from recycled cooking grease, which typically contains a mixture of different oils. As a result, no clear comparison can be made for this sample to any of the substances in Table 5.

Table 5. Analysis of common oils and fats.

\begin{tabular}{|l|l|l|l|l|l|l|l|}
\cline { 2 - 9 } \multicolumn{1}{|c|}{} & \multicolumn{2}{l|}{ Carboxylic Acid Content (weight \%) } \\
\hline Compound & Comments & Palmitic & Stearic & Oleic & Linoleic & Lenoleic & Erucic \\
\hline & & C16:0 & C18:0 & C18:1 & C18:2 & C18:3 & C22:1 \\
\hline Canola & & 4.5 & $1-2$ & $55-63$ & $20-31$ & $9-10$ & $1-2$ \\
\hline Palm & & 42 & 4 & 42 & 10 & & \\
\hline Soybean & & $32-46.3$ & $4-6.3$ & $37-53$ & $6-12$ & & \\
\hline & & 9 & 2 & 32 & 53 & & \\
\hline Tallow & & $2.3-11$ & $2.4-6$ & $22-30.8$ & $49-53$ & $2-10.5$ & \\
\hline Tallow (beef) & & 23 & 19 & 42 & 3 & & \\
\hline
\end{tabular}

\subsection{IQT Testing of Biodiesel Samples and Blends}

As part of their in-kind contribution to this project, Chevron completed ignition quality tester (IQT) studies on about twenty biodiesel samples collected by USC. Results are shown in Table 6, where the last 
two columns indicate the measured cetane number, repeated to test the reproducibility of the measurement. These results provide a additional criteria for determining good fuel-surrogate blends to represent biodiesels from different sources in engine simulations.

Table 6. Results of IQT testing of biodiesel samples and biodiesel/ULSD blends.

\begin{tabular}{|c|c|c|c|c|}
\hline Lab \# & Client \# & Date & First Run DCN D6890 & Second Run DCN D6890 \\
\hline 09-00672 & Methyl Caprate & 01/07/09 & 52.8 & 53.2 \\
\hline $09-01094$ & $5 \%$ Methyl Caprate $+95 \%$ ULSD & $01 / 07 / 09$ & 49.3 & 49.3 \\
\hline 09-01095 & $20 \%$ Methyl Caprate $+80 \%$ ULSD & $01 / 07 / 09$ & 49.5 & 49.6 \\
\hline 09-01084 & $5 \%$ Methyl Stearate + 95\% ULSD & $01 / 07 / 09$ & Not Soluable & Not Soluable \\
\hline $09-01085$ & $20 \%$ Methyl Stearate $+80 \%$ ULSD & $01 / 07 / 09$ & Not Soluable & Not Soluable \\
\hline $09-01086$ & $5 \%$ Methyl Butyrate + 95\% ULSD & 01/07/09 & 49.0 & 48.2 \\
\hline 09-01087 & $20 \%$ Methyl Butyrate $+80 \%$ ULSD & $01 / 07 / 09$ & 43.8 & 43.2 \\
\hline $09-01090$ & $5 \%$ Fame $-1+95 \%$ ULSD & $01 / 07 / 09$ & 51.6 & 52.0 \\
\hline 09-01091 & $20 \%$ Fame $-1+80 \%$ ULSD & $01 / 07 / 09$ & 52.0 & 51.7 \\
\hline $09-01092$ & $5 \%$ Fame $-2+95 \%$ ULSD & $01 / 07 / 09$ & 52.3 & 52.0 \\
\hline $09-01093$ & $20 \%$ Fame $-2+80 \%$ ULSD & 01/07/09 & 54.5 & 54.0 \\
\hline $09-01088$ & $5 \%$ Methyl Crotonate $+95 \%$ ULSD & $01 / 07 / 09$ & 48.6 & 48.8 \\
\hline 09-01089 & $20 \%$ Methyl Crotonate $+80 \%$ ULSD & $01 / 07 / 09$ & 44.8 & 45.0 \\
\hline $09-00414$ & Fame fact \# 8 USC-01 & $01 / 07 / 09$ & 52.4 & 51.7 \\
\hline $09-00415$ & Fame fact \# 9 USC-07 & $01 / 07 / 09$ & 59.2 & 58.4 \\
\hline $09-00416$ & Methyl Stearate favt \# 5 & $01 / 07 / 09$ & Not Soluable & Not Soluable \\
\hline $09-00417$ & Methyl Crotonate fact \# 7 & $01 / 07 / 09$ & 8.0 & 7.9 \\
\hline $09-00418$ & Methyl Butyrate fact \# 6 & 01/07/09 & Not Measurable & Not Measurable \\
\hline $09-00413$ & ULSD D7769 Fact \# 4 & $01 / 07 / 09$ & 49.0 & 48.6 \\
\hline
\end{tabular}




\section{Fundamental Experiments of Biodiesels and Surrogates}

To measure fundamental combustion properties of the biodiesel fuel samples and the model surrogates, USC designed and built a heated counterflow. This burner system is unique in that it contains both internal liquid heating and external heating by ceramic heaters. The burner can be heated up to $300{ }^{\circ} \mathrm{C}$ to ensure temperature uniformity throughout the reactant gas lines. In addition, the internal liquid heat also serves the purpose of regulating nozzle temperatures over time. The development of the system addressed several challenges in performing fundamental experiments on long-chain biodiesel fuels. The main ones pertain to achieving steady operation while preventing the fuel from reacting before it reaches the burner. These are two partially contradicting requirements. Achieving steady flow requires that the vaporization is obtained rapidly, which in turn implies that the temperatures of the vaporization chamber have to be high. On the other hand, high temperatures can result in fuel cracking, which has been confirmed experimentally. It therefore required several iterations through trial and error as well as design modifications to achieve those goals. This iteration was aided by frequent comparison between model predictions and experimental measurements on several renditions of the burner apparatus and experimental procedures. The models were able to highlight inconsistencies between different fuels studied, which ultimately led to discovery of repeatability issues in the experiments. These issues were then addressed carefully and rigorously at USC, through careful analysis of each component of the measurement. The result was a high quality set of fundamental combustion data that were used to test and verify the models and the surrogate approach.

In the following sub-section, we describe in some detail the evolution of the experimental facility as well as the learning obtained on necessary experimental procedures. Section 2.2 then reports on the data measured using the revised apparatus and methodology.

\subsection{Experimental Apparatus Development}

These experiments are difficult and USC learned that, without the care and rigorous testing of assumptions as described above, it is relatively easy to produce data that are neither reliable nor accurate. With a focus on scientific integrity of the methods being used, then, USC spent significant time reviewing the measurements to assure that they were of the highest quality possible. One outcome of this study was a re-design of the vaporization system that provides more reliable vaporization-without-cracking of the liquid fuels. They also determined the effect of the thermal boundary layer near the burner and the sensitivity of the measurement to the radial location of the probe. These additional studies provide a much better idea of the uncertainty and potential pitfalls for these types of measurements. In addition, a deeper understanding of the experimental sensitivities enables better use of the data in model development and validation.

\subsubsection{Vaporization System Upgrade}

The upgraded vaporization system has the capability to handle heavier liquid fuels including real biodiesels. The stainless steel vaporization chamber used previously was substituted with a glass chamber to prevent cracking and coking at high temperatures. Additionally, a quartz nebulizer with a flush capillary lapped nozzle has been integrated to the system to introduce the fuel as a fine aerosol into the chamber; the details are shown in Figure 1. Photographs of the actual setup are also shown in Figure 2. This allows for complete vaporization to occur at lower temperatures. The result is more constant vaporization and the prevention of fuel cracking. 


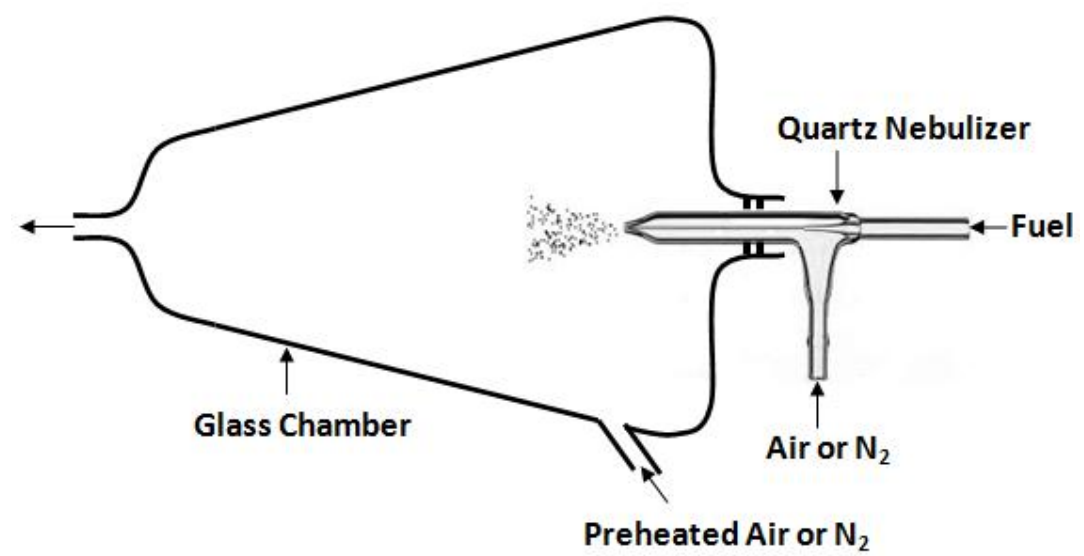

Figure 1. Schematic of the upgraded vaporization system.
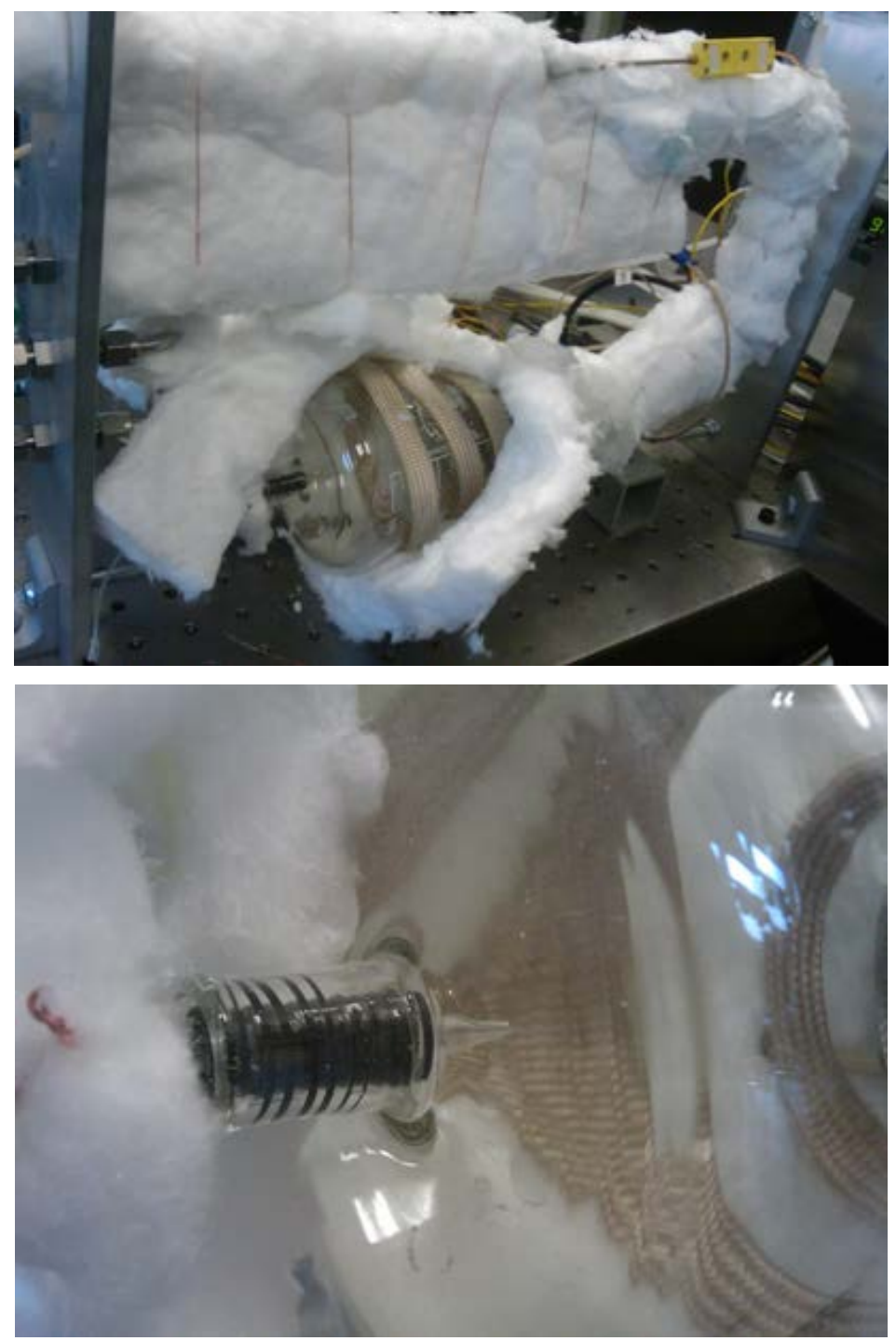

Figure 2. Photographs of the upgraded vaporization system. 


\subsubsection{Effect of Thermal Boundary Layer on Radial Temperature Profile}

In addition to vaporization, USC undertook a thorough investigation of the effects of thermal boundary layers in the burner on the measurement of laminar flame speeds and extinction strain rates. Figure 3 depicts the configuration of the heated burner used for the current experiments. To attain an unburned gas temperature of around $130^{\circ} \mathrm{C}$ for the lower jet, the burner walls are heated with high-performance ceramic heating jackets. When the entire system reaches thermal steady state, the temperatures of the burner and nozzle walls are around $150{ }^{\circ} \mathrm{C}$ and $140{ }^{\circ} \mathrm{C}$, respectively. The unburned gas temperature is measured at the center of the nozzle with an uncoated R-type thermocouple. The tip of the thermocouple is $0.1 \mathrm{~mm}$ in diameter, and can provide fast response and highly accurate measurements.

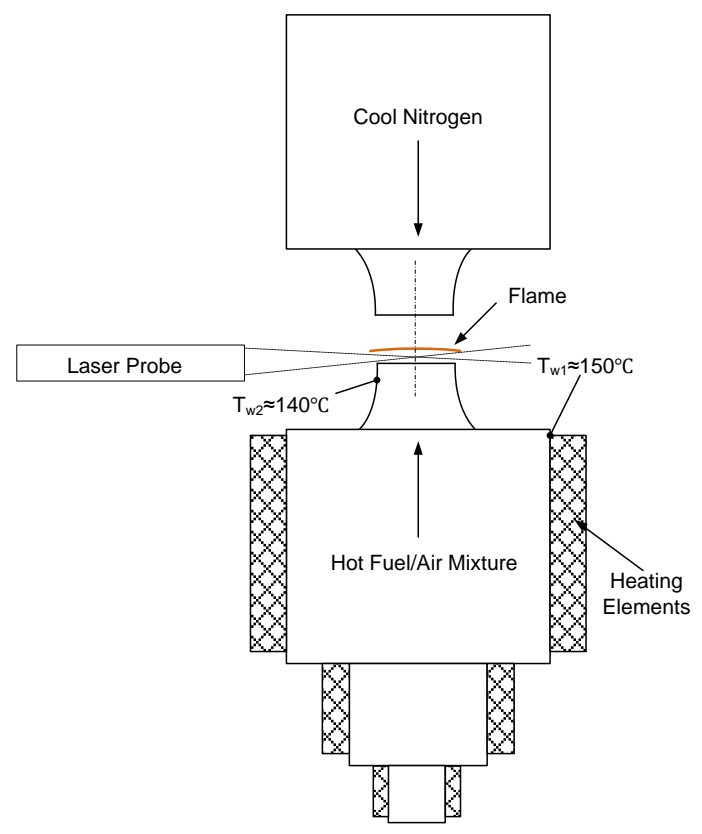

Figure 3. Burner configuration.

Due to the heat transfer between the nozzle wall and the fuel/air mixture, the radial temperature profile at the exit of the nozzle is non-uniform, as shown in Figure 4. The non-uniformity is more severe at higher exit temperatures. This thermal boundary layer directly affects the velocity profile of the jet, and hence the shape of the flame as shown in Figure 5. Therefore, the measurement point for velocity should be aligned very carefully to the burner centerline. Otherwise the non-uniform velocity profile may introduce errors into the reference flame-speed measurements. For example, accidental placement of the laser probe 1-2 $\mathrm{mm}$ away from the system centerline can result in higher reference flame speeds due to thermal effects. 


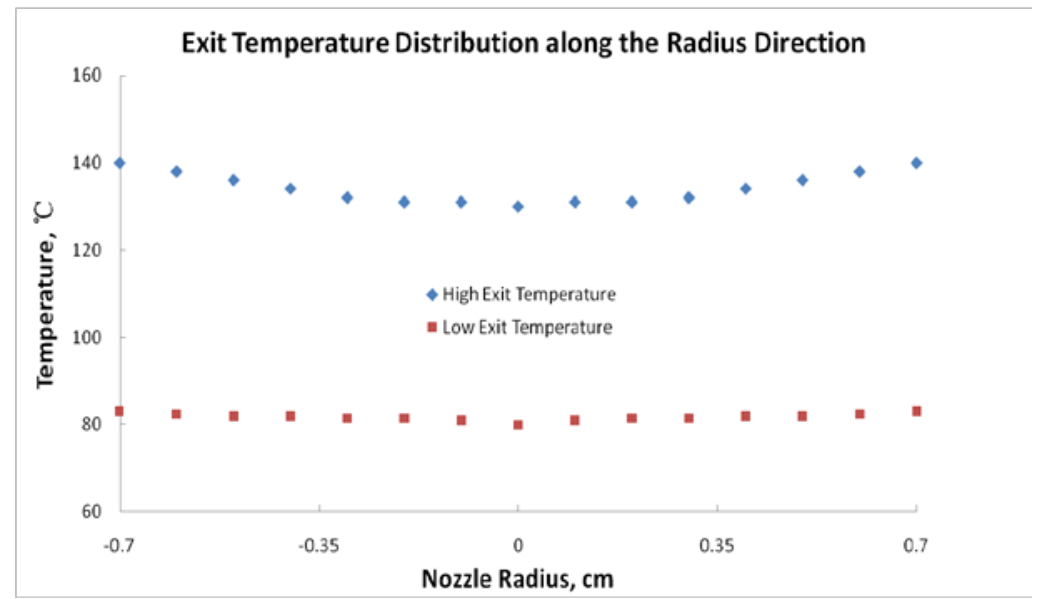

Figure 4. Radial temperature distribution at the nozzle exit.

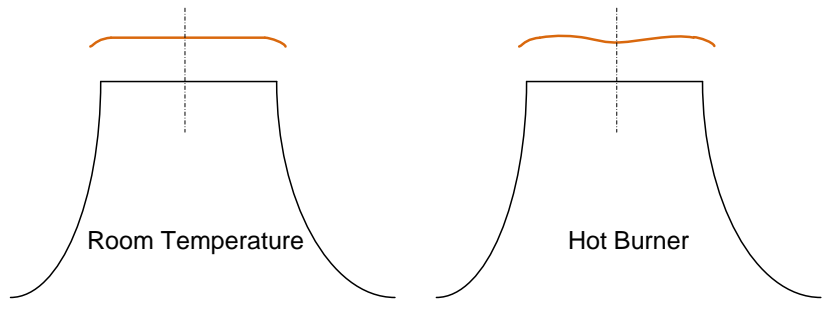

Figure 5. Flame shape at different exit temperatures.

\subsubsection{Effect of Flow Rate on Burner Exit Temperature}

By plotting the reference flame speed, $S_{u, r e f}$, against the strain rate, $K$, the laminar flame speed, $S_{u}^{o}$, could be determined by extrapolating the reference flame speed to zero stretch as indicated in Figure $6 . K$ is varied by changing the flow rate through the burner using a bypass system. However, along with the change of flow rate, the heat-transfer rate between the mixture and the wall also changes, thus affecting the gas exit temperature. Figure 7 depicts the exit temperature variation with $K$. As expected, results indicate that if the flow rate decreases by opening the bypass, the gas exit temperature increases. The typical effect of the unburned gas temperature on laminar flame speed is shown in Figure 8. Consequently, if a temperature correction is not applied to the raw data, the extrapolation would yield incorrect laminar flame speeds at elevated temperatures. 


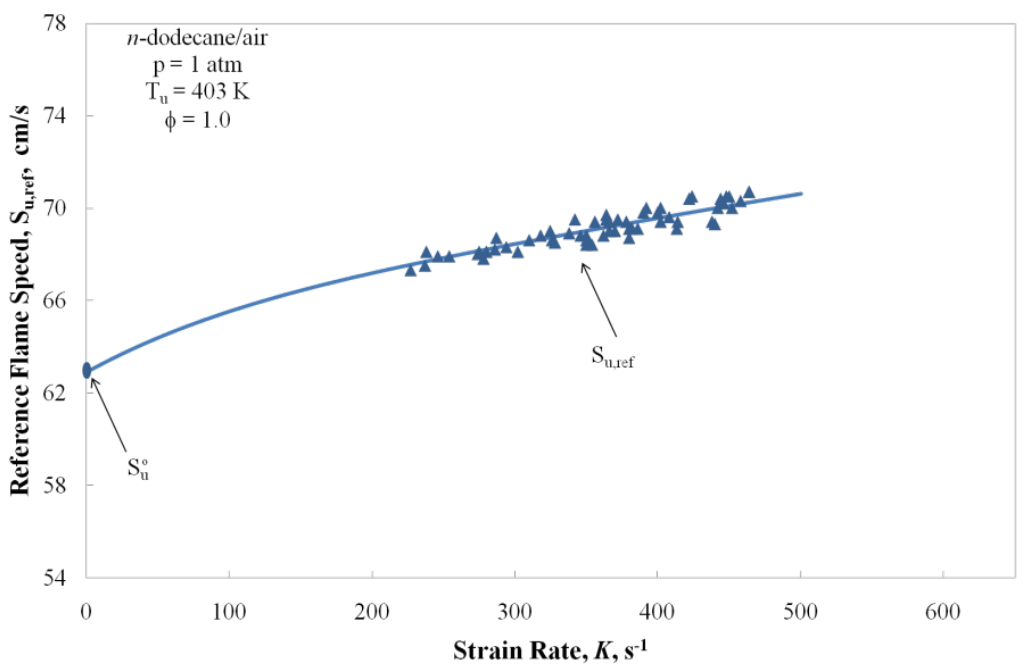

Figure 6. Laminar flame speed determination.

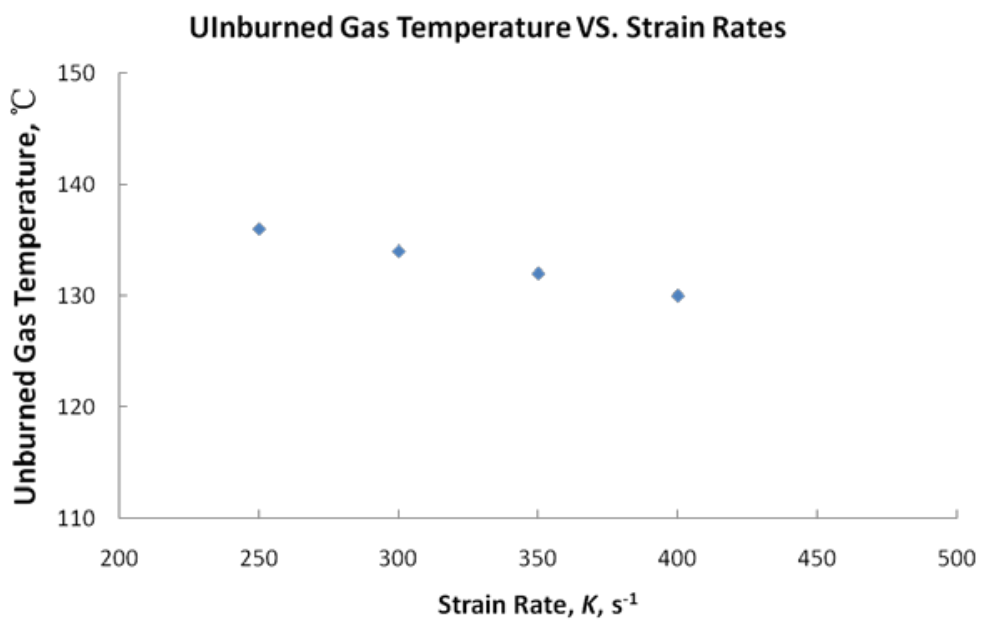

Figure 7. Variation of exit temperature versus strain rate. 


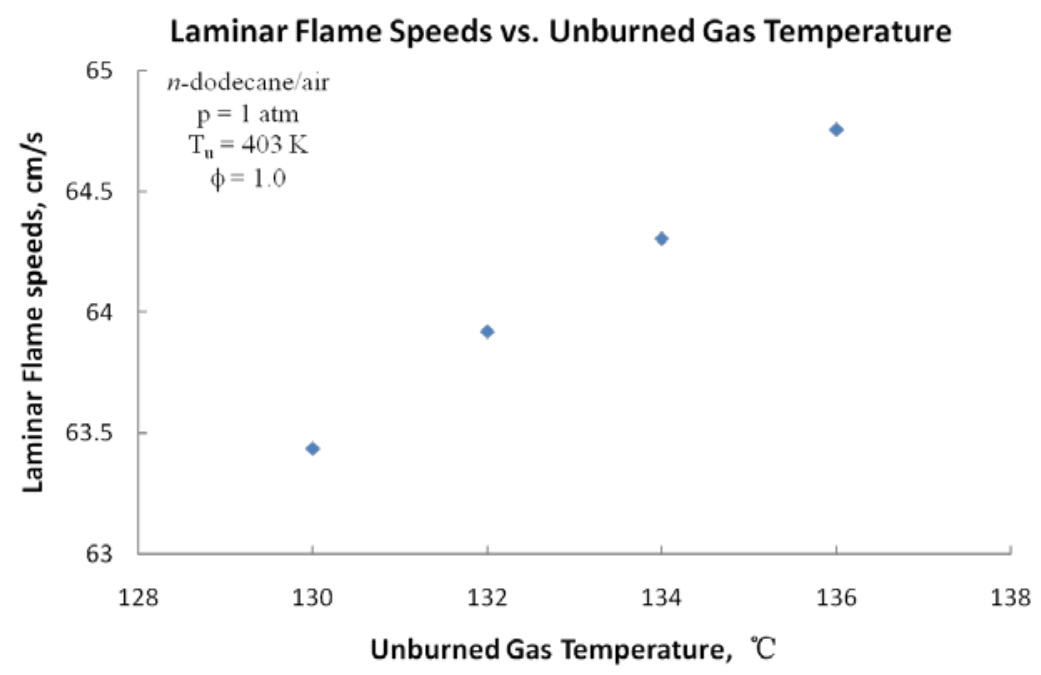

Figure 8. Variation of laminar flame speed with unburned gas temperature.

Figure 9 shows the reference flame speed variation for stoichiometric toluene/air mixtures at different exit temperatures with no temperature correction. As observed, the slope of the raw data is positive at room temperature. However, if the exit temperature is increased to $80^{\circ} \mathrm{C}$, the slope becomes flatter and finally becomes negative when the temperature reaches $130^{\circ} \mathrm{C}$. From the theory of stretched flames, it is known that the slope of the raw data should be sensitive only to the mixture Lewis number, such that the unburned mixture temperature should not change the slope of the data. Figure 10 shows the raw data from Figure 9 corrected using the results from Figure 7. Here, as expected, the slope of the raw data at different exit temperatures remains the same.

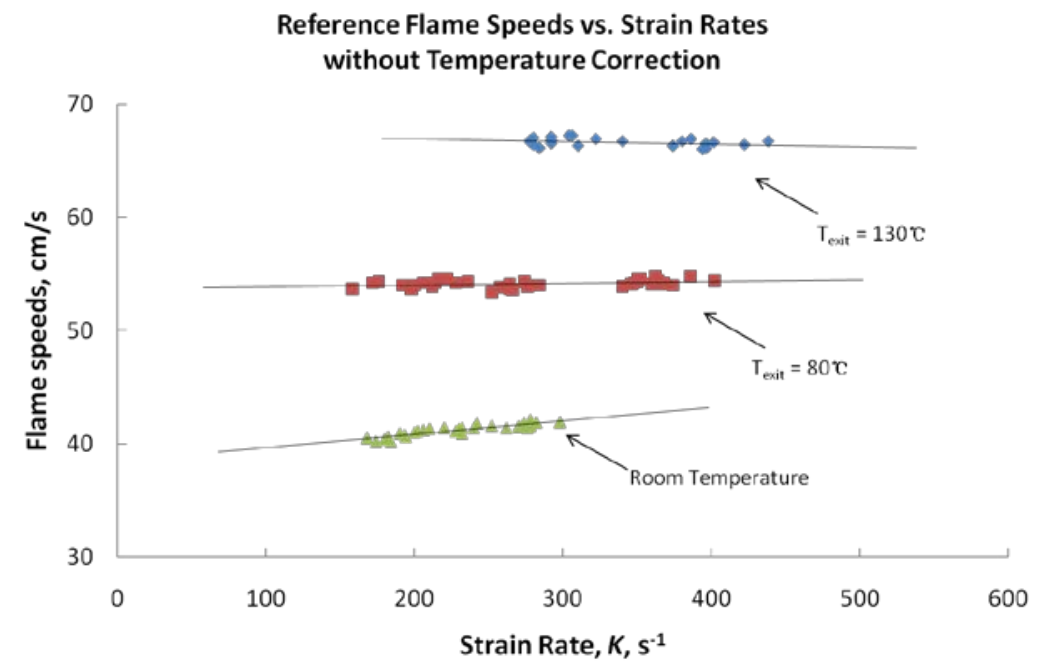

Figure 9. Variation of the reference flame speed with strain rate with no temperature correction. 


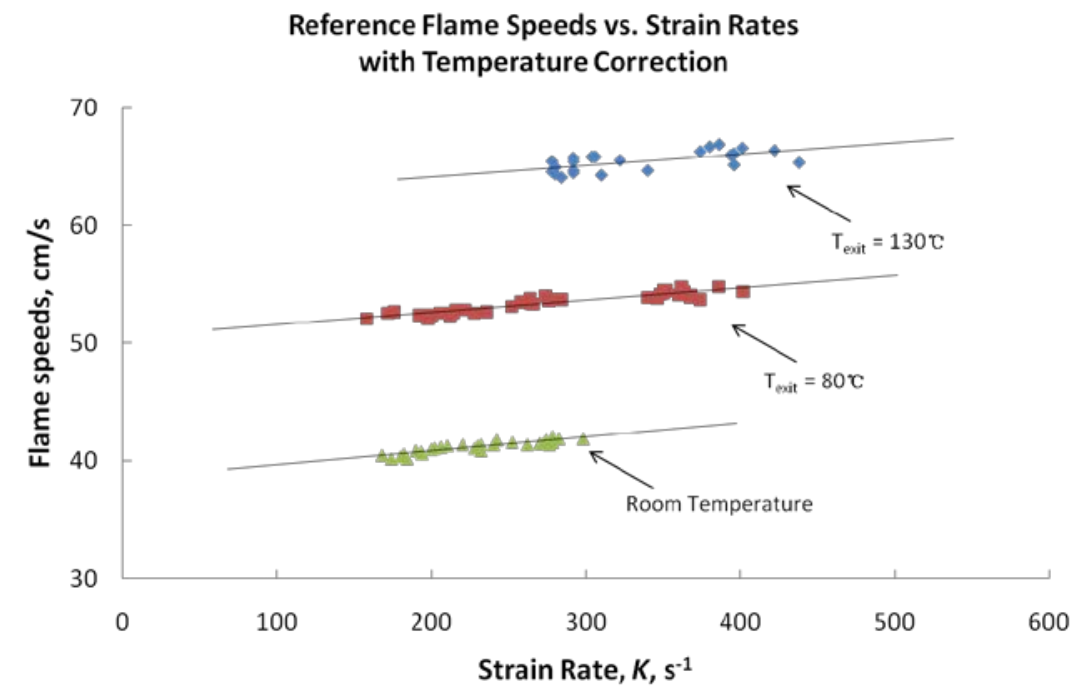

Figure 10. Variation of the reference flame speed versus strain rate with temperature correction, showing the expected independence of slope vs. strain rate with initial temperature.

\subsubsection{Effect of Probe Location on Flame Speeds in Counterflow Flames}

Next, USC looked at the effect of radial location on the exit velocity components, reference flame speeds and stretch rates. Figure 11 depicts the variation along the radial distance from the centerline, $r$, of the radial velocity component, $v$, and the axial velocity component, $u$, near the nozzle exit, for a stoichiometric methane/air flame at room temperature. The variation of $v$ along $r$ is linear, as is expected for the counterflow configuration. However, the profile of the axial velocity, $u$, starts deviating from that of a plug flow away from the centerline. Figure 12 indicates that the measured minimum axial velocity, $u_{\min }$, and maximum absolute axial strain rate in the preflame region, $|d u / d x|_{\max }$, also increase away from the centerline. The values of $u_{\min }$ and $|d u / d x|_{\max }$ at the centerline are chosen as the reference flame speed, $S_{u, r e f}$ and imposed strain rate, $K$, respectively. The deviation of the above values is significant for $r>1$ $\mathrm{mm}$.
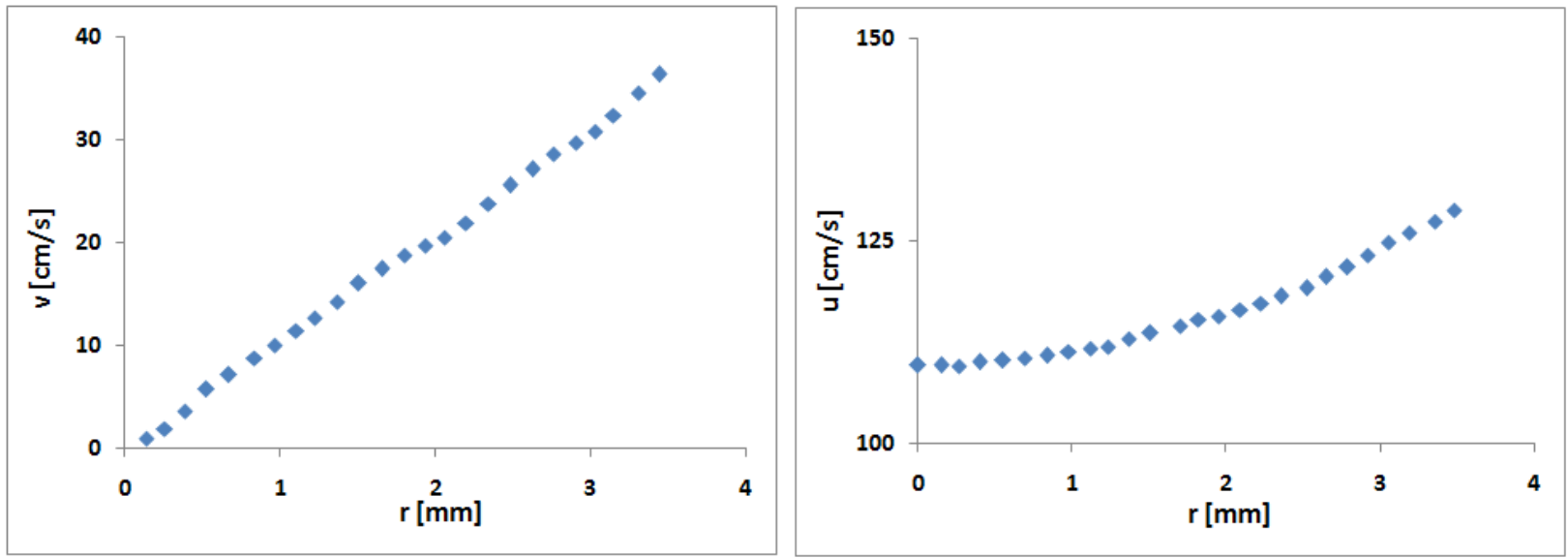

Figure 11. Radial variation of the radial and axial exit velocity components of a counterflow jet at room temperature. 

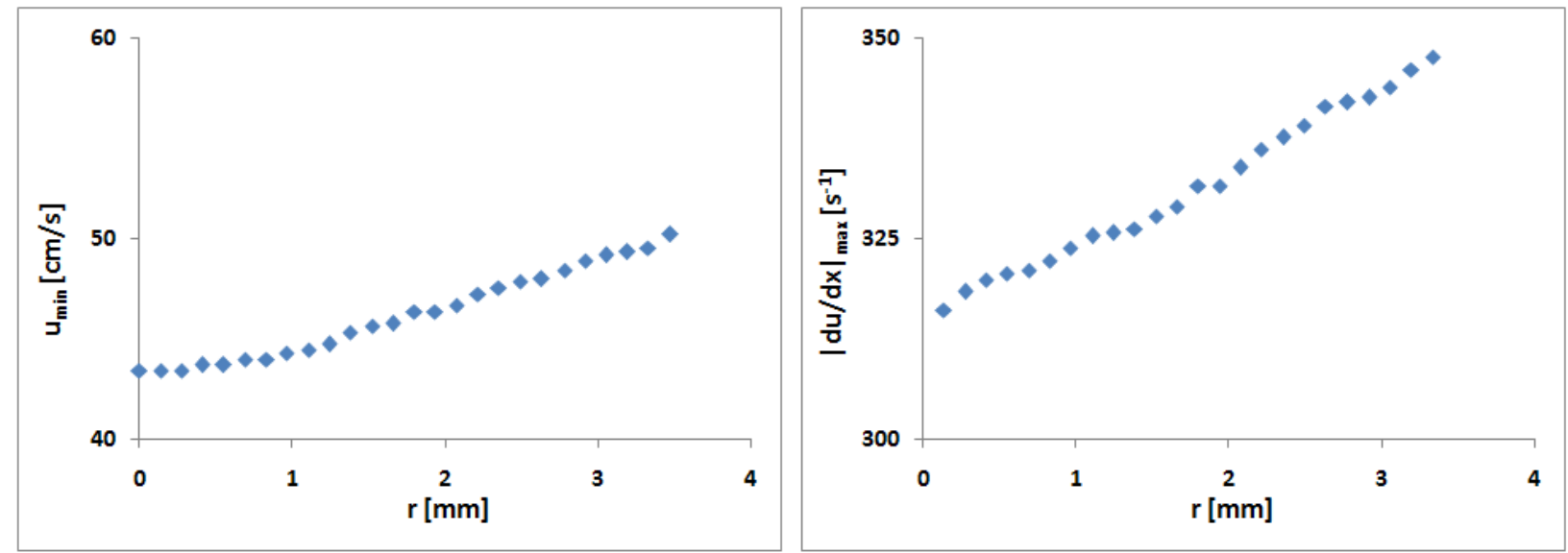

Figure 12. Radial variation of the minimum axial velocity and maximum absolute axial strain rate for flames at room temperature.

Similar results are shown below in Figure 13 and Figure 14, for the case of a stoichiometric methane/air flame at an unburned mixture temperature of $130^{\circ} \mathrm{C}$. The deviation of $u_{\min }$ and $|d u / d x|_{\max }$ is even more severe in this case due to the higher flame speeds and the thermal boundary layer discussed earlier.
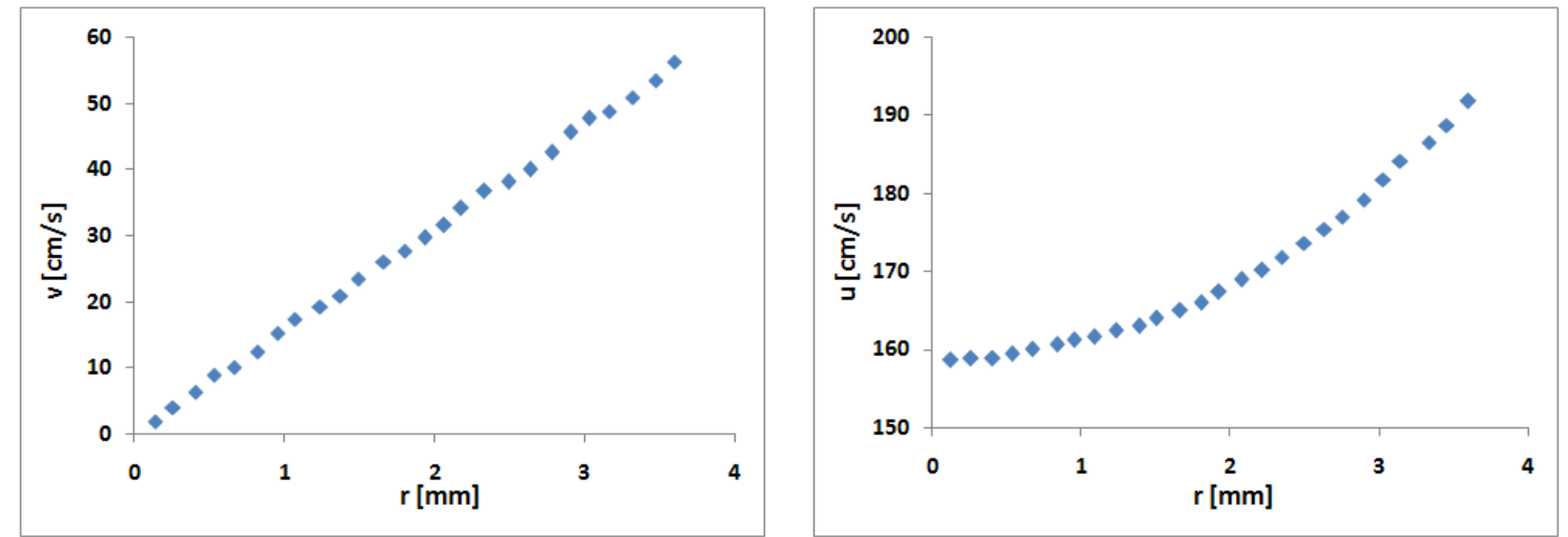

Figure 13. Radial variation of the radial and axial exit velocity components of a counterflow jet at elevated temperature. 

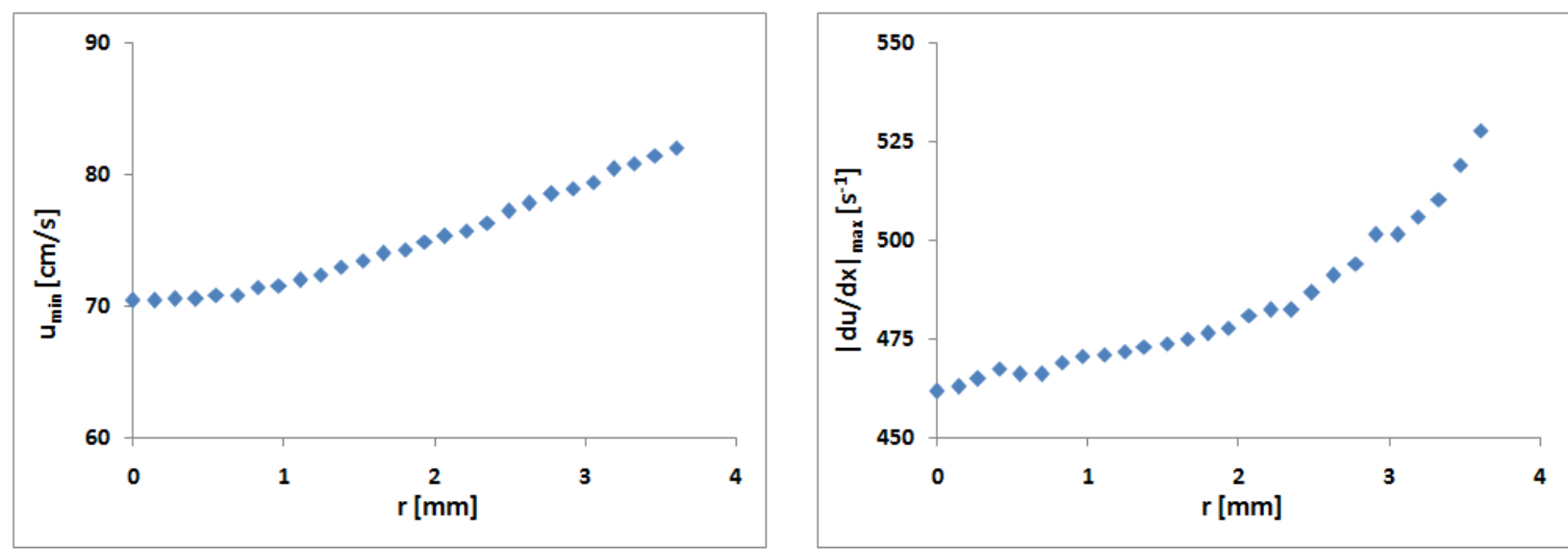

Figure 14. Radial variation of the reference flame speed and stretch rate for a flame at elevated temperature.

This observed increase in $u_{\min }$ away from the centerline could be attributed to flame curvature. As depicted in Figure 15 for a stoichiometric methane/air flame at room temperature, the location of $u_{\min }$ away from the nozzle exit increases in the radial direction. Thus, the shape of the flame, which can be deduced from these locations, is actually not perfectly flat. The slope of the flame surface increases with radius, as shown in Figure 16. However, if the total velocities are projected onto a direction that is perpendicular to the flame surface at any given radial location and the minimum value in the pre-flame region is taken, the actual $S_{u, r e f}$ can be obtained. As opposed to $u_{\min }, S_{u, r e f}$ stays constant away for a significant distance away from the centerline as shown in Figure 17. Therefore, the value of $u_{\min }$ can be used as the actual $S_{u, r e f}$ only close to centerline, otherwise the aforementioned correction has be used.

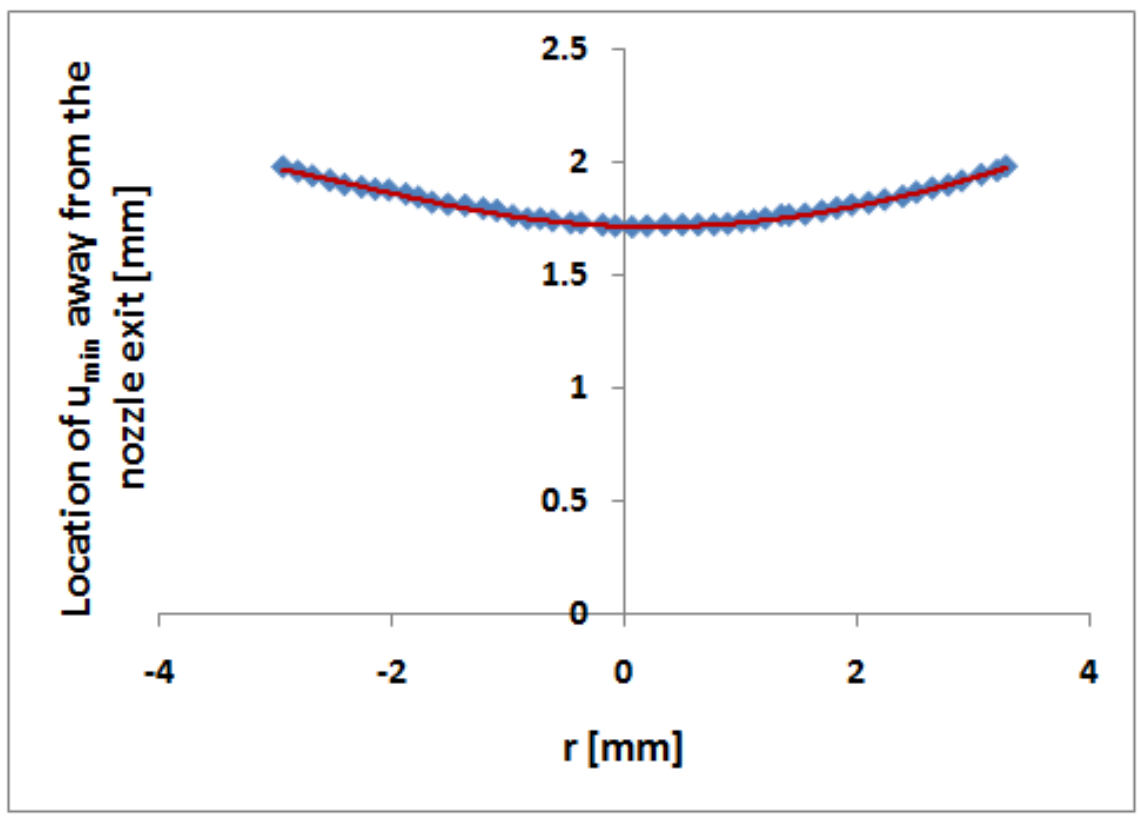

Figure 15. Radial variation of the $u_{\min }$ location relative to the nozzle exit. 


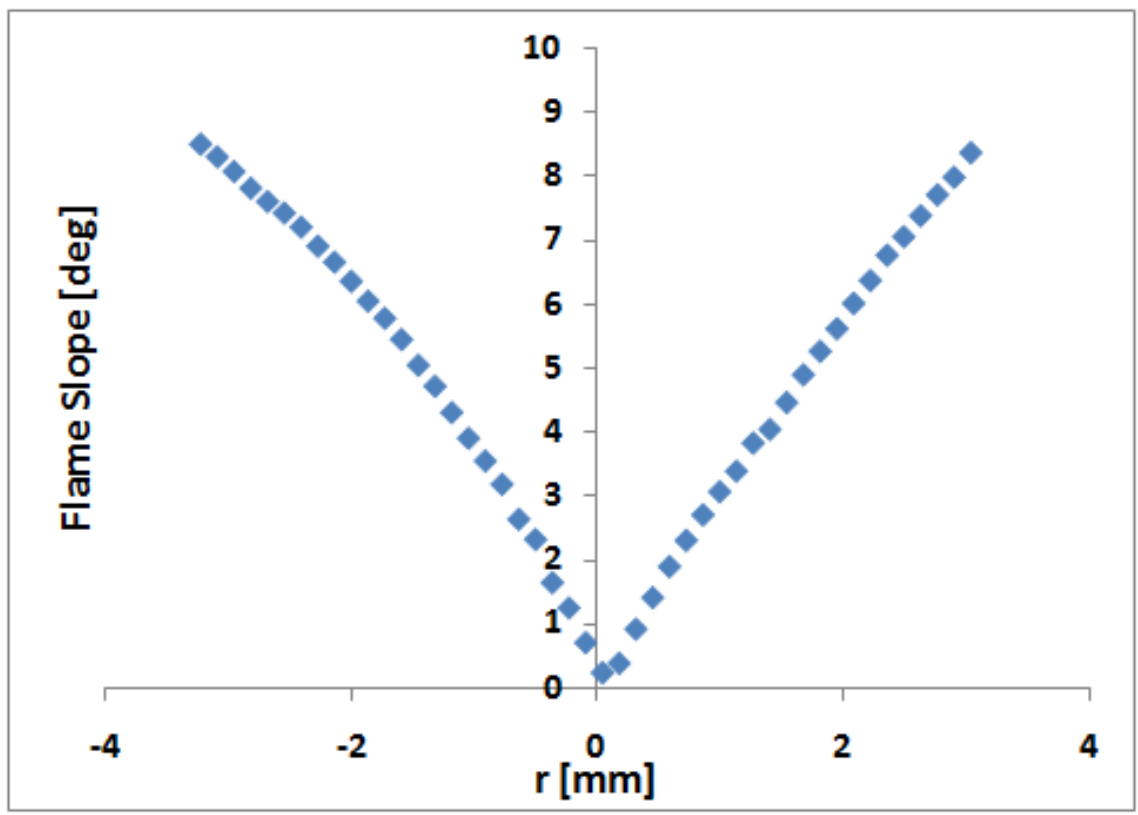

Figure 16. Radial variation of the slope of the flame surface.

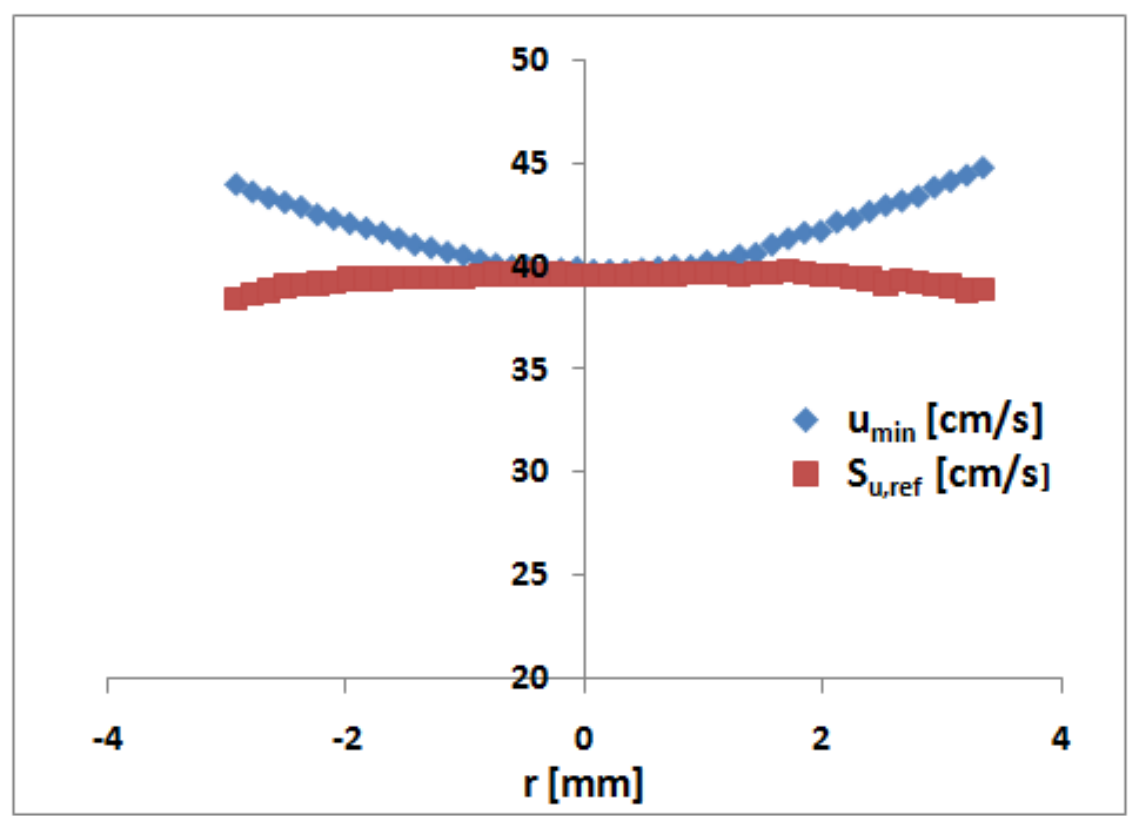

Figure 17. Radial variation of the $u_{\min }$ and $S_{u, r e f}$

This situation can easily lead to erroneous flame-speed measurements; we therefore conclude from the investigations above the absolute necessity of taking the reference flame speed and axial strain rate measurements very close to the nozzle centerline where the flame curvature is mild. Thus, frequently observed discrepancies with data obtained from other research groups using the counterflow configuration could be attributed to such effects. 


\subsubsection{Development of a Laser Extinction System For Measuring Soot}

USC also upgraded their experimental capabilities with the addition of a system for high-resolution laser extinction measurements of soot volume concentration. Soot, a cluster of carbon atoms larger than the surrounding fuel, air, and $\mathrm{N}_{2}$, absorbs light. By transmitting a laser through a sooting flame, the amount of light absorbed can be calculated and, through an established process, be reversed to find the soot volume fraction.

The system consists of a 1-mW helium-neon laser mounted on a precision $\mathrm{y}$-z traverse. The laser beam can be focused to a minimum thickness of $0.1 \mathrm{~mm}$ with a $20-\mathrm{cm}$ plano-convex lens and mounted so as to traverse the flames between burners in the horizontal plane. Laser beam intensity is recorded by a ThorLabs PDA 100A amplified photo-detector. This photo-detector has a sensitive diameter of approximately $6-8 \mathrm{~mm}$. The traverse mechanism is manually operated and allows for better than 10micron stepping resolution. Due to the large detection area of the photo-detector the system can be configured to permit the detector to remain stationary while only the laser is moved; this greatly simplifies the implementation of this technique on more complex apparatuses and limits its sensitivity to vibrations. Photo-detector output is recorded by both a Fluke Digital Multimeter averaged over a period of 20 seconds for each position and a Tektronix 3630 oscilloscope. The reference readings $\left(I_{0}\right)$ are performed without a flame or with a non-sooting flame and then readings with a sooting flame $(I)$ are taken to yield the line of sight transmittance $\left(I / I_{0}\right)$. Following Wang, Du, Sung, and Law [4], the local extinction coefficient $k_{\text {ext }}$ is obtained through deconvolution of the integral:

$$
-\ln \left(\frac{I(y)}{I_{0}}\right)=2 \int_{y}^{\infty} k_{e x t}(r) \frac{r}{\sqrt{r^{2}-y^{2}}} d r
$$

The soot volume fraction $\left(F_{v}\right)$ is then obtained from the relationship,

$$
k_{e x t}=\frac{6 \pi}{\lambda} \operatorname{Im}\left[\frac{m^{2}-1}{m^{2}+2}\right] F_{v},
$$

where $\lambda$ is the wavelength of the laser beam $-632.8 \mathrm{~nm}-$ and $m$ is the complex refractive index, $m=1.58$ - 0.57i. Figure 18 shows a schematic of the set-up and Figure 19 shows a photo of the experimental setup.

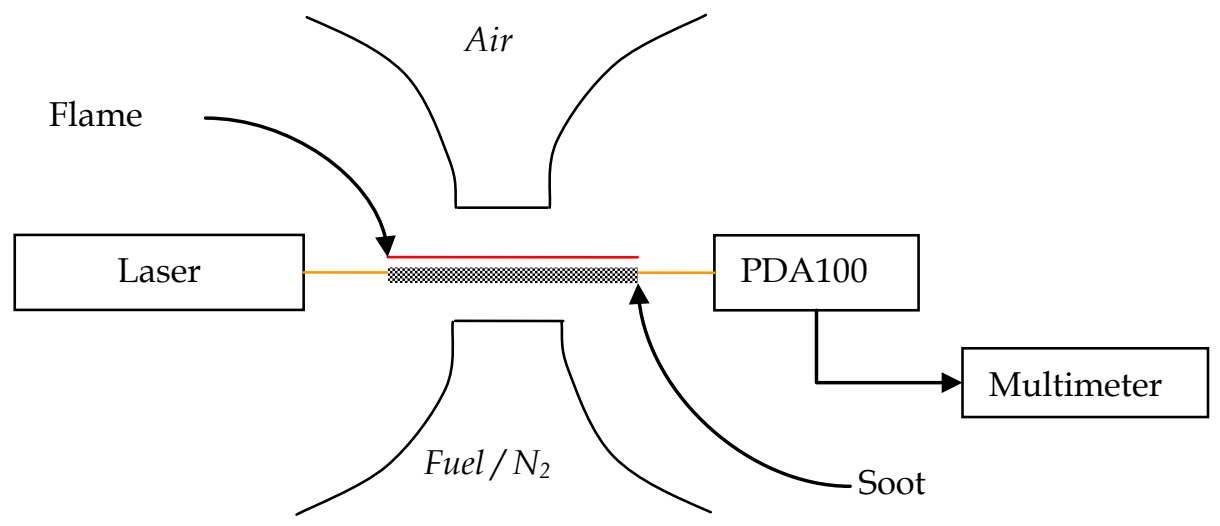

Figure 18. Schematic of a non-premixed sooting flame with laser light extinction set-up. 


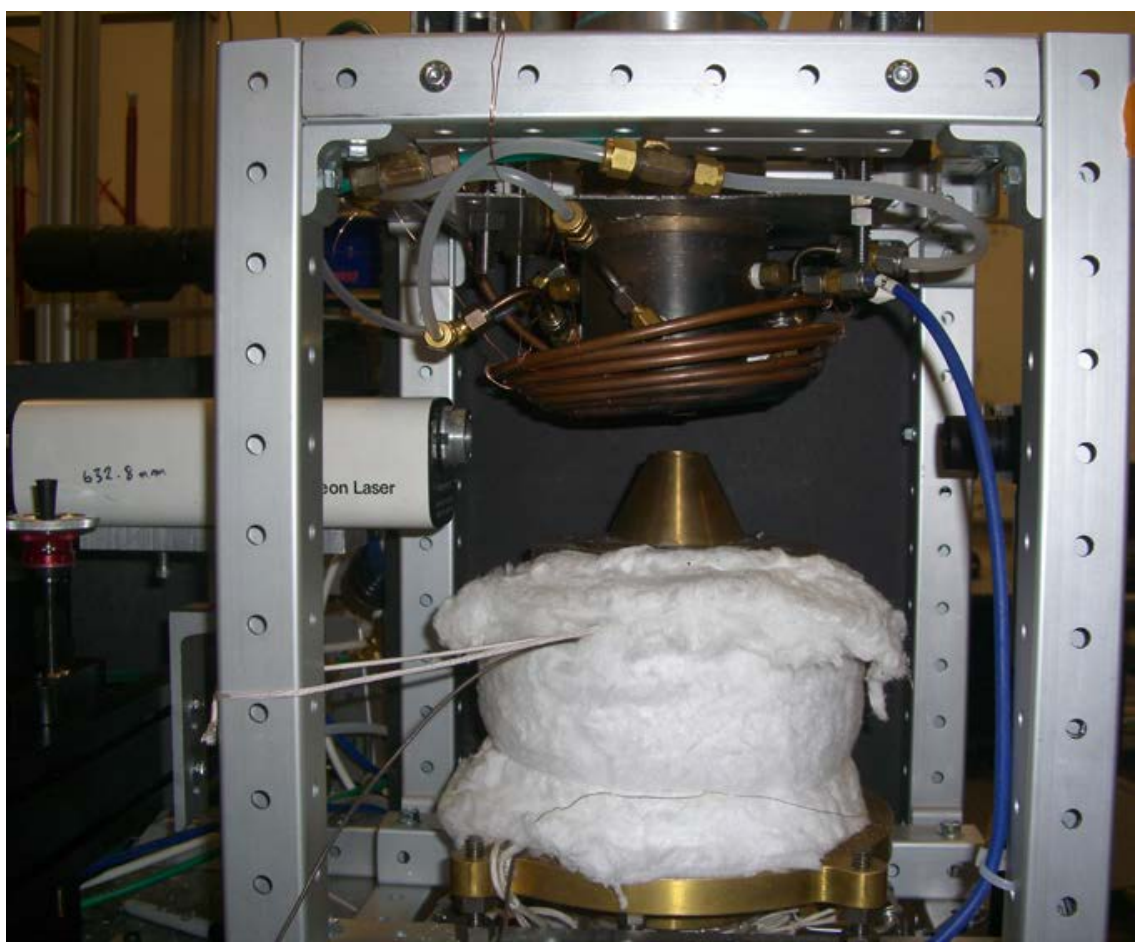

Figure 19. Picture of current set-up of a non-premixed sooting flame with a laser light extinction set-up.

The apparatus has been tested using an ethylene- $\mathrm{N}_{2}$ mixture with a 0.297 fuel mole fraction and a 0.339 fuel mole fraction. One data set for the 0.297 fuel mole fraction (Flame A), and one for the 0.339 fuel mole fraction (Flame B), are plotted as line of sight transmittance $\left(I / I_{0}\right)$ vs. distance from the bottom burner in Figure 20. Flames A and B start sooting and stop sooting in roughly the same location from the exit of the bottom burner, but show significant difference across the flame. The reported data in Figure 20 are very preliminary (with large uncertainty bars) and meant to just demonstrate that the system output is what is expected qualitatively. In the next section the next steps will be described. During the testing it was found that it is necessary to allow the laser and photo-detector to warm up for at least 30 minutes to ensure stable reference readings. 


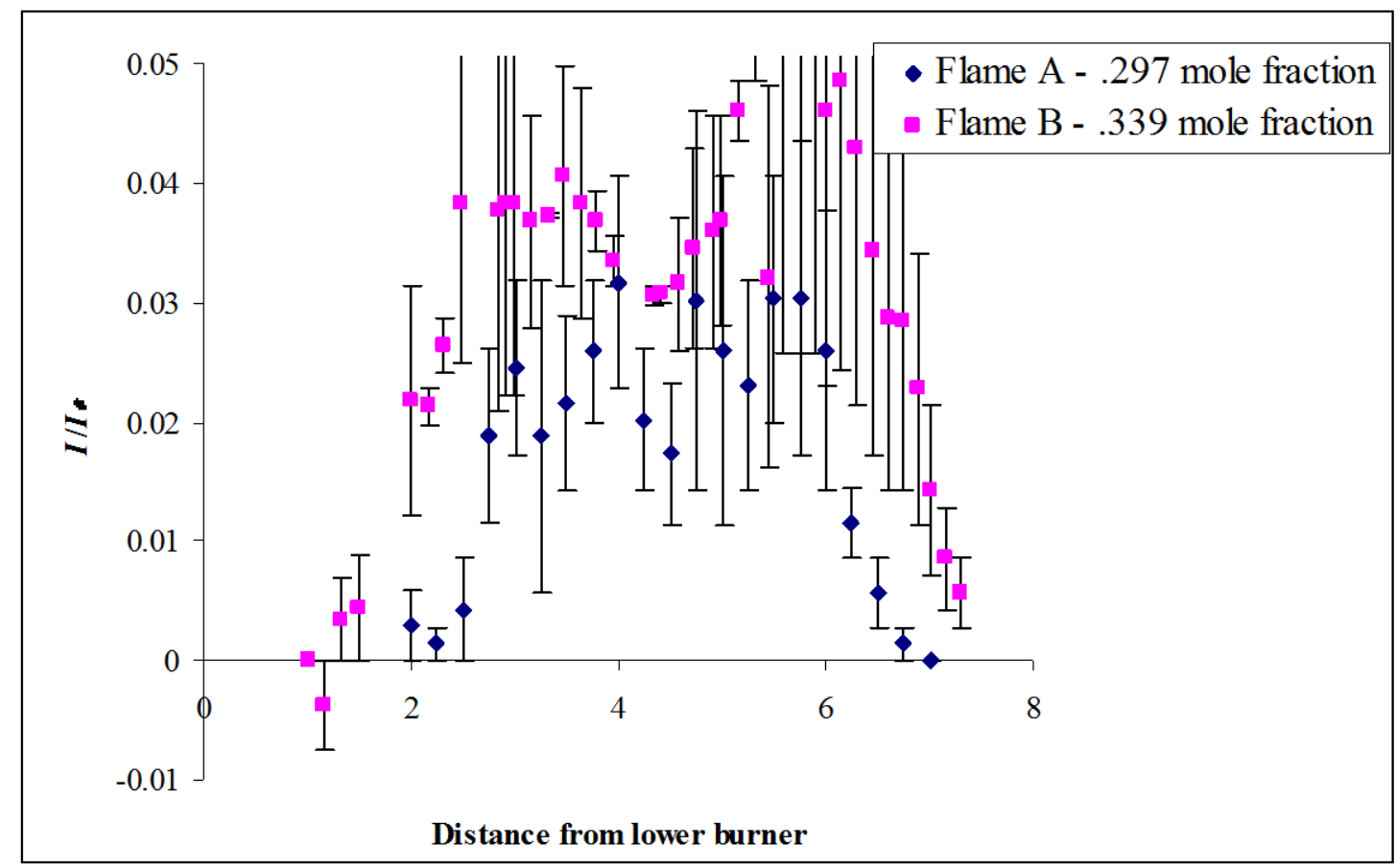

Figure 20. Line of transmittance fraction $\left(I_{0}\right)$ vs. distance from bottom burner.

As shown in Figure 20, there is significant scatter in the data and attendant uncertainty bars. This is likely associated with unsteadiness of the flame related to air-currents and burner alignment. Repeatability and reliability of the data will have to be assured before any definitive data is produced, but the system has been shown to function correctly and has sufficient sensitivity to be of much use in measuring liquid fuels once properly configured. An enclosure will need to be built to accommodate the sooting flames for health purposes, provide an $\mathrm{N}_{2}$ environment for eliminating the secondary diffusion flames caused by reaction with the ambient air, and shield the flame from air currents associated with manually adjusting the traverse mechanism. Adding pure $\mathrm{O}_{2}$ to the top flow will increase the temperature and provide a larger range of soot-producing flames. In the near future a special thermocouple will be incorporated, which will sample the temperature of the flame, allowing it to be regulated or held constant.

\subsection{Flame Measurements}

At the conclusion of these experimental system enhancements and verification, USC was able to take a large set of data for biodiesel surrogates and biodiesel samples, including flame-speed, extinction, and $\mathrm{NO}_{\mathrm{x}}$ emissions measurements. These data were used to verify and improve the kinetics models as discussed in the next section of this report.

\subsubsection{Laminar Flame Speeds}

Measurements of methyl-butanoate/air, methyl-crotonate/air flames at atmospheric pressure and an unburned mixture temperature, $T_{\mathrm{u}}=60^{\circ} \mathrm{C}$, were made using the new vaporization system. In addition, the laminar flame speeds of $n$-pentane were measured under the same experimental conditions. These laminar flame speeds are shown in Figure 21 for a wide range of $\phi$. The maximum laminar flame speed value occurs at $\phi \sim 1.10$. Compared to methyl-butanoate/air mixtures, the laminar flame speeds of methyl-crotonate/air mixtures are slightly higher especially for rich fuel-air mixtures. The presence of oxygen in the methyl-butanoate and methyl-crotonate results in their laminar flame speeds peaking at a higher equivalence $(\sim 1.1)$ compared to $n$-pentane $(\sim 1.05)$ 


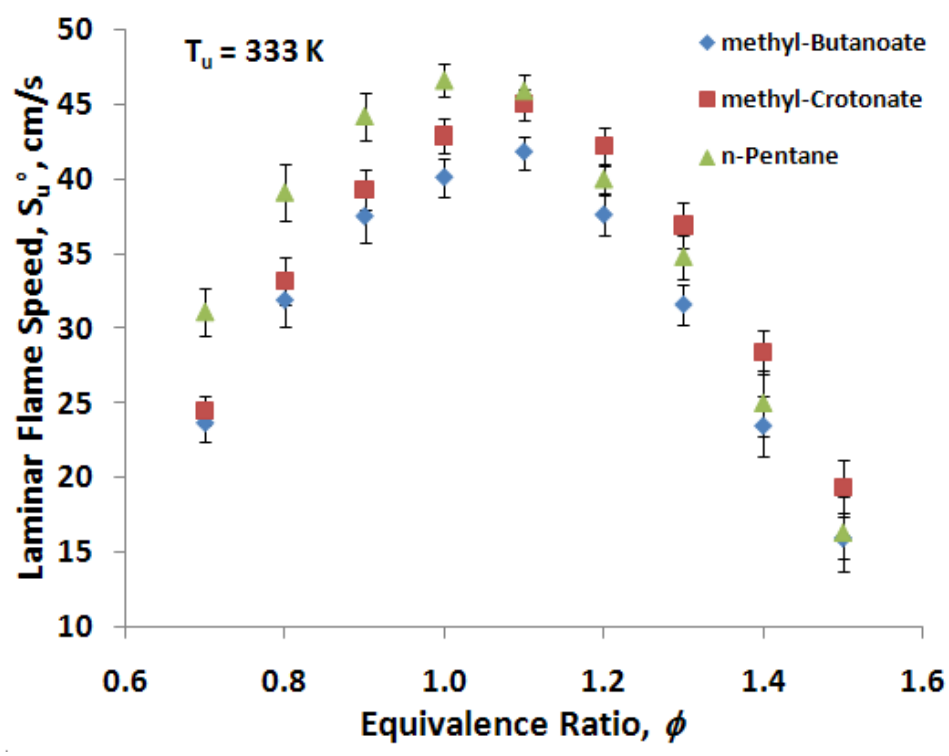

Figure 21. Experimentally determined laminar flame speeds of methyl-butanoate/air, methyl-crotonate/air and $n$-petane/air mixtures at an unburned mixture temperature of $60^{\circ} \mathrm{C}$ as functions of equivalence ratio, $\phi$.

The laminar flame speeds of methyl-butanoate/air, methyl-crotonate/air flames at atmospheric pressure and $T_{\mathrm{u}}=130^{\circ} \mathrm{C}$ were also measured. These laminar flame speeds are shown in Figure 22 for a wide range of $\phi$, along with those of methyl-decanoate/air mixtures. The laminar flame speeds of methylbutanoate/air mixtures are similar to those of methyl-decanoate/air mixtures. The laminar flame speeds of methyl-crotonate/air mixtures are slightly higher than those of methyl-butanoate/air and methyldecanoate/air mixtures, especially under rich conditions.

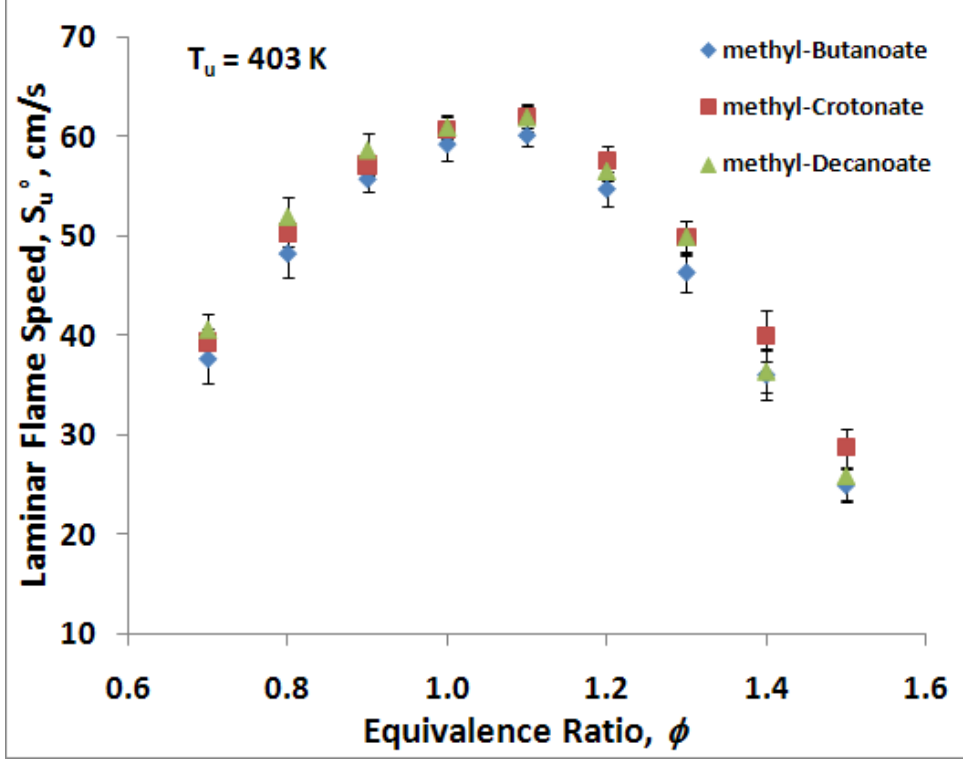


Figure 22. Experimentally determined laminar flame speeds of methyl-butanoate/air, methyl-crotonate/air and methyl-decanoate/air mixtures at an unburned mixture temperature of $130^{\circ} \mathrm{C}$ as functions of equivalence ratio, $\phi$.

The laminar flame speeds of a biodiesel surrogate/air mixture at atmospheric pressure and $T_{u}=130{ }^{\circ} \mathrm{C}$ were also measured. The proposed surrogate of $15 \%$ methyl-butanoate, $35 \%$ methyl-crotonate, and $50 \%$ $n$-decane was considered. These laminar flame speeds are shown in Figure 23 for a wide range of $\phi$, along with those of $n$-decane/air and methyl-decanoate/air mixtures. Within experimental uncertainty, the laminar flame speeds of all three mixtures can be considered identical.

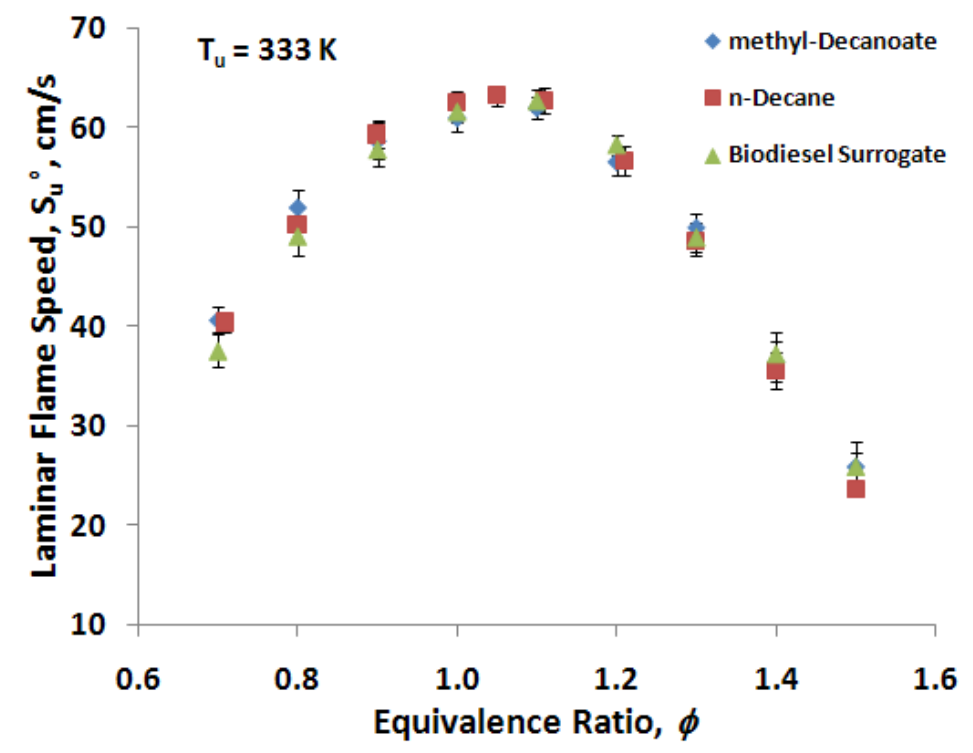

Figure 23. Experimentally determined laminar flame speeds of methyl-decanoate/air, $n$-decane/air and a biodiesel surrogate/air mixtures at an unburned mixture temperature of $130^{\circ} \mathrm{C}$ as functions of equivalence ratio, $\phi$.

\subsubsection{Flame-Extinction Strain Rates}

In addition to laminar flame speeds, USC also measured extinction strain rates for the surrogate-fuel components. These data provide complementary tests to the flame-speed data for the high-temperature reaction mechanism. In addition, they provide an additional test of the similarity between different fuel components for high-temperature flame conditions.

Figure 24 shows a comparison between methyl butanoate, methyl crotonate and an alkane of similar size (carbon number), $n$-pentane. From this comparison, we can see that for these smaller components, there appear to be significant differences in the strain rate when the non-ester chain is compared with the methyl esters, especially under rich conditions, where n-pentane appears to be more resistant to extinction than methyl butanoate, with methyl crotonate falling in between the two. For the fuel lean conditions a similar spread occurs, with the least difference between the fuels around stoichiometric conditions. We also note, however, that the higher the extinction strain rate, the larger the experimental uncertainties, as shown by the error bars. 


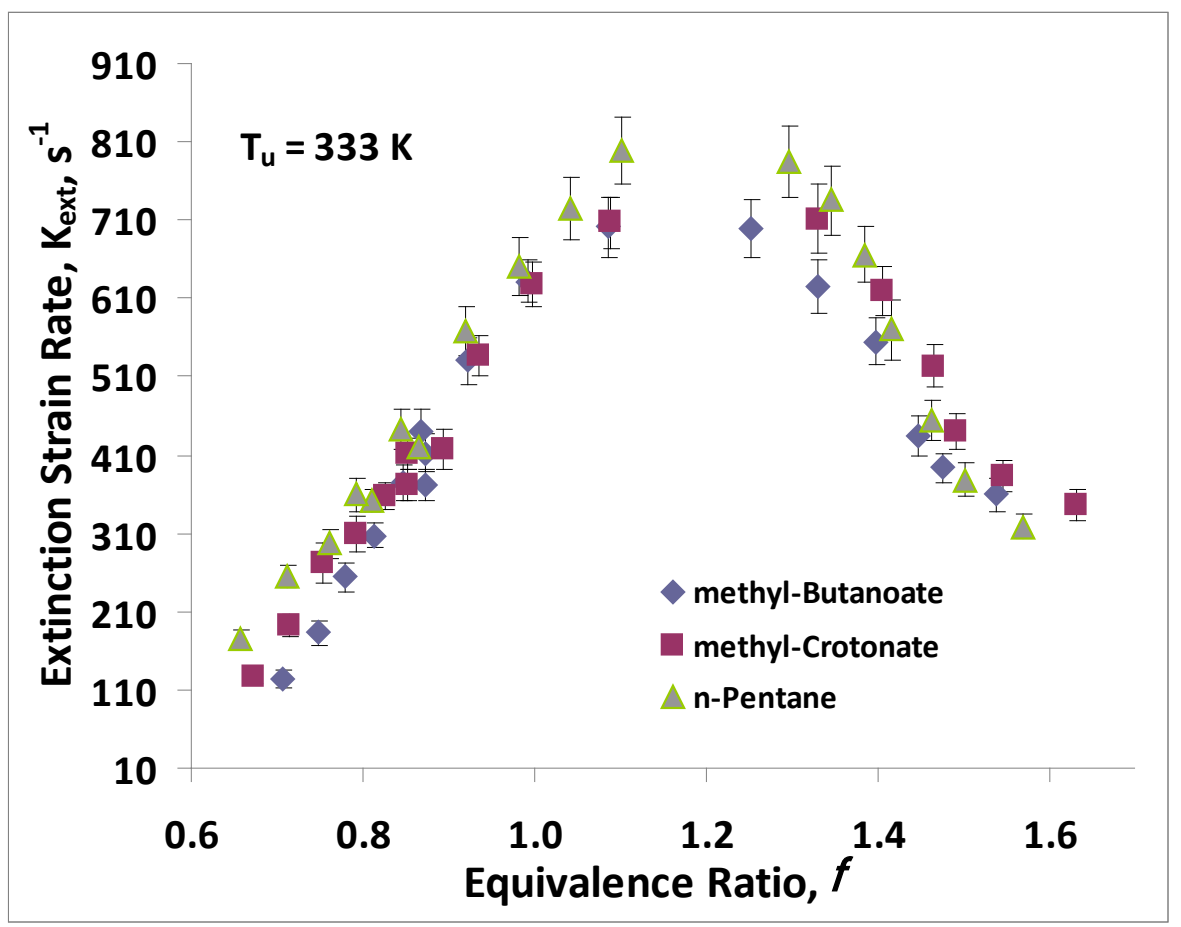

Figure 24. Measured flame-extinction strain rates for methyl butanoate, methyl crotonate, and $n$-pentane, for an unburned temperature of $333 \mathrm{~K}$, as a function of equivalence ratio. Symbols include bars to indicate uncertainties in the measurements.

In Figure 25, extinction strain rates are compared for methyl decanoate and straight-chain alkanes of similar size to this larger methyl ester. In these results, we see almost no discernable difference between the three fuels considered. There is a slight ordering of the extinction strain rates at rich/nearstoichiometric conditions with the alkanes showing slightly higher extinction strain rate than methyl decanoate and $n$-decane slightly higher than $n$-dodecane. However, again the experimental uncertainties in this region are the highest, such that this difference may be within such uncertainties. 


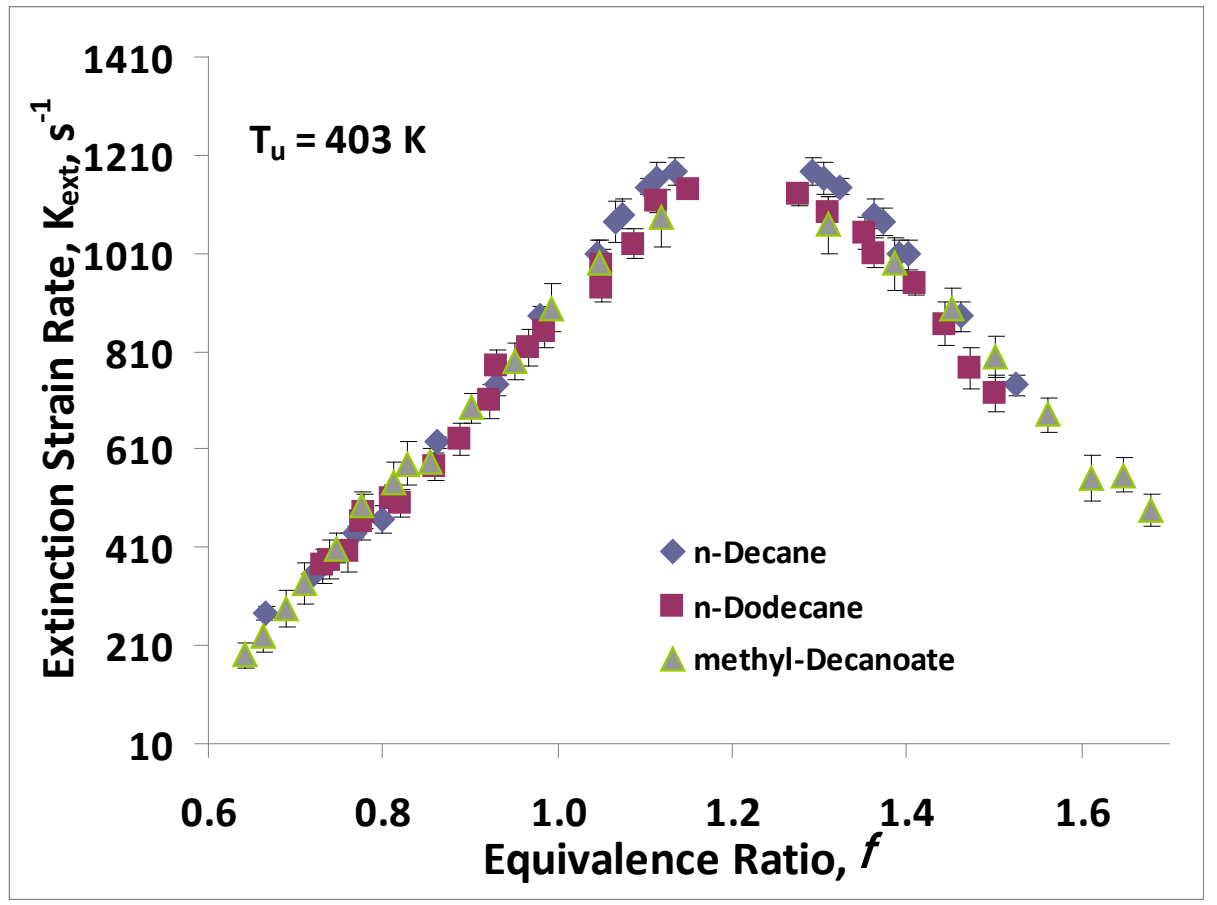

Figure 25. Measured flame-extinction strain rates for methyl decanoate, $n$-decane, and $n$-dodecane, for an unburned temperature of $403 \mathrm{~K}$, as a function of equivalence ratio. Symbols include bars to indicate uncertainties in the measurements.

Given the similarity of the larger alkanes, it is not surprising that Figure 26 indicates little difference between a surrogate blend containing 50\% $n$-decane and the pure $n$-dodecane and methyl-decanoate measurements. However, this result also demonstrates the effectiveness of using a simpler surrogate that contains only the smaller methyl esters combined with a longer alkane molecule to represent the longerchain methyl ester. This appears to be very effective for high-temperature conditions, but remains to be tested for low-temperature ignition behavior. 


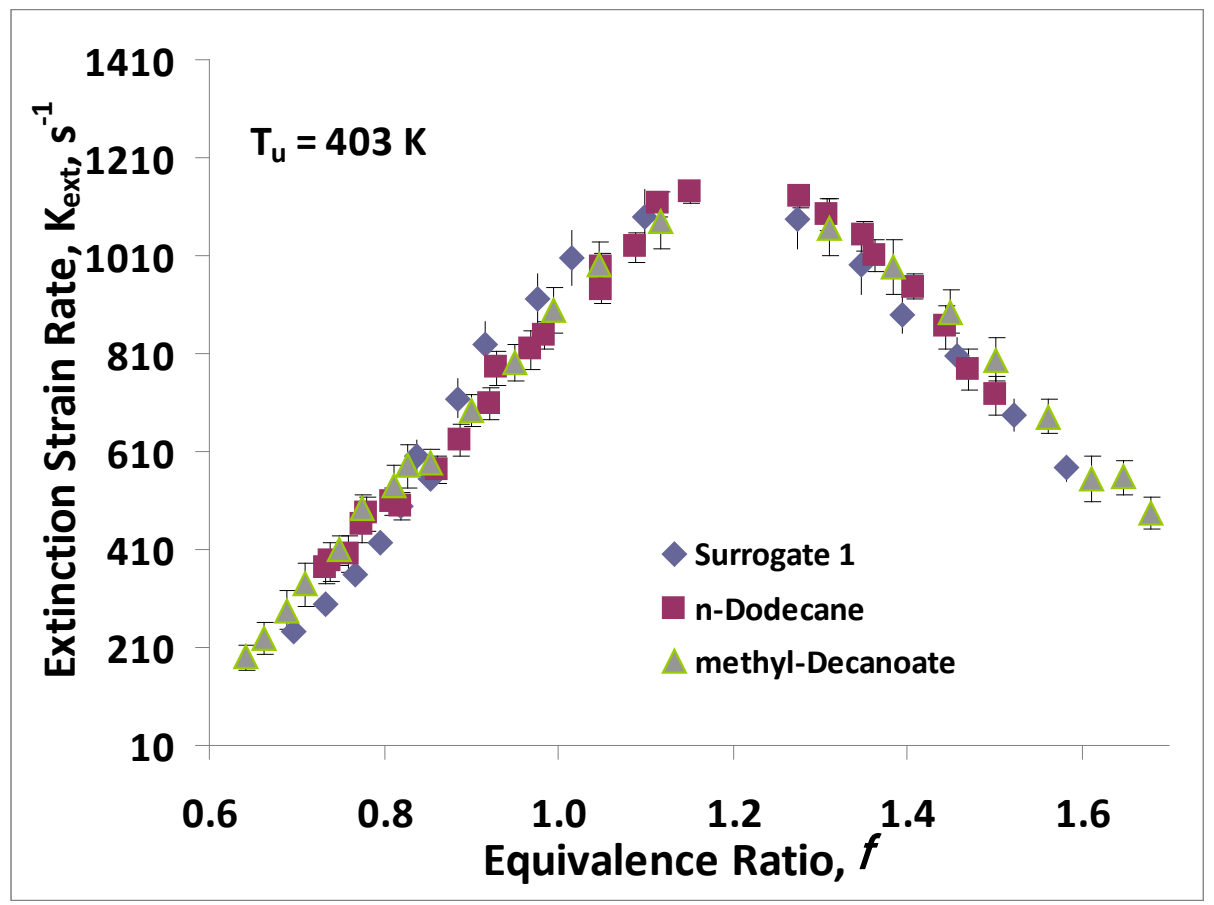

Figure 26. Measured flame-extinction strain rates for a Surrogate mixture, comprised of $15 \%$ methyl butanoate, $35 \%$ methyl crotonate and 50\% $n$-decane, compared with data for neat $n$-dodecane and methyl decanoate, for an unburned temperature of $403 \mathrm{~K}$, as a function of equivalence ratio. Symbols include bars to indicate uncertainties in the measurements.

\subsection{3. $\mathrm{NO}_{\mathrm{x}}$ Produced in Flames}

Experiments were also performed to measure the $\mathrm{NO}_{\mathrm{x}}$ formation from model-biodiesel flames. The flames were established by counterflowing a preheated fuel/air jet against an opposing $\mathrm{N}_{2}$ jet at ambient temperature. $\mathrm{NO}_{\mathrm{x}}$ sampling was accomplished by continuously withdrawing gases from within the flame using a quartz-cooled microprobe and then directing the sample towards a Chemiluminescence $\mathrm{NO}_{x}$ analyzer. Also, an accurate probe positioning system was established that includes a Cathetometer that can locate the position of the probe relative to the bottom burner within 25 micrometers.

The experimentally determined $\mathrm{NO}_{x}$ concentration profiles for methyl-butanoate/air, methylcrotonate/air, and $n$-pentane/air mixtures at $\phi=0.8,1.0$ and 1.2 and $T_{\mathrm{u}}=60{ }^{\circ} \mathrm{C}$ are plotted in Figure 27 through Figure 29. All three flames were at a global strain rate of $168 \mathrm{~s}^{-1}$, defined as twice the nozzle exit velocity divided by the separation distance between the top and bottom nozzles. The $\mathrm{NO}_{x}$ concentrations are highest for methyl-crotonate and lowest for methyl-butanoate flames. On the fuel-lean side, the $\mathrm{NO}_{\mathrm{x}}$ produced is mainly due to the thermal mechanism. Due to the presence of a double bond in methylcrotonate, more energy is released during oxidation resulting in the highest flame temperature among the three fuels, which promotes the thermal $\mathrm{NO}_{x}$ formation. For $\phi \geq 1.0$, the maximum $\mathrm{NO}_{\mathrm{x}}$ concentrations are almost the same for the methyl-crotonate and $n$-pentane flames, and lowest for the methyl-butanoate flames. 


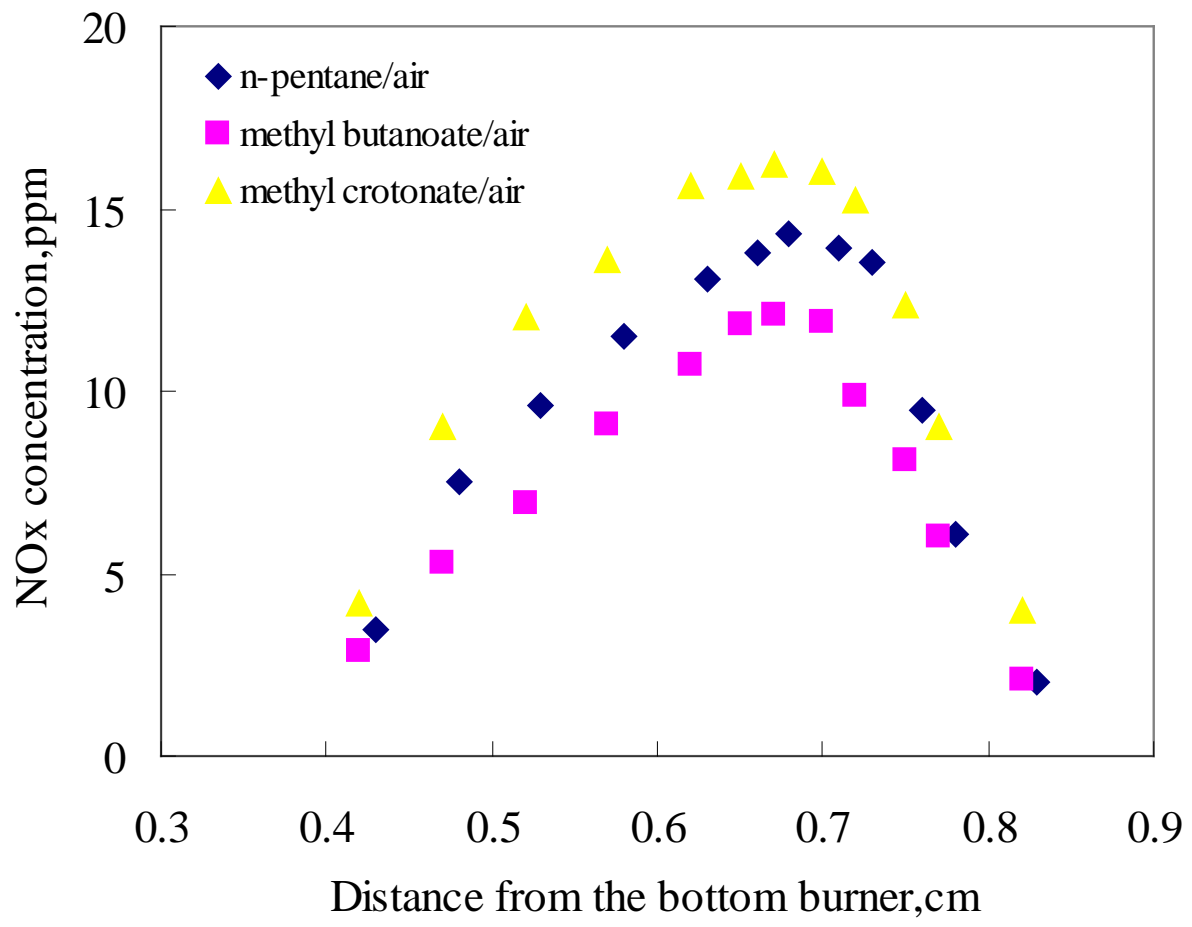

Figure 27. Experimentally determined NOx concentration profiles as a function of distance from the bottom burner for $n$-pentane/air, methyl-butanoate/air and methyl-crotonate/air flames (equivalence ratio $=0.8, K=168 \mathrm{~s}^{-1} ; \mathrm{T}_{\mathrm{u}}=60^{\circ} \mathrm{C}$ ). 


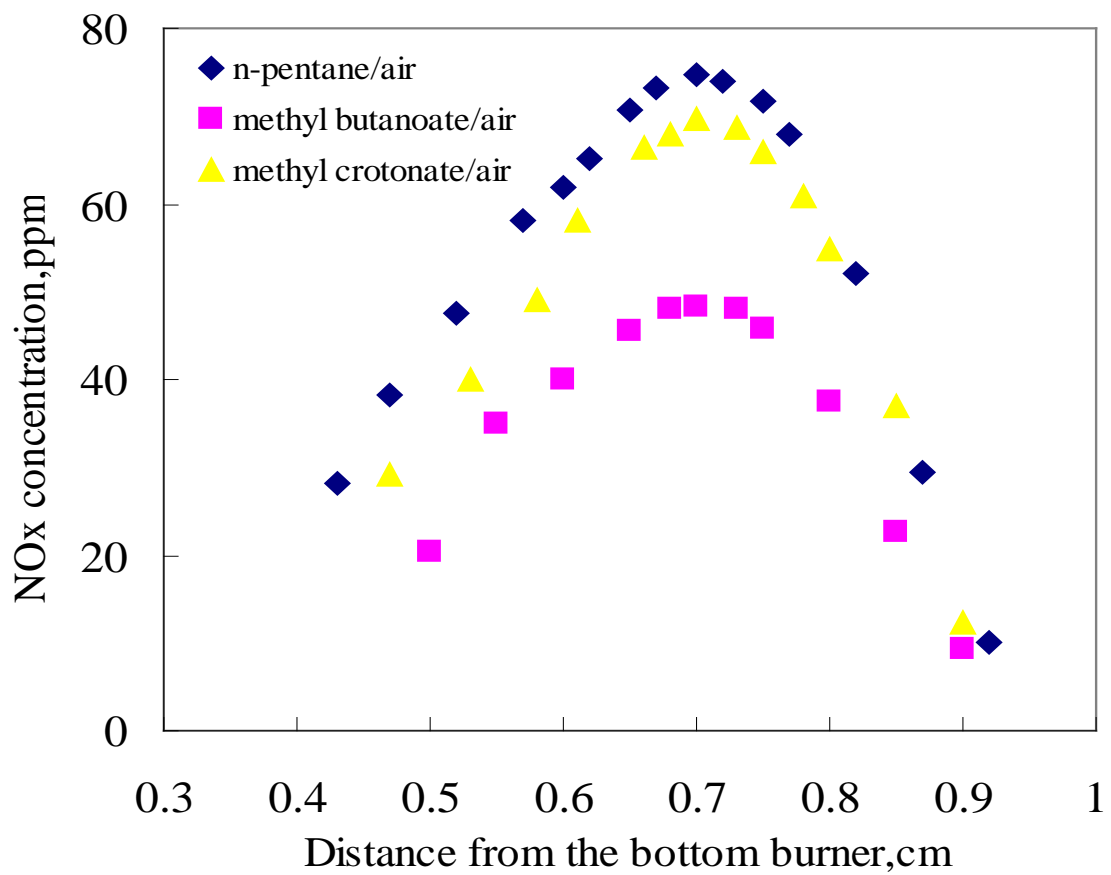

Figure 28. Experimentally determined $\mathrm{NO}_{x}$ concentration profiles as a function of distance from the bottom burner for $n$-pentane/air, methyl-butanoate/air and methyl-crotonate/air flames (equivalence ratio=1.0, $K=168 \mathrm{~s}^{-1} ; T_{\mathrm{u}}=60^{\circ} \mathrm{C}$ ).

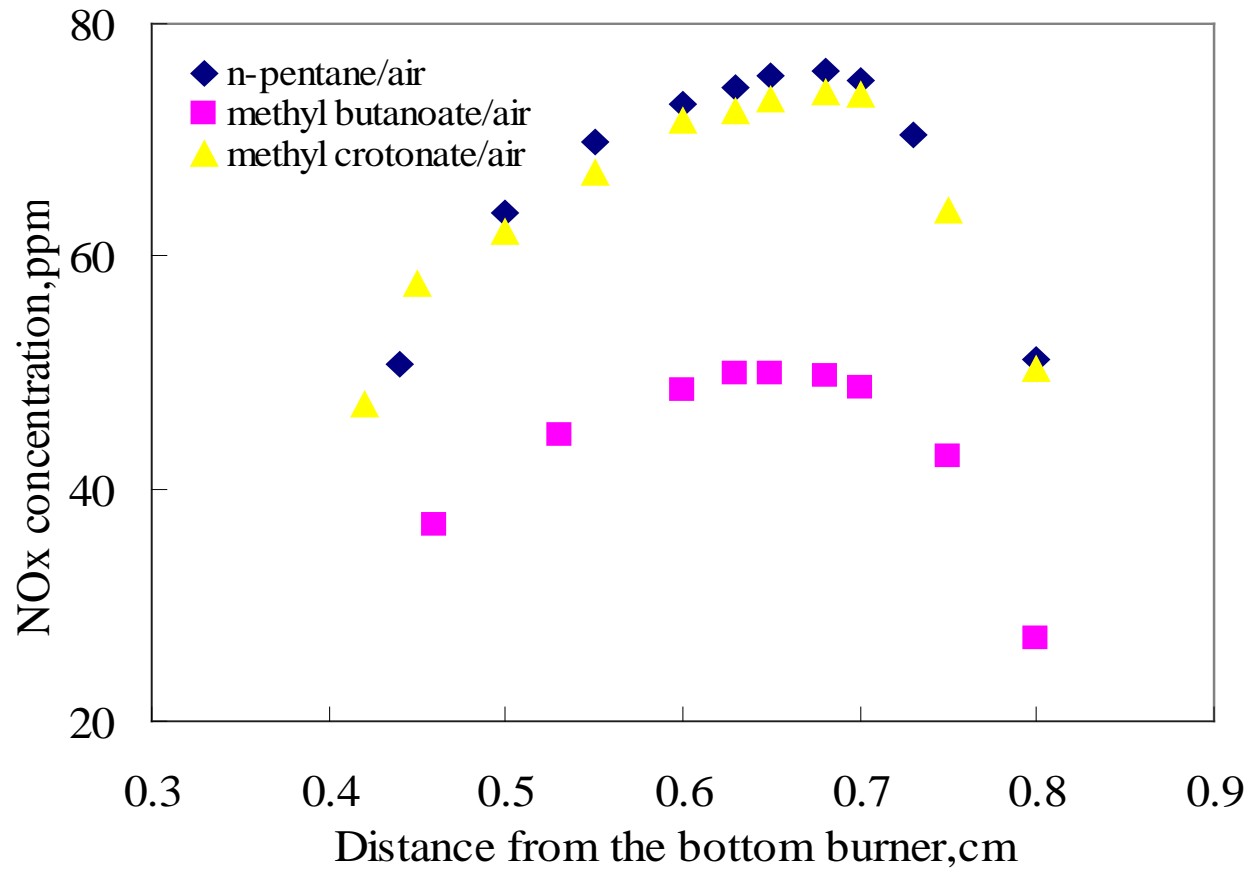

Figure 29. Experimentally determined $\mathrm{NO}_{x}$ concentration profiles as a function of distance from the bottom burner for $n$-pentane/air, methyl-butanoate/air and methyl-crotonate/air flames (equivalence ratio=1.2, $K=168 \mathrm{~s}^{-1} ; T_{\mathrm{u}}=60^{\circ} \mathrm{C}$ ). 
The experimentally determined $\mathrm{NO}_{\mathrm{x}}$ concentrations for methyl-decanoate/air, $n$-decane/air and $n$-dodecane/air mixtures at $\phi=0.8,1.0$ and 1.2 and $T_{u}=130{ }^{\circ} \mathrm{C}$ are depicted in Figure 30 through Figure 32. All three flames were studied at a global strain rate of $168 \mathrm{~s}^{-1}$. It can be seen that $\mathrm{NO}_{\mathrm{x}}$ concentrations are almost the same for $n$-decane and $n$-dodecane flames, but they are the lowest for the methyl-decanoate flames.

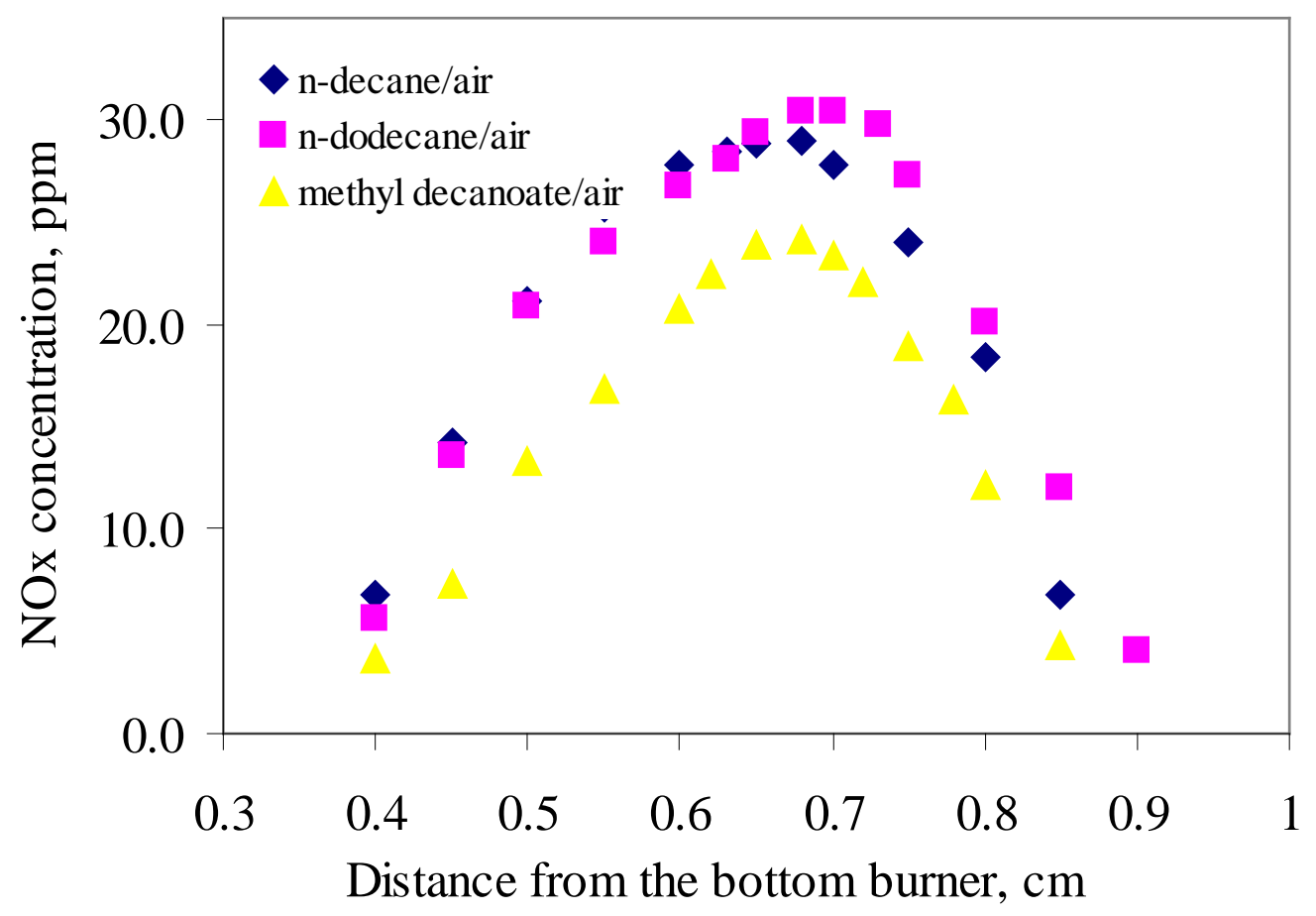

Figure 30. Experimentally determined $\mathrm{NO}_{x}$ concentration profiles as a function of distance from the bottom burner for $n$-decane/air, $n$-dodecane/air, and methyl-decanoate/air flames (equivalence ratio $=0.8, K=168 \mathrm{~s}^{-1} ; T_{\mathrm{u}}=130{ }^{\circ} \mathrm{C}$ ). 


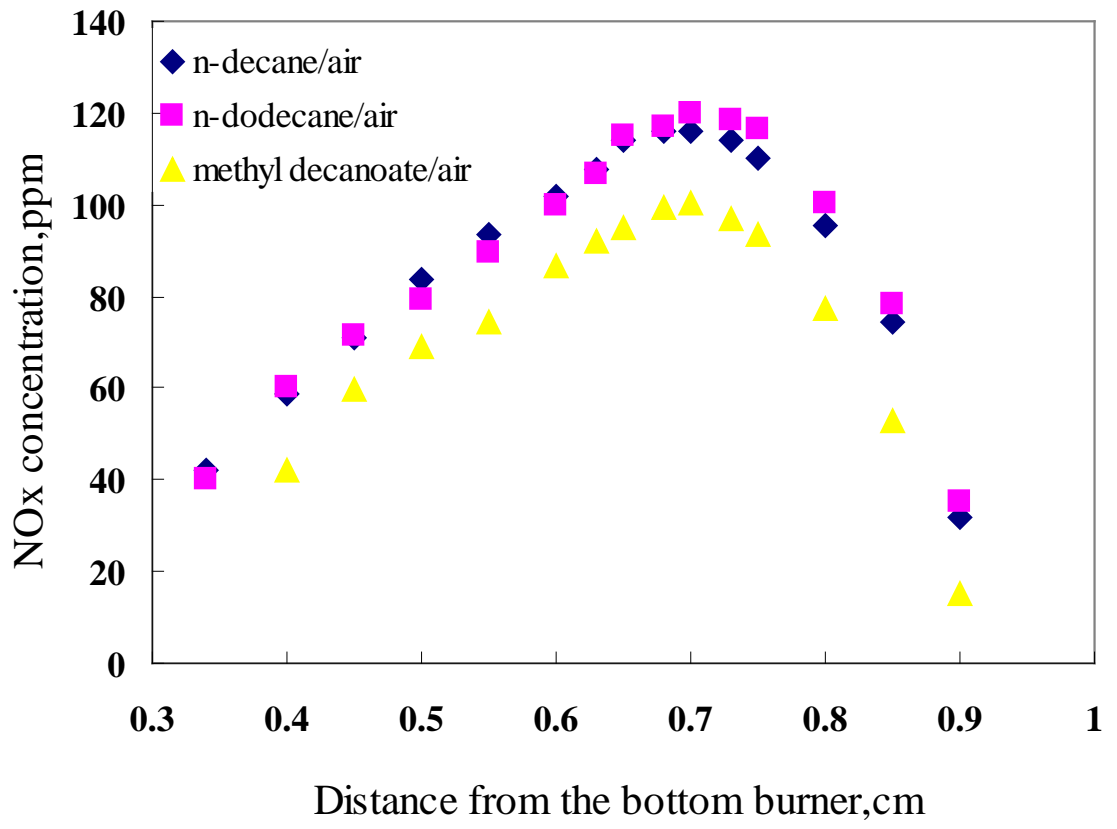

Figure 31. Experimentally determined $\mathrm{NO}_{x}$ concentration profiles as a function of distance from the bottom burner for $n$-decane/air, $n$-dodecane/air and methyl-decanoate/air flames (equivalence ratio=1.0, $K=168 \mathrm{~s}^{-1} ; T_{\mathrm{u}}=130{ }^{\circ} \mathrm{C}$ ).

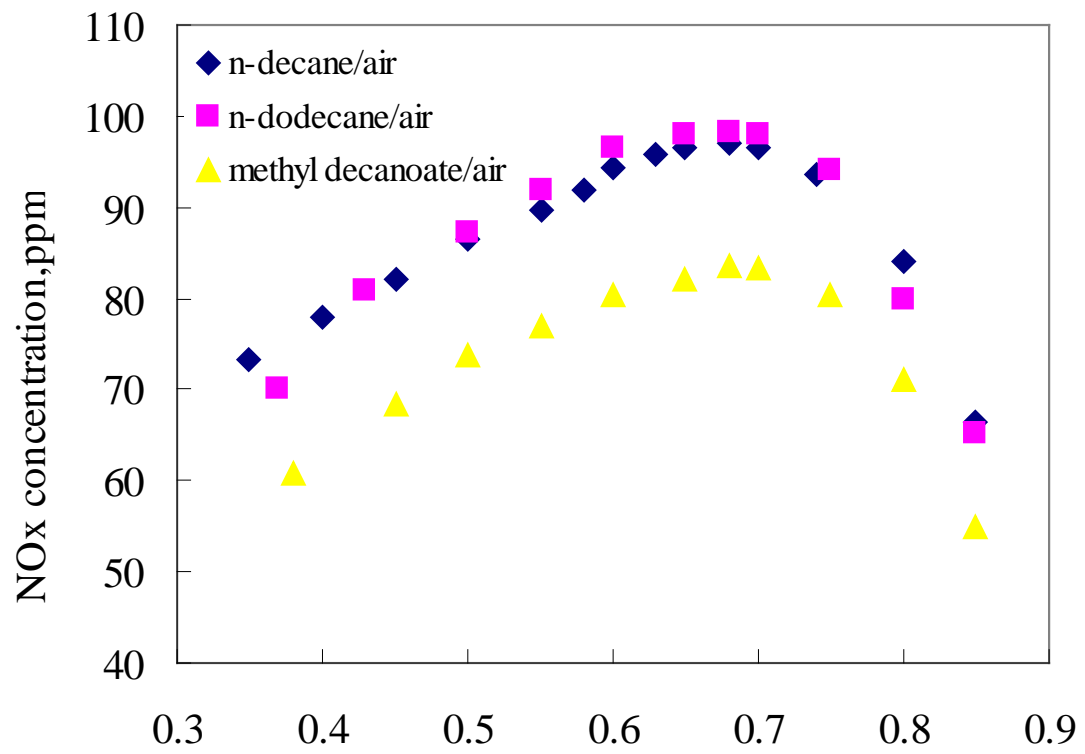

Distance from the bottom burner,cm

Figure 32. Experimentally determined $\mathrm{NO}_{x}$ concentration profiles as a function of distance from the bottom burner for $n$-decane/air, $n$-dodecane/air and methyldecanoate/air flames (equivalence ratio=1.2, $K=168 \mathrm{~s}^{-1} ; T_{\mathrm{u}}=130{ }^{\circ} \mathrm{C}$ ). 


\section{Kinetic Model Development for Biodiesel Models}

To develop a model biodiesel fuel for use in engine simulations, we needed to have a detailed reaction mechanism that adequately represented combustion behavior of the model-fuel components, and a composition of those components that adequately represented real biodiesel. Based on the biodiesel survey results, we knew we needed to represent long-chain methyl esters, and we believed we could do this through a combination of smaller methyl esters and long-chain alkanes. We first assembled a mechanism that contained methyl butanoate and methyl crotonate and combined this with a detailed mechanism for $n$-dodecane. We later tested this against inclusion of a longer-chain methyl ester, methyl decanoate in the model-fuel blend. To do these comparisons, however, it was first necessary to build confidence in the component mechanisms, through comparison with fundamental data. In this section we describe the mechanism assembly procedure, followed by the approach to identifying a good surrogate-fuel blend. The next section then presents validation tests of the surrogate-fuel mechanisms against experimental data, as well as comparisons of the biodiesel surrogate against data taken with real biodiesel fuels.

\subsection{Assembly of Mechanisms and a Surrogate-Component Palette}

A mechanism for methyl butanoate was first obtained through collaboration with Lawrence Livermore National Laboratories [5], for use as a simple surrogate for bio-fuels that contain methyl esters. To facilitate use in flame simulations, this mechanism was reduced to a high-temperature-only version, eliminating reactions and species that only contribute to low-temperature kinetics involved in ignition. In addition, work progressed on an $n$-hexadecane (n-cetane) mechanism [6, 7] that provides reaction paths for combustion of large alkanes up to $n$-hexadecane, including dodecane and decane, for both low and high-temperature kinetics. The combination of reaction-path and reaction-rate rules used in developing the mechanism for the small methyl-ester component represented by methyl butanoate, together with the long-chain alkane mechanisms provided the two main pieces of foundation required for building a long-chain methyl-ester mechanism, such as methyl stearate. By assembling and testing these smaller components first, we were able to test the rate rules and mechanism sub-components prior to assembly of the larger fuel mechanism.

After high-temperature extraction, the merged mechanism was further reduced by removing large species with carbon number greater than twelve (12). This high-temperature version of the combined mechanism was then further developed and improved. The following additions and modifications were incorporated into the merged mechanism:

- Missing species transport parameters were estimated.

- The methyl crotonate sub-mechanism was improved by adding hydrogen abstraction reactions from vinyllic- and allylic- carbons, as well as some missing dissociation reactions.

- The core mechanism for smaller fuel components $\left(C_{0}-C_{3}\right)$ was updated, based on recent studies $[8,9]$.

The resulting biodiesel-surrogate mechanism consists of 549 species and 3245 reactions. All of these updates resulted in improved flame-speed predictions for the components of the model biodiesel, which was needed to address some issues observed in the comparison of the family of alkane mechanisms using similar rate rules against measurements in the flame experiments.

We benchmarked the models against existing experimental data available from the USC flame facility for a gaseous fuel to eliminate any experimental issues surrounding the liquid-fuel handling for this stage of mechanism validation. The simulations employed the flame-speed calculator module in the CHEMKIN software suite [1] for the simulations. Results showing model comparisons with flamespeeds for propane, for example, are shown in Figure 33. This figure also demonstrates efforts at Reaction Design to improve the chemistry mechanism data towards better agreement with the measured flamespeed data. The results show good agreement between the model and the experimental data, with the updated chemistry model.

Page 40 of 93 


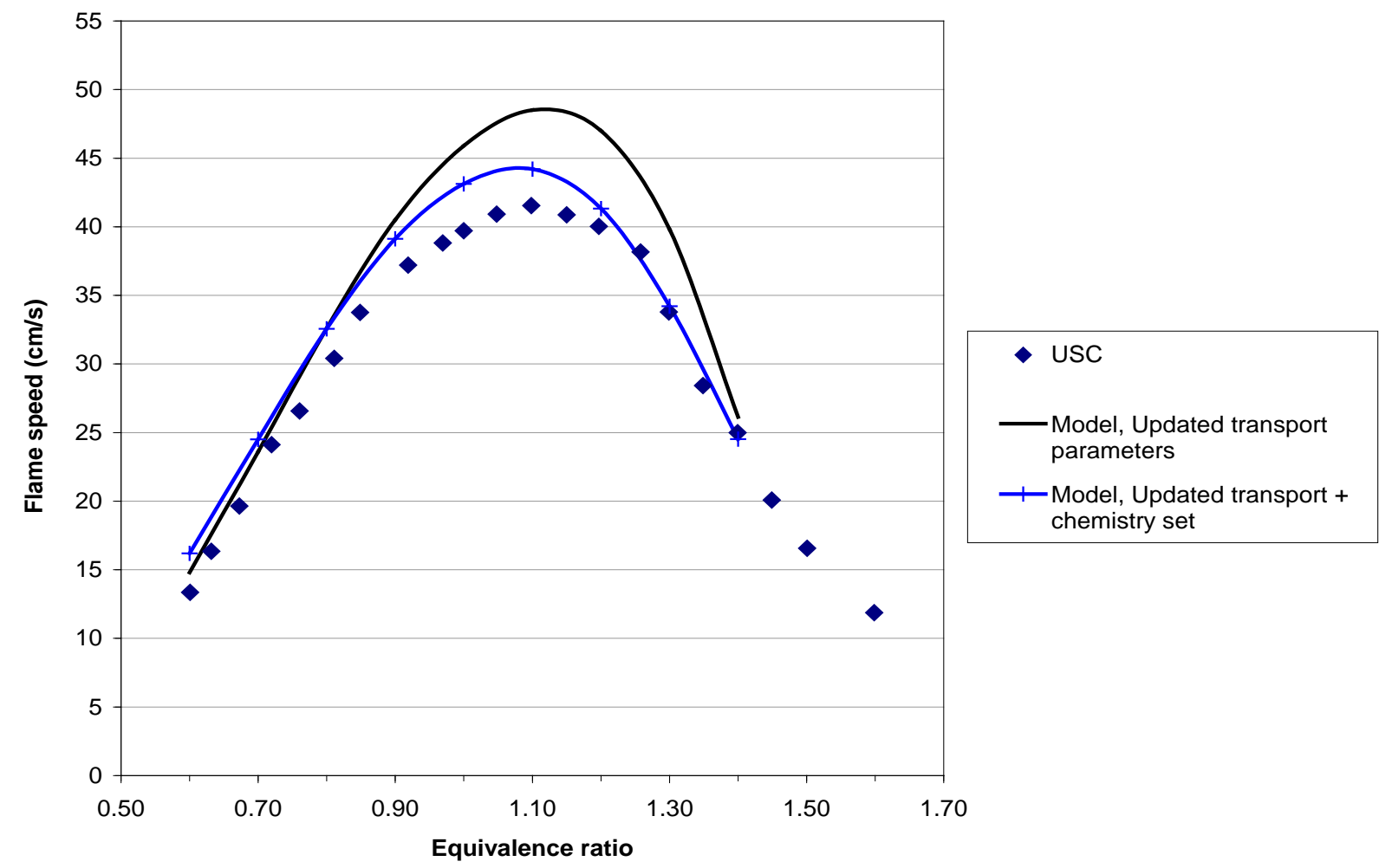

Figure 33. Experimentally determined laminar flame speeds of $\mathrm{C}_{3} \mathrm{H}_{8}$ /air mixtures at atmospheric pressure and $300 \mathrm{~K}$ along with simulation results using a detailed propane chemistry mechanism.

We next focused on a chemical kinetics mechanism for modeling a 3-component biodiesel surrogate containing $n$-dodecane, methyl butanoate, and methyl crotonate. We then assembled a detailed chemical kinetics mechanism for a heavier methyl ester, methyl decanoate $\left(\mathrm{C}_{9} \mathrm{H}_{19} \mathrm{C}(=\mathrm{O}) \mathrm{OCH}_{3}\right)$, which is described in more detail below. In addition, we expanded the capability of the surrogate mechanisms for predictions of polycyclic aromatic hydrocarbons (PAH) and soot, which is described in Section 3.1.2. This allowed use of a more realistic surrogate for biodiesel. Normal decane was also added to the surrogate palette, mainly because there are more fundamental data available for $n$-decane than $n$-dodecane. By validating $n$-decane fuel performance, then, we could deduce the validity of the $n$-dodecane submechanism that shares the same rate rules and various core sub-mechanisms.

\subsubsection{Development of a Mechanism for Methyl Decanoate}

The $C_{5}$ methyl esters in the original surrogate are much smaller than those found in a typical biodiesel, which contains $\mathrm{C}_{16}$ or larger carbon chains. To close this gap of size difference in methyl-ester components, we added the methyl decanoate chemistry to the existing mechanism. This allows methyl decanoate to serve as an optional component of a biodiesel surrogate.

Recently several researchers reported detailed mechanisms for large methyl esters. Herbinet et al. [10] developed the first detailed mechanism for methyl decanoate. Naik and Westbrook [11] later developed a mechanism for methyl stearate that also includes high-temperature kinetics for methyl decanoate. The Herbinet et al. mechanism is based on slightly different underlying assumptions than our existing biodiesel mechanism. For example, they include reactions of isomers of alkenyl radicals, whereas our biodiesel mechanism uses a lumped form of such radicals. The Naik and Westbrook mechanism, however, has a similar underlying structure to the biodiesel mechanism assembled under this project. We 
therefore opted to incorporate the methyl decanoate sub-mechanism using the Naik and Westbrook mechanism as a source for the methyl decanoate reactions, since the merging of reaction data was more straightforward. The high-temperature methyl decanoate sub-mechanism was first extracted from the source mechanism [11] and then merged into the biodiesel mechanism containing the other fuel components. The methyl decanoate sub-mechanism increased the size of the biodiesel mechanism by 187 species and 1564 reactions. Since the transport properties were unavailable in the literature, we then estimated the transport parameters for all of the added species based on estimates of their critical properties.

Using large mechanisms for flame simulations is computationally expensive and can be prohibitive under some conditions. Therefore, to facilitate comparisons of model simulations using the biodiesel surrogate with the USC flame data, we next reduced the biodiesel mechanism for high-temperature conditions by selectively removing the species that are unimportant for high-temperature combustion. This hightemperature extraction is performed routinely without losing any important kinetics information for those conditions. The resulting high-temperature biodiesel mechanism, including the $\mathrm{NO}_{\mathrm{x}}$ chemistry, contains 771 species and 5350 elementary reactions.

\subsubsection{Soot Precursor Formation Mechanisms}

Several works in the literature report mechanisms that are meant to predict polycyclic aromatic hydrocarbons (PAHs) from the combustion of small alkanes and alkenes such as ethylene, methane, propane. PAHs are widely viewed as precursors to soot formation. The hydrogen-abstraction-acetyleneaddition (HACA) mechanism of molecular weight growth from unsaturated $\mathrm{C}_{2}$ hydrocarbon flames reported by Frenklach and coworkers [12] is one of the popular mechanisms developed more than a decade ago. Appel et al. [13] later improved their mechanism further by refining the rate constants for several important pathways. In the last five years, other researchers have considered more reaction pathways to better describe the PAH chemistry. Skjoth-Rasmussen et al. [14] studied PAH formation pathways from fuel-rich methane oxidation in a laminar flow reactor. Richter et al. [15] developed a mechanism for PAH formation in benzene flames. Recently Zhang et al. [16] developed a mechanism to describe various benzene formation pathways in several fuels. Most of these works have focused on small, gaseous hydrocarbon fuels and one of our goals is to extend this work to be more relevant for use with diesel/biodiesel fuels and engine conditions.

To develop a more comprehensive detailed reaction mechanism, we began by gathering the kinetics knowledge available in the literature on various PAH reaction pathways. We first assembled the gasphase PAH chemistry by adding the Appel et al. [13] PAH sub-mechanism to the current biodiesel surrogate mechanism, including methyl decanoate chemistry as described above. We then added the PAH sub-mechanisms from the works of Zhang et al. [16] and Skjoth-Rasmussen et al. [14]. The addition of these PAH sub-mechanisms increased the size of the biodiesel mechanism by 159 species and 831 reactions. We expect these sources of PAH formation pathways to provide a reasonably good starting point for future mechanism improvements.

\subsubsection{Low-Temperature Mechanism Development for Engine Simulations}

The fuel-combustion mechanisms developed for the conditions of the USC experiments described in Section 2 require only high temperature kinetics. Limiting the mechanism to high-temperature chemistry also keeps the size of the mechanism contained, making it possible to use the fully detailed mechanism for 1-D flame simulations. However, application to an internal-combustion engine simulation requires low temperature kinetics as well as high-temperature kinetics, since the engine will span the entire range of temperatures during compression and expansion in the engine cycle. To make the results of this work more applicable to engine simulations, then, we extended the high temperature mechanisms described above by including specific low-temperature reaction paths for the 3-component surrogate, which is discussed in next section (Table 7). The low temperature reactions for methyl butanoate and methyl 
crotonate have been imported from the Fisher et al. [5] mechanism, and those for n-dodecane and smaller n-alkanes have been imported from the Westbrook et al. [7] mechanism.

\subsection{Identification of Appropriate Surrogate-Fuel Blends}

Based on the fuel survey and analyses described in Section 1, as well as other information from the literature [17], we know that biodiesel sources contain a mixture of unsaturated and saturated C18-chain carboxylic acids. They are converted to methyl-esters by a transesterification process during biodiesel production. The biodiesels therefore usually contain both saturated and unsaturated C18 long-chain methyl esters (methyl lineolate, methyl oleate, methyl stearate, and methyl palmitate).

\subsubsection{Initial Surrogate Blend Proposed}

To represent such large methyl-esters in pure biodiesel (B100) in engine simulations, we first proposed a simple and generic bio-diesel surrogate as a starting point. Such a generic model may be adjusted in terms of composition to represent a specific biodiesel fuel from a specific source. Table 7 shows the first composition of the model biodiesel proposed.

Table 7. Initial 3-component model biodiesel studied.

\begin{tabular}{|l|c|c|}
\hline Component & Mol. \% & Structure \\
\hline Methyl crotonate & 35 & \\
\hline Methyl butanoate & 15 & 50
\end{tabular}

Here, methyl crotonate and methyl butanoate are used to represent unsaturated and saturated methylesters in biodiesel, respectively. $n$-Dodecane is used to represent the long straight-chain part of the longchain methyl-esters. This combination of a small-chain methyl-ester and a long-chain alkane (Table 7) is expected to produce the combustion characteristics of the long-chain methyl-esters found in biodiesel. In addition, they should mimic the emissions and fuel structure of real biodiesel.

\subsubsection{Improved Surrogate Blend}

The initial surrogate was constructed using the available components for which reaction mechanisms were available or under development. Table 8 lists this surrogate as Surrogate 1 and shows that this surrogate will represent certain properties such as cetane number $(\mathrm{CN}), \mathrm{H} / \mathrm{C}$ molar ratio, and $\mathrm{C} / \mathrm{O}$ molar ratio that are close to a typical soy or rapeseed based biodiesel. However, there was room for improving the surrogate definition to match more closely the properties of biodiesel. Surrogate 2 in Table 8 contains methyl decanoate, $n$-heptane, and 1-heptene, providing a better match to the $\mathrm{CN}, \mathrm{H} / \mathrm{C}$ and $\mathrm{C} / \mathrm{O}$ ratio of a biodiesel. These are important properties for simulating combustion and emissions characteristics of a biodiesel in an engine. The development of a mechanism for high temperature oxidation of methyl decanoate enabled the consideration of Surrogate 2 as well as Surrogate 1. However, with both Surrogate 1 and 2, it is not possible to match exactly the $\mathrm{H} / \mathrm{C}$ ratio of a typical biodiesel. This could potentially impact predictions of soot emissions. To better match these properties, more unsaturated components are required in the surrogate, such as di- and tri-unsaturated olefins of heptane, methyl decanoate, and/or 1heptene. During this project, we did not have ready access to mechanisms for these compounds and development from scratch was outside of the project scope. Methyl oleate (Surrogate 3) would match all of the properties important for combustion and emissions behavior of a biodiesel; however, much work is still required to assemble a detailed mechanism for this large methyl ester. The work performed on 
methyl stearate [11] is an important first step towards building a direct mechanism for methyl oleate, but the enormous size of the mechanism also indicates some of the challenges we will have for building a direct biodiesel model. We therefore believe there is value in using the surrogate-blend approach such as that used in Surrogate 1 and Surrogate 2 for biodiesel simulation in engines.

Table 8. Various possible surrogates for a typical biodiesel. Composition is in mol $\%$.

\begin{tabular}{|l|l|l|l|l|}
\hline $\begin{array}{l}\text { Components / } \\
\text { Properties }\end{array}$ & $\begin{array}{l}\text { Surrogate 1 } \\
\text { (3-component) }\end{array}$ & $\begin{array}{l}\text { Surrogate 2 } \\
\text { (3-component) }\end{array}$ & $\begin{array}{l}\text { Surrogate 3 } \\
\text { (1-component) }\end{array}$ & Biodiesel $^{\dagger}$ \\
\hline Methyl butanoate & 15 & - & - & - \\
\hline Methyl crotonate & 35 & - & - & - \\
\hline$n$-Dodecane & 50 & - & - & - \\
\hline Methyl decanoate & - & 50 & - & - \\
\hline$n$-Heptane & - & 7 & - & - \\
\hline 1-Heptene & - & 43 & - & - \\
\hline Methyl oleate & - & - & 100 & - \\
\hline Cetane number & 42 & 48 & 57 & $48-56$ \\
\hline H/C molar ratio & 2.04 & 2.01 & 1.89 & $1.84-1.89$ \\
\hline C/O molar ratio & 8.5 & 9.5 & 9.5 & 9.5 \\
\hline
\end{tabular}

† Approximate properties for soy- and rapeseed-based biodiesels.

‡ Estimated approximate values. 


\section{Validation of Surrogate Component Mechanisms}

To test the validity of the mechanisms assembled for fuel components that comprise a biodiesel surrogate model, we simulated a variety of flame and other experiments using the detailed kinetics models, comparing results to measured data. The first components studied were methyl butanoate, which is the smallest methyl ester considered. This was tested against laminar flame speeds, flame-extinction strain rates, and $\mathrm{NO}_{x}$ measurements performed at USC. In addition to the USC flame data, we included comparisons to ignition-delay measurements in shock tubes and species measurements in opposed-flow flames, as reported in the public literature. Together, these comparisons validated the mechanism predictive capabilities. The main discrepancy noted in these comparisons were for the extinction strain rates; however, there are sufficient uncertainties in the measured values to make it difficult to conclude that further mechanism development is needed. We also performed validation studies for another methyl ester, methyl crotonate. In addition, we compared simulation predictions for the $n$-dodecane surrogate component with the USC data for flames. For this component, the predictions agreed very well with the laminar flame-speed and extinction measurements. Later, we added two new components to our "palette" of biodiesel surrogate components: methyl decanoate and n-decane. USC was able to make flame measurements for methyl decanoate and we were also able to assemble a wide range of $3^{\text {rd }}$-party data for $n$-decane and $n$-dodecane validation. The results of comparisons of these biodiesel components to the available experimental data are reported here. All the simulations discussed in this section have been performed using CHEMKIN-PRO software [1], using CHEMKIN's Flame Speed Calculator, Flame Extinction model, Perfectly Stirred Reactor Model, and Closed Homogeneous Batch Reactor Model, as appropriate, to model the specific experiments described.

\subsection{Details about the Computational Method for Simulating Flames}

The Flame-speed Calculator in CHEMKIN-PRO [1] uses a non-uniform grid that is successively and automatically adapted based on solution gradients on initially coarse grids. The relative gradient and curvature parameters for the grid refinement, which control the degree of resolution at locations of sharp gradients and curvatures in the solutions, have both been set to 0.1 . This results in a typical number of grid points being 170 to 230 . Mixture averaged transport properties were used in this study.

The following provides details of the validation-study results for each of the surrogate-fuel components. Then, Section 5 presents direct comparisons between the model-fuel blend and data for actual biodiesel samples, from fundamental flame experiments using the samples directly.

In general, extinction calculations are computationally very expensive, even more so than flame-speed calculations. Moreover, use of multicomponent transport significantly increases calculation overhead. Since the primary focus has been to improve and test the reaction mechanism, we used mixture-averaged transport formulation (and thermal diffusion) for most extinction simulations. However, a couple of simulations were also conducted with multi-component transport. Shown in Figure 34 is the comparison of extinction strain rates predicted with the new mechanism using mixture-averaged vs. multicomponent transport; both also using thermal diffusion. It can be seen that the maximum error is less than $10 \%$. Since the extinction strain rates predicted by the previous mechanism (also using mixture-averaged transport) were more than $50 \%$ higher than the experimental data, the use of mixture averaged transport for testing the new mechanism is justified. The extinction calculations were performed with the reduced 127-species mechanism for MB and 160-species mechanism for $n$-dodecane. 


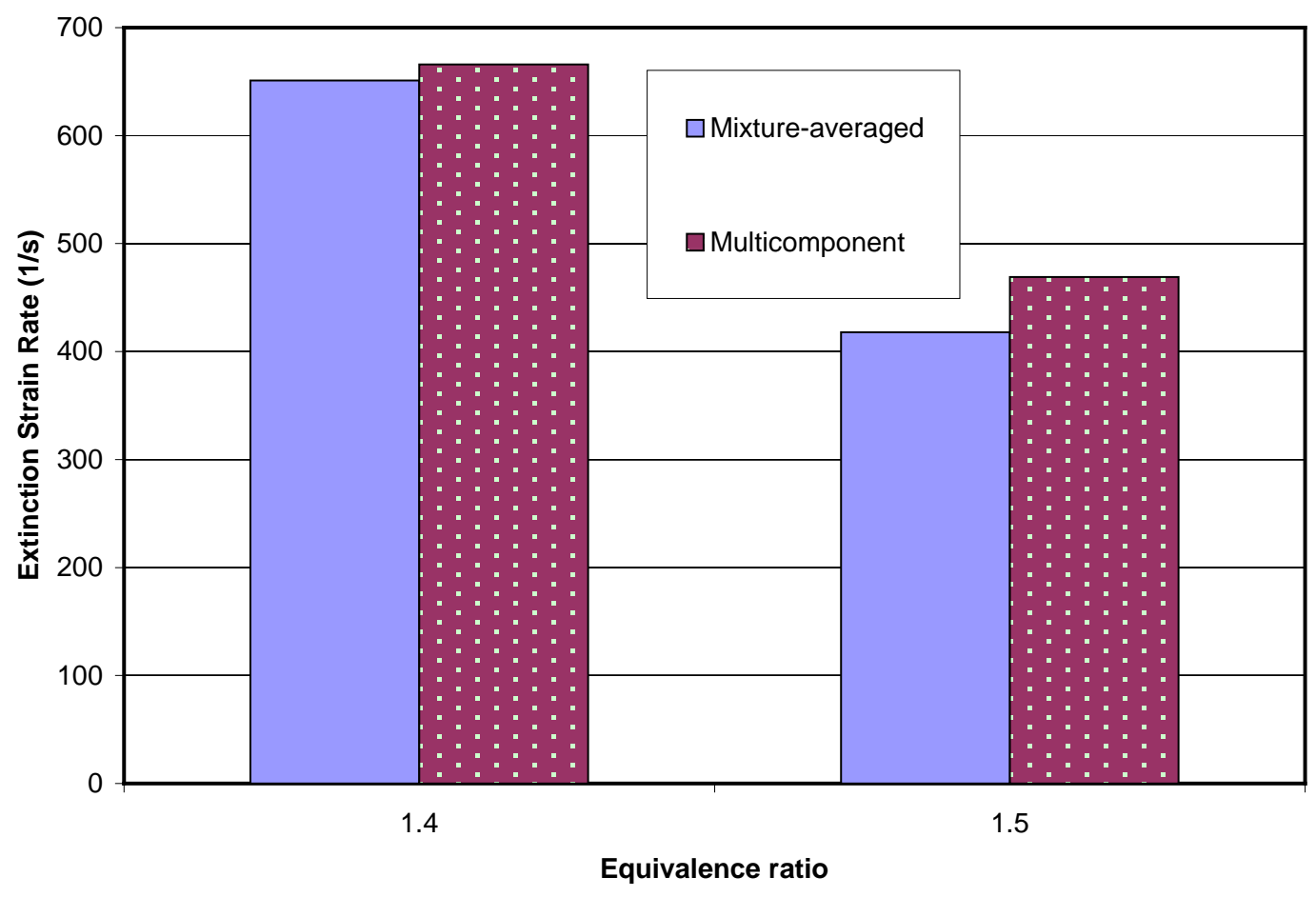

Figure 34. Effect of transport model on calculated extinction strain rates for methyl butanoate/air flames.

\subsection{Validation of Surrogate Components: Methyl Butanoate and Methyl Crotonate}

For the smaller methyl esters, methyl butanoate and methyl crotonate, some experimental data were available in the literature, in addition to the flame data obtained by USC. This allowed more thorough testing of the mechanism, which also builds up confidence in the rate rules used in the larger methyl ester mechanism, where fewer data are available. In this project, we assembled data from as many sources as possible to cover conditions of interest to engine simulation, and tested the model under those conditions. Results are reported below for each type of experiment considered.

\subsubsection{Laminar Flame Speeds}

Figure 35 shows comparison of the predicted flame speeds of methyl butanoate and methyl crotonate to those measured at USC. The unburned fuel-air mixture temperature is $333 \mathrm{~K}$ at $1 \mathrm{~atm}$. Predictions using the high-temperature version of one of the literature mechanisms used to build the current mechanism, referred to as the Fisher mechanism [5], are also shown. Originally, flame speeds were overpredicted by as much as $20 \mathrm{~cm} / \mathrm{s}$ for methyl crotonate (MC) and $14 \mathrm{~cm} / \mathrm{s}$ for methyl butanoate (MB) using the Fisher mechanism. Such over-prediction was consistent throughout the range of equivalence ratios. The mechanism developed in this project, however, resulted in improved flame-speed predictions for both methyl-ester components. Predicted flame speeds for MB using Reaction Design's mechanism are higher by $<10 \mathrm{~cm} / \mathrm{s}$ than the data over the entire range of equivalence ratios $(\phi)$. For $M C$, the agreement is as good as that for MB under fuel-lean conditions and the values are very close for these two components. On the fuel-rich side $(\phi>1.1)$, predicted flame speeds for MC are systematically higher than those for MB, which reproduces the trend that is observed in the measurements when comparing the two fuels. 
Furthermore, Figure 38 and Figure 37 show that the models for MB and MC capture well the effect of an increase in unburned mixture temperature on flame speed over the range of equivalence ratios tested.
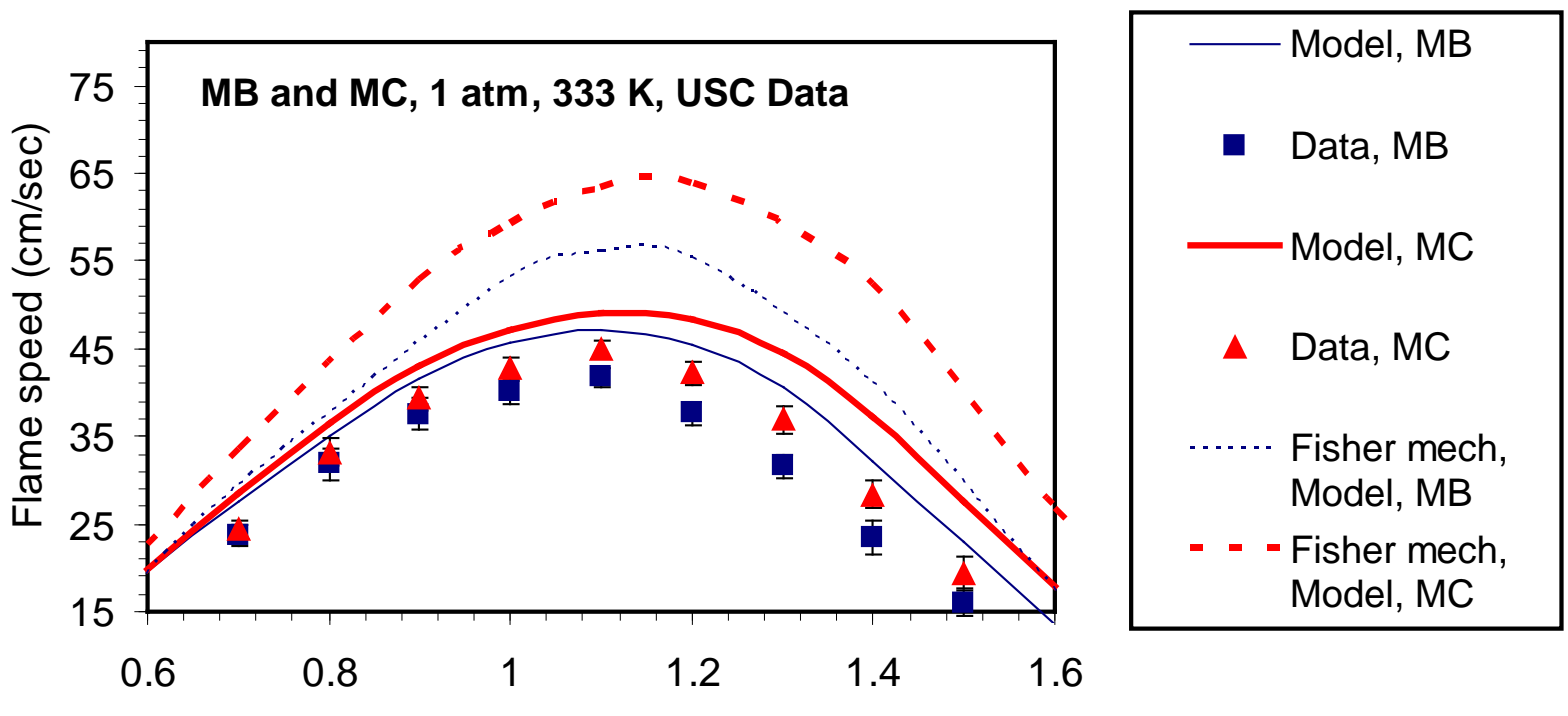

Equivalence ratio

Figure 35. Comparison of predicted flame speeds of methyl butanoate (MB) and methyl crotonate (MC) to those measured at USC at unburned mixture temperature of $333 \mathrm{~K}$ at $1 \mathrm{~atm}$. Lines represent predictions and symbols represent the experimental values. The dashed/dotted lines indicates the original models for these components reported by Fisher [5].

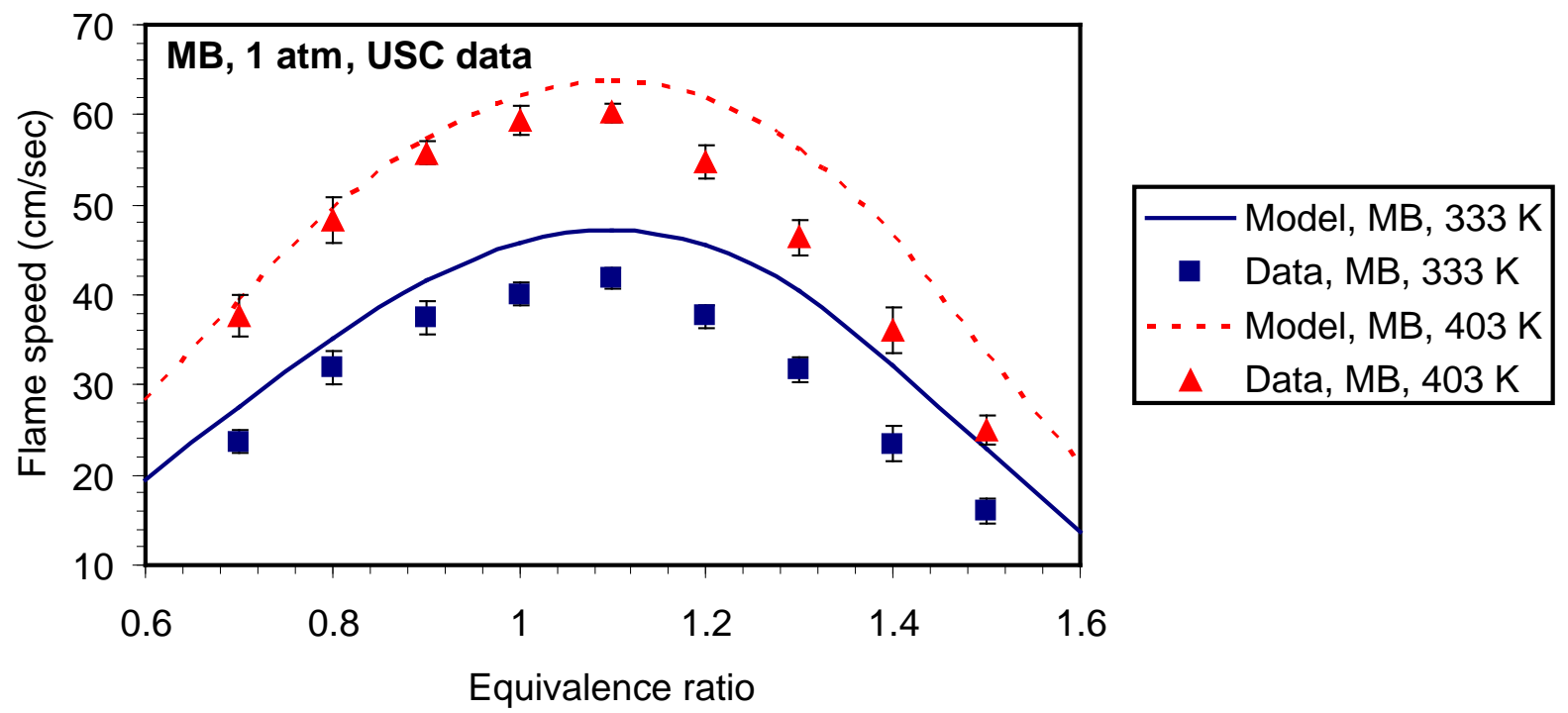

Figure 36. Comparison of predicted flame speeds of MB to those measured at USC at two different unburned mixture temperature of $333 \mathrm{~K}$ and $403 \mathrm{~K}$, at $1 \mathrm{~atm}$. Lines represent predictions and symbols represent the experimental values. 


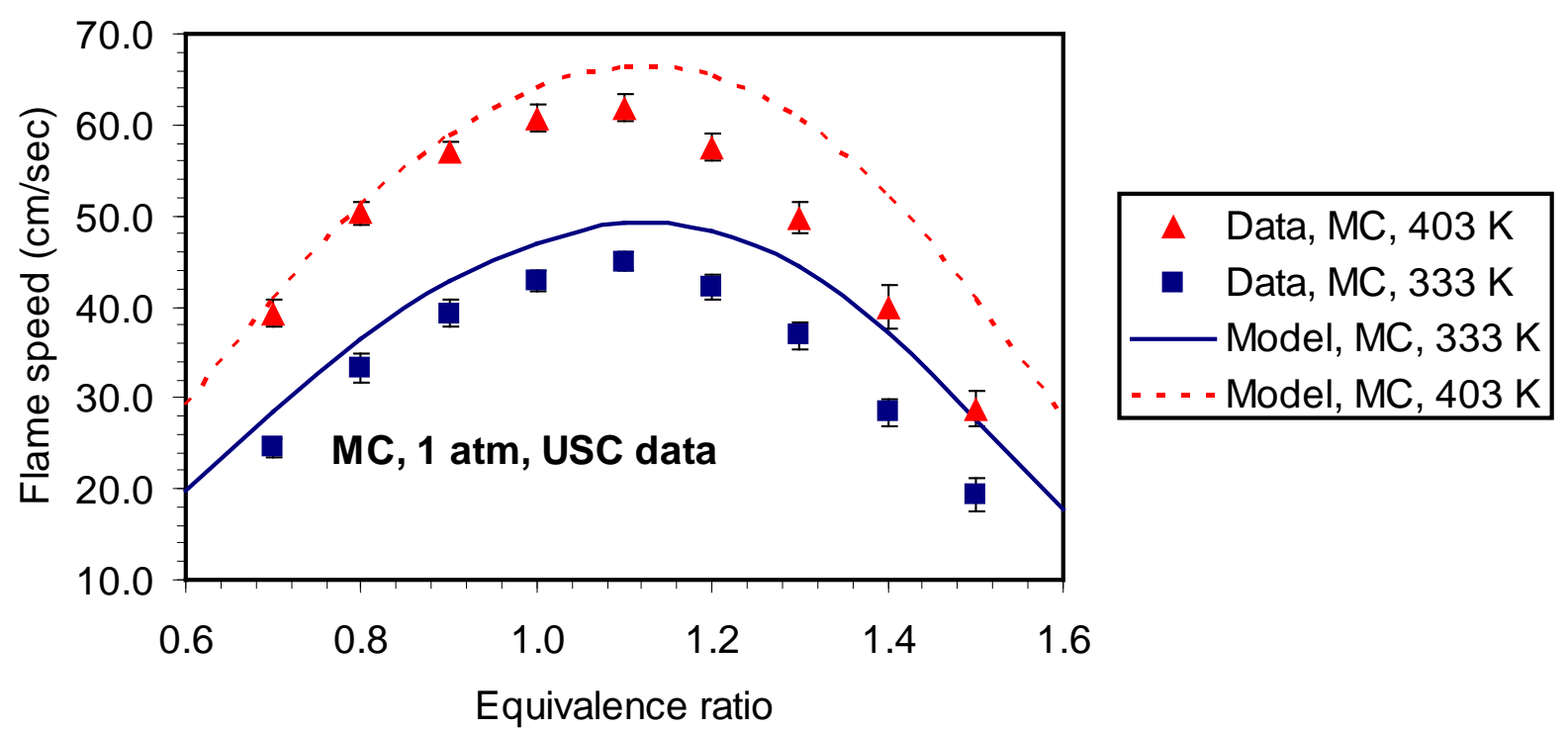

Figure 37. Comparison of predicted flame speeds of MC to those measured at USC at two different unburned mixture temperature of $333 \mathrm{~K}$ and $403 \mathrm{~K}$, at $1 \mathrm{~atm}$. Lines represent predictions and symbols represent the experimental values.

\subsubsection{Flame Extinction Strain Rates}

Extinction calculations were also performed for methyl butanoate flames. Figure 38 shows comparisons of the extinction strain rates predicted with the new mechanism against the experimental data for MB. Also shown are the predicted values with the mechanism assembled at the start of the project. It can be seen that although the new mechanism is still over-predicting the extinction strain rates, it is significantly better than the previous mechanism. 


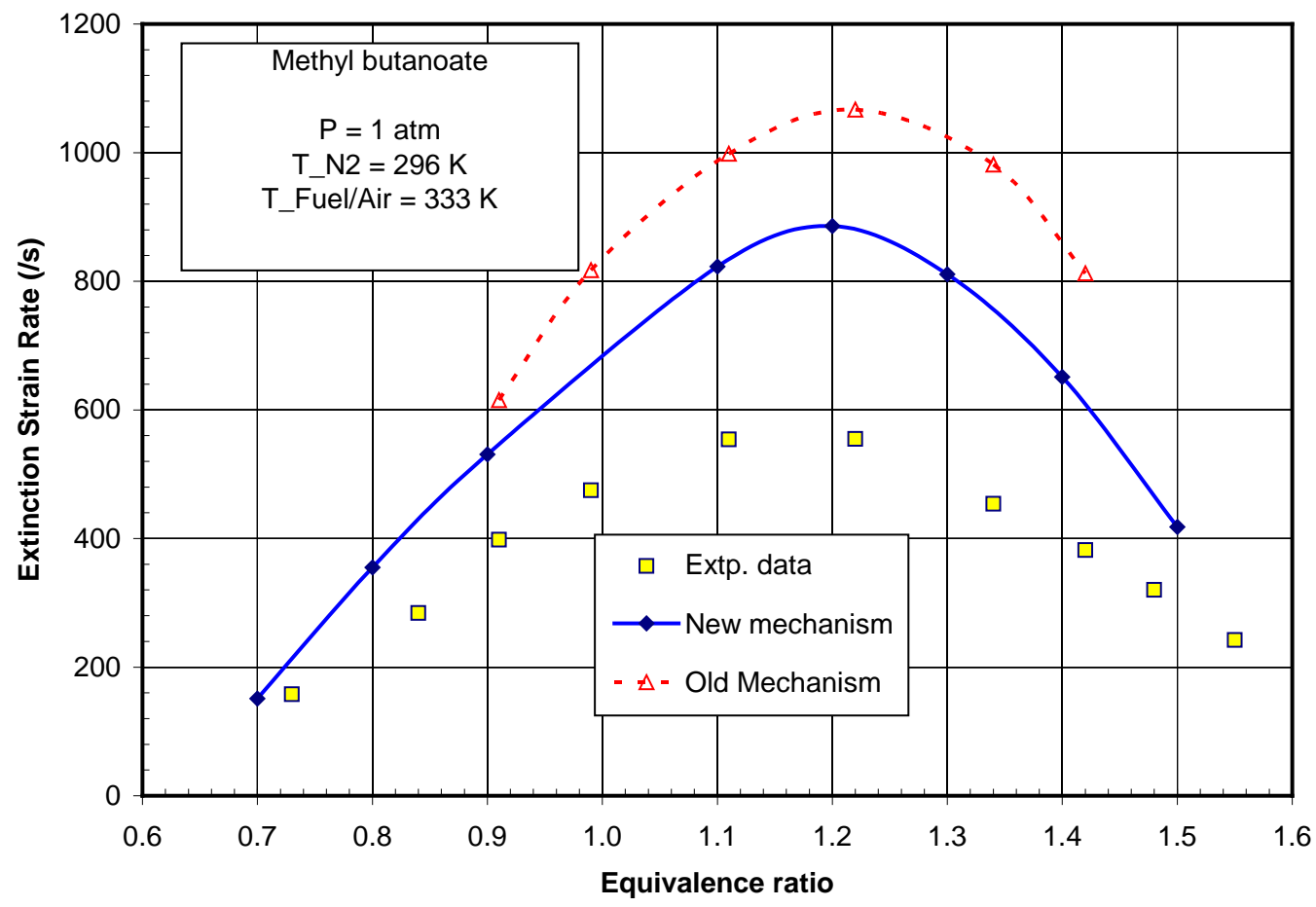

Figure 38. Comparison of predicted and measured extinction strain rate of methyl butanoate/air mixture at $333 \mathrm{~K}, 1 \mathrm{~atm}$ using opposed flow flame configuration.

\subsubsection{Opposed-flow Flame Species Measurements}

An opposed-flow simulation was performed to compare numerical predictions with the results from recently published experimental data of Gail et al. [18]. The oxidizer was $42 \% \mathrm{O}_{2}$ and $58 \% \mathrm{~N}_{2}$ with an inlet velocity of $14 \mathrm{~cm} / \mathrm{s}$, while the fuel was $4.7 \% \mathrm{MB}$ and $95.3 \% \mathrm{~N}_{2}$ with an inlet velocity of $13 \mathrm{~cm} / \mathrm{s}$. The nozzle separation distance was $2 \mathrm{~cm}$ and the operating pressure was $0.101 \mathrm{MPa}$. The experimentally measured temperature profile has been used in the simulation. Shown in Figure 39 through Figure 42 are the plots of various species. It can be seen that while the agreement is very good for the species $\mathrm{CO}$, $\mathrm{CO}_{2}$, and $\mathrm{C}_{2} \mathrm{H}_{4}$, methane and acetylene are over-predicted. Also the computed consumption rate of $\mathrm{MB}$ appears to be smaller in the low-temperature region. The experimentally measured peak temperature in Figure 39 shows the flame almost equi-distant from the fuel and oxidizer inlets. Figure 40 shows model predictions with peak $\mathrm{CO}$ concentration slightly on the fuel-rich side, consistent with the experimental data. $\mathrm{CO}_{2}$ measurements, on the other hand, peak closer to the center of the domain, and the model predictions are again consistent with the experimental data. Figure 41 and Figure 42 show only one-half of the domain, to focus on events happening on the fuel side. Figure 41 and Figure 42 show the profiles of the hydrocarbon species methane, ethane, ethylene, propene and acetylene. These were some of the major hydrocarbon species measured. These species peak on the fuel-rich side, and close to the center of the domain. Ethylene has the highest concentration of all the hydrocarbons shown, for both the measurements and the predictions, followed by methane. The model predicts ethylene concentrations well, but over-predicts methane. The alkyne species, acetylene, and the larger alkane and alkene species, in Figure 42, have relatively lesser concentrations than ethylene and methane. The model predicts these trends well. The location and value of the peaks are well predicted for most of the hydrocarbons, although their concentrations are slightly under-predicted in the low-temperature region. More work is needed in this area; however, it can be said that the full MB mechanism gives satisfactory results. 


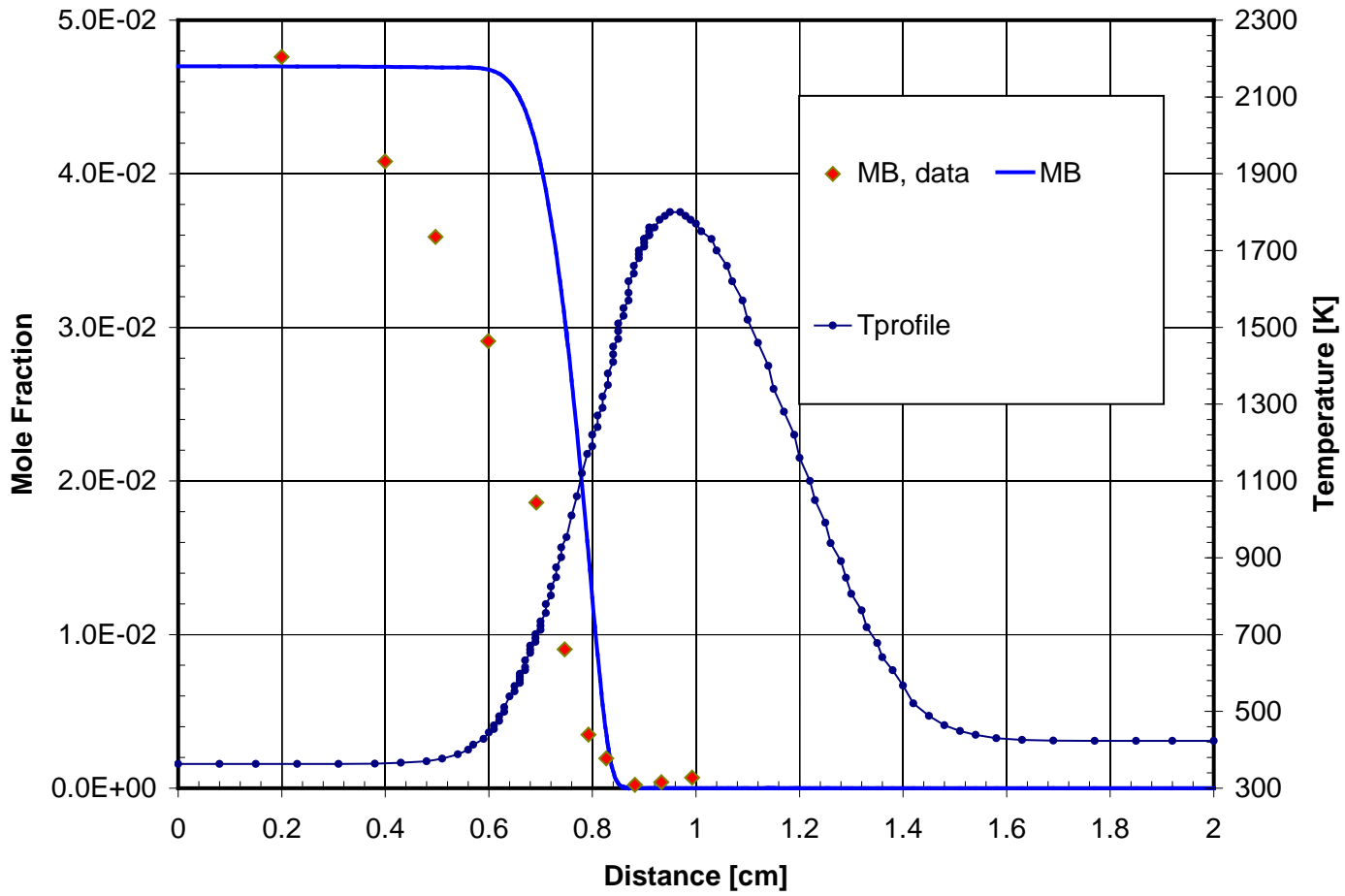

Figure 39. Comparison of predicted and measured concentration of methyl butanoate in opposed-flow flame configuration. Also shown is the measured temperature profile which is used as input to the simulation.

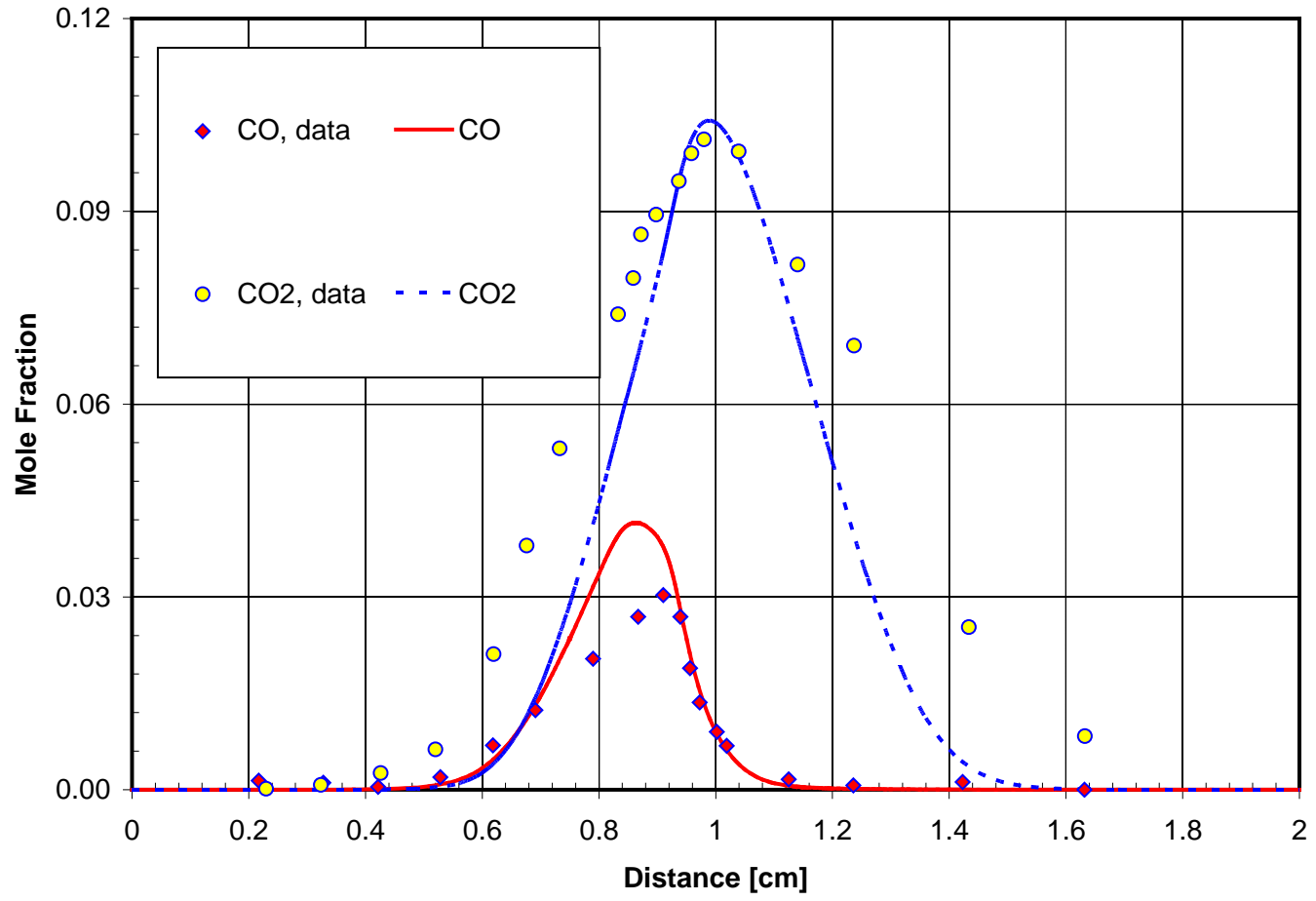

Figure 40. Predicted and measured $\mathrm{CO}$ and $\mathrm{CO}_{2}$ in oxidation of $4.7 \%$ methyl butanoate in opposed-flow configuration. 


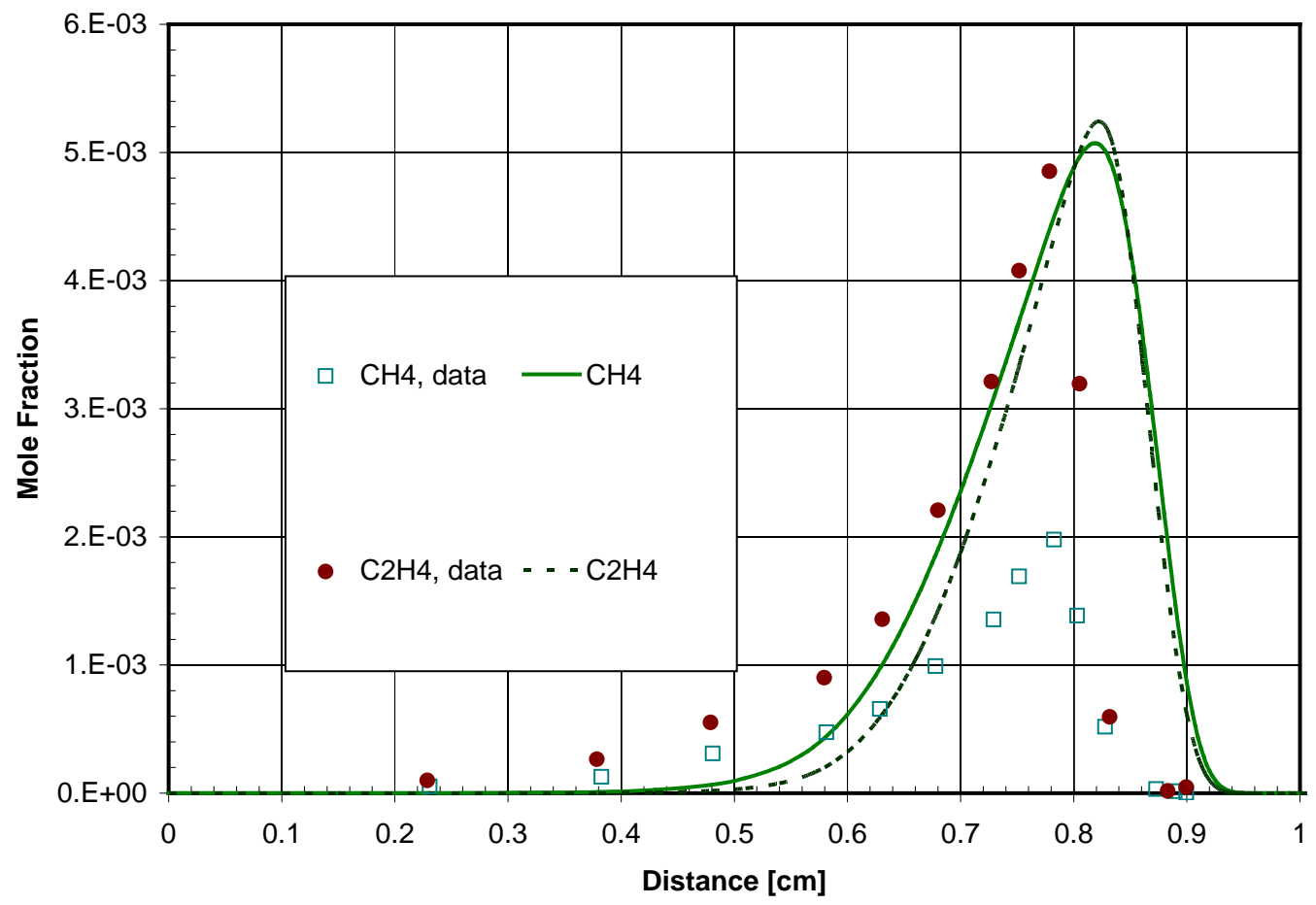

Figure 41. Predicted and measured $\mathrm{CH}_{4}$ and $\mathrm{C}_{2} \mathrm{H}_{4}$ in oxidation of $4.7 \%$ methyl butanoate in the opposed-flow configuration.

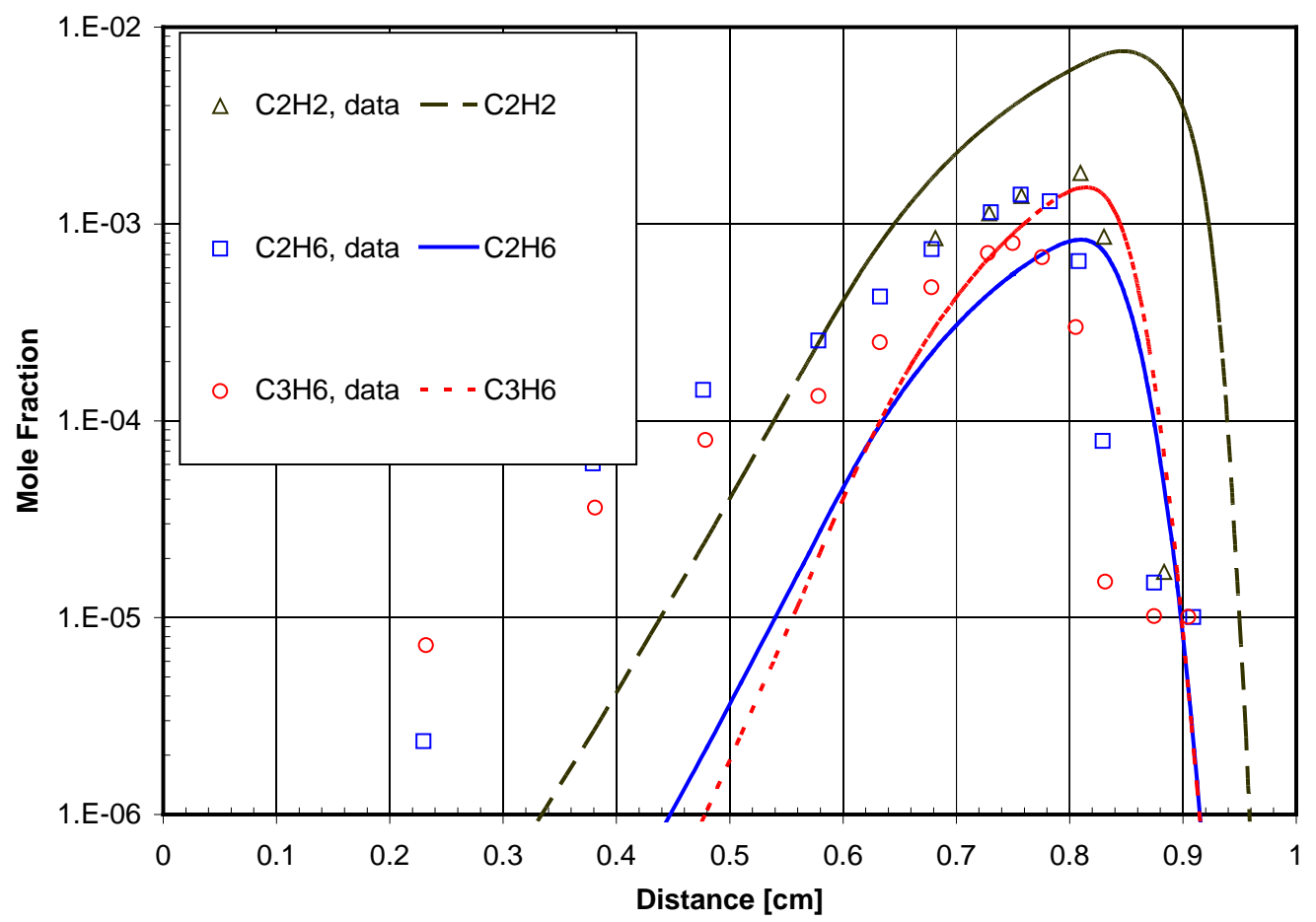

Figure 42. Predicted and measured $\mathrm{C}_{2} \mathrm{H}_{2}, \mathrm{C}_{2} \mathrm{H}_{6}$, and $\mathrm{C}_{3} \mathrm{H}_{6}$ in oxidation of $4.7 \%$ methyl butanoate in the opposed-flow configuration. 


\subsubsection{Shock-tube Ignition Measurements}

To further test the high-temperature behavior of the mechanism, ignition simulations were conducted to compare against the shock-tube ignition data in the literature [19]. These simulations used the constantvolume, closed, homogeneous reactor model from CHEMKIN software. The temperature profile inflection point was used to assess the ignition time. Shown in Figure 43 and Figure 44 are comparisons of measured and predicted ignition times for MB. The mechanism yields very good qualitative and quantitative agreement over the range of pressures and equivalence ratios studied.

These additional data comparisons build confidence in the underpinnings of the chemistry model and allow us to narrow any issues observed under other conditions to reaction paths that dominate or experimental issues that may be present under those specific conditions.

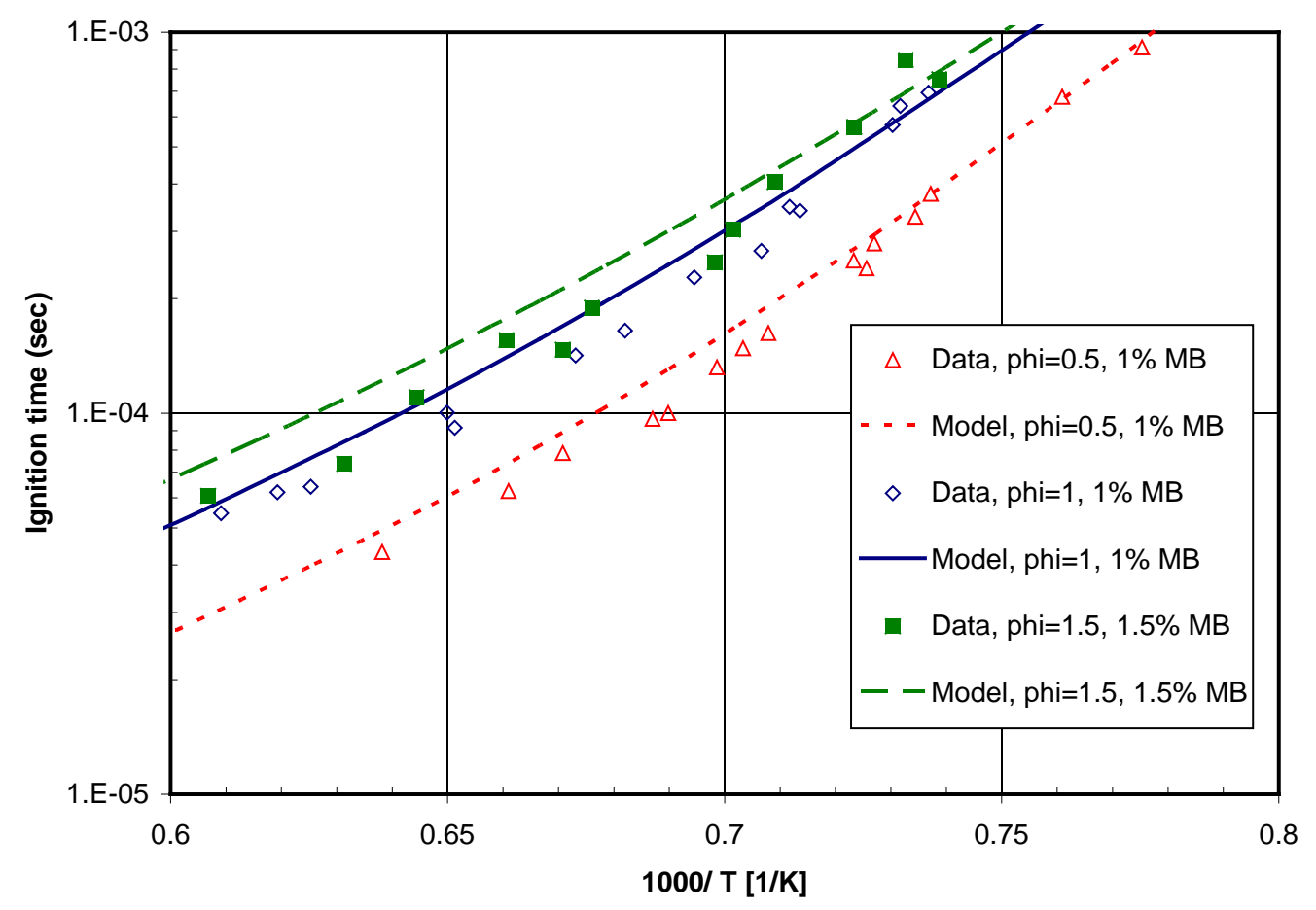

Figure 43. Comparison of predicted and measured ignition delay for methyl butanoate

[19]. Three different equivalence ratios are used. The pressure is set to $1 \mathrm{~atm}$. 


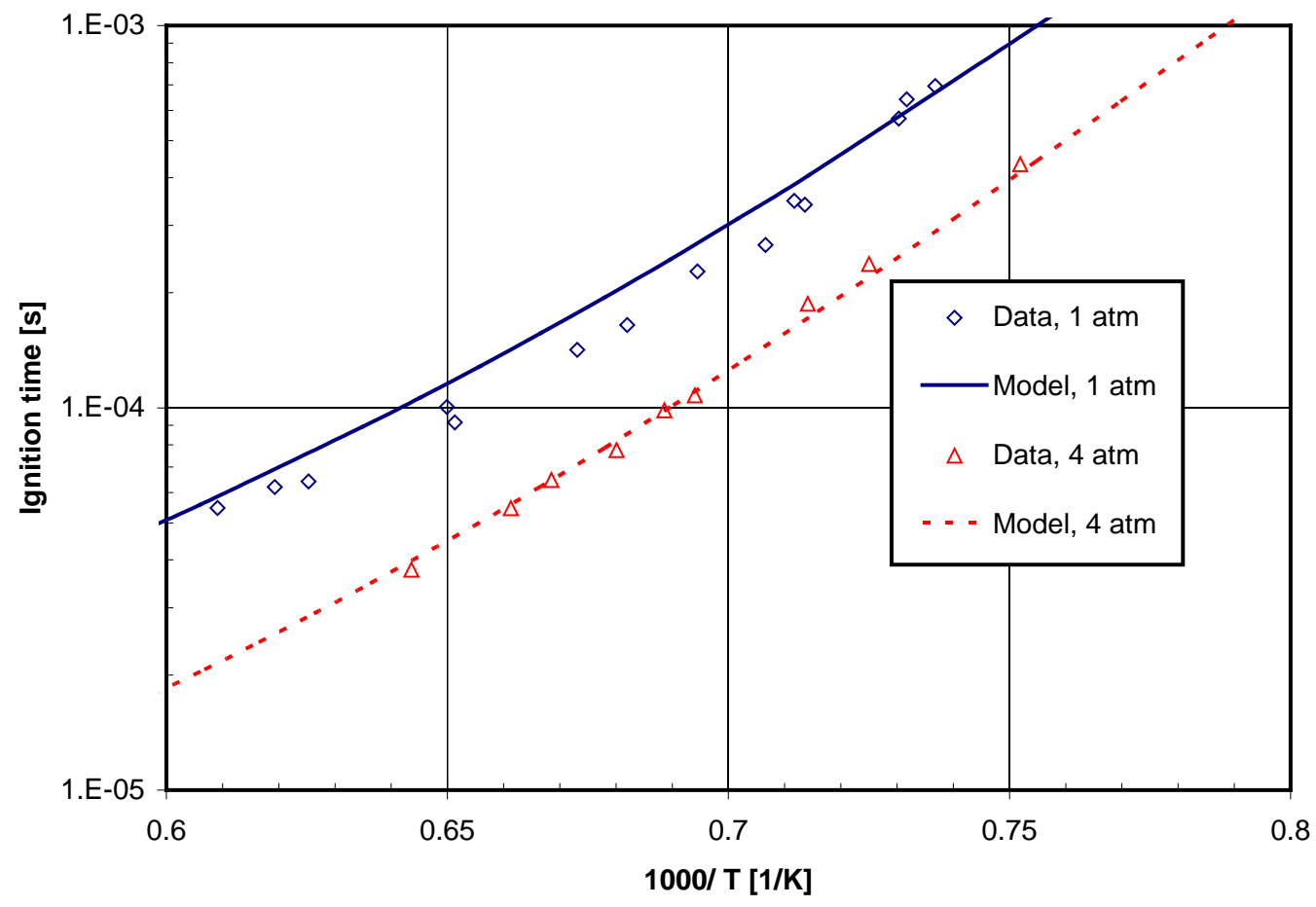

Figure 44. Comparison of predicted and measured ignition delay for methyl butanoate. Equivalence ratio is set to unity.

\subsection{Validation of Surrogate Component: Methyl Decanoate}

For methyl decanoate, we compared our detailed kinetics model with laminar flame-speed data from USC. The flame-speed data was produced after the upgrades to the USC flame facility as discussed above, and includes a measure of the data uncertainty in the form of experimental error bars.

\subsubsection{Laminar Flame Speeds}

We first tested the methyl decanoate sub-mechanism by comparing against the laminar flame-speed data from USC. Comparison of the predicted and measured laminar flame speed for methyl decanoate at an unburned mixture temperature of $403 \mathrm{~K}$ at $1 \mathrm{~atm}$ is shown in Figure 45 . This comparison shows very good agreement in fuel-lean conditions and acceptable agreement in fuel-rich conditions. 


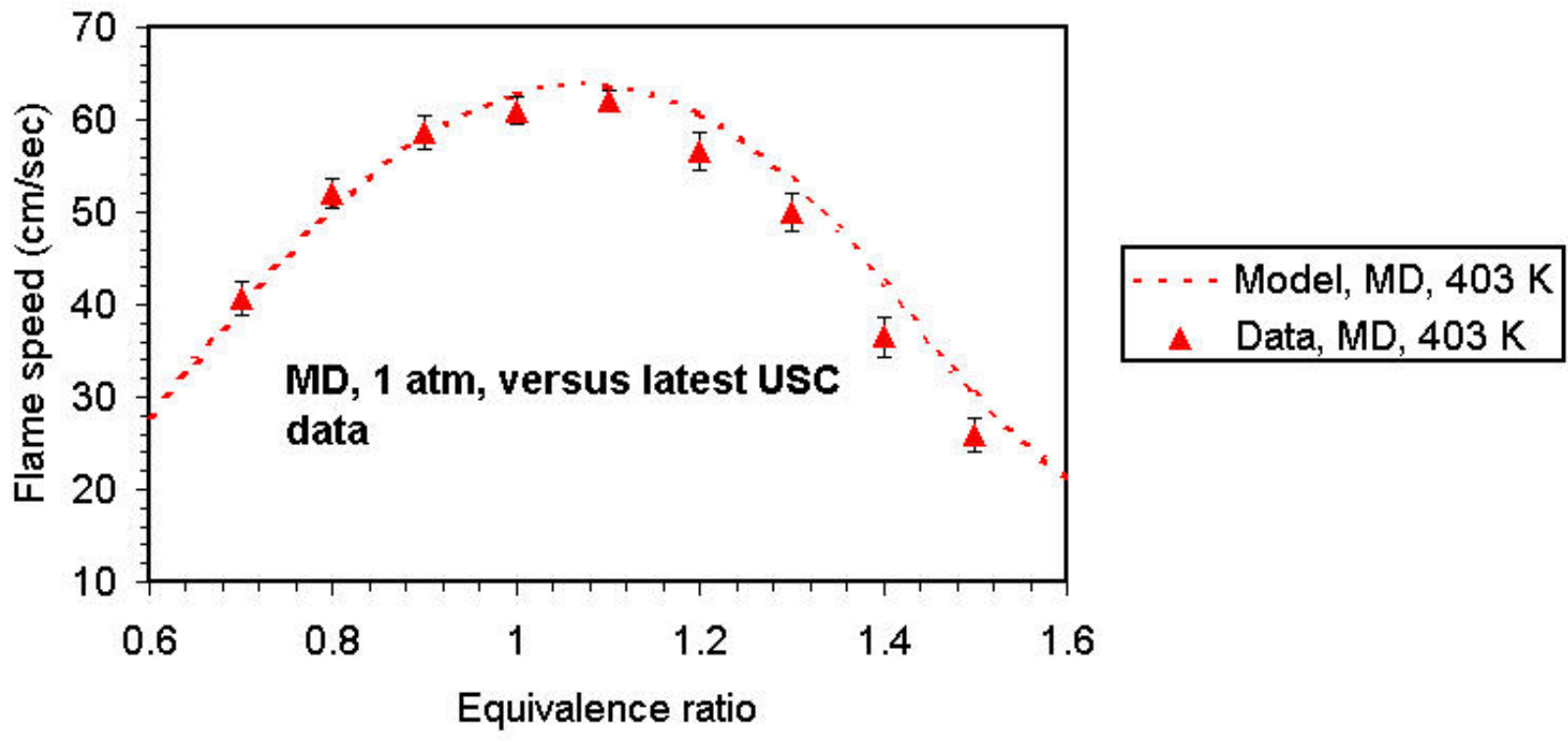

Figure 45. Comparison of the predicted and measured laminar flame speeds for methyl decanoate.

\subsection{Validation of Surrogate Component: $n$-Decane}

To provide more flexibility in the biodiesel surrogate blending and also to build confidence in the $n$-dodecane model (for which there is limited experimental data), we performed a wide range of validation test for $n$-decane using the biodiesel surrogate mechanism. The data considered was selected to span conditions of interest to internal combustion engine operation. These data include ignition delay times, laminar flame speeds, and species measurements in flames.

\subsubsection{Ignition-delay Times}

Table 9 shows the operating conditions under which ignition-delay times of $n$-decane mixtures have been measured in shock-tube experiments. All the experiments used reflected shock waves. The data in Table 9 cover both low- and high-temperature regimes, including the negative-temperature-coefficient (NTC) region. 
Table 9. $n$-Decane shock-tube experiments in the literature.

\begin{tabular}{|l|l|l|l|l|l|}
\hline Source & Year & $\begin{array}{l}\text { Pressure } \\
\text { (bar) }\end{array}$ & $\begin{array}{l}\text { Initial } \\
\text { temperature } \\
\text { (K) }\end{array}$ & $\begin{array}{l}\text { Equivalence } \\
\text { ratio }\end{array}$ & Diluent \\
\hline $\begin{array}{l}\text { Pfahl et al. } \\
{[20]}\end{array}$ & 1996 & $13-50$ & $650-1300$ & $0.5-2$ & Air \\
\hline $\begin{array}{l}\text { Zhukov et } \\
\text { al. [21] }\end{array}$ & 2008 & $13-80$ & $800-1300$ & $0.5-1$ & Air \\
\hline $\begin{array}{l}\text { Dean et al. } \\
{[22]}\end{array}$ & 2007 & 8.9 & $1070-1800$ & 1 & Air \\
\hline $\begin{array}{l}\text { Horning et } \\
\text { al. [23] }\end{array}$ & 2002 & $1-6$ & $1300-1700$ & $0.5-2$ & Ar \\
\hline $\begin{array}{l}\text { Olchanski et } \\
\text { al. [24] }\end{array}$ & 2006 & $2-10$ & $1250-1600$ & $0.5-1$ & Ar \\
\hline
\end{tabular}

The CHEMKIN-PRO closed homogeneous reactor model was used to simulate the shock-tube experiments, with the reported pressure and temperature data behind the shock waves serving as the starting conditions for the simulation. Since reflected shock waves have been used in both the experiments, constant volume simulations have been performed. Ignition times presented here have been calculated based on the temperature inflection point in the temperature vs. time profile predicted. Parameter studies have been performed to cover the range of experimental conditions; for the range of temperature covered, simulations have been performed for steps of $25-\mathrm{K}$-increase in temperature.

\section{High-Temperature Regime}

Figure 46 compares the calculated ignition-delay times with the experimental data of Zhukov et al. [21] for a stoichiometric $n$-decane/air mixture, at a pressure of $13 \mathrm{~atm}$. The predictions agree well with the experimental data over the (high) temperature range shown.

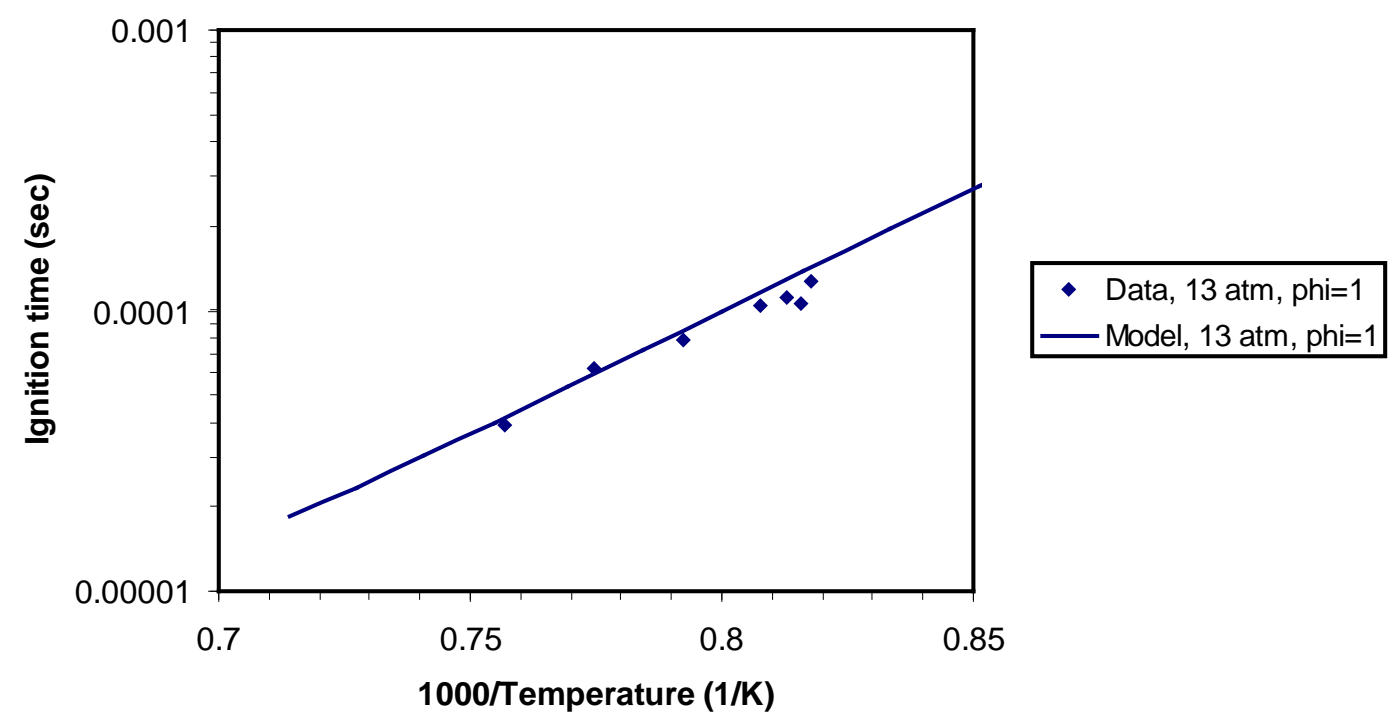

Figure 46. Calculated $n$-decane/air ignition delay times compared with the data of Zhukov et al. [21]. Conditions include pressure of $13 \mathrm{~atm}$ and a stoichiometric mixture. 
Figure 47 compares model predictions with the experimental data of Pfahl et al. [20] for a stoichiometric $n$-decane/air mixture, at a pressure of $13 \mathrm{~atm}$. The predictions also compare well with the data at these temperatures.

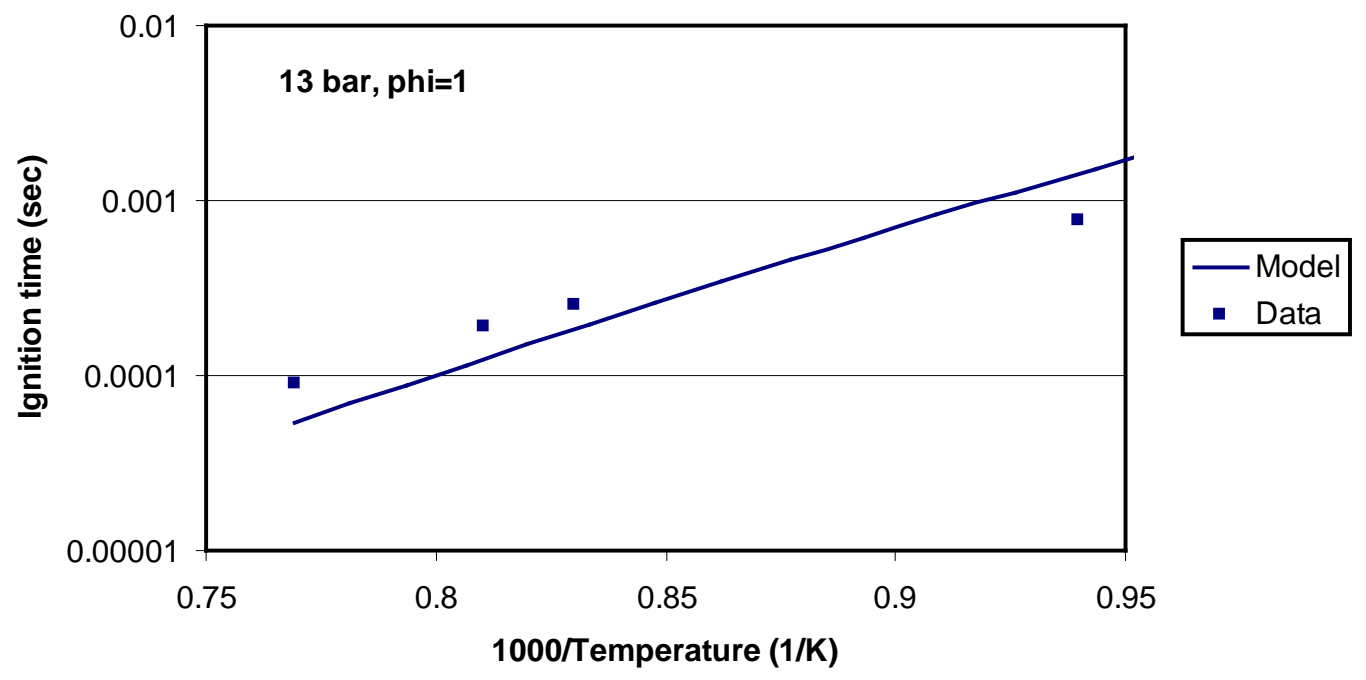

Figure 47. Calculated $n$-decane/air ignition-delay times compared with the data of Pfahl et al. [20]. Conditions include pressure of $13 \mathrm{~atm}$ and a stoichiometric mixture.

Figure 48 compares the calculated ignition-delay times with the experimental data of Dean et al. [22], at $8.9 \mathrm{~atm}$ and for a stoichiometric mixture of $n$-decane/air. Dean et al. estimated the uncertainty in their ignition-delay times as $10-15 \%$ [22]. The calculated values agree well with the experimental data, for these high temperatures.

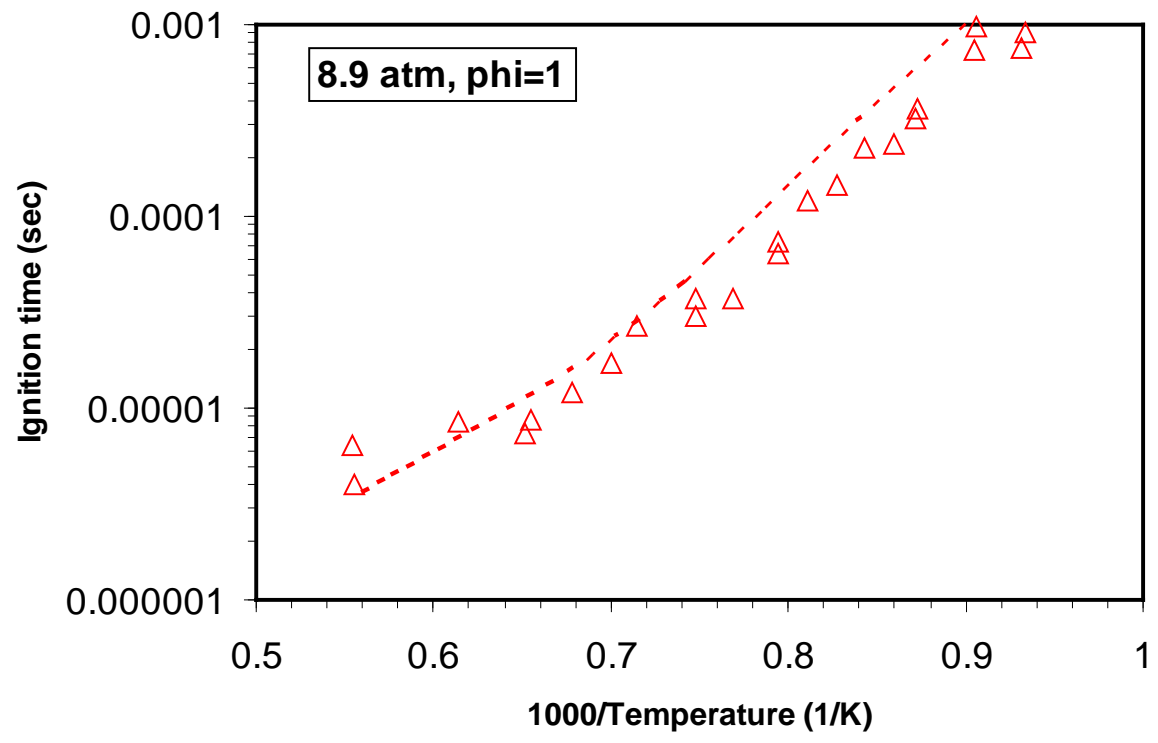

\begin{tabular}{|cc|}
\hline$\Delta$ & Data \\
\hline-- & - Model \\
\hline
\end{tabular}

Figure 48. Calculated ignition times for $n$-decane/air mixtures at $8.9 \mathrm{~atm}$, in comparison with the experimental data of Dean et al. [22]. 
Olchanski et al. [24] and Horning et al. [23] performed several experiments with $n$-decane $/ \mathrm{O}_{2} / \mathrm{Ar}$ mixtures, but instead of reporting the data, they reported correlations of the data for a range of temperatures, concentrations and pressures. While we would prefer to compare to the actual data instead of correlations, the data were not reported. We therefore show some comparisons with their correlations, with the caveat that agreements or discrepancies with their correlations could be clouded by uncertainties in the correlations themselves. Figure 49 compares the calculated ignition-delay times with the correlation of Olchanski et al. [24] for an $n$-decane/ $\mathrm{O}_{2} / \mathrm{Ar}$ mixture with an equivalence ratio of 0.5 and with $85 \mathrm{~mol} \%$ Ar. Ignition times are shown for $2 \mathrm{~atm}$ and $10 \mathrm{~atm}$, over a temperature range of 1200-1600 K. The model shows faster ignition than the correlation, but shows the correct trends as a function of temperature and pressure.

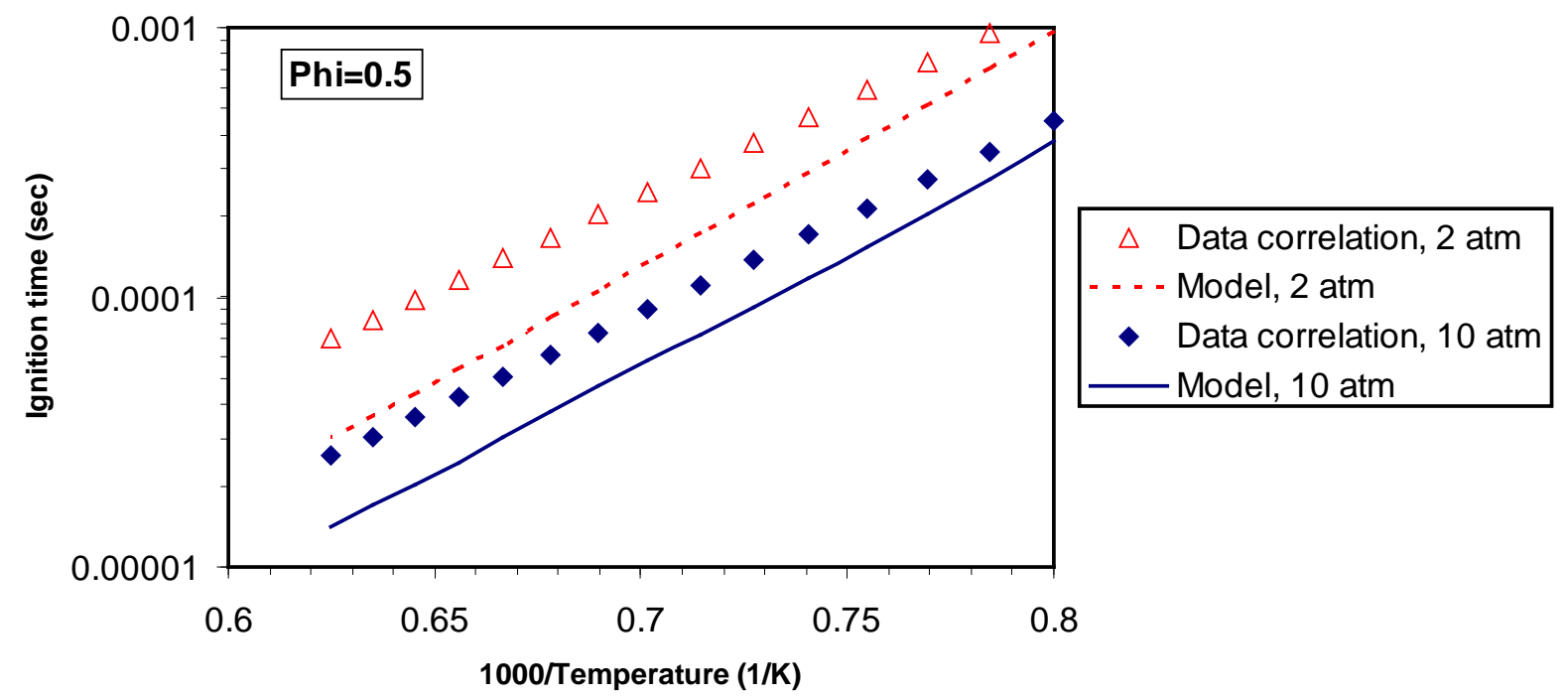

Figure 49. Calculated ignition times for $n$-decane/air mixtures at 2 and $10 \mathrm{~atm}$, in comparison with the experimental data correlation of Olchanski et al. [24].

Figure 50 shows the ignition times for an $n$-decane $/ \mathrm{O}_{2} /$ Ar mixture at $6 \mathrm{~atm}$, for an equivalence ratio of 2 $\left(\mathrm{O}_{2}\right.$ mole fraction $\left.=0.1\right)$. The model predictions show a smaller slope than that of the data correlation of Horning et al. [23]. 


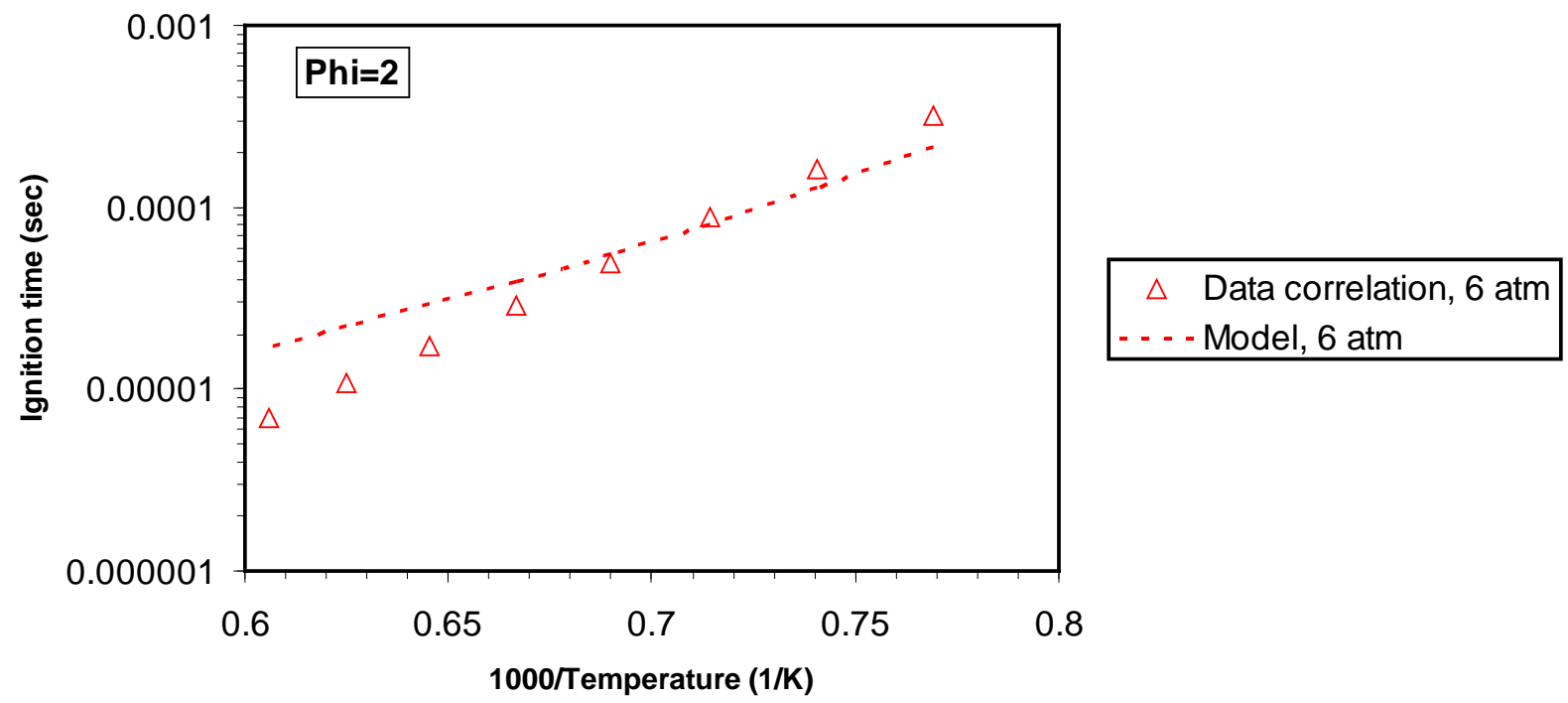

Figure 50. Calculated ignition times for $n$-decane/air mixtures at 6 atm, in comparison with the experimental data correlation of Horning et al. [23] for an equivalence ratio of $2\left(\mathrm{O}_{2}\right.$ mole fraction=0.1).

\section{Low-Temperature Regime}

Figure 51 shows a representative validation case for low-temperature chemistry for n-decane. Figure 51 compares the model results with the shock-tube experimental data of Pfahl et al. [20]. A fuel-lean ndecane/air mixture is used at a pressure of 13 bar. The results compare well, predicting the negative temperature coefficient (NTC) regime well. The NTC regime starts $\sim 750 \mathrm{~K}$ and extends to $\sim 900 \mathrm{~K}$.

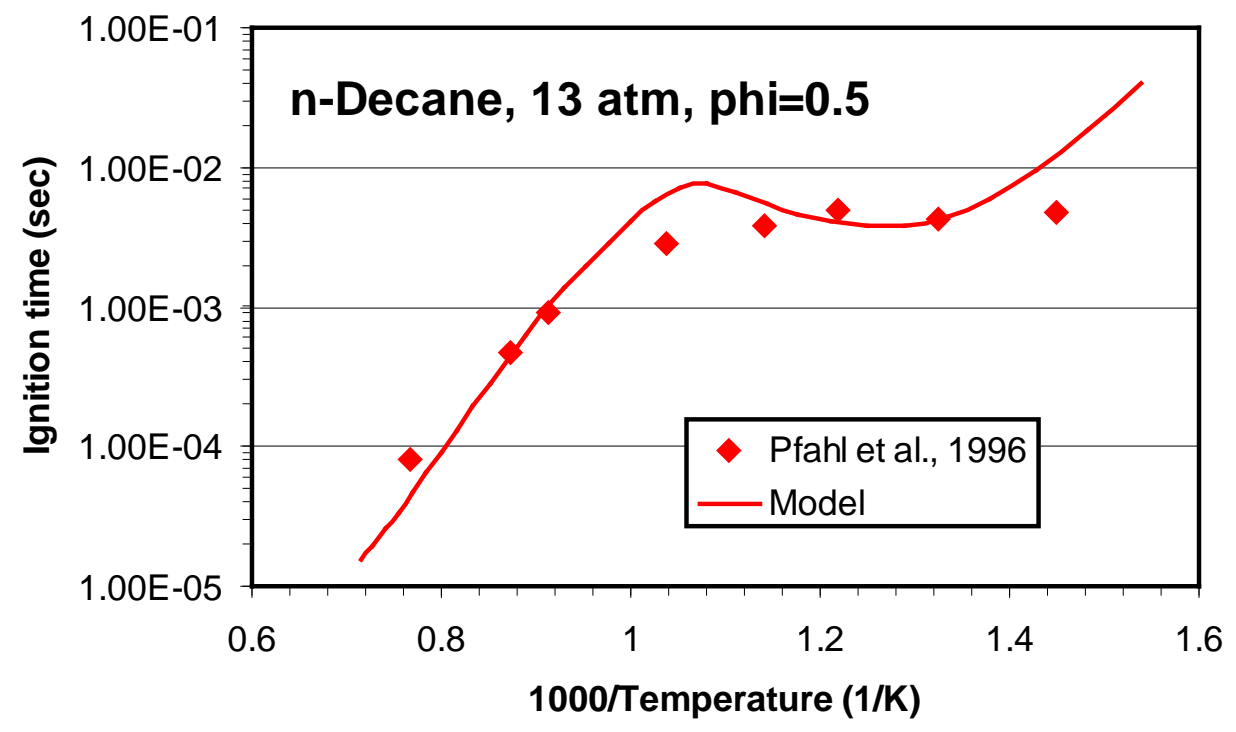

Figure 51. Ignition delay times for an $\mathbf{n}$-decane/air mixture at $\mathbf{1 3} \mathrm{atm}$ and an equivalence ratio of 0.5 . 


\subsubsection{Laminar Flame Speeds}

As discussed in Section 2.1.3, there is some uncertainty regarding the extraction of laminar flame speeds from measurements in stretched flames. USC has observed noticeable differences in laminar flame speeds determined using linear vs. non-linear extrapolation of data. As seen in Figure 52, different extrapolation techniques may significantly affect laminar flame speeds as reported in the literature, especially under fuel-rich conditions. We expect the non-linear extrapolation method to provide a more accurate indication of the laminar flame speed value that would be predicted using a one-dimensional flamespeed simulator. All data from the USC Flame Facility that is reported here employs the non-linear extrapolation method, unless explicitly stated otherwise.

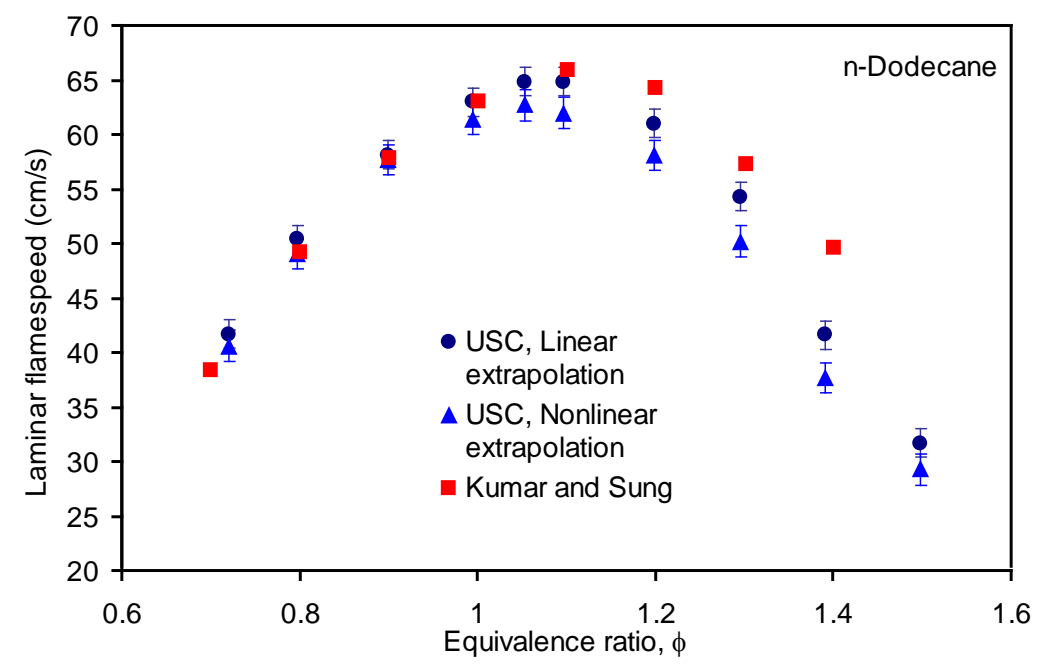

Figure 52. Impact of linear and non-linear extrapolation of flame velocity to zero stretch to obtain laminar flame speed of $n$-dodecane using opposed flow burner configuration at USC Flame Facility. Data from Kumar and Sung [25] are based on linear extrapolation method.

Kumar et al. used linear extrapolation, and Figure 53 shows a plot from their paper showing the extrapolation to zero stretch rate. The figure provides an idea of the uncertainty involved in extrapolation, especially for the fuel-rich case. 


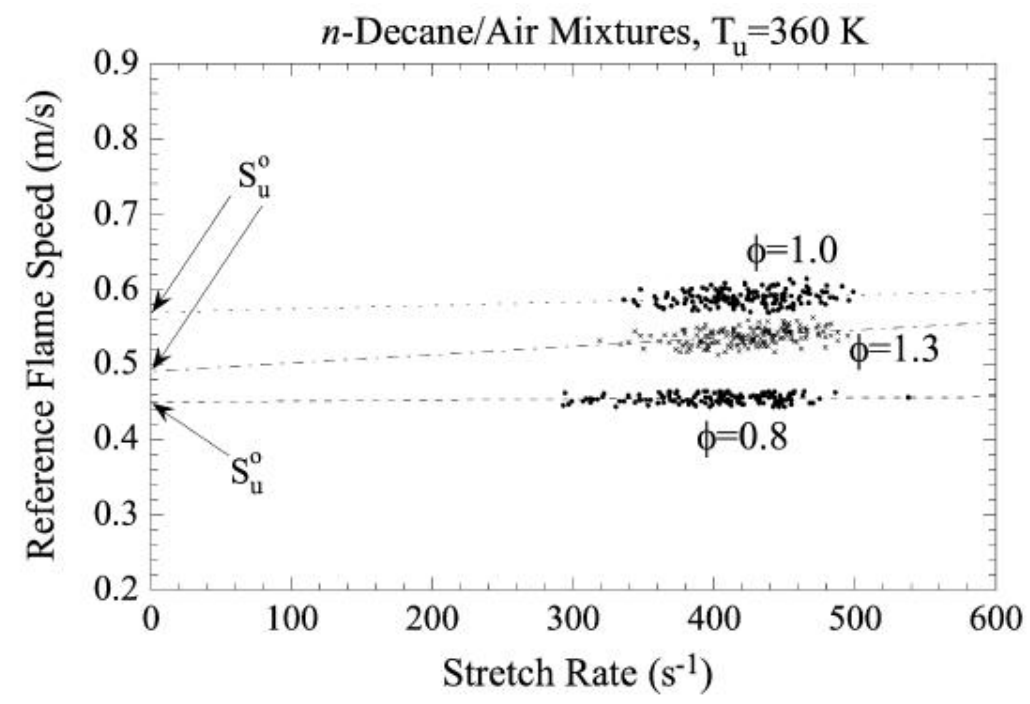

Figure 53. Plot from paper of Kumar et al. [25] showing extrapolation to zero stretch rate.

Comparisons of the predicted laminar flame speeds for $n$-decane to the experimental data of USC and Kumar et al. at $400 \mathrm{~K}$ are shown in Figure 54. With focus on the USC data, our current mechanism provides improved flame-speed predictions over the presented range of equivalence ratios, within the USC experimental error estimation.

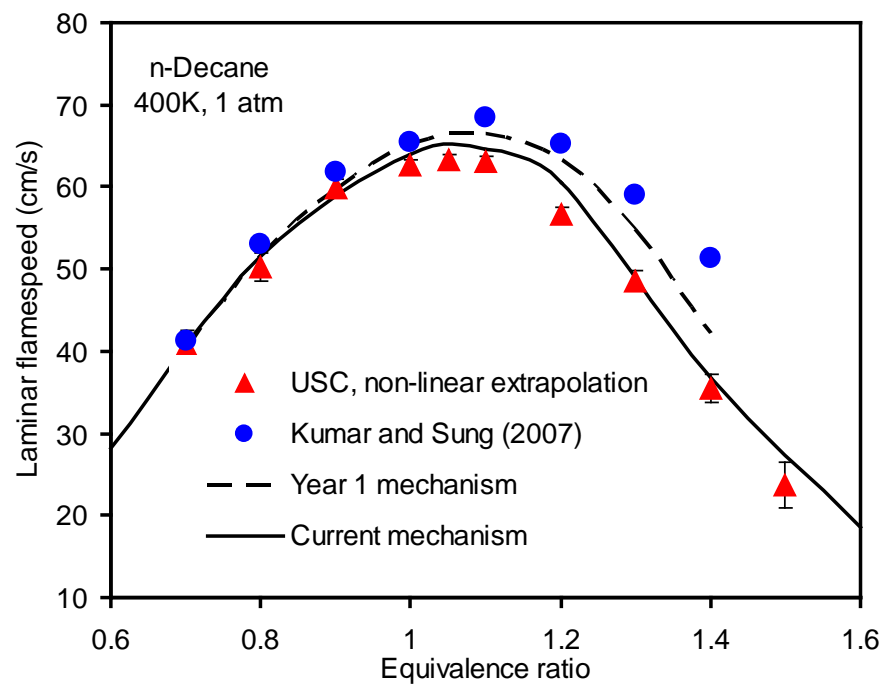

Figure 54. Comparison of predicted laminar flame speed of $n$-decane to the experimental data from USC and Kumar and Sung [25].

\subsubsection{Burner-Stabilized Flames}

Delfau et al. and Doute et al. studied rich $n$-decane combustion using burner-stabilized flames. Delfau et al. studied the combustion at low pressure $(6 \mathrm{kPa})$ and an equivalence ratio of 1.9 (n-decane/ $\mathrm{O}_{2} / \mathrm{Ar}$ ), while Doute et al. used atmospheric pressure and an equivalence ratio of 1.7 (n-decane/ $\mathrm{O}_{2} / \mathrm{N}_{2}$ ). Table 10 shows the range of operating conditions for their burner-stabilized flame experiments. Delfau et al. used molecular beam-mass spectrometer technique, and Doute et al. used gas chromatography. 
Table 10. $n$-Decane burner-stabilized flame experiments in the literature.

\begin{tabular}{|l|l|l|l|l|}
\hline Source & Year & $\begin{array}{l}\text { Pressure } \\
\mathbf{( a t m})\end{array}$ & Equivalence ratio & $\begin{array}{l}\text { Inlet gas velocity } \\
\text { (cm/sec) }\end{array}$ \\
\hline Delfau et al. [26] & 1990 & 0.06 & 1.9 & 18.6 \\
\hline Doute et al. [27] & 1997 & 1 & 1.7 & 11.7 \\
\hline
\end{tabular}

The modeling of these experiments has been performed under fixed-temperature conditions, using the temperature profile reported in the papers. Doute et al. estimated the uncertainty in their temperature measurements as $\pm 5 \%$.

Figure 55 to Figure 59 compare the calculated species profiles for the fuel-rich $n$-decane $/ \mathrm{O}_{2} / \mathrm{N}_{2}$ flame at atmospheric pressure, with the experimental data of Doute et al. The conditions include atmospheric pressure and an equivalence ratio of 1.7 (mole \%: 3.2\% n-decane, 28.6\% $\mathrm{O}_{2}, 68.2 \% \mathrm{~N}_{2}$ ). The inlet velocity was $11.7 \mathrm{~cm} / \mathrm{sec}$. The measured temperature used by Doute et al. was used directly in the modeling.

The comparisons show good agreement for most species. Figure 55 shows the profiles of the fuel and oxidizer, $n$-decane and $\mathrm{O}_{2}$. These reactants are seen to be consumed within $\sim 2 \mathrm{~mm}$ from the burner, and the model predictions agree well with this observation.

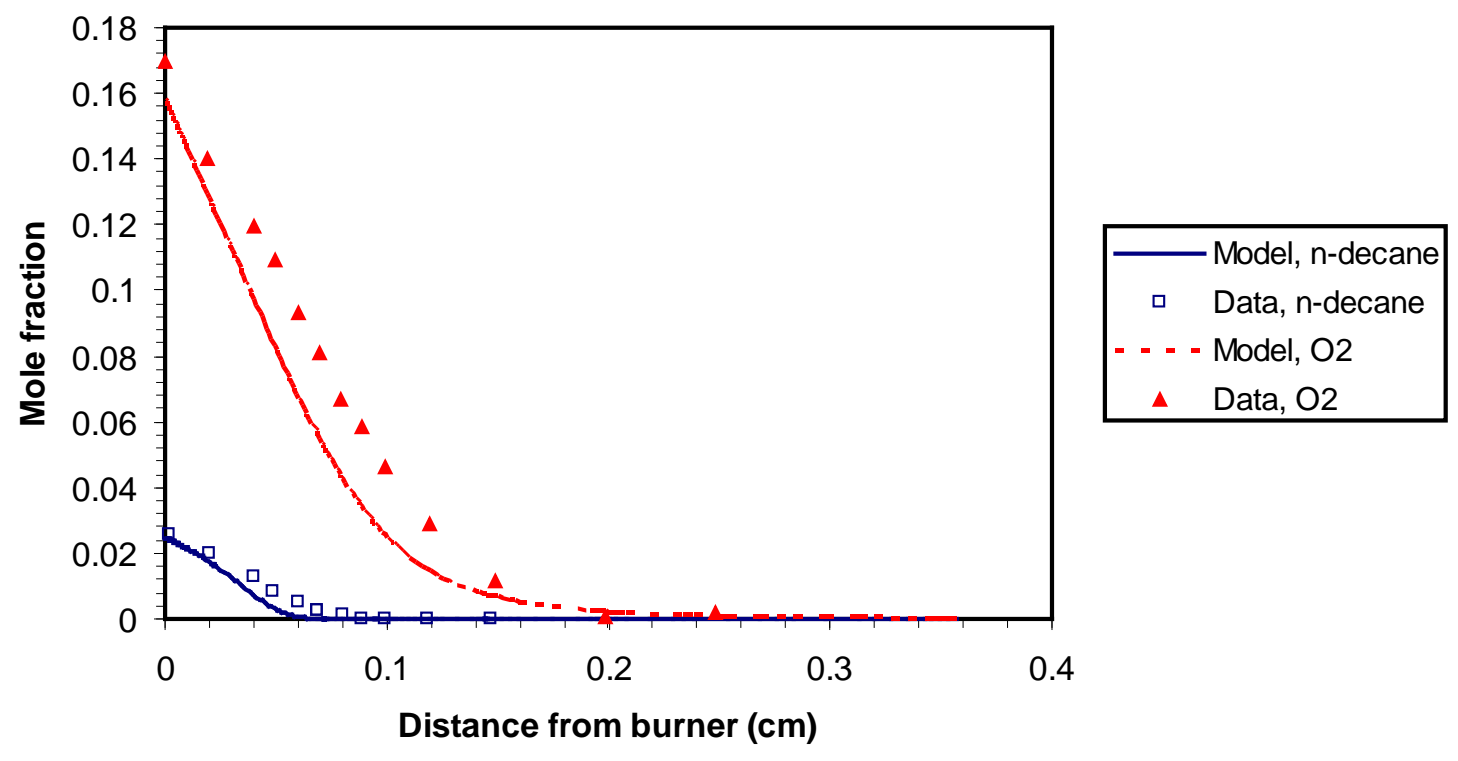

Figure 55. Calculated $n$-decane and $\mathrm{O}_{2}$ concentration profiles for the $n$-decane $/ \mathrm{O}_{2} / \mathrm{N}_{2}$ premixed burner-stabilized flame with an equivalence ratio of 1.7 , compared with the data of Doute et al. [27]. Inlet velocity $=11.7 \mathrm{~cm} / \mathrm{sec}$, pressure $=1 \mathrm{~atm}$, reactant mole fractions: $n$ decane $=0.032, \mathrm{O}_{2}=0.286, \mathrm{~N}_{2}=0.682$.

Figure 56 shows the profiles for $\mathrm{CO}$ and $\mathrm{CO}_{2}$. For these fuel-rich conditions, more $\mathrm{CO}$ is formed than $\mathrm{CO}_{2}$, and the model predictions follow the correct trends. 


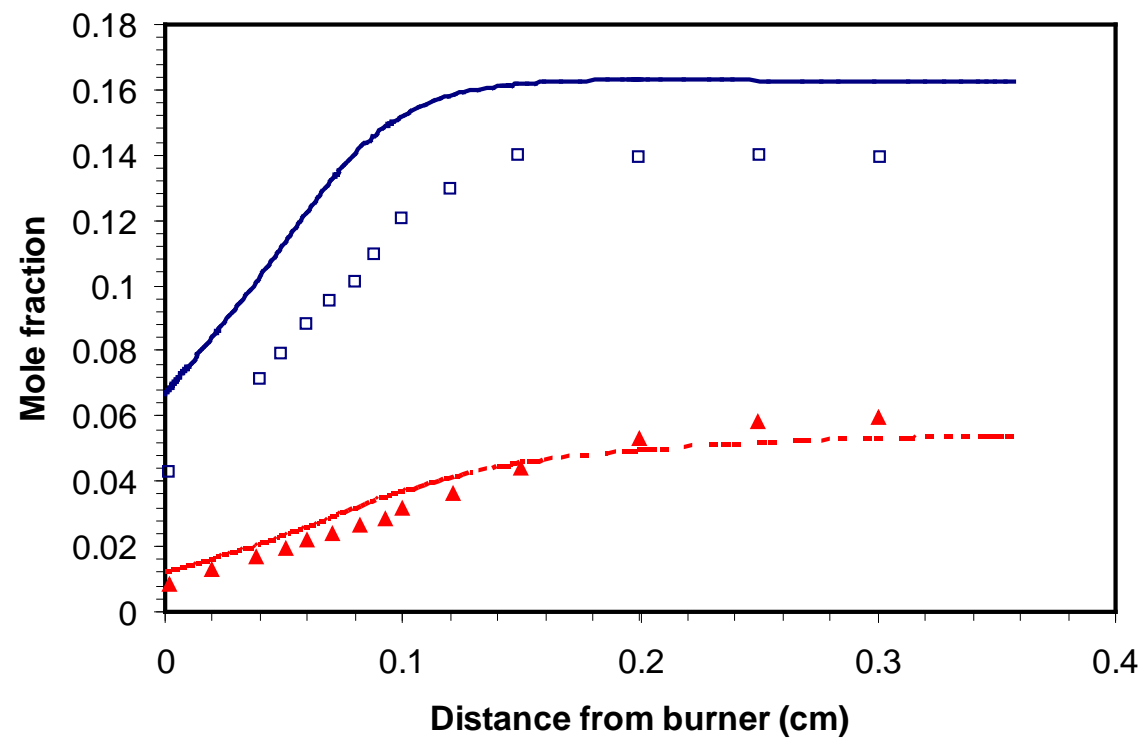

Figure 56. Calculated $\mathrm{CO}$ and $\mathrm{CO}_{2}$ concentration profiles for the $\mathrm{n}$ decane $/ \mathrm{O}_{2} / \mathrm{N}_{2}$ premixed burner-stabilized flame with an equivalence ratio of 1.7 , compared with the data of Doute et al. [27]. Inlet velocity $=11.7 \mathrm{~cm} / \mathrm{sec}$, pressure $=1 \mathrm{~atm}$, reactant mole fractions: $n$-decane $=0.032, \mathrm{O}_{2}=0.286, \mathrm{~N}_{2}=0.682$.

Figure 57 shows the profile for another major product, $\mathrm{H}_{2}$. Most of the $\mathrm{H}_{2}$ is formed by $\sim 0.15 \mathrm{~cm}$, and the model predicts this well.

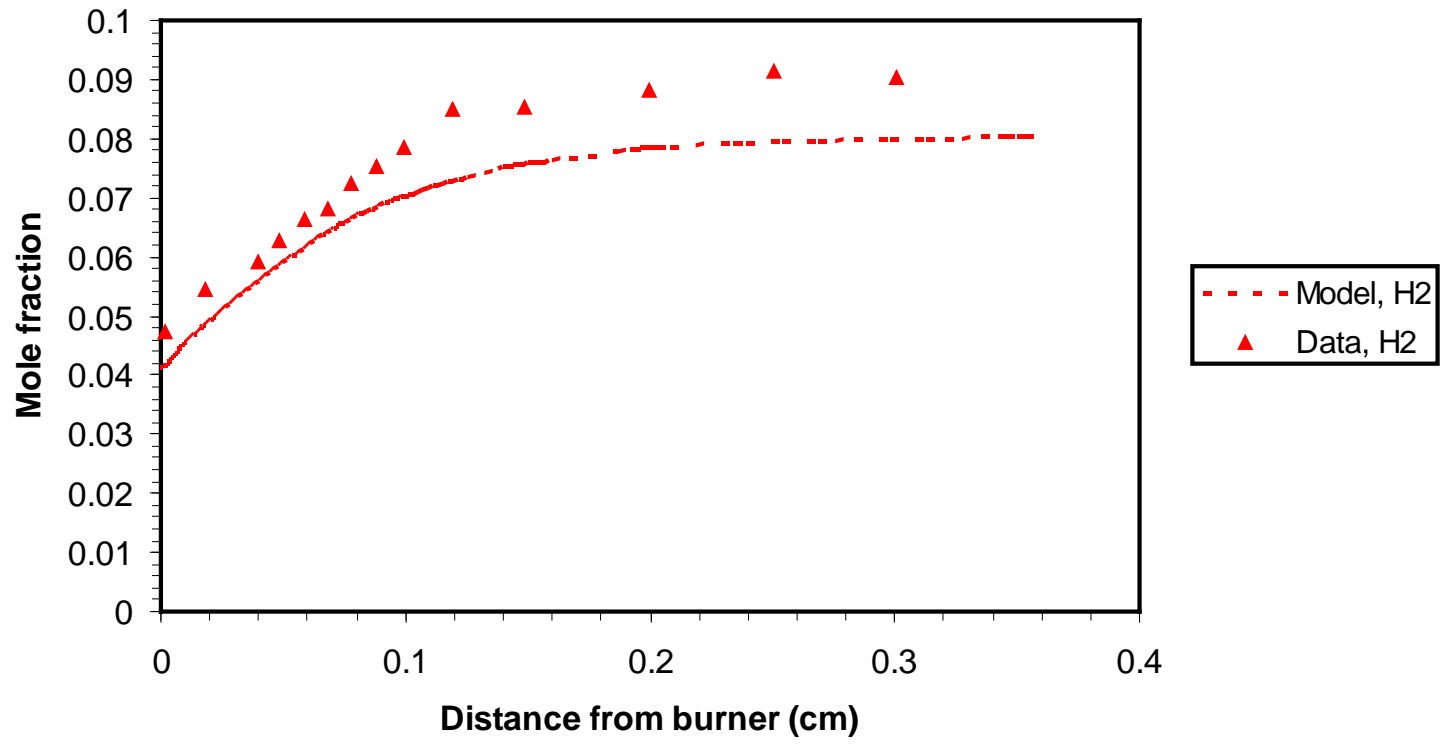

Figure 57. Calculated $\mathrm{H}_{2}$ concentration profile for the $n$-decane/ $\mathrm{O}_{2} / \mathrm{N}_{2}$ premixed burnerstabilized flame with an equivalence ratio of 1.7 , compared with the data of Doute et al. [27]. Inlet velocity $=11.7 \mathrm{~cm} / \mathrm{sec}$, pressure $=1$ atm, reactant mole fractions: $n$-decane $=0.032, \mathrm{O}_{2}=0.286, \mathrm{~N}_{2}=0.682$.

Figure 58 shows the profiles of the major hydrocarbon species ethylene and acetylene. The location of the ethylene peak concentration is captured well, but the magnitude of the peak is under-predicted by the model. However, the model predicts correctly that ethylene has the highest peak concentration of all 
stable hydrocarbons. Acetylene, which is a potential soot precursor, has a significant concentration under these fuel-rich conditions, and the model prediction of the acetylene profile agrees well with the experimental data.

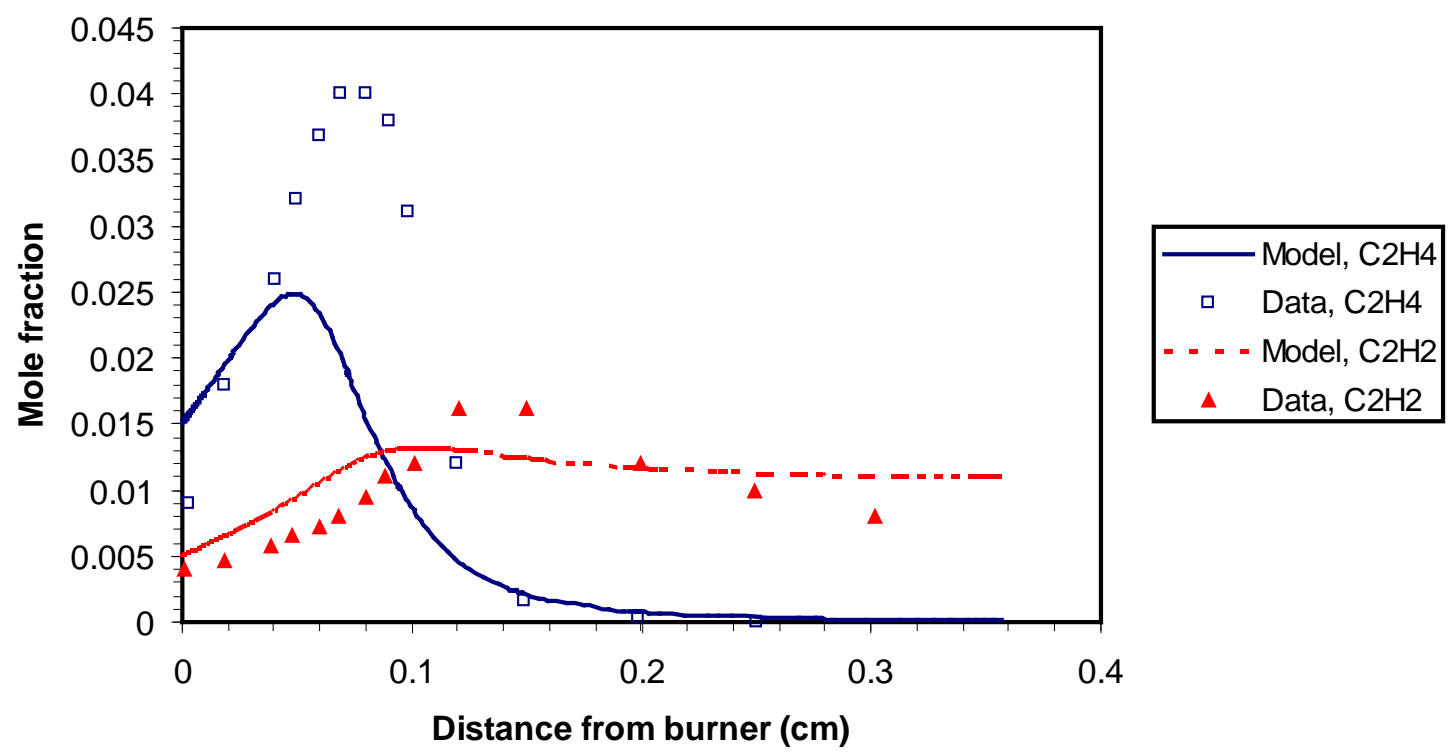

Figure 58. Calculated $\mathrm{C}_{2} \mathrm{H}_{4}$ and $\mathrm{C}_{2} \mathrm{H}_{2}$ concentration profiles for the $n$-decane/ $\mathrm{O}_{2} / \mathrm{N}_{2}$ premixed burner-stabilized flame with an equivalence ratio of 1.7 , compared with the data of Doute et al. [27]. Inlet velocity $=11.7 \mathrm{~cm} / \mathrm{sec}$, pressure $=1 \mathrm{~atm}$, reactant mole fractions: $n$-decane $=0.032, \mathrm{O}_{2}=0.286, \mathrm{~N}_{2}=0.682$.

Figure 59 shows other major hydrocarbons. Both the alkanes methane and ethane have lower concentrations than the alkene (ethylene) and alkyne (acetylene) in Figure 58. The model predicts the correct trend that more methane is formed than ethane. While the model predictions agree well with the experimental data for methane, the model under-predicts the peak for ethane; however, the concentration of ethane is small compared to the other hydrocarbons shown. 


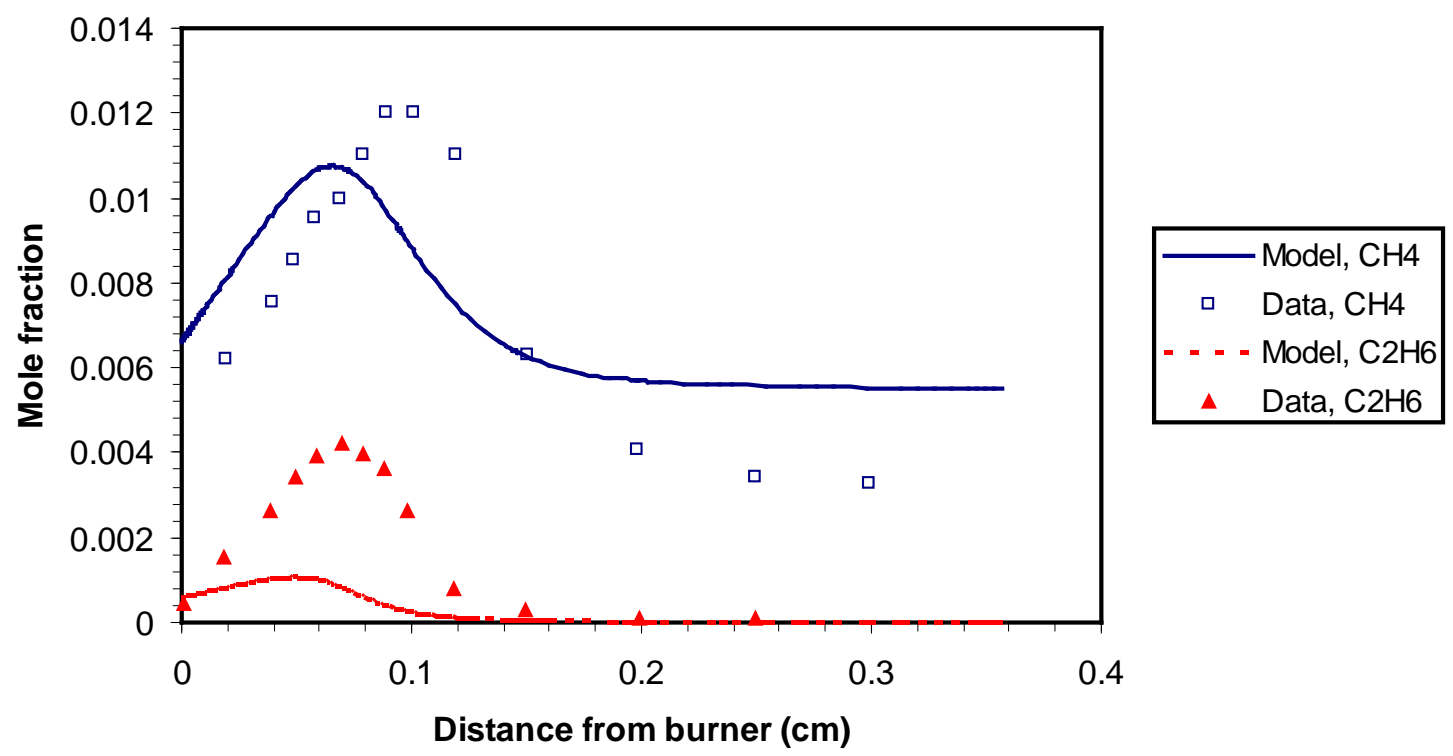

Figure 59. Calculated $\mathrm{CH}_{4}$ and $\mathrm{C}_{2} \mathrm{H}_{6}$ concentration profiles for the $n$-decane/ $\mathrm{O}_{2} / \mathrm{N}_{2}$ premixed burner-stabilized flame with an equivalence ratio of 1.7, compared with the data of Doute et al. [27]. Inlet velocity $=11.7 \mathrm{~cm} / \mathrm{sec}$, pressure $=1 \mathrm{~atm}$, reactant mole fractions: $\mathrm{n}$ decane $=0.032, \mathrm{O}_{2}=0.286, \mathrm{~N}_{2}=0.682$.

Figure 60 and Figure 61 show the comparisons of model predictions with the experimental data of Delfau et al. The experimental temperature profile of Delfau et al. was used as a constraint in the modeling. This case used an equivalence ratio of 1.9.

The fuel-rich n-decane/ $\mathrm{O}_{2} / \mathrm{Ar}$ combustion occurs at a low pressure of $6 \mathrm{kPa}$ and at an equivalence ratio of 1.9 (mole \%: $5.1 \%$ n-decane, $41.2 \% \mathrm{O}_{2}, 53.7 \% \mathrm{Ar}$ ). The inlet velocity was $18.6 \mathrm{~cm} / \mathrm{sec}$. These simulations have also been performed using fixed-temperature conditions specified by the experimental temperature profile. Figure 60 shows the profiles of major products $\mathrm{CO}$ and $\mathrm{CO}_{2}$. Since this is a fuel-rich case, significantly more $\mathrm{CO}$ is formed than $\mathrm{CO}_{2}$. The reactions seem to occur within $\sim 1 \mathrm{~cm}$ from the burner surface, and the model is able to capture that effect. 

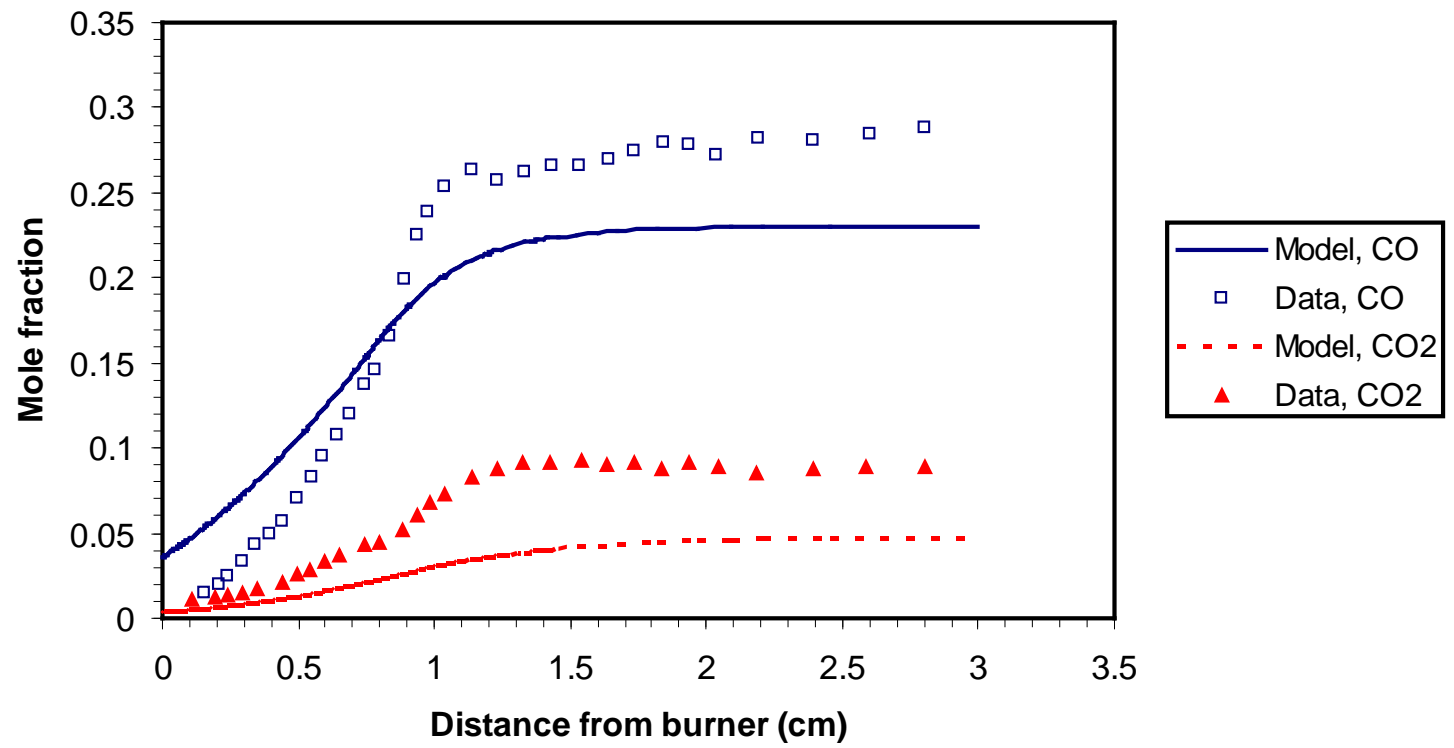

Figure 60. Calculated $\mathrm{CO}_{2}$ and $\mathrm{CO}$ concentration profiles for $\mathbf{n}$ decane/ $/ \mathrm{O}_{2} / \mathrm{Ar}$ premixed burner-stabilized flame with an equivalence ratio of 1.9, compared with the data of Delfau et al. [26]. Inlet velocity $=18.6 \mathrm{~cm} / \mathrm{sec}$, pressure $=1 \mathrm{~atm}$, reactant mole fractions: $\mathrm{n}$ decane $=0.051, \mathrm{O}_{2}=0.412, \mathrm{Ar}=0.537$.

Figure 61 shows the profile of the major hydrocarbon intermediate ethylene. The model predictions for the ethylene profile and its peak value are consistent with the experimental data.

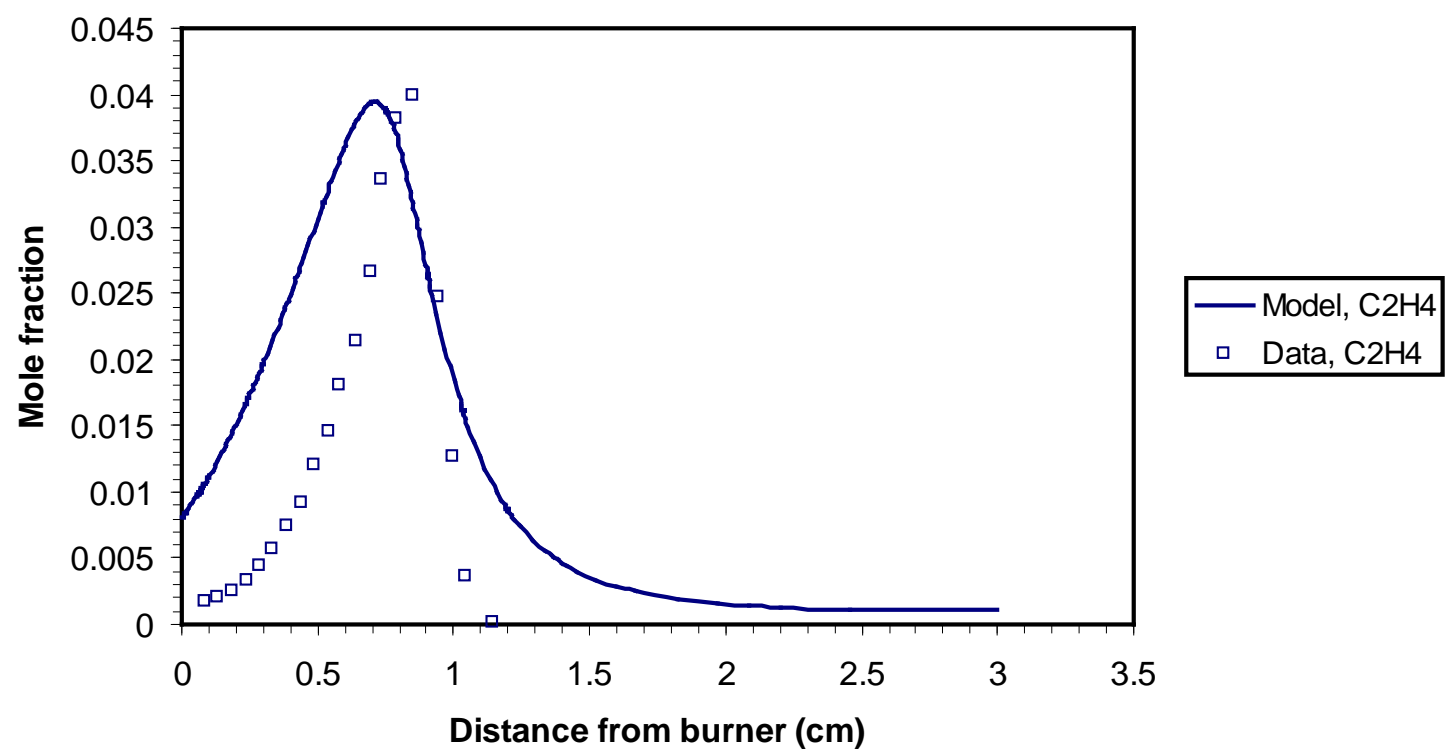

Figure 61: Calculated $\mathrm{C}_{2} \mathrm{H}_{4}$ concentration profiles for $n$ decane $/ \mathrm{O}_{2} / \mathrm{Ar}$ premixed burnerstabilized flame with an equivalence ratio of 1.9, compared with the data of Delfau et al. [26]. Inlet velocity $=18.6 \mathrm{~cm} / \mathrm{sec}$, pressure $=1 \mathrm{~atm}$, reactant mole fractions: $\mathrm{n}$ decane $=0.051, \mathrm{O}_{2}=0.412, \mathrm{Ar}=0.537$.

Overall, the model predicts consistent trends of species profiles for both the low-pressure conditions of Delfau et al. and the atmospheric conditions of Doute et al. 


\subsection{Validation of Surrogate Component: $n$-Dodecane}

The n-Dodecane mechanism was first tested successfully against USC flame-speed and flame-extinction data. However, in recognition of the fact that flame conditions do not sufficiently test the mechanism for application to engine conditions, we sought out additional data under different conditions for comparison. We found literature data that provided ignition-delay times and compared the model to these measurements.

\subsubsection{Laminar Flame Speeds}

Comparison of predicted laminar flame speeds of $n$-dodecane to the experimental data from USC and from the literature is shown in Figure 62. These comparison show good agreement with the USC data, where they have used careful extrapolation of results from their raw measurements. The extrapolation method appears to affect the measurement values most for the fuel-rich cases. For the higher temperature case, the only data available is from Kumar and Sung, where linear extrapolation method was used. This suggests that the model provides very good agreement with the data, within the uncertainty of the experimental measurements.

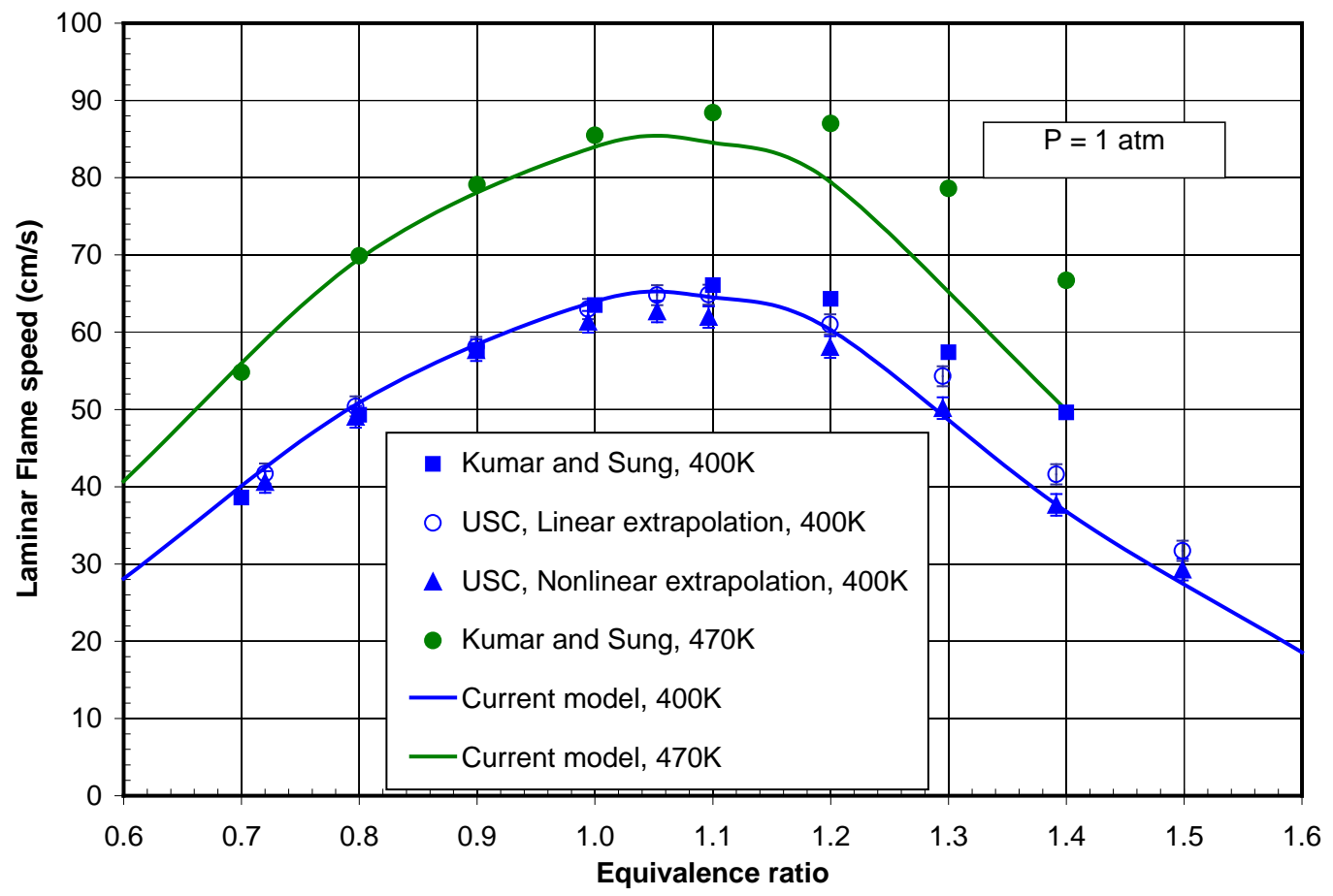

Figure 62. Comparison of predicted and measured laminar flame speeds for $\mathbf{n}$-dodecane/ air flames. Pressure is $1 \mathrm{~atm}$ while unburned gas temperatures of $400 \mathrm{~K}$ and $470 \mathrm{~K}$ are used.

\subsubsection{Extinction Strain Rates}

Extinction calculations were also performed for n-dodecane. Figure 63 shows comparison of extinction strain rates as a function of equivalence ratio for $\mathrm{n}$-dodecane / air flames. The operating conditions are: $\mathrm{P}$ $=1 \mathrm{~atm}$, premixed fuel/air mixture at $403 \mathrm{~K}$ from one nozzle and pure nitrogen $\left(\mathrm{N}_{2}\right)$ at $296 \mathrm{~K}$ from other. The nozzle separation distance is $7 \mathrm{~mm}$. It can be seen that the mechanism updates result in a marked improvement compared to the mechanism used at the start of the project, and that the overall agreement 
with experimental data is very good. The calculated extinction strain rates are only marginally higher near stoichiometric conditions.

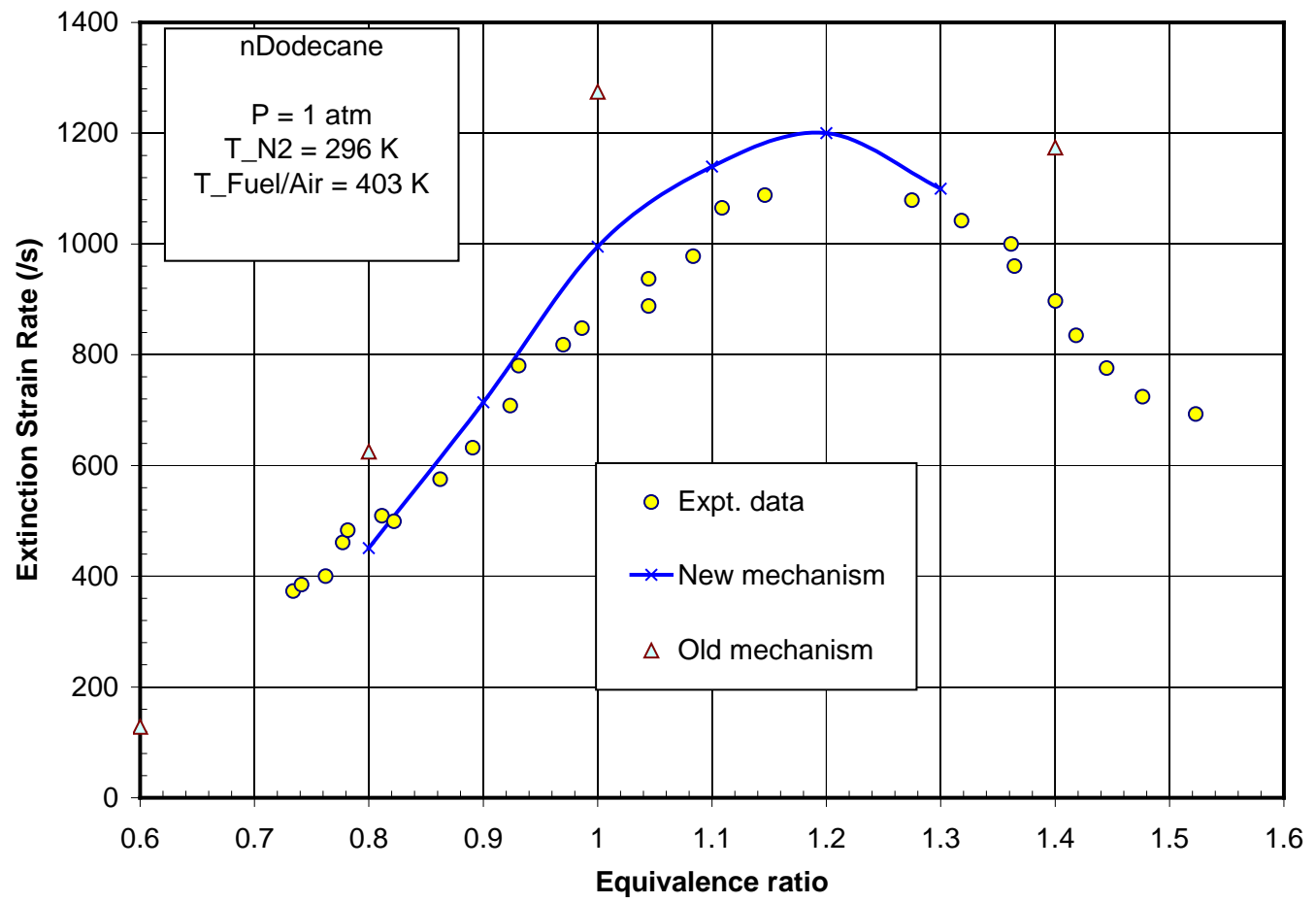

Figure 63. Comparison of predicted and measured extinction strain rate of n-dodecane/air mixture at $403 \mathrm{~K}, 1 \mathrm{~atm}$ using opposed flow flame configuration.

\subsubsection{Ignition-delay Times}

\section{High-Temperature Regime}

Figure 64 compares the calculated ignition-delay times with the experimental data of Hanson et al. [28] for a stoichiometric n-dodecane/air mixture, at a pressure of $20 \mathrm{~atm}$. The predicted ignition time at temperatures above $1100 \mathrm{~K}$ are within a factor of two, which is reasonable given the difficulty and uncertainty of the measurements for such a large hydrocarbon fuel. However, the mechanism could not capture the faster ignition measured near $1000 \mathrm{~K}$. This is due to the lack of low temperature kinetics in the preliminary version of the mechanism used in these calculations. We later added the lowtemperature components to the mechanism, which provided better comparisons in the low-temperature regime as described below. The low-temperature kinetics are important for full engine simulation but not required for simulations of flame experiments. Also, we note that the data from Hanson, et al., was preliminary, pre-published data. 


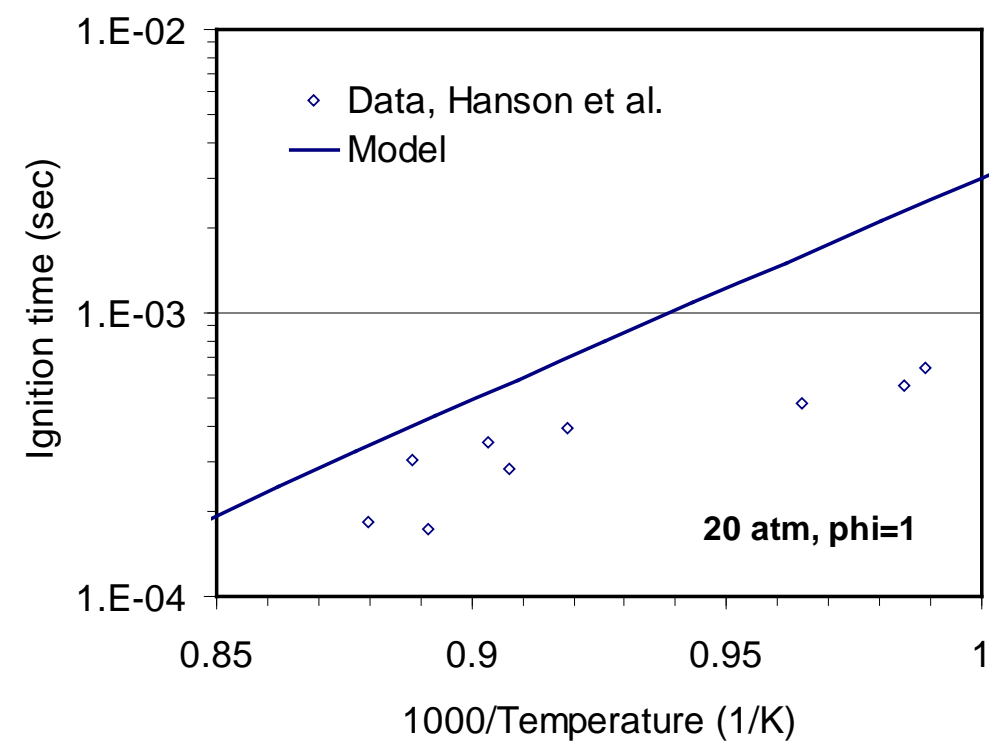

Figure 64. Calculated $n$-dodecane/air ignition-delay times compared with the data of Hanson et al. Conditions include pressure of $20 \mathrm{~atm}$ and a stoichiometric mixture.

\section{Low-Temperature Regime}

Figure 65 show a representative validation case for low-temperature chemistry for n-dodecane. Figure 65 compares the model results with the experimental data of Vasu et al. [29] for auto-ignition of ndodecane/air mixtures behind reflected shocks at $20 \mathrm{~atm}$. The results show the correct trends for the NTC regime, but also show an overprediction at ignition delay times above 1 microsec. For these longer ignition-delay measurements, some non-idealities in the shock-tube measurement may be present.

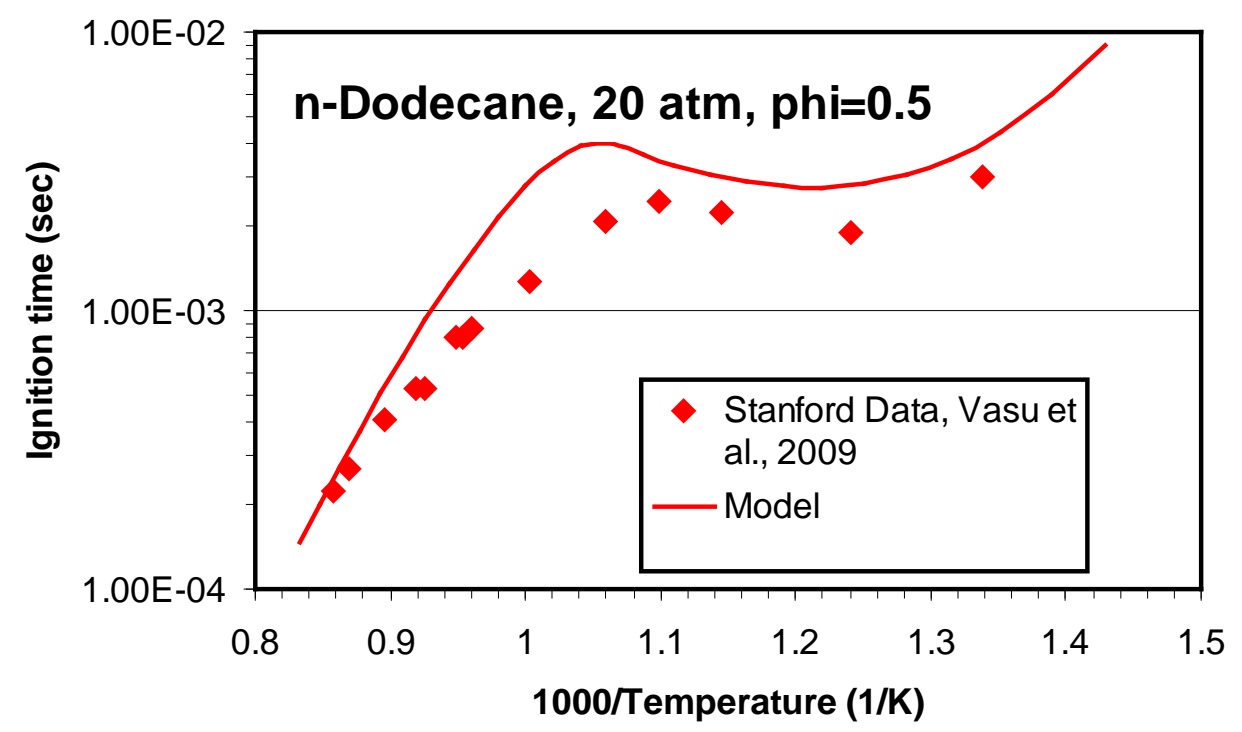

Figure 65 Ignition delay times for an n-dodecane/air mixture at $20 \mathrm{~atm}$ and an equivalence ratio of 0.5 . 


\subsection{Conclusions of the Component Mechanism Validation Studies}

Validation data have been collected from the literature for n-decane, n-dodecane and methyl decanoate, to complement the experimental data from USC. These data from the literature include:

- Ignition Times from Shock Tube

- Laminar Flame Speeds

- $\quad$ Species Profiles from Burner-Stabilized Flames

Ignition-delay times and laminar flame speeds have been used as validation data. In addition, species profiles from burner-stabilized flames have also been used, since they further illuminate whether the reaction pathways are captured well. Sometimes, conditions that are uncharted in fundamental laboratory experiments are of interest for engine modeling - higher pressures and effect of mixtures, for instance. Matching species profiles, in addition to the flame speeds and ignition times, therefore provide more confidence in the validity of the mechanism over potential uncharted conditions.

Overall, the biodiesel surrogate mechanism predicts well the ignition-delay times and laminar flame speeds of the components studied, over a wide range of conditions. The species profiles also show the correct trends overall, although there are some quantitative discrepancies in some of the profiles. Some small updates could be performed on the mechanism to improve these predictions. However, for the purposes of understanding the fuel-component combustion behavior, the mechanism performs well overall.

\subsection{Validation of $\mathrm{NO}_{\mathrm{x}}$ emissions Predictions}

Using the same counter-flow burner assembly, USC has made measurements of $\mathrm{NO}_{\mathrm{x}}$, using heated premixed fuel/air from the bottom burner and inert nitrogen at room temperature from the top burner. Measurements for $C_{5}$ hydrocarbons $n$-pentane, methyl butanoate, and methyl decanoate have been obtained with an equivalence ratio of 0.8 and a mixture temperature of $323 \mathrm{~K}$, at $1 \mathrm{~atm}$ and with a global strain rate of $1201-\mathrm{s}^{-1}$. Figure 66 shows predicted $\mathrm{NO}_{\mathrm{x}}$ that is in excellent agreement with the data. Most $\mathrm{NO}_{\mathrm{x}}$ was found to be in the form of $\mathrm{NO}$ under these flame conditions. The fact that the relatively similar sized fuels and two different (small) methyl esters produce $\mathrm{NO}_{\mathrm{x}}$ in significantly different quantities is also useful information in determining the fundamental effects of biodiesel on engine emissions behavior. 


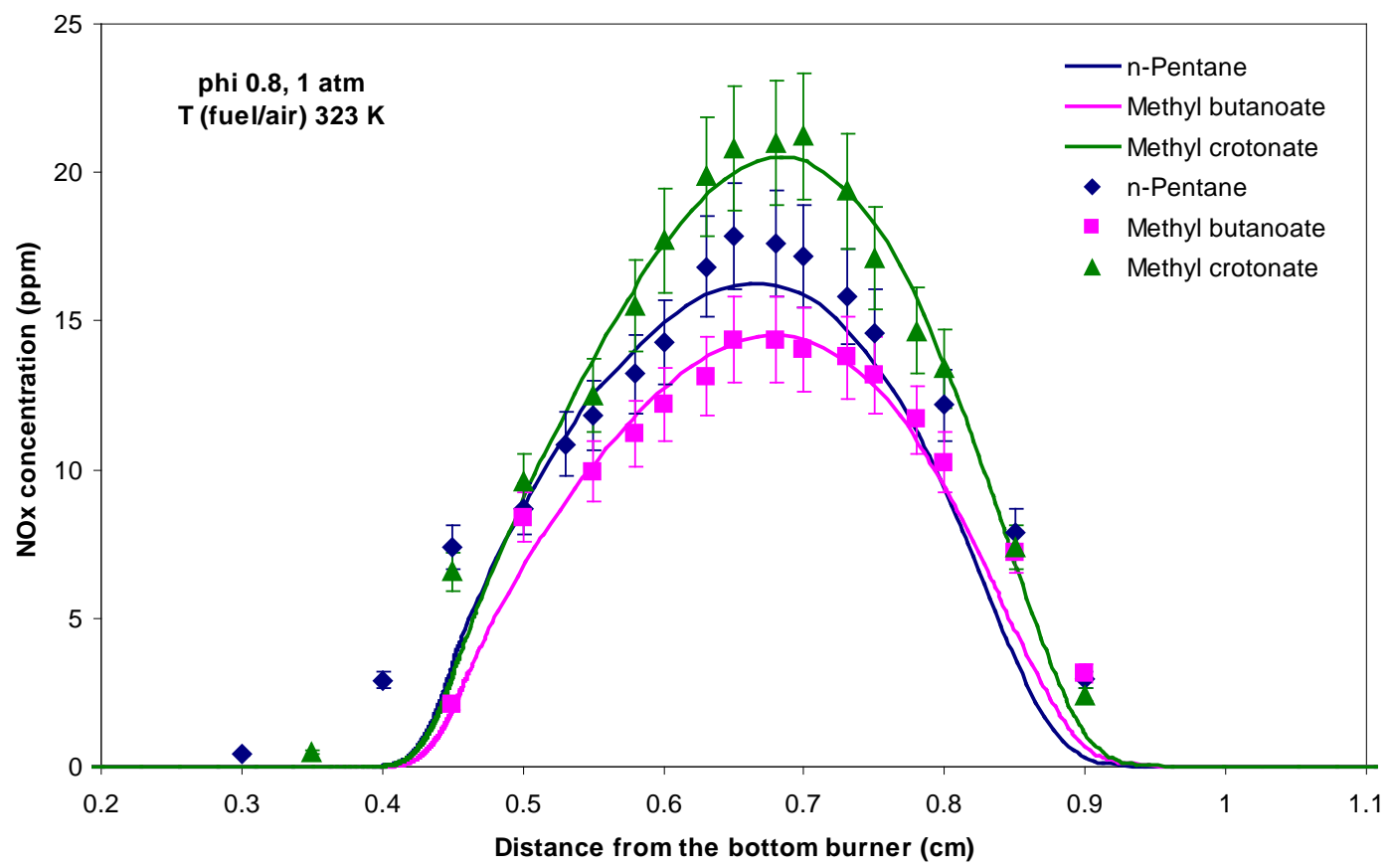

Figure 66. Comparison of predicted and measured $\mathrm{NO}_{\mathrm{x}}$ from $n$-pentane, methyl butanoate, and methyl crotonate. Premixed fuel/air is injected at $323 \mathrm{~K}$ from the bottom burner and nitrogen at room temperature from the top burner.

For heavier fuels, $n$-decane and methyl decanoate, the experiments employed a higher burner temperature of $403 \mathrm{~K}$, with an equivalence ratio of 0.83 with a global strain rate of $1251-\mathrm{s}^{-1}$. Figure 67 shows predicted $\mathrm{NO}_{x}$ (mostly in the form of $\mathrm{NO}$ ) that is significantly lower than the initially obtained measured data, by as much as $20 \mathrm{ppm}$ for $n$-decane and $30 \mathrm{ppm}$ for methyl decanoate. 


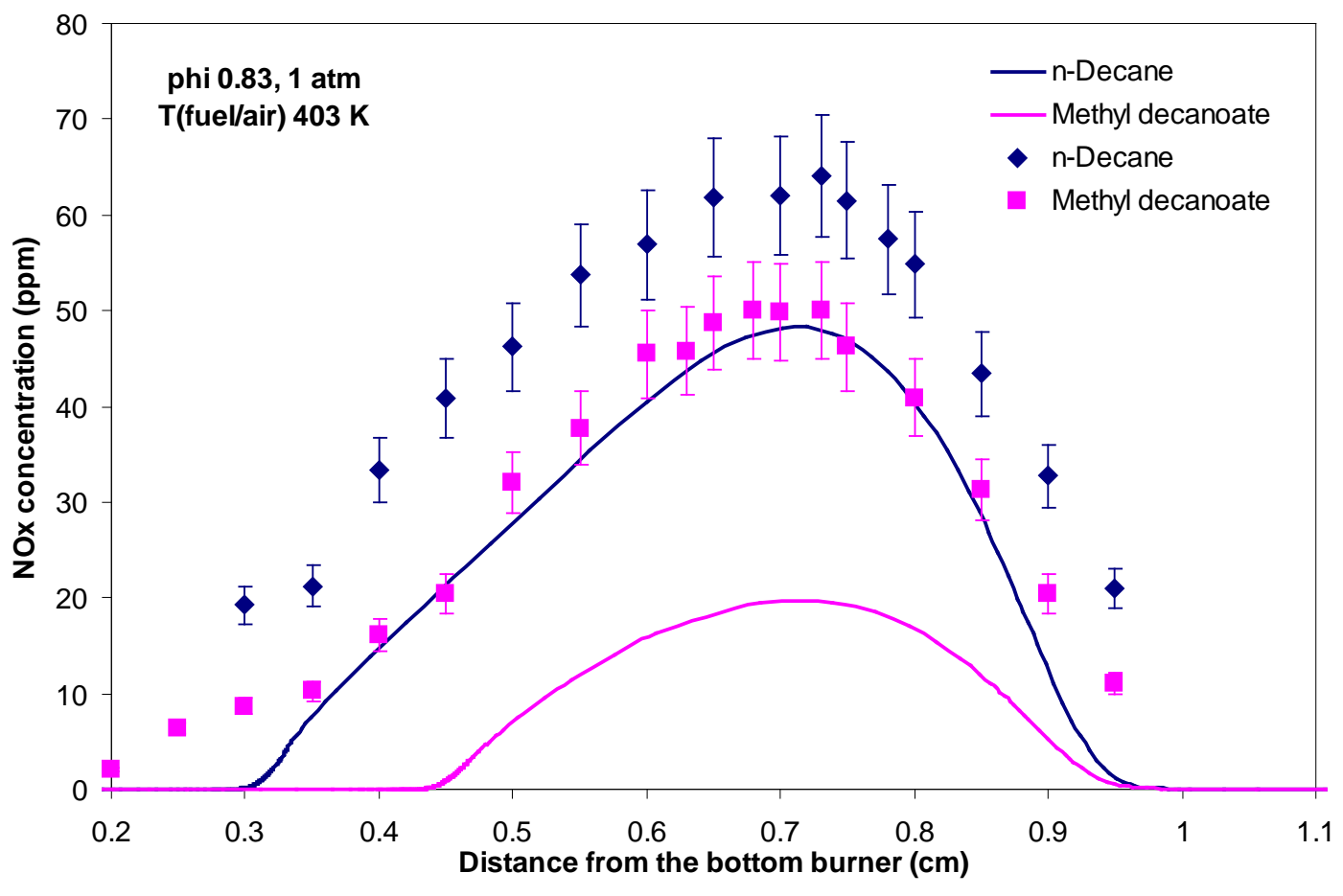

Figure 67. Comparison of predicted $\mathrm{NO}_{\mathrm{x}}$ from $n$-decane and methyl decanoate with initial measurements obtained from USC. Premixed fuel/air is injected at $403 \mathrm{~K}$ from the bottom burner and nitrogen at room temperature from the top burner.

To investigate the reason for the under-prediction of $\mathrm{NO}_{\mathrm{x}}$ for these heavier fuels, we performed rate and sensitivity analyses for NO under the conditions of $n$-pentane (where predictions are good) and for $n$-decane (where predictions are off by $\sim 20 \%$ ). For $n$-pentane (Figure 68 ) most NO is produced from thermal- $\mathrm{NO}_{x}$ pathways. $\mathrm{N}_{2} \mathrm{O}$ and $\mathrm{NNH}$ pathways also contribute to the total $\mathrm{NO}$ significantly. Reactions of $\mathrm{O}$ radical with $\mathrm{NNH}$ and $\mathrm{N}_{2}$ are the most sensitive reactions for $\mathrm{NO}$ concentrations. $\mathrm{NO}$ concentrations do not appear to be sensitive to any reactions of fuel or smaller hydrocarbons. This indicates that the type and size of the fuel molecule should not directly affect $\mathrm{NO}_{x}$, but only the pool of $\mathrm{O}$ and $\mathrm{H}$ radicals and the flame temperature will impact $\mathrm{NO}_{x}$ emissions. 

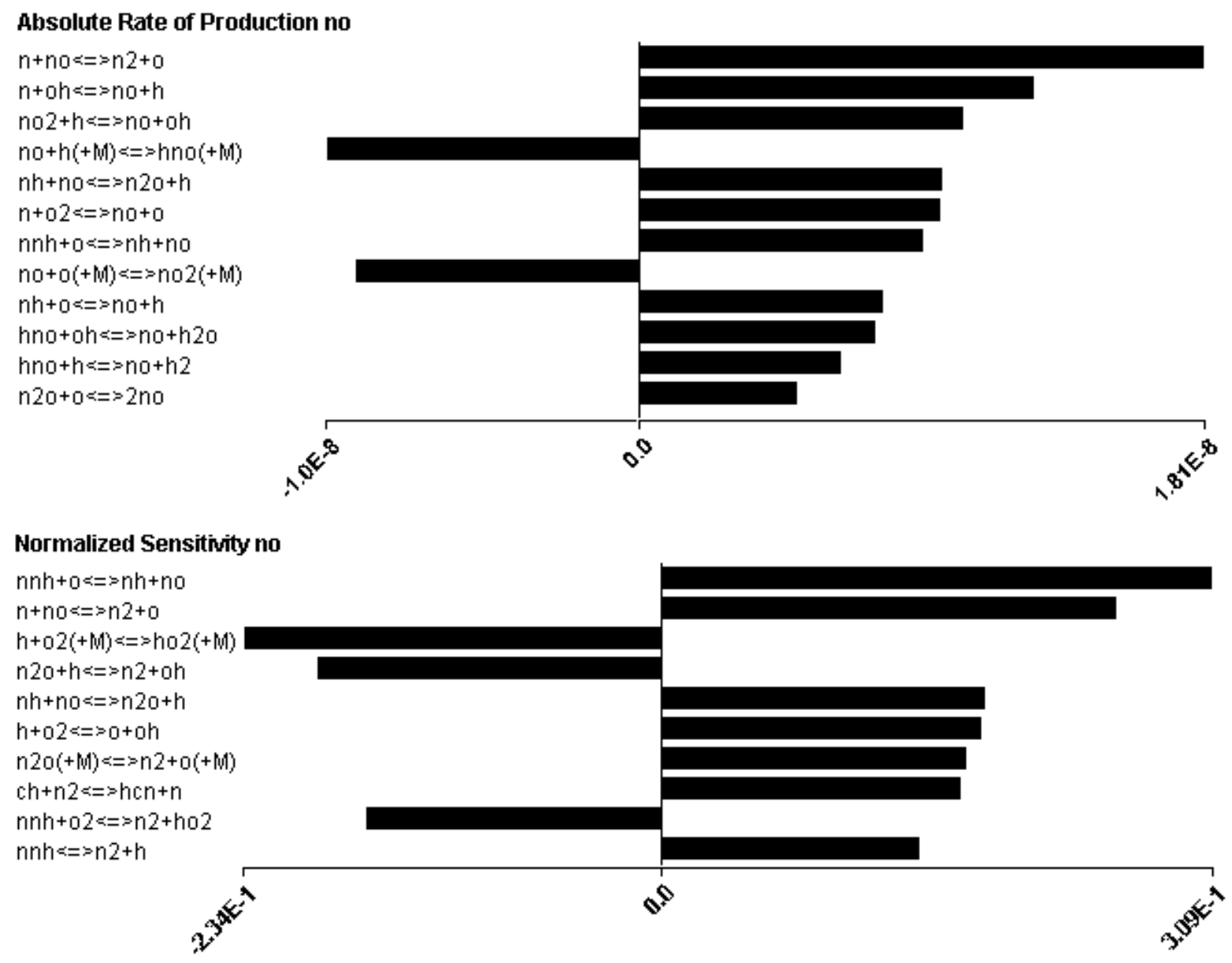

Figure 68. Rate of production and sensitivity analysis for NO near the peak for the n-pentane flame shown in Figure 66.

For $n$-decane (Figure 67), all major production pathways for $\mathrm{NO}$ are similar to those identified for $n$-pentane. However, the peak temperature for the $n$-pentane flame was $1921 \mathrm{~K}$ whereas that for $n$-decane is $2088 \mathrm{~K}$. Higher flame temperatures slightly skew the $\mathrm{NO}$ production in $n$-decane towards thermal-NOx. Sensitivity analysis for $\mathrm{NO}$ revealed that most reactions that were important for $\mathrm{NO}_{x}$ production for $n$-pentane are also important for $n$-decane. Based on the similarities between $\mathrm{NO}_{x}$ production pathways in the two flames, USC investigated the possibility of experimental inconsistencies for the $\mathrm{NO}_{\mathrm{x}}$ measurements made for the larger hydrocarbons, which are more difficult than the $n$-pentane measurements. They identified some issues with the reproducibility of the measurements and then generated new data with revised procedures.

The results of a re-visiting of the experimental procedures are shown in Figure 69, which compares the same $\mathrm{NO}_{x}$ predictions for a methyl decanoate/air flame agreeing with the new experimental data. Here, the model agrees very well with the experimental data. A premixed stream of methyl decanoate/air enters from one of the nozzles at $403 \mathrm{~K}$, while nitrogen enters from the other nozzle at $296 \mathrm{~K}$. The strain rate was $166 \mathrm{sec}^{-1}$. The $\mathrm{NO}_{\mathrm{x}}$ values in the figure are on a ppmd basis (ppm on dry basis). We note that the model did not change from Figure 67, but the data now are more consistent with those taken for other fuels. 


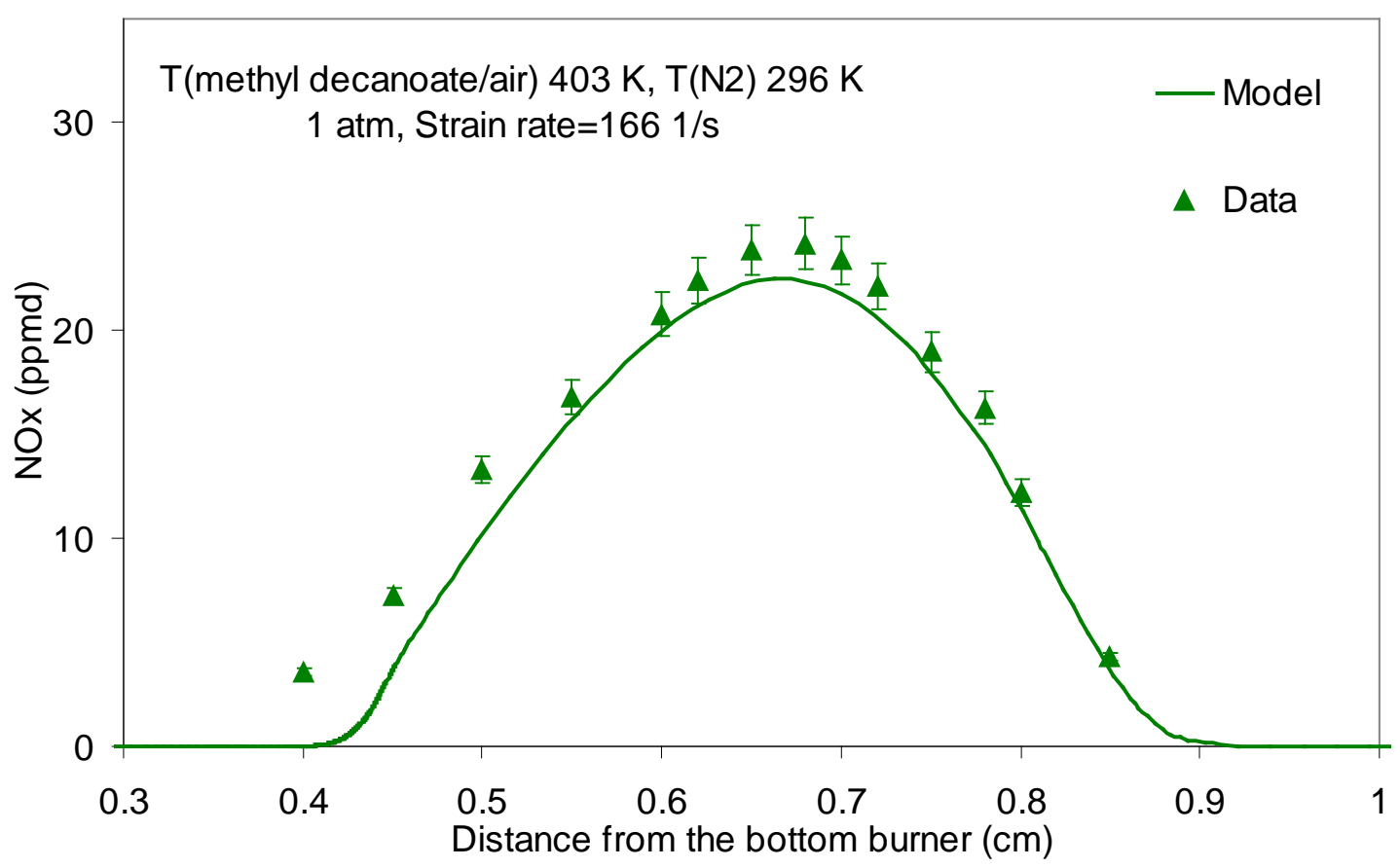

Figure 69 Comparison of predicted and the latest measured $\mathrm{NO}_{x}$ values for methyl decanoate/air flames. Symbols represent experimental data and lines represent model predictions.

Figure 70 and Figure 71 show $\mathrm{NO}_{x}$ concentrations for several $n$-dodecane/air flames. Figure 70 shows the effect of strain rate on the $\mathrm{NO}_{x}$ values, and Figure 71 shows the effect of equivalence ratio on the $\mathrm{NO}_{\mathrm{x}}$ values.

Figure 70 is for a fuel-lean mixture with an equivalence ratio of 0.8 . The primary effect of varying strain rates is the structure of the flame. Figure 70 shows the calculated temperature profiles of the two flames. The peak flame temperature for the lower strain rate case $\left(120 \mathrm{sec}^{-1}\right)$ is $55 \mathrm{~K}$ higher than that for the higher strain rate case. This could play a role in increased thermal $\mathrm{NO}_{\mathrm{x}}$. The model is able to capture these trends. However, the model under-predicts the $\mathrm{NO}_{\mathrm{x}}$ values by $\sim 20 \%$ in both cases. The peak $\mathrm{NO}_{\mathrm{x}}$ values are seen close to the center of the domain (distance between the two nozzles is $1.4 \mathrm{~cm}$ ), and the model is able to capture this location. 


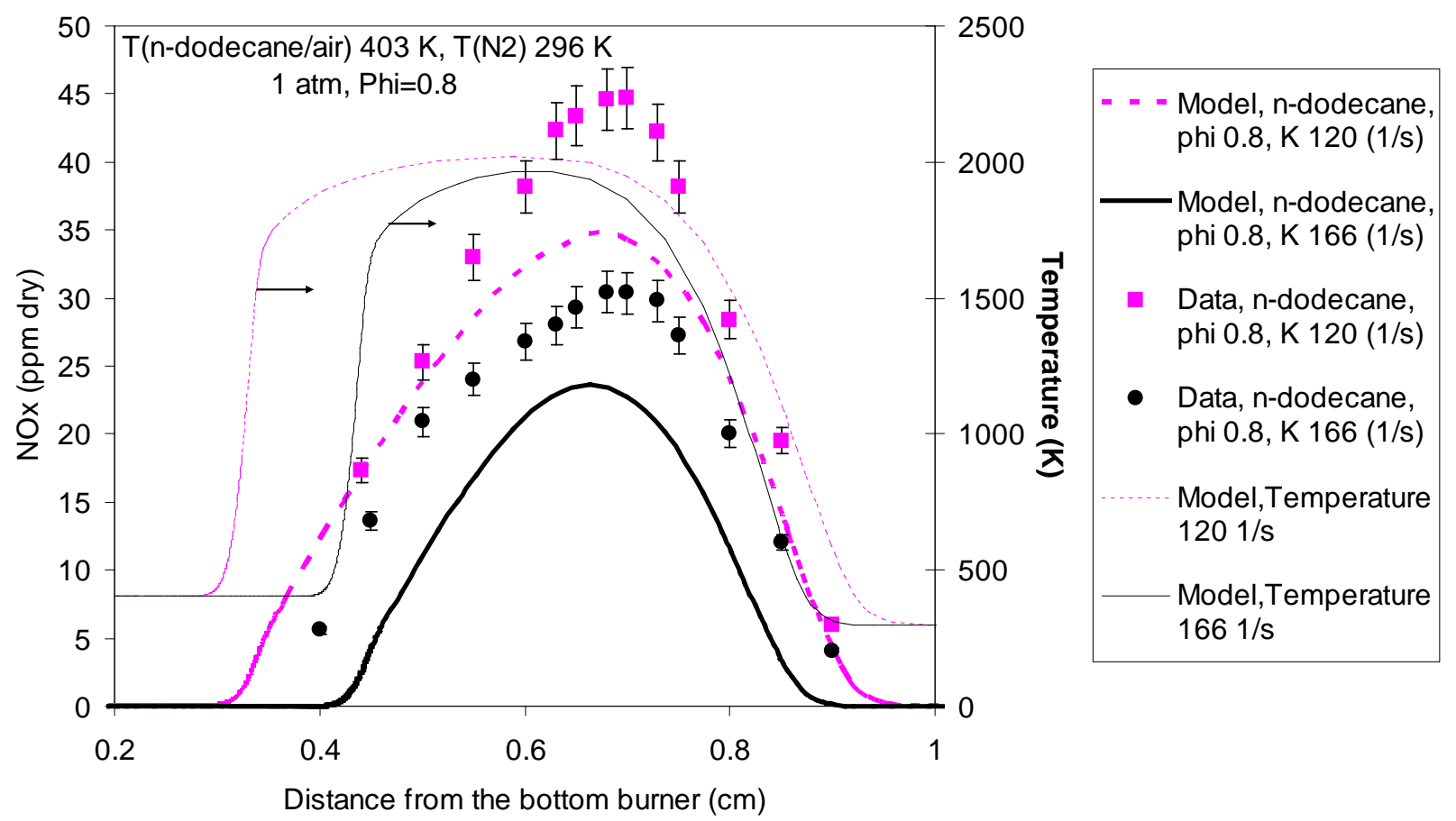

Figure 70. Effect of strain rate on $\mathrm{NO}_{\mathbf{x}}$. Comparison of predicted and measured $\mathrm{NO}_{\mathrm{x}}$ values for $n$-dodecane/air flames at strain rates of 120 and $166 \mathrm{sec}^{-1}$, with an equivalence ratio of 0.8 .

Figure 71 shows the effect of equivalence ratio on $\mathrm{NO}_{x}$ production, at a constant strain rate of $166 \mathrm{sec}^{-1}$. The model is able to capture the trends, although it consistently under-predicts $\mathrm{NO}_{x}$ values. The captured trends include the fuel-lean case showing the least $\mathrm{NO}_{x}$ concentrations, and the stoichiometric case showing the highest $\mathrm{NO}_{\mathrm{x}}$ concentrations. 


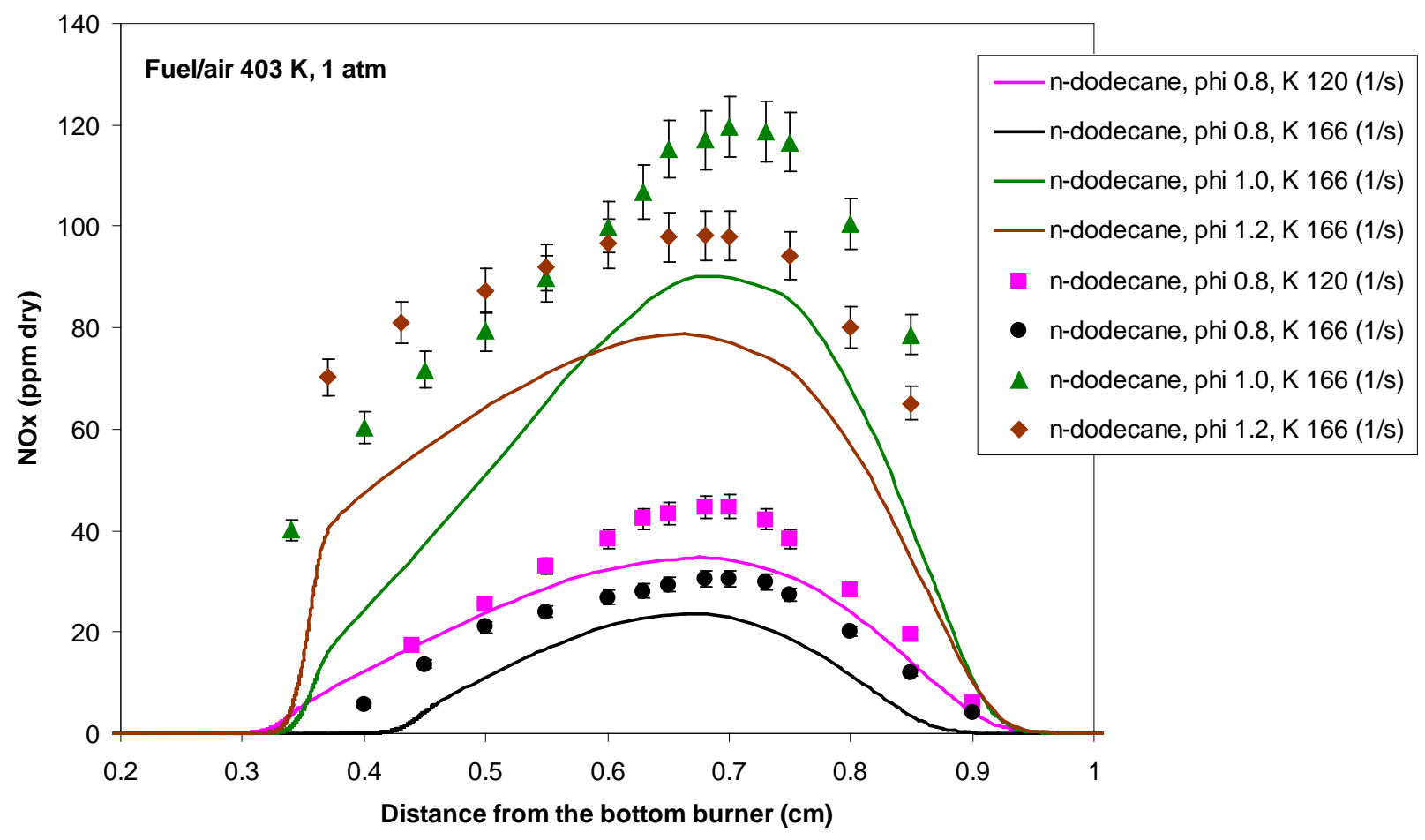

Figure 71. Effect of equivalence ratio on $\mathrm{NO}_{\mathrm{x}}$. Comparison of predicted and measured $\mathrm{NO}_{x}$ values for $n$-dodecane/air flames at equivalence ratios of 0.8-1.2. Symbols represent experimental data and lines represent model predictions.

Comparisons of predicted and measured $\mathrm{NO}_{\mathrm{x}}$ for two $n$-alkane/air flames, namely $n$-decane/air and $n$-dodecane/air flames are shown in Figure 72. Measured $\mathrm{NO}_{x}$ peak is around $30 \mathrm{ppmd}$ (ppm on dry basis) for both $n$-decane and $n$-dodecane flames. The model under-predicts the peak $\mathrm{NO}_{\mathrm{x}}$ by 4 ppmd for $n$-decane and by 7 ppmd for $n$-dodecane. However, the trends with different conditions are captured well. In this way, we removed the difficult-to-explain discrepancies between agreement across different fuels, by obtaining more accurate $\mathrm{NO}_{\mathrm{x}}$ measurements. 


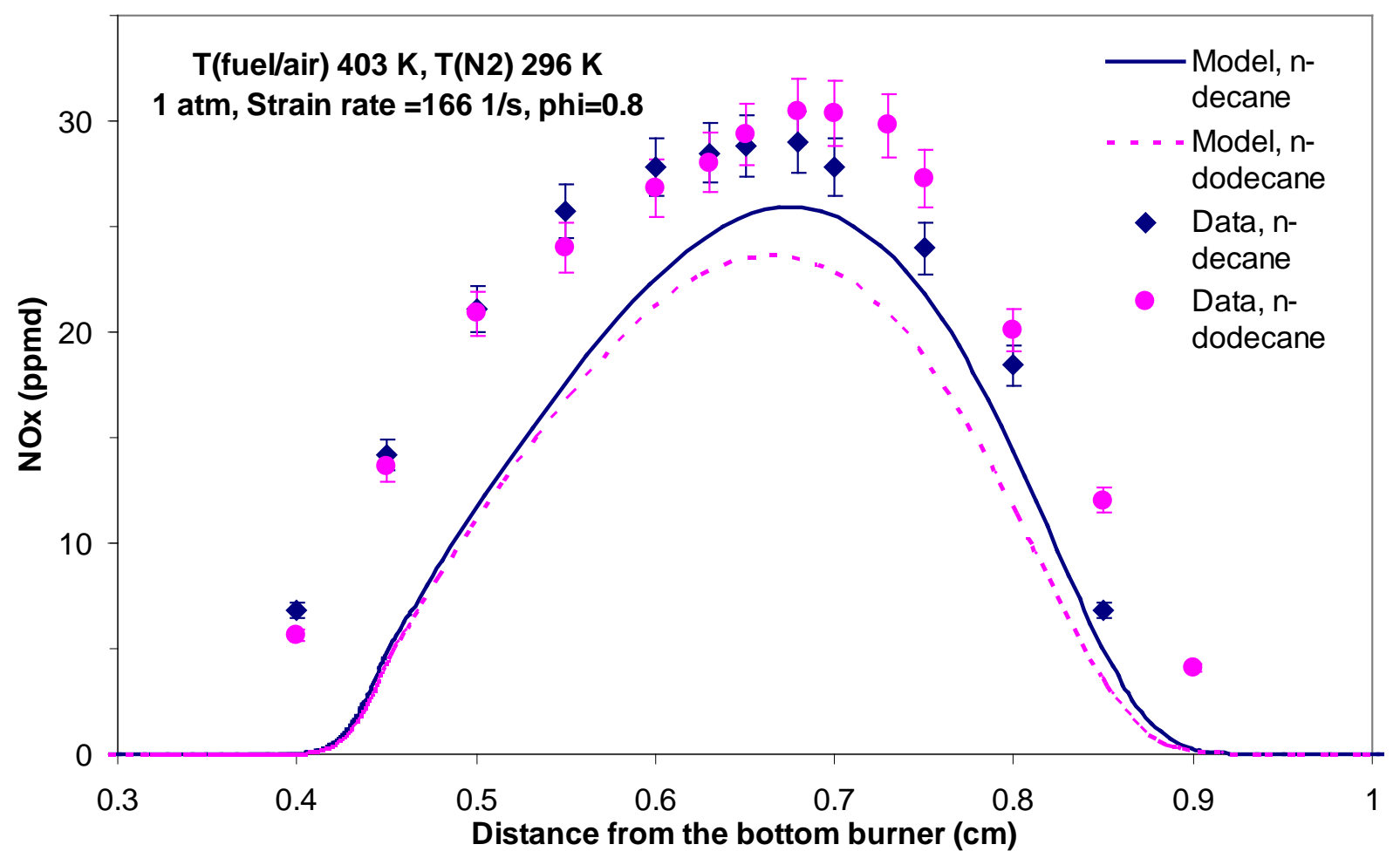

Figure 72. Comparison of predicted and measured $\mathrm{NO}_{\mathrm{x}}$ levels for $n$-decane/air and $n$-dodecane/air flames with an equivalence ratio of 0.8 . Symbols represent experimental data and lines represent model predictions.

In order to estimate the impact of uncertainty of various experimental parameters on $\mathrm{NO}_{\mathrm{x}}$, we also performed an uncertainty analysis on (1) burner velocities and (2) nitrogen nozzle temperatures. Uncertainty in fuel/air burner temperature was not considered for the uncertainty analysis, since that burner is heated and maintained at a specified temperature, whereas the temperature of the nitrogen burner was not controlled. The Uncertainty Analysis feature in CHEMKIN-PRO was used for the simulations. As shown in Figure 73, a 5\% relative standard deviation in nozzle velocities can change the peak $\mathrm{NO}_{x}$ level by 7 ppmd. Uncertainty in the nitrogen burner temperature can also significantly affect the $\mathrm{NO}_{x}$ levels at distances closer to that burner. Considering the impact of these experimental uncertainties on $\mathrm{NO}_{x}$ levels, we concluded from this that the model predictions for $n$-decane and $n$-dodecane in Figure 72 may be considered to be within the range of experimental accuracy. However there appears to be a slight systematic under-prediction over all fuels that warrants further investigation. 


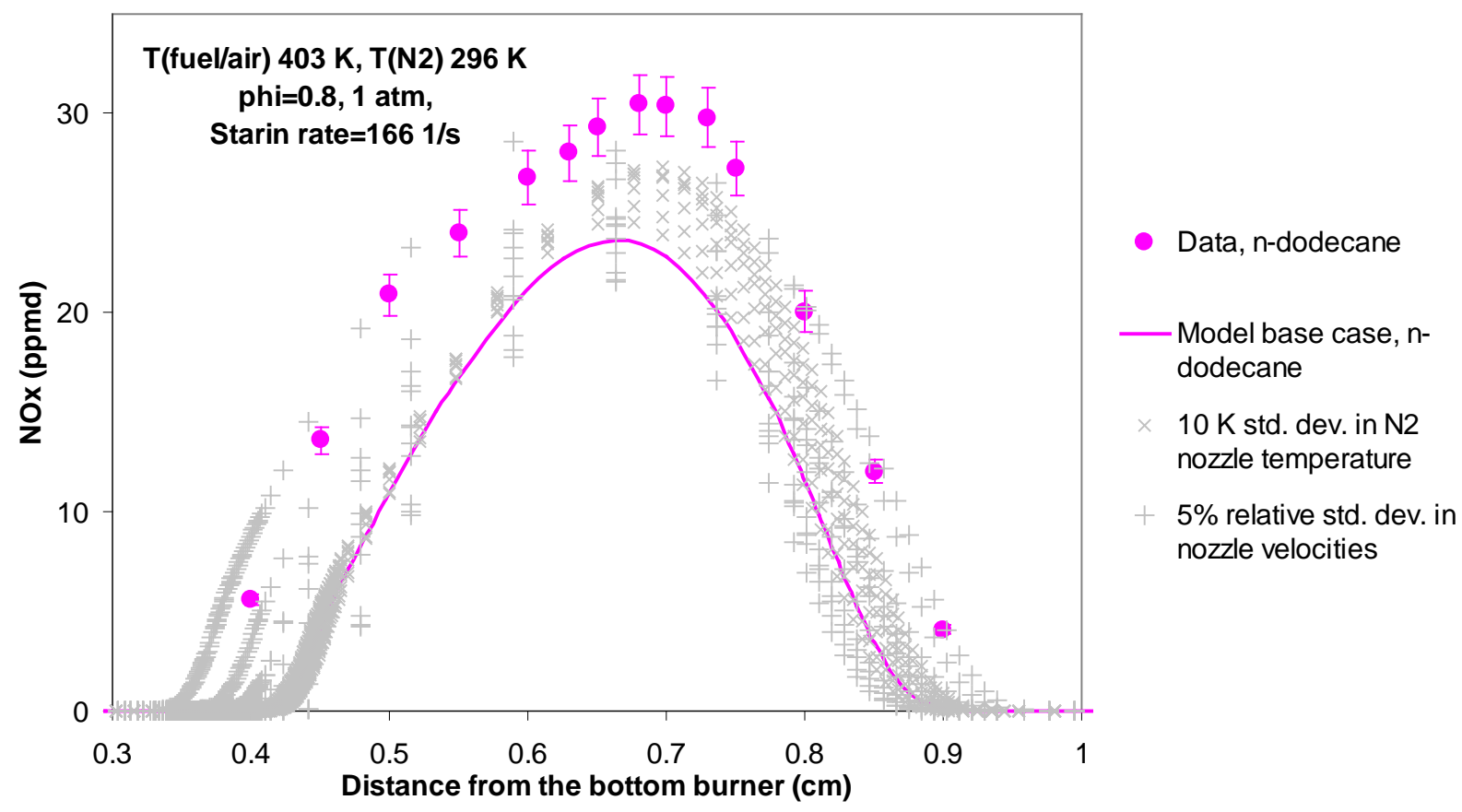

Figure 73. Impact of uncertainty in nozzle velocities and nitrogen burner (top burner) temperature on $\mathrm{NO}_{x}$ predictions for $n$-dodecane/air flames. Gray symbols represent predictions from Uncertainty Analyses in CHEMKIN-PRO. Filled circles are the experimental data.

\subsection{Testing of Soot Precursor Predictions}

In addition to $\mathrm{NO}_{x}$ emissions behavior, we are also interested in the predictive capabilities of the model for soot emissions. While the USC facility is gearing up to make soot-extinction measurements, we sought out data that could test the model predictions of soot precursors.

Many researchers have performed PAH and soot measurements for burner stabilized flames of small hydrocarbon fuels (e.g., ethylene, methane, and propane). To test the PAH mechanism recently incorporated into the biodiesel mechanism, we started by testing the PAH formation for fuel-components that represent core components of the biodiesel surrogate $\left(\mathrm{C}_{3}\right.$ and smaller). We started with two sets of experimental data for simulation under sooting flame conditions with equivalence ratio of 2.5 at $1 \mathrm{~atm}$. These were: (1) Senkan and Castaldi [30] propane $/ \mathrm{O}_{2}$ flame diluted with $45.1 \%$ Ar, and (2) Wang et al. [31] ethylene $/ \mathrm{O}_{2}$ flame diluted with $68.9 \%$ Ar. Senkan and Castaldi measured profiles of various product species but did not measure soot. Wang et al. did not report the measured PAH species profiles but reported the measured particle density, diameter, and volume fraction. The CHEMKIN-PRO Premixed Burner-Stabilized Flame model was used for simulations based on the measured temperature profile.

Comparisons of various species predicted and measured by Senkan and Castaldi are shown in Figure 74 through Figure 77. Major products acetylene $\left(\mathrm{C}_{2} \mathrm{H}_{2}\right)$ and benzene $\left(\mathrm{C}_{6} \mathrm{H}_{6}\right)$ are predicted reasonably well. Propyne-propadiene $\left(\mathrm{C}_{3} \mathrm{H}_{4}\right)$ and butadiene $\left(\mathrm{C}_{4} \mathrm{H}_{2}\right)$ are slightly under-predicted. Trends in PAH species naphthalene, phenanthrene, and pyrene are captured by the model, but the predicted levels were more than an order of magnitude lower than those observed between 4 to $16 \mathrm{ppm}$. Under-prediction of these soot precursors will potentially result in under-prediction of soot particles. However, further improvement of these soot-precursor formation models is likely beyond the scope and funding of this project. 


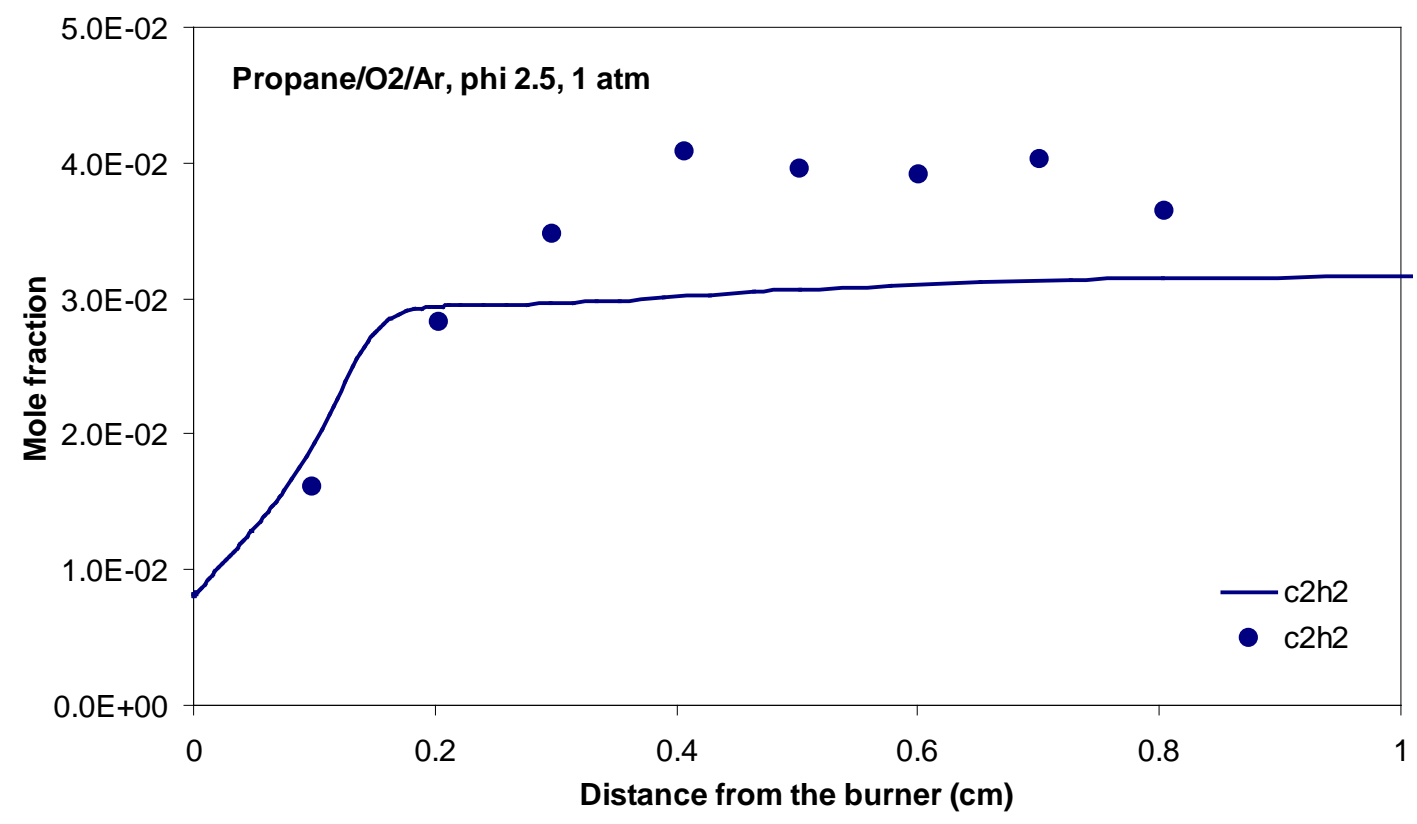

Figure 74. Comparison of predicted and measured acetylene profile by Senkan and Castaldi [30] for a burner stabilized propane flame.

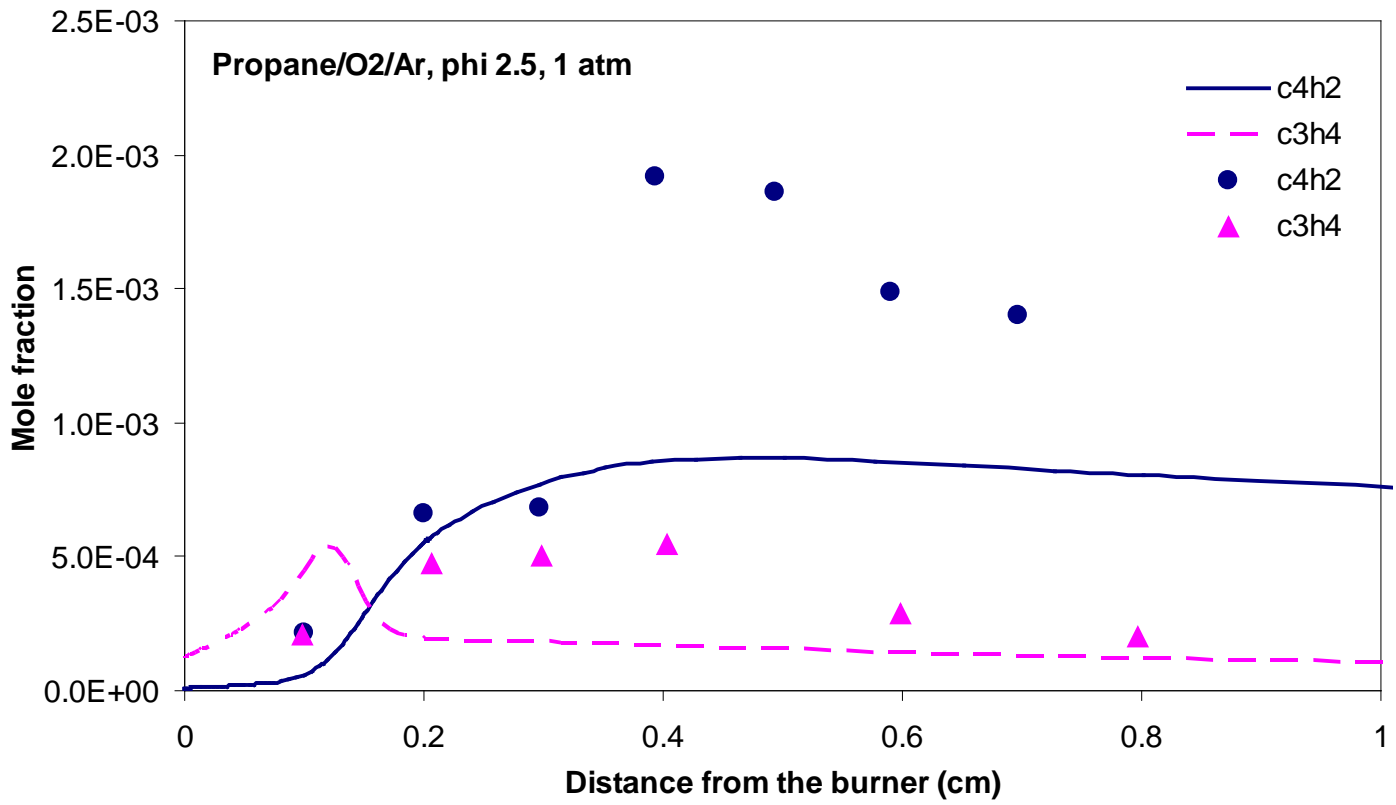

Figure 75. Comparison of predicted and measured propyne-propadiene $(\mathrm{C} 3 \mathrm{H} 4)$ and butadiene (C4H2) profile by Senkan and Castaldi [30] for a burner stabilized propane flame. 


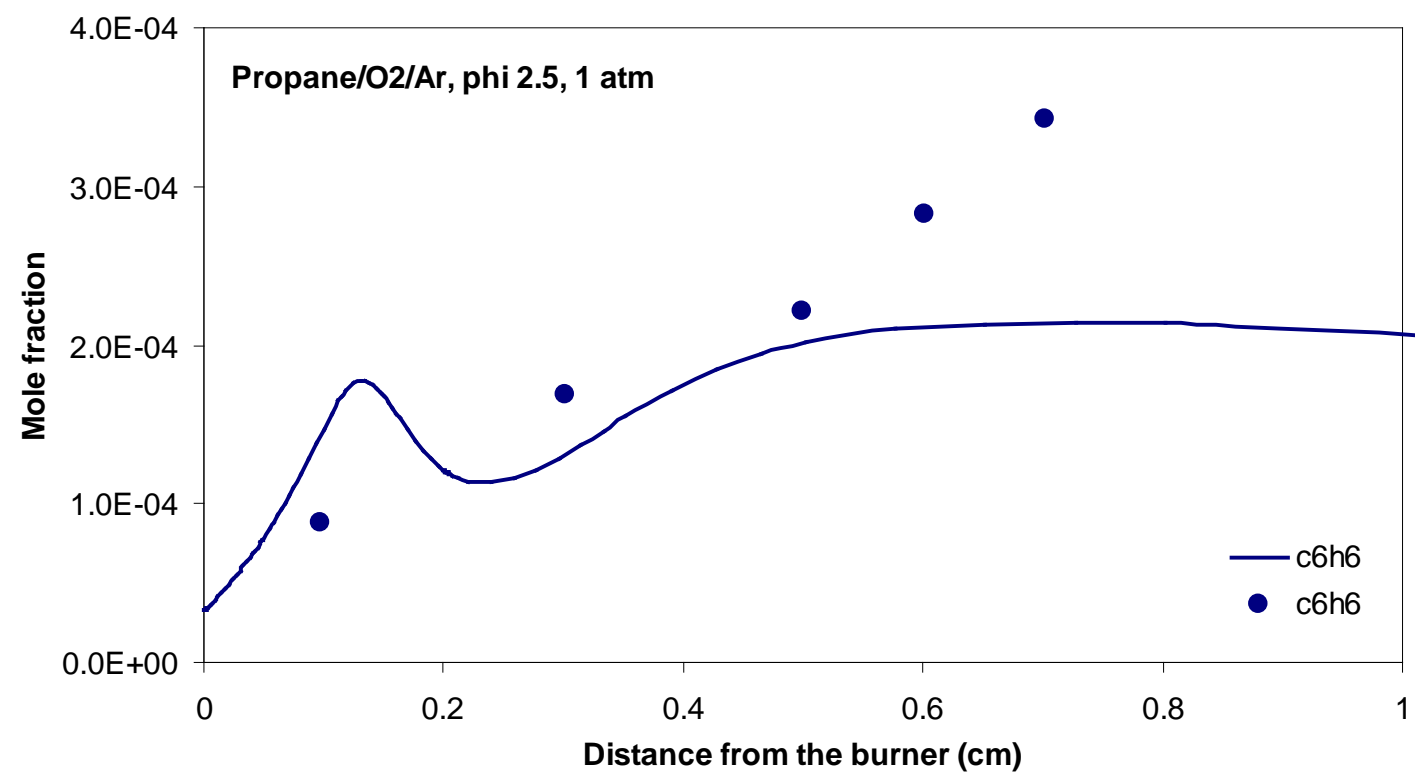

Figure 76. Comparison of predicted and measured benzene profile by Senkan and Castaldi [30] for a burner stabilized propane flame.

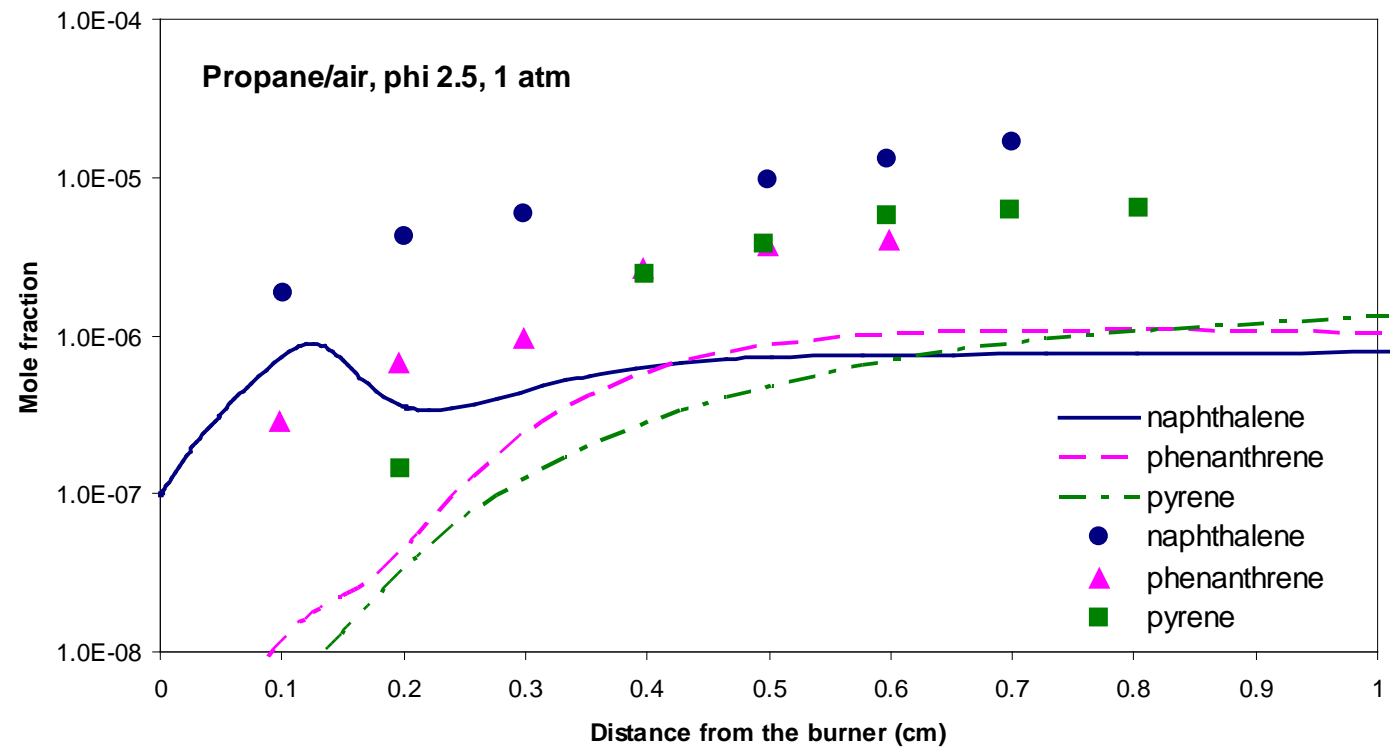

Figure 77. Comparison of predicted and measured PAH species profiles by Senkan and Castaldi [30] for a burner stabilized propane flame.

\subsubsection{Effects of Molecular Structure on PAH and $\mathrm{NO}_{x}$ Emissions}

To get insight into the tendency of methyl esters compared to $n$-alkanes, we performed simulations for three fuels: methyl butanoate, methyl crotonate, and n-pentane. Simulations were of burner stabilized premixed fuel/air laminar flames at $1 \mathrm{~atm}$ with equivalence ratio of 2 and an inlet temperature of $550 \mathrm{~K}$. Figure 78 shows the adiabatic flame temperatures for three fuels. As seen in the figure, methyl crotonate shows the highest adiabatic flame temperature of $1743 \mathrm{~K}$ whereas methyl butanoate shows the lowest peak temperature of $1691 \mathrm{~K}$. 


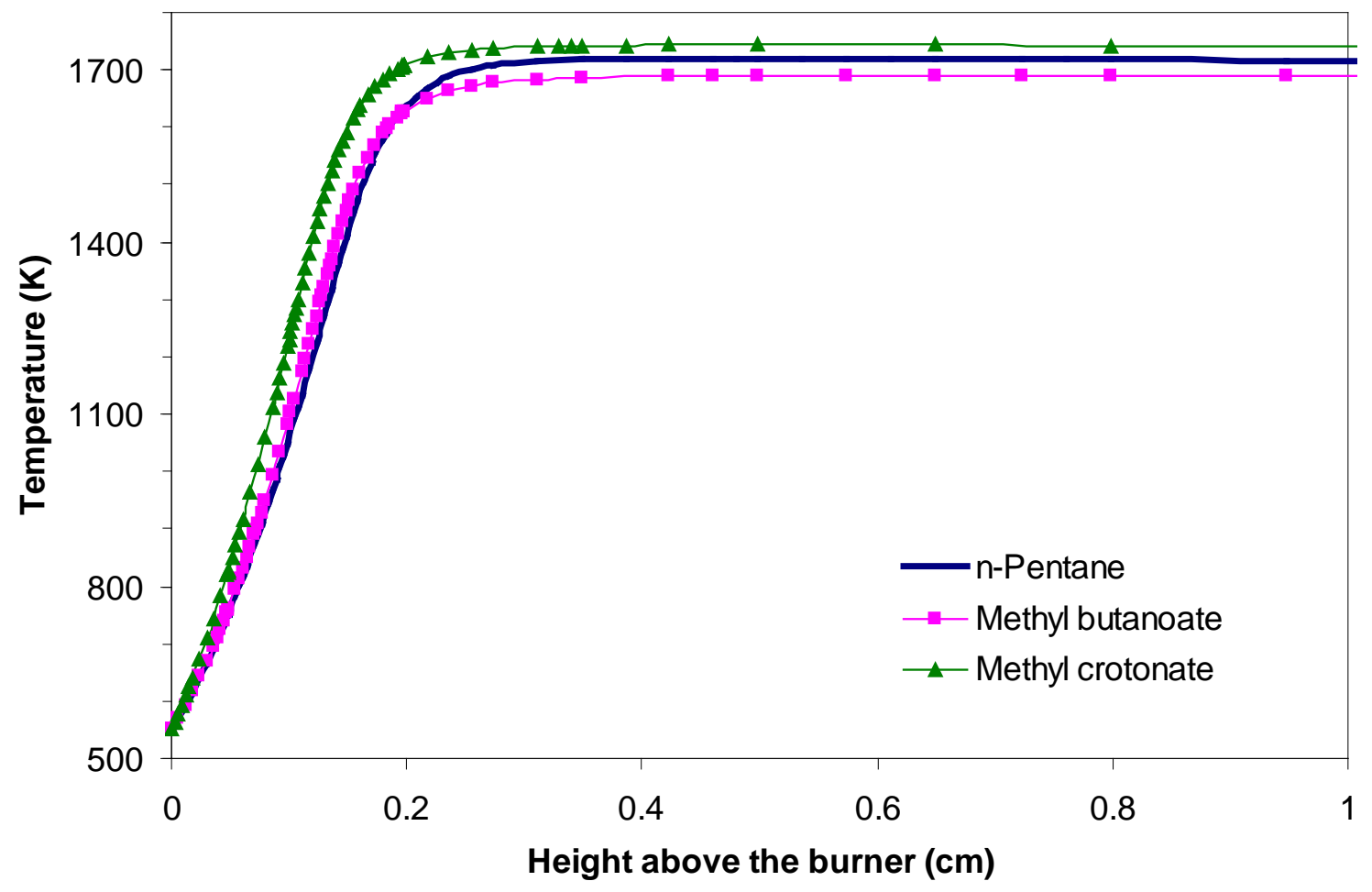

Figure 78. Predicted adiabatic temperature profiles for burner stabilized premixed fuel/air flames at $1 \mathrm{~atm}$ with equivalence ratio of 2 and inlet temperature of $550 \mathrm{~K}$.

Figure 79 to Figure 83 show predicted species profiles for the flames of three fuels. The species shown are some of the important soot precursors, such as acetylene $\left(\mathrm{C}_{2} \mathrm{H}_{2}\right)$, propyne and propadiene $\left(\mathrm{C}_{3} \mathrm{H}_{4}\right)$, 1,3-butadiene $\left(\mathrm{C}_{4} \mathrm{H}_{2}\right)$, benzene $\left(\mathrm{C}_{6} \mathrm{H}_{6}\right)$, as well as total $\mathrm{NO}_{x}$ emissions. To try to separate out the effect of fuel flame temperature and fuel structure on the emissions predictions, we ran these cases both using adiabatic-flame assumptions and using a common fixed-temperature profile. For the fixed-temperature profile, we used the adiabatic temperature profile predicted for the I-pentane flame (Figure 78). The comparison of species in $n$-pentane flames with fixed temperature methyl esters flames signify the effect of structure and allow one to separate the thermodynamic effect from kinetic effect. Under adiabatic flame conditions $n$-pentane shows the highest levels for all the soot precursors. However, for fixedtemperature conditions, methyl crotonate shows the highest levels of soot precursors. Under all conditions, methyl butanoate has the lowest levels of soot precursors. In contrast, total $\mathrm{NO}_{\mathrm{x}}$ emissions under adiabatic conditions are higher for the methyl esters with methyl crotonate showing the highest $\mathrm{NO}_{x}$ levels. However, under fixed-temperature flame conditions, the methyl esters show lower levels of total $\mathrm{NO}_{x}$ than those from the $n$-pentane flame. For all flames, $\mathrm{HCN}$ and $\mathrm{NH}_{3}$ contribute much more towards total $\mathrm{NO}_{x}$ than $\mathrm{NO}$, due to the lack of oxygen under fuel-rich conditions. 


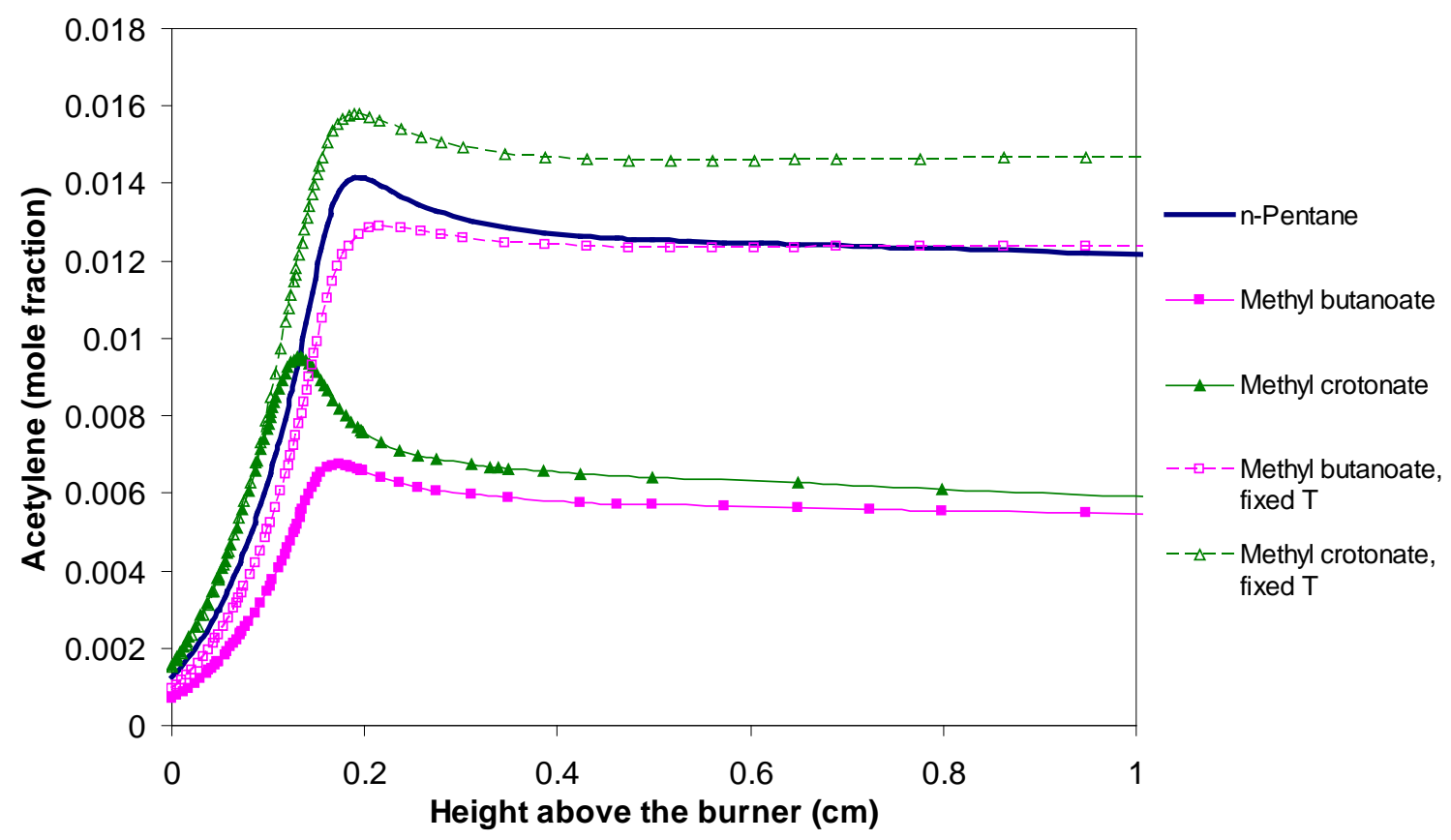

Figure 79. Predicted profiles of acetylene concentrations in burner stabilized premixed fuel/air adiabatic flames at 1 atm with equivalence ratio of 2 and inlet temperature of $550 \mathrm{~K}$. Dashed lines represent predictions using the fixedtemperature profile.

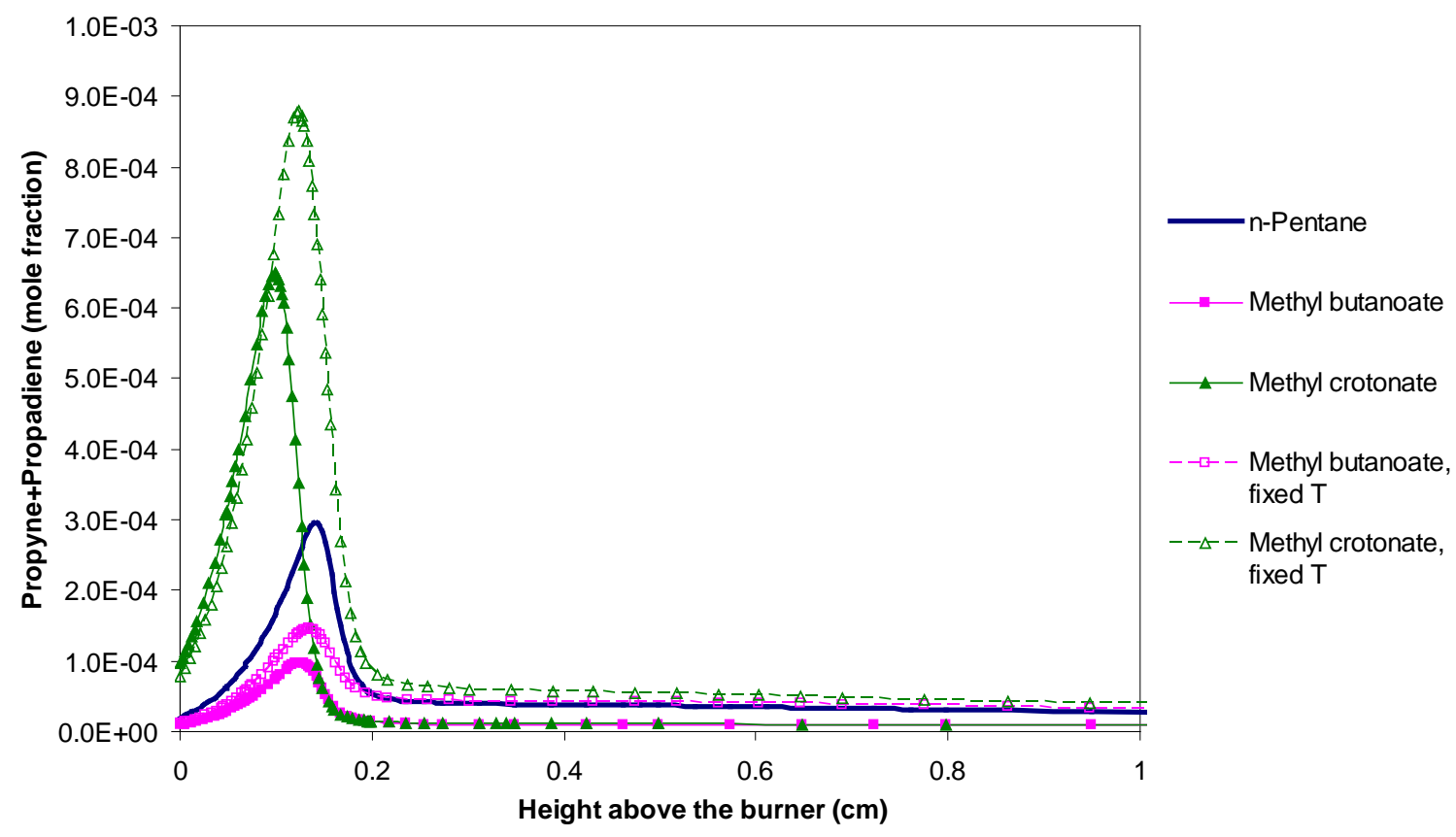

Figure 80. Predicted profiles of propyne+propadiene concentrations in burner stabilized premixed fuel/air adiabatic flames at $1 \mathrm{~atm}$ with equivalence ratio of 2 and inlet temperature of $550 \mathrm{~K}$. Dashed lines represent predictions using the fixed-temperature profile. 


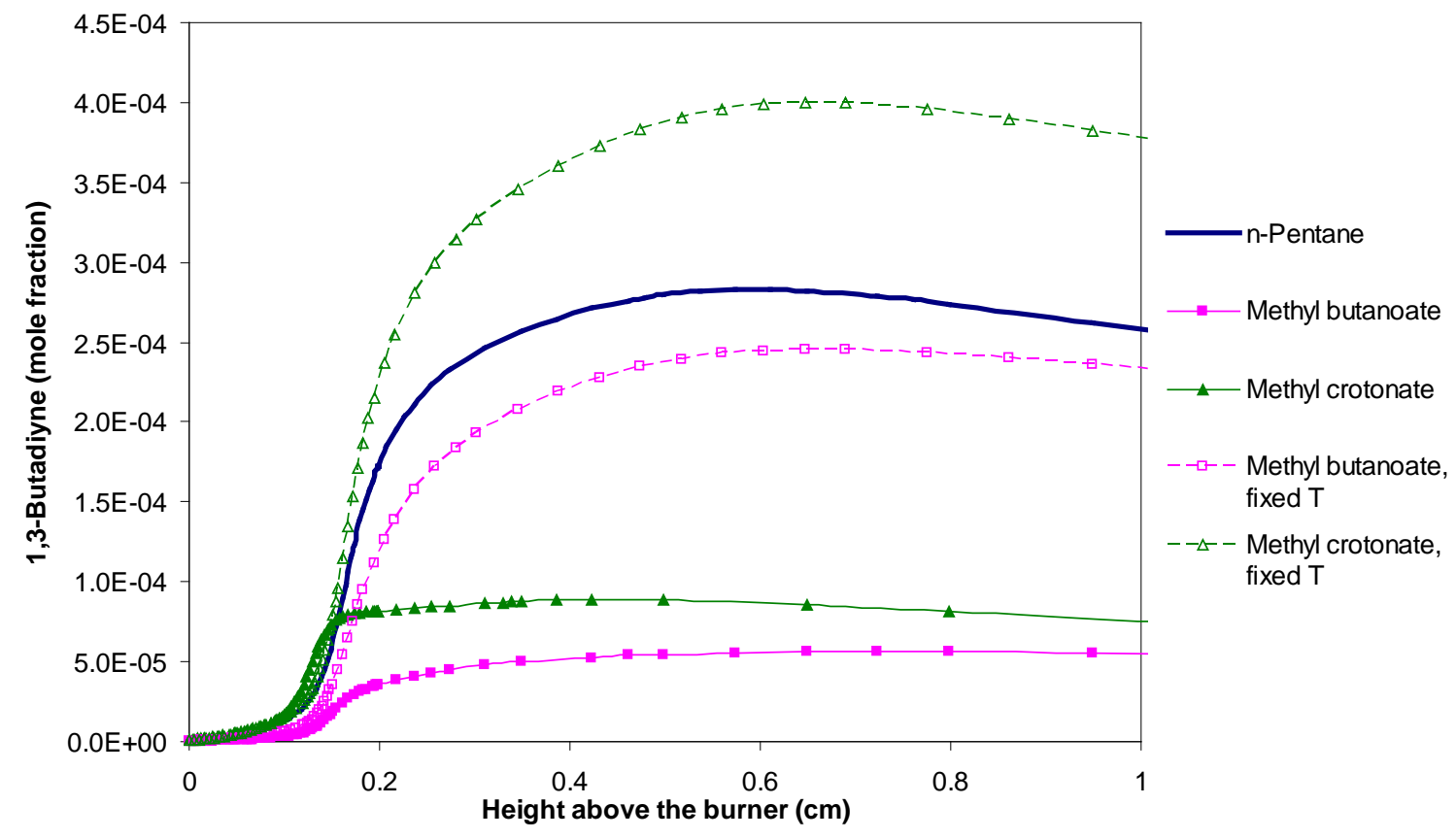

Figure 81. Predicted profiles of 1,3-butadiyne concentrations in burner stabilized premixed fuel/air adiabatic flames at $1 \mathrm{~atm}$ with equivalence ratio of 2 and inlet temperature of $550 \mathrm{~K}$. Dashed lines represent predictions using the fixed-temperature profile. 


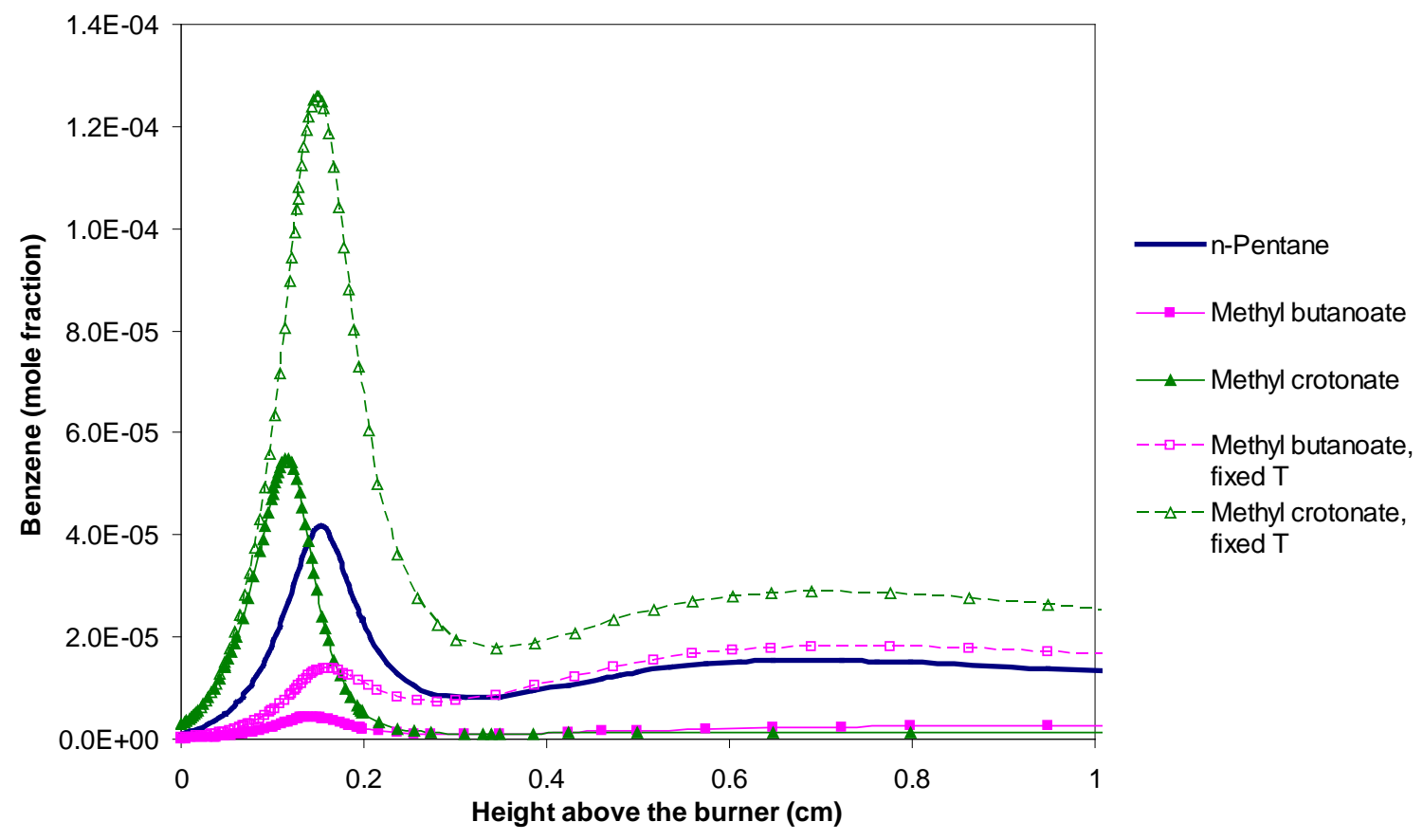

Figure 82. Predicted profiles of benzene concentrations in burner stabilized premixed fuel/air adiabatic flames at $1 \mathrm{~atm}$ with equivalence ratio of 2 and inlet temperature of $550 \mathrm{~K}$. Dashed lines represent predictions using the fixedtemperature profile.

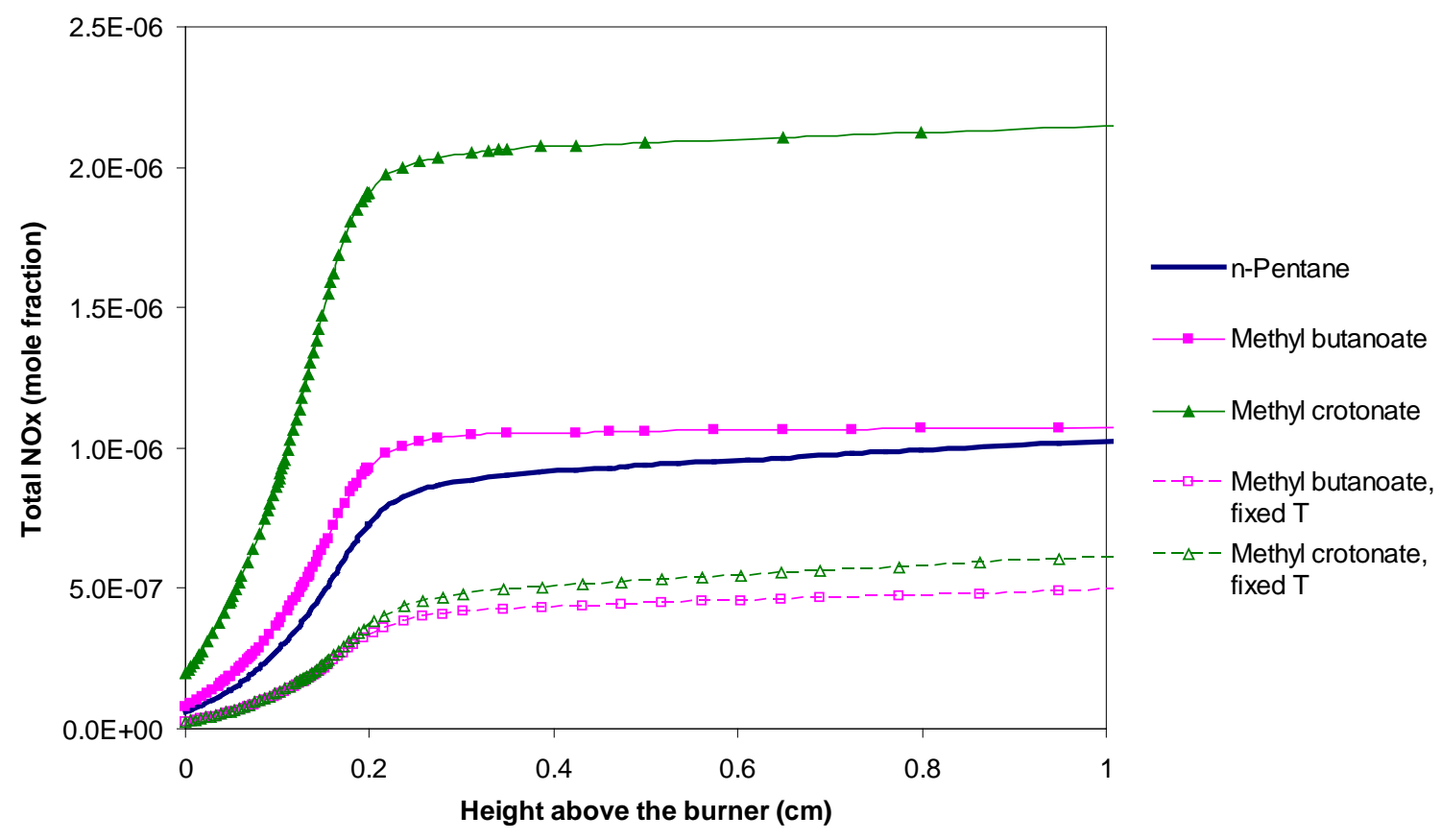

Figure 83. Predicted profiles of total $\mathrm{NO}_{x}$ concentrations in burner stabilized premixed fuel/air adiabatic flames at $1 \mathrm{~atm}$ with equivalence ratio of 2 and inlet temperature of $550 \mathrm{~K}$. Dashed lines represent predictions using the fixedtemperature profile. 
From this study, we find that the kinetics tends to produce higher levels of soot precursors for methyl crotonate than for $n$-pentane, followed by methyl butanoate. The kinetics also tends to produce lower levels of $\mathrm{NO}_{x}$ under fuel-rich flames of methyl esters than under similar conditions for $n$-pentane flames. As the same time, thermodynamic effects determined by the energy content of the fuel tend to lower the soot precursors in the methyl esters compared to $n$-pentane, but increase $\mathrm{NO}_{\mathrm{x}}$ emissions with a more pronounced impact for the unsaturated methyl crotonate. 


\section{Comparisons of B100 Data and Biodiesel Surrogate}

With confidence gained from the comparisons for individual fuel components, the full mechanism was next used to simulate conditions where data for diesel fuel is available. Results from these studies are reported here.

\subsection{Laminar Flame Speeds}

USC obtained laminar flame-speed measurements for two B100 biodiesel samples. These measurements were made at USC using the samples obtained from Cargill - labeled as "USC-01" in the fuel analysis, as well as from Nexsol (USC-02). Both samples are soy-derived biodiesels with similar compositions and with over $80 \mathrm{~mol} \%$ unsaturated $\mathrm{C}_{18}$ chain esters. We used the 3-component biodiesel surrogate (n-dodecane/methyl butanoate/methyl crotonate: 50/15/35 mol \%) for the flame simulations for both biodiesels. As shown in Figure 84: (1) measured data for both biodiesel samples are almost identical, and (2) predictions are reasonably close to the experimental data. The observed peak in the laminar flame speed of $96.3 \mathrm{~cm} / \mathrm{s}$ is within $2 \%$ of that predicted peak value. However, the predictions are shifted towards higher fuel/air ratios by approximately 0.005 in fuel/air mass ratio. This shift is equivalent to a shift of approximately 0.06 in equivalence ratio. Results of shifting the model predictions by this amount are shown by the dashed line in Figure 84 to illustrate this point.

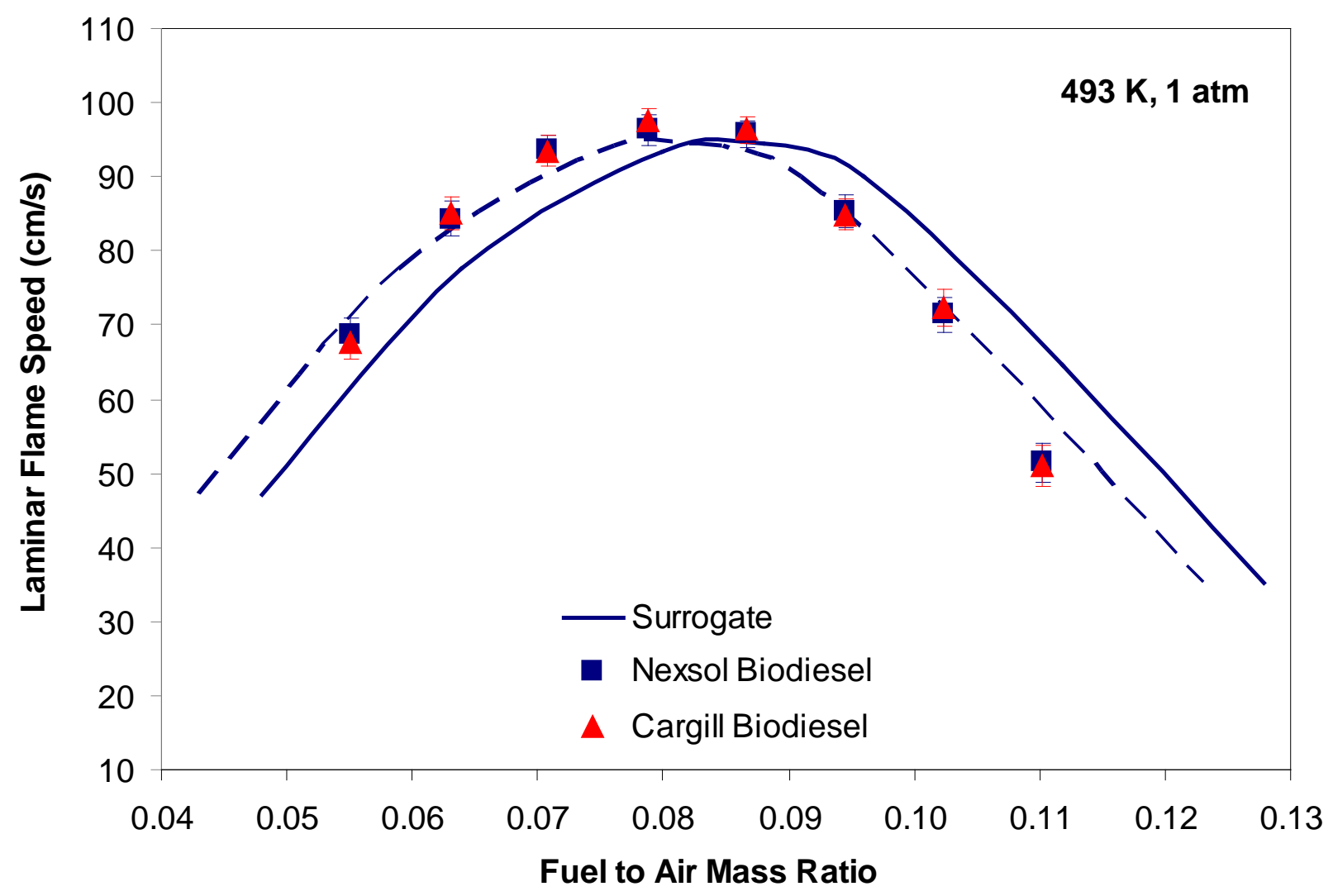

Figure 84. Comparison of the measured laminar flame speeds for Nexol biodiesel (USC02) at unburned mixture temperature of $493 \mathrm{~K}$ at $1 \mathrm{~atm}$, and those predicted using the 3-component surrogate containing $n$-dodecane/methyl butanoate/methyl crotonate. The dashed line shows model predictions shifted to the left by 0.005 fuel/air mass ratio. 
USC also measured flame speeds for a surrogate-fuel mixture: 15\% MB, 35\% MC, 50\% n-decane. Comparison with these measurements and the same surrogate model are shown in Figure 85. Here we see very good agreement between the model and the data.

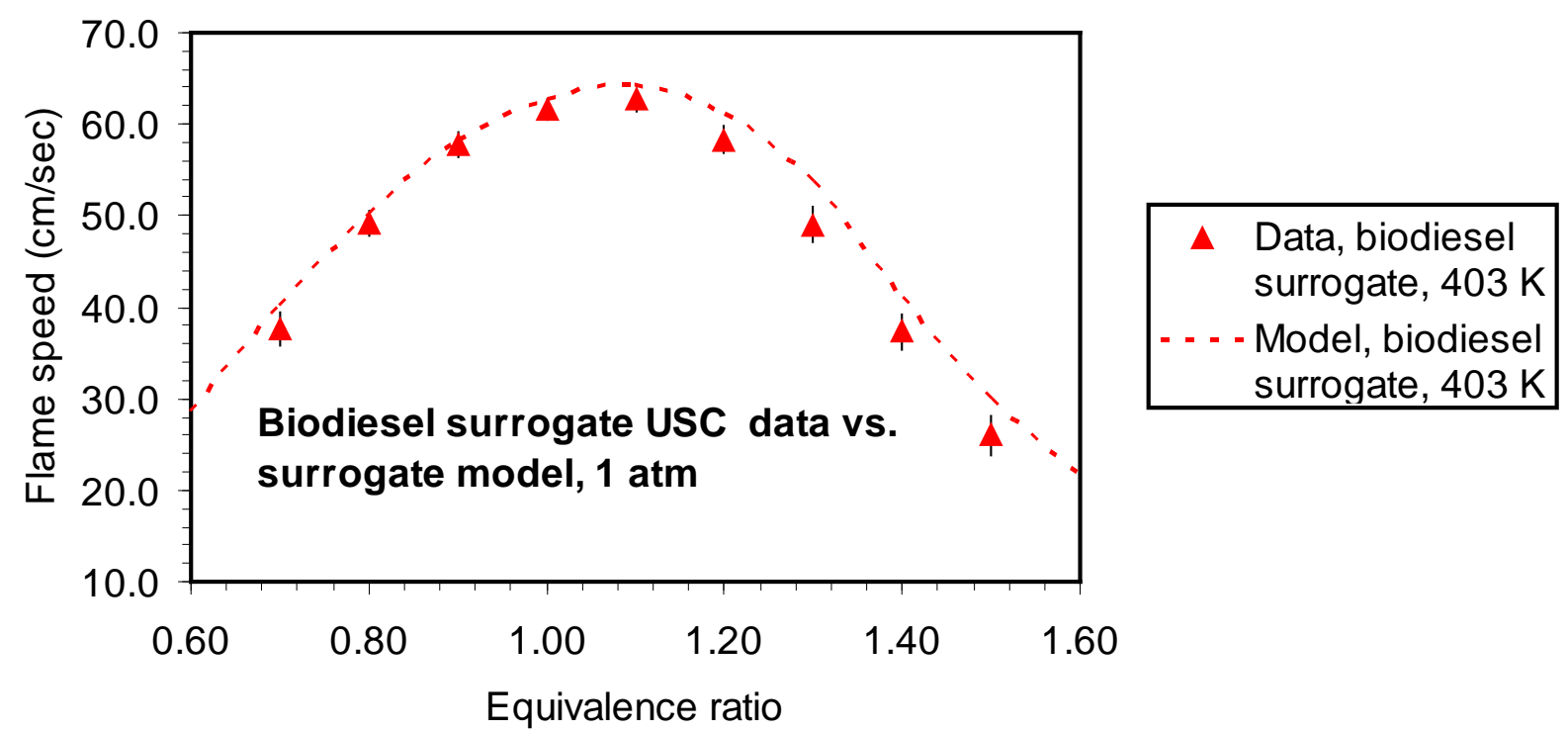

Figure 85. Comparison of the measured laminar flame speeds for the surrogate blend, $15 \% \mathrm{MB}, 35 \% \mathrm{MC}, 50 \% \mathrm{n}$-decane, at unburned mixture temperature of $403 \mathrm{~K}$ at $1 \mathrm{~atm}$, and those predicted using the same 3-component blend.

\subsection{Ignition Delay Data}

In addition to flame-speed data, we also compared with available data from other sources that allows comparison of expected (simulated) biodiesel behavior to real diesel behavior over a wider range of conditions. The proposed biodiesel Surrogate 1 (50\% n-dodecane, 35\% MC, and 15\% MB), discussed above, was used for the simulation. The results shown in Figure 86 correspond to an equivalence ratio of 0.5 . The pressure is $6 \mathrm{~atm}$ and initial reactant composition is diesel (surrogate) fuel and $21 \% \mathrm{O}_{2}$ and $79 \%$ Ar. It can be seen that numerical calculations for biodiesel are in excellent agreement with the experimental results [28] for diesel. Since we would expect that the real diesel and biodiesel fuels would behave similarly (by design), this adds a further level of confidence to the chemistry model and to the surrogate-blend proposed. 


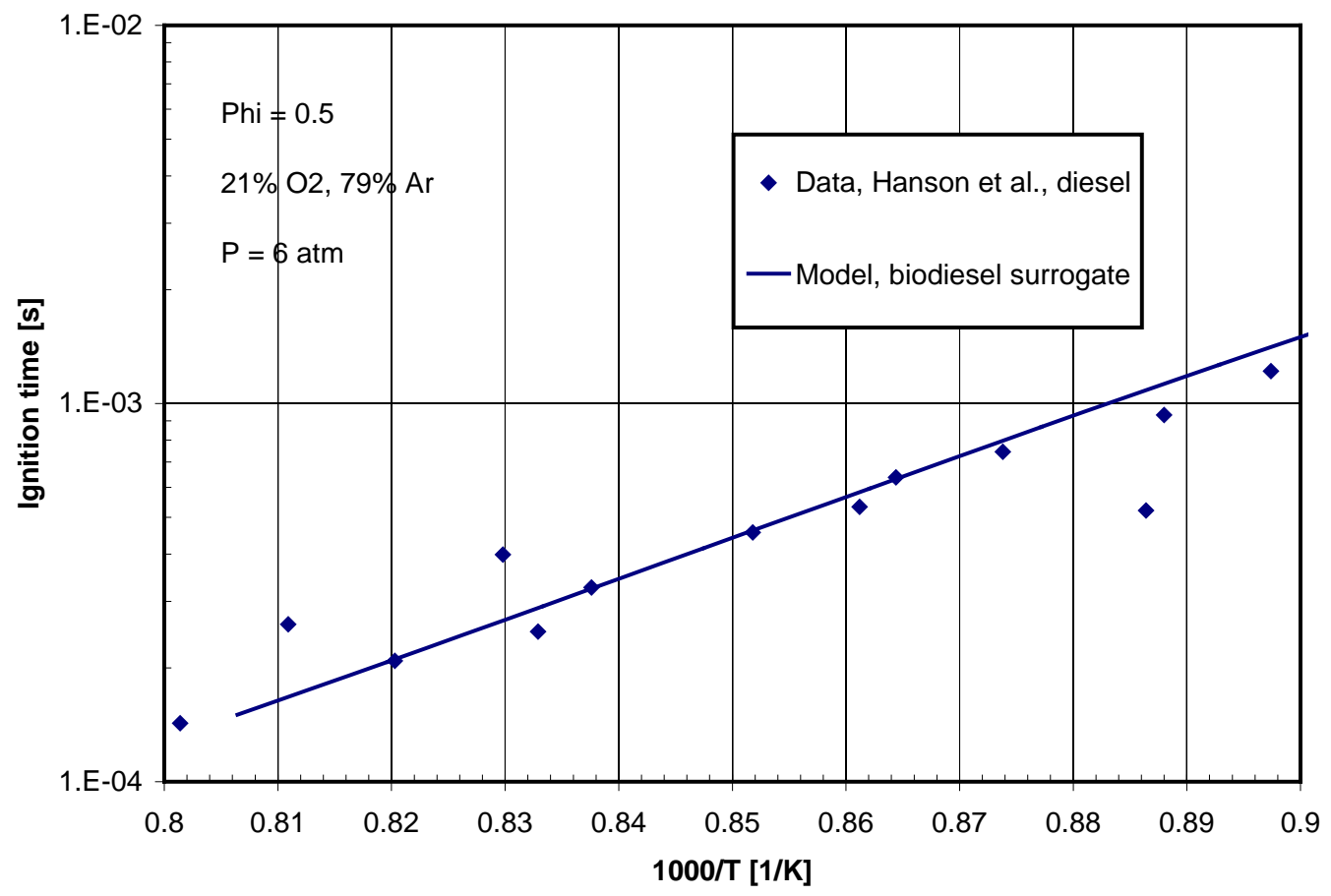

Figure 86. Comparison of calculated ignition delay for biodiesel surrogate with experimental data for diesel [28]. 


\subsubsection{Reaction Path Analysis}

It is useful to identify important reaction pathways in the model-biodiesel flame. Reaction path analysis for all three components in the model-biodiesel flame is shown in Figure 87 for $10 \%$ fuel conversion under the conditions in high-temperature flames with unburned temperature of $470 \mathrm{~K}$. The Reaction Path Analyzer in CHEMKIN-PRO [1] has been used to generate these paths. The radical pool including $\mathrm{H}, \mathrm{O}$, $\mathrm{OH}, \mathrm{HO} 2$, and $\mathrm{CH} 3$ is not shown in the plot, as these radicals are instead represented by various colors of lines to decrease the clutter in the diagram (green for $\mathrm{H}$, red for $\mathrm{O}$, blue for $\mathrm{OH}$, pink for $\mathrm{HO}$, and yellow for $\mathrm{CH} 3$ ). As seen in Figure 87, all the components of the model fuel quickly reduce to smaller hydrocarbons, typically C3 and smaller. Mechanistically, the components in the blend interact with each other through this common pool of smaller hydrocarbons. In addition, methyl crotonate ("mb2d" in the diagram) and methyl butanoate (" $\mathrm{mb}$ " in the diagram) form "early" $\mathrm{CO}_{2}$ via ch3oco (radical of methyl formate). Methyl crotonate produces large amounts of intermediate aldehydes, whereas methyl butanoate and $n$-dodecane produce intermediate olefins. 

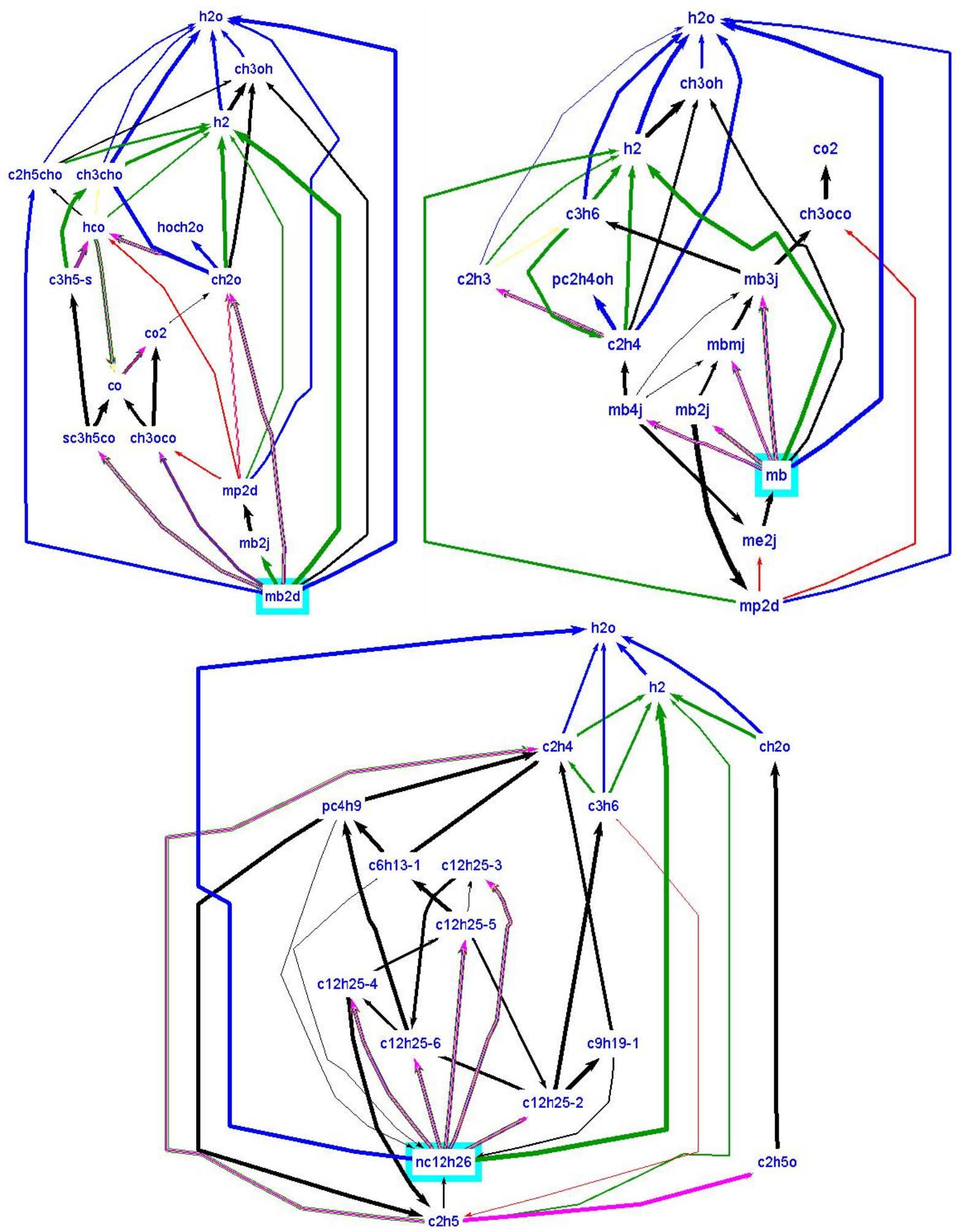

Figure 87. Reaction path diagrams for methyl crotonate (mb2d) (top left), methyl butanoate $(\mathrm{mb})$, and $n$-dodecane (nc12h26) (bottom) at $10 \%$ conversion of model biodiesel under conditions of freely propagating flame at $1 \mathrm{~atm}$ and unburned mixture temperature of $470 \mathrm{~K}$. 


\section{Automated Mechanism Reduction}

A guided mechanism reduction process has been packaged into a facility called the Reaction Workbench, which is an add-on capability for CHEMKIN that is under development. The Reaction Workbench can perform reduction based on targeted properties such as flame speeds including a parameter study over several variables such as temperature and equivalence ratio. The Workbench automatically produces the smallest skeletal mechanism that meets certain user-specified criteria, such as tolerances for certain targeted predictions. Two methods for producing skeletal mechanisms are included as options: the Directed Relation Graph (DRG) method [2] and the Principle Component Analysis (PCA) method [32, 33]. Using Reaction Workbench with DRG, a reduced skeletal mechanism was obtained to predict the flame speeds within 5\% accuracy over all temperatures and equivalence ratio conditions. The smallest mechanism that met this criterion contained 143 species and 969 reactions. This represents a more than $70 \%$ reduction in size over the master mechanism, with respect to number of species. The number of species in the simulation typically determines the solution time. Comparison of the predicted flame speeds using both master and skeletal mechanism for the 3-component biodiesel is shown in Figure 88. Here we can see the very good agreement obtained over the whole range of conditions.

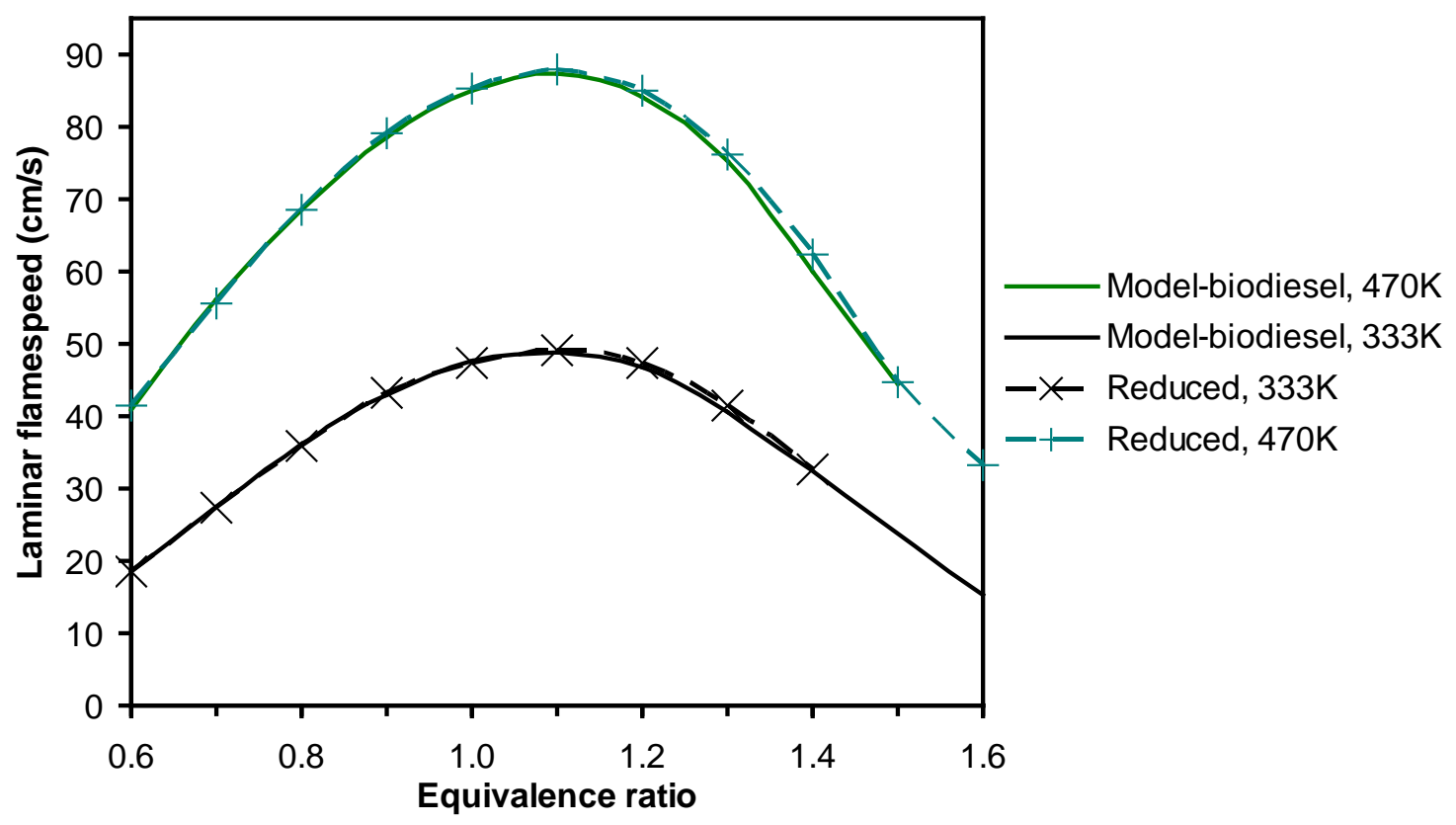

Figure 88. Comparison of the predicted flame speeds using the full master vs. skeletal mechanism for a 3-component biodiesel surrogate. 


\section{Summary and Conclusions}

During this project, we completed a major and thorough validation of a set of biodiesel surrogate components, allowing us to begin to evaluate the fundamental combustion characteristics for B100 fuels. Major findings and outcomes are as follows:

- Samples collected from certified biodiesel manufacturers in the U.S. allowed chemical analysis and testing that produced a unique combination of data for model development and verification.

- Measurements of Cetane Number for about 20 certified biodiesel samples provide additional information for determining a good biodiesel surrogate for simulation.

- An initial biodiesel surrogate-blend model was proposed, consisting of n-decane, methylbutanoate, and methyl crotonate.

- A detailed mechanism for the biodiesel surrogate was assembled and systematically improved, based on discrepancies between model and experimental data. The resulting model was shown to reproduce important properties of the biodiesel samples under combustion conditions.

- A methyl decanoate mechanism was added to the surrogate to provide a better methyl ester representation for the biodiesel surrogate.

- The surrogate model was further extended to include a more comprehensive soot-precursor mechanism that was tested against experiments for small hydrocarbon fuels. Results show that some issues remain with the PAH formation pathways, although addressing these issues was outside of the scope of this project.

- Extensive validation of each of the proposed biodiesel surrogate fuel components generally show good agreement between the models and data and provide confidence in the chemistry models. A range of components have been included in the surrogate to provide flexibility in matching biodiesel fuels by extending the biodiesel surrogate-component "palette".

- Major improvements to the USC flame measurement techniques and facility have enabled more reliable and reproducible data for large biodiesel fuels. The first biodiesel flame-speed measurements were produced and compared successfully with our initial biodiesel surrogate model predictions.

- Analysis of the reaction paths for $\mathrm{NO}_{x}$ formation raised questions about differences observed experimentally between different fuel components. This led to a closer look at the reproducibility of the experiments and an improvement of experimental procedures to address issues uncovered.

- $\mathrm{NO}_{x}$ emissions measurements for alkanes and methyl esters provided further testing of the model predictions. The biodiesel surrogate model predicts the measured $\mathrm{NO}_{x}$ ppm well within experimental uncertainty for the smaller and larger hydrocarbons, once uncertainties in the experimental procedures were addressed.

- Using simulation alone with the validated biodiesel-surrogate components, we investigated the effects of molecular structure and kinetics vs. thermodynamics in producing $\mathrm{NO}_{\mathrm{x}}$ and soot precursors. We found that these effects compete, making broad conclusions about the relative production of $\mathrm{NO}_{\mathrm{x}}$ and soot for different fuels under engine conditions very difficult to make. However the models prove to be an effective tool for investigating such issues. 


\section{References}

1. CHEMKIN-PRO Release 15081, Reaction Design, San Diego, CA, 2008.

2. T. Lu and C. K. Law, "A directed relation graph method for mechanism reduction," Proceedings of the Combustion Institute, 30: 1333-1341, 2005.

3. T. Lu and C. K. Law, "On the applicability of directed relation graphs to the reduction of reaction mechanisms," Combustion and Flame, 146: 472-483, 2006.

4. H. Wang, D. X. Du, C. J. Sung, and C. K. Law, "Experiments and Numerical Simulation on Soot Formation in Opposed-Jet Ethylene Diffusion Flames," Proceedings of the Combustion Institute, 26: 2359-2368, 1996.

5. E. M. Fisher, W. J. Pitz, H. J. Curran, and C. K. Westbrook, "Detailed chemical kinetic mechanisms for combustion of oxygenated fuels," Proceedings of the Combustion Institute, 28: 1579-1586, 2000.

6. C. K. Westbrook, W. Pitz, O. Herbinet, H. J. Curran, and E. J. Silke, "A Detailed Chemical Kinetic Reaction Mechanism for Combustion of n-Alkanes from n-Octane to n-Hexadecane," Combustion and Flame, 156: 181-191, 2009.

7. C. K. Westbrook, W. J. Pitz, O. Herbinet, E. J. Silke, and H. J. Curran, "A Detailed Chemical Kinetic Reaction Mechanism For n-Alkane Hydrocarbons From n-Octane to n-Hexadecane," in Proceedings of the Western States Section of The Combustion Institute. Livermore, CA, USA, 2007.

8. M. O'Conaire, H. J. Curran, J. M. Simmie, W. J. Pitz, and C. K. Westbrook, "A Comprehensive Modeling Study of Hydrogen Oxidation," Int. J. Chem. Kinet., 36: 603-622, 2004.

9. C. V. Naik and A. M. Dean, "Detailed Kinetic Modeling of Ethane Oxidation," Combustion and Flame, 145: 16-37, 2006.

10. O. Herbinet, W. J. Pitz, and C. K. Westbrook, "Detailed chemical kinetic oxidation mechanism for a biodiesel surrogate," Combustion and Flame, 154: 507-528, 2008.

11. C. V. Naik and C. K. Westbrook, "Kinetic Modeling of Combustion Characteristics of Real Biodiesel Fuels," 6th US National Combustion Meeting, Ann Arbor, MI, 2009.

12. M. Frenklach and H. Wang, "Detailed Mechanism and Modeling of Soot Particle Formation," in Soot Formation in Combustion: Mechanisms and Models, H. Bockhorn, Ed. Berlin: Springer-Verlag, 1994, pp. 165-192.

13. J. Appel, H. Bockhorn, and M. Frenklach, "Kinetic Modeling of Soot Formation with Detailed Chemistry and Physics: Laminar Premixed Flames of $\mathrm{C}_{2}$ Hydrocarbons," Combustion and Flame, 121: 122-136, 2000.

14. M. S. Skjøth-Rasmussen, P. Glarborg, M. Østberg, J. T. Johannessen, H. Livbjerg, A. D. Jensen, and T. S. Christensen, "Formation of polycyclic aromatic hydrocarbons and soot in fuel-rich oxidation of methane in a laminar flow reactor," Combustion and Flame, 136: 91-128, 2004.

15. H. Richter, S. Granata, W. H. Green, and J. B. Howard, "Detailed modeling of PAH and soot formation in a laminar premixed benzene/oxygen/argon low-pressure flame," Proceedings of the Combustion Institute, 30: 1397-1405, 2005.

16. H.-Y. Zhang and J. T. McKinnon, "Elementary Reaction Modeling of High-Temperature Benzene Combustion," Combust. Sci Tech., 107: 261 - 300, 1995.

17. O. Herbinet, W. J. Pitz, and C. K. Westbrook, "Detailed Chemical Kinetic Oxidation Mechanism for a Biodiesel Surrogate," Proceedings of the Combustion Institute, Livermore, CA, USA, 2007. 
18. S. Gaïl, M. J. Thomson, S. M. Sarathy, S. A. Syed, P. Dagaut, P. Diévart, A. J. Marchese, and F. L. Dryer, "A wide-ranging kinetic modeling study of methyl butanoate combustion," Proceedings of the Combustion Institute, 31: 305-311, 2007.

19. S. Dooley, H. Curran, and J. Simmie, "Autoignition measurements and a validated kinetc model for the biodiesel surrogate, methyl butanoate," Combustion and Flame, 153: 2-32, 2008.

20. U. Pfahl, K. Fieweger, and G. Adomeit, "Self-ignition of diesel-relevant hydrocarbon-air mixtures under engine conditions," 26th Symposium (International) on Combustion, 1996.

21. V. P. Zhukov, V. A. Sechenov, and A. Y. Starikovskii, "Autoignition of n-decane at high pressure," Comb. Flame, 153: 130-136, 2008.

22. A. J. Dean, O. G. Penyazkov, K. L. Sevruk, and B. Varatharajan, "Autoignition of surrogate fuels at elevated temperatures and pressures," Proceedings of the Combustion Institute, 31: 2481-2488, 2007.

23. D. C. Horning, D. F. Davidson, and R. K. Hanson, "Study of the High-Temperature Autoignition of nAlkane/O2/Ar Mixtures," Journal of Propulsion and Power, 18: 363-371, 2002.

24. E. Olchanski and A. Burcat, "Decane Oxidation in a Shock Tube," International Journal of Chemical Kinetics, 38: 703-713, 2006.

25. K. Kumar and C.-J. Sung, "Laminar Flame Speeds and Extinction Limits of Preheated nDecane $/ \mathrm{O}_{2} / \mathrm{N}_{2}$ and n-Dodecane/ $\mathrm{O}_{2} / \mathrm{N}_{2}$ Mixtures," Comb. Flame, 151: 209-224, 2007.

26. J.-L. Delfau, M. Bouhria, M. Reuillon, O. Sanogo, R. Akrich, and C. Vovelle, "Experimental and Computational Investigation of the Structure of a Sooting Decane- $\mathrm{O}_{2}-\mathrm{Ar}$ Flame," Proceedings of the Combustion Institute, 23: 1567 - 1572, 1990.

27. C. Doute, J.-L. Delfau, and C. Vovelle, "Modeling of the structure of a premixed n-decane flame," Combustion Science and Technology, 130: 269-313, 1997.

28. R. K. Hanson, D. F. Davidson, D. Haylett, A. Farooq, S. Vasu, and S. Ranganath, "Shock Tube / Laser Diagnostics for Fuel and Surrogate Kinetics," NIST Fuels Summit, Gaithersburg, MD, 2008.

29. S. S. Vasu, D. F. Davidson, Z. Hong, and R. K. Hanson, "Shock Tube Study of Methylcyclohexane Ignition over a Wide Range of Pressure and Temperature," Energy \& Fuels, 23: 175-185, 2009.

30. S. Senkan and M. Castaldi, "Formation of Polycyclic Aromatic Hydrocarbons (PAH) in the Methane Combustion: Comparative New Results from Premixed Flames," Combust. Flame, 107: 141 - 150, 1996.

31. H. Wang, B. Zhao, B. Wyslouzil, and K. Streletzky, "Small-angled Neutron Scattering of Soot Formed in Laminar Premixed Ethylene Flames," Proc. Comb. Inst., 29: 2749-2757, 2002.

32. S. Vajda and T. Turanyi, "Principle component analysis for reducing the Edelson-Field-Noyes model of the Belousov- Zhabotinsky reaction," J. Phys. Chem. A., 90: 1664-1670, 1986.

33. S. Vajda, P. Valko, and T. Turanyi, "Principle component analysis of kinetic models," International Journal of Chemical Kinetics, 17: 55-81, 1985. 